\title{
Antoine REDIER
}

(1924)

\section{La guerre des femmes.}

\section{Histoire de Louise de Bettignies et de ses compagnes.}

Un document produit en version numérique par Diane Brunet, bénévole,

Diane Brunet, bénévole, guide, Musée de La Pulperie, Chicoutimi

Courriel: Brunet_diane@hotmail.com

Dans le cadre de: "Les classiques des sciences sociales"

Une bibliothèque numérique fondée et dirigée par Jean-Marie Tremblay, professeur de sociologie au Cégep de Chicoutimi

Site web: http://classiques.uqac.ca/

Une collection développée en collaboration avec la Bibliothèque

Paul-Émile-Boulet de l'Université du Québec à Chicoutimi

Site web: http://bibliotheque.uqac.ca/ 


\section{Politique d'utilisation de la bibliothèque des Classiques}

Toute reproduction et rediffusion de nos fichiers est interdite, même avec la mention de leur provenance, sans l'autorisation formelle, écrite, du fondateur des Classiques des sciences sociales, Jean-Marie Tremblay, sociologue.

Les fichier des Classiques des sciences sociales ne peuvent sans autorisation formelle:

- être hébergé (en fichier ou page web, en totalité ou en partie) sur un serveur autre que celui des Classiques.

- servir de base de travail à un autre fichier modifié ensuite par tout autre moyen (couleur, police, mise en page, extraits, support, etc...),

Les fichiers (.html, .doc, .pdf., .rtf, .jpg, .gif) disponibles sur le site Les Classiques des sciences sociales sont la propriété des Classiques des sciences sociales, un organisme à but non lucratif composé exclusivement de bénévoles.

Ils sont disponibles pour une utilisation intellectuelle et personnelle et, en aucun cas, commerciale. Toute utilisation à des fins commerciales des fichiers sur ce site est strictement interdite et toute rediffusion est également strictement interdite.

L'accès à notre travail est libre et gratuit à tous les utilisateurs. C'est notre mission.

Jean-Marie Tremblay, sociologue

Fondateur et Président-directeur général, LES CLASSIQUES DES SCIENCES SOCIALES. 
Du même auteur

Méditations dans la Tranchée, Fayot, 1916, un vol. Ouvrage couronné par I'Académie française.

Pierrette, roman, Fayot, 1917, un vol.

Le Mariage de Lison, roman, Payot, 1918, un vol.

Le Capitaine, Payot, 1919, un vol.

Léone, roman, Payot, 1920, un vol.

Sous presse :

Antoine REDIER, Comme disait Monsieur de Tocqueville... Paris: LIBRAIRIE ACADÉMIQUE PERRIN ET CIE, LIBRAIRES-ÉDITEURS, 1925, 301 pp. [Livre disponible dans Les Classiques des sciences sociales. JMT.] 
Cette édition électronique a été réalisée par Diane Brunet, bénévole, guide, Musée de La Pulperie, Chicoutimi à partir de :

Antoine REDIER

LA GUERRE DES FEMMES. Histoire de Louise de Bettignies et de ses compagnes.

Paris : Les Éditions de la Vraie France, 1924, 317 pp.

Polices de caractères utilisée :

Pour le texte: Times New Roman, 12 points.

Pour les citations : Times New Roman, 12 points.

Pour les notes de bas de page : Times New Roman, 12 points.

Édition électronique réalisée avec le traitement de textes Microsoft Word 2008 pour Macintosh.

Mise en page sur papier format : LETTRE (US letter), 8.5’’ x 11’’)

Édition numérique réalisée le 11 octobre 2009 à Chicoutimi, Ville de Saguenay, province de Québec, Canada.

\section{Fait avec}

Macintosh 
Antoine REDIER

LA GUERRE DES FEMMES.

Histoire de Louise de Bettignies et de ses compagnes.

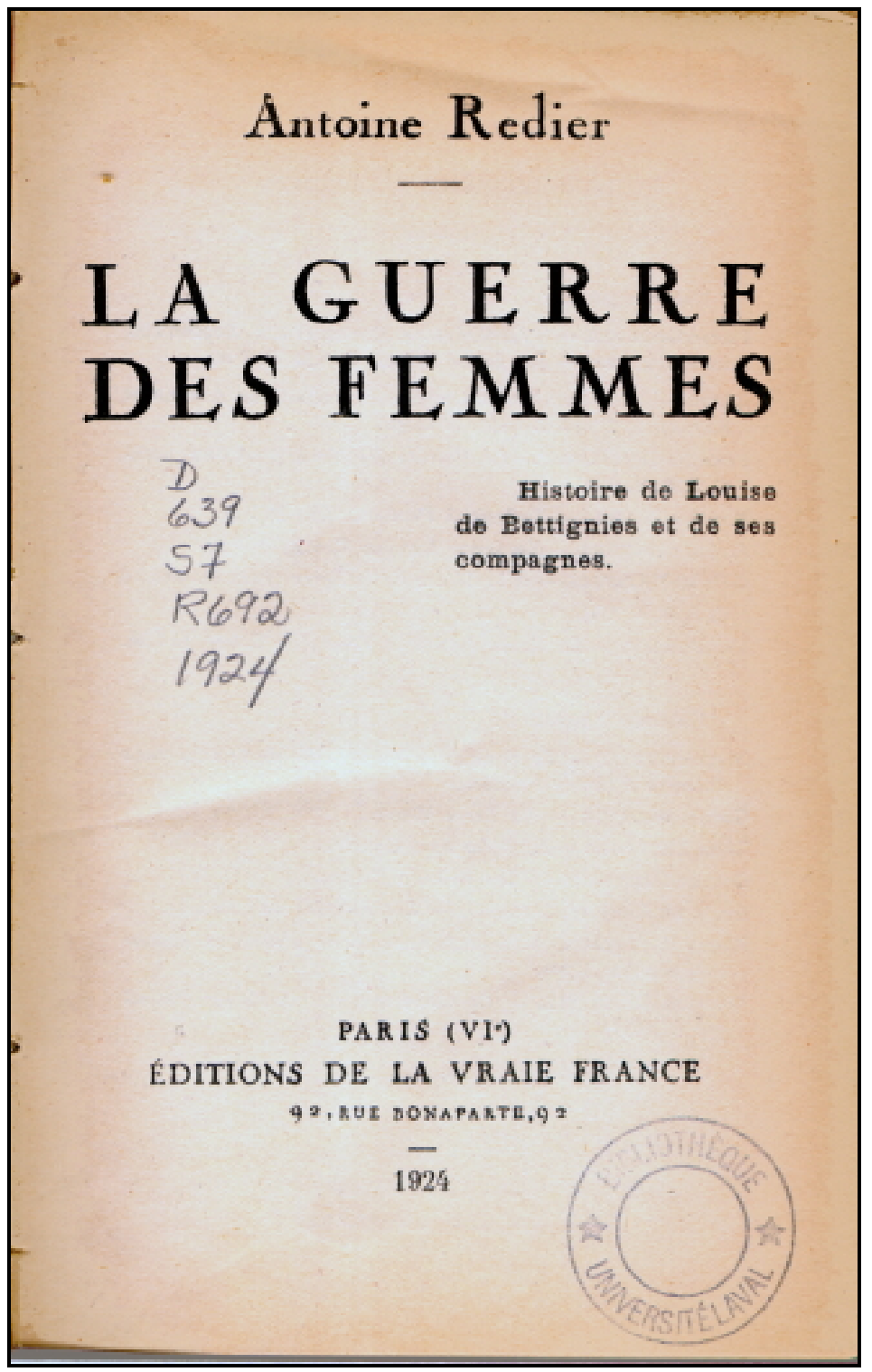

Paris : Les Éditions de la Vraie France, 1924, 317 pp. 


\section{Table des matières}

DÉDICACE, Noël 1923

Chapitre I. $\quad$ Alice

Chapitre II. Charlotte

Chapitre III. Albert

Chapitre IV. Au travail

Chapitre V. Dans la souricière

Chapitre VI. Pour avoir ri

Chapitre VII. Le manteau écossais

Chapitre VIII. Le policier Goldsmith

Chapitre IX. L'auditeur Stoëber

Chapitre X. En Allemagne

Chapitre XI. Le cachot

Chapitre XII. La croix de bois

ÉPILOGUE 


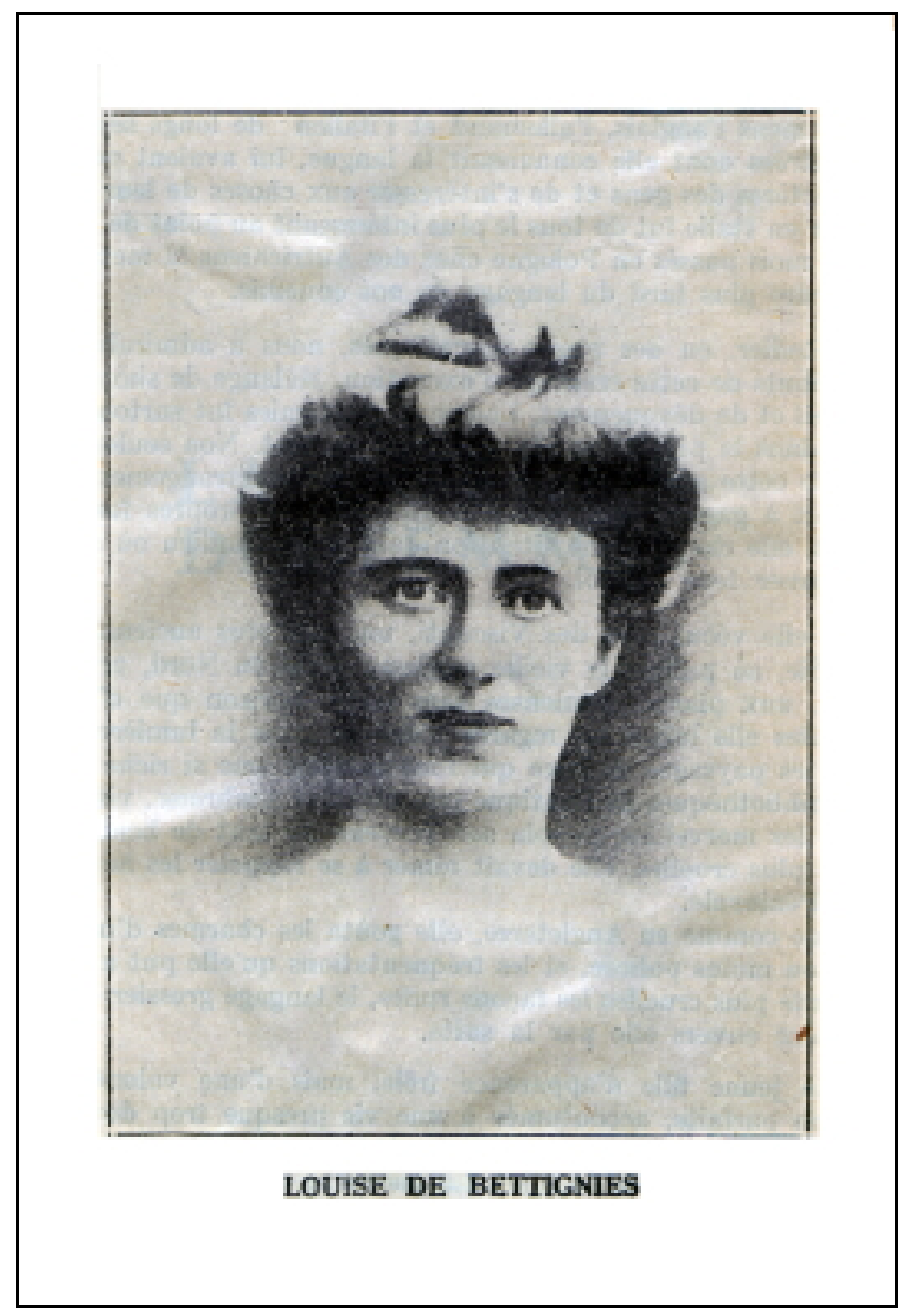




\section{LA GUERRE DES FEMMES.}

Histoire de Louise de Bettignies et de ses compagnes.

\section{DÉDICACE}

$\underline{\text { Retour à la table des matières }}$

Je dédie ce livre à la mémoire d'une des plus nobles femmes qui aient jamais honoré le nom français. Louise de Bettignies est peu connue, et ce n'est pas à l'éloge de ceux qui ont mission d'informer le public. J'ai l'ambition d'aider par mon témoignage à réparer cette injustice des hommes, dont ne pâlit pas seulement la gloire d'une jeune fille héroïque et charmante, mais la couronne française, qu'il ne faut priver d'aucun de ses fleurons.

Je me tourne aussi vers d'autres jeunes filles, celles qui ont vécu comme Louise de Bettignies de grandes heures, et qui ne sont pas mortes. Celles-là, si je voulais, leur apportant mon hommage, les nommer comme je les vois, j'inscrirais ici ces seuls mots : Aux vraies mortes.

Car je les plains et je sens toute la mélancolie d'un destin qui fut si grand et se mesure maintenant à notre taille misérable. Quand on a pensé, senti, agi d'une certaine haute façon, il est triste de s'abimer en plein vol, mais plus triste de redescendre doucement sur la terre, pour y traîner, dans la foule médiocre, des jours sans consolation.

Je pense aux plus humbles d'entre elles, qui ne connaissent ni les compensations matérielles ni cette paix du cœur qu'apporte parfois la richesse avec ses loisirs. Elles ont éprouvé, parmi des souffrances sans nom, quelques-unes de ces joies dont le souvenir embaume une âme pour toujours, mais il y a le contact avec la bassesse humaine qu'elles avaient cessé de voir et qui s'étale maintenant avec 
cynisme et va les étouffer. Je les plains. On a mis un ruban, deux rubans à leur corsage, et c'est tout. Elles passent, et les hommes et les femmes qui courent par les rues, cherchant de l'or ou des plaisirs, ne se détournent pas pour les voir. J'en connais de sublimes, qui ne se marieront jamais. Pourquoi ? Pas de dot. Mais leur, âme robuste, et le feu qui brûle dans leurs cœurs, et ces preuves qu'elles ont données de leur bravoure devant les hommes, les choses et la mort, qu'en font-ils, les épouseurs?

On ne leur donne même pas leur part de gloire, car c'est aux morts que vont les couronnes et les discours, les livres aussi. Oui, j'ai choisi Louise de Bettignies, parce qu'elle a été la plus belle parmi les mortes. Peut-être aurais-je fait une œuvre plus opportune en racontant l'histoire d'une de nos sœurs vivantes. Elles ont le cœur lourd de, souvenirs magnifiques, et ceux qu'elles ont voulu sauver au prix de leur sang les éclaboussent ou les dédaignent et les laisseraient mourir de faim sans un regard. J'ai voulu qu'il y eût un sourire pour elles dans mon livre. Il ne faut pas que les vivantes soient jalouses de la paix qu'a trouvée la morte, ni des hommages qu'à mon appel lui rendra, j'espère, la postérité.

Je l'ai appelé La Guerre des Femmes, mon récit de la vie héroïque et de la mort de Louise de Bettignies, parce que j'ai entendu célébrer toutes les femmes qui, comme elle, ont fait la guerre. La première qui ait retenu mon attention fut cette Ceneviève Hennet de Goutel, âme de feu, qui disait, après avoir pansé l'horrible blessure d'un soldat « Il ne sait pas que sur sa pauvre plaie rongée, en grattant les croûtes et les lambeaux de chair décomposée, et en respirant la pourriture qui s'en exhalait, j'ai vraiment passé une heure divine. » Celle-là était de ce côté-ci du front et elle est morte en Roumanie d'avoir servi sa patrie comme une amante.

Mais voici toutes les autres que j'ai rencontrées autour de Louise de Bettignies sur les routes de la France et de la Belgique occupées ou dans les prisons d'Allemagne. Les unes couraient la nuit, poussant devant elles des hommes que traquait l'ennemi, et les conduisant par étapes à la frontière hollandaise, d'où ils gagnaient les armées de l'Entente. D'autres recueillaient des renseignements sur l'occupant et les portaient aussi à la frontière. Deux noms de Françaises devraient être connus et honorés de nous tous : ceux de Louise Thuliez, de Lille, et de Marie-Léonie Vanhoutte, de Roubaix. On les trouvera dans mon récit, surtout celui de la dernière, qui fut le lieutenant de mon héroïne. Et toutes les autres, nous les verrons ré- 
unies à la fin, dans la geôle sinistre où l'ennemi les jetait à mesure que les dénonciations ou la malchance s'abattaient sur elles.

Nous qui avons tiré de la guerre, malgré ses horreurs, tant de grands souvenirs, nous serions coupables de ne pas saluer très bas ces femmes qui se sont battues à leur façon. Leur sacrifice a sauvé des milliers d'entre nous, et c'est de quoi nous émouvoir. Et puis, vivantes ou mortes, on peut bien les mettre dans la gloire : elles ont toutes fini de vivre, car leur sensibilité, plus aiguë que la nôtre, mesure mieux dans quel bas-fond la paix a replacé les humains, qu'on voyait si beaux au feu des combats.

Ainsi c'est au petit nombre de celles qui se sont jetées dans la bataille que j'ai consacré ces pages, mais les tribulations et les tourments de toutes les autres, des mères, des épouses, des fiancées, des sœurs, j'envie celui qui saura bien nous les conter. J'ai toujours pensé que le temps où l'on se battait avait été dur aux honnêtes femmes, elles souffraient autrement que nous, et sans les glorieuses compensations dont s'enivre en face du danger toute âme bien faite. Leur devoir était à la maison, qu'il fallait garder. Impuissant à honorer ces vestales selon leurs mérites, je leur offre des deux mains ce livre, et plus pieusement à l'une d'elles, qui veillait alors sur mon foyer, sur mes fils, et qui, l'épreuve finie, m'a tout rendu, avec sa tendresse agrandie.

Noël 1923.

A. R. 


\section{LA GUERRE DES FEMMES.}

Histoire de Louise de Bettignies et de ses compagnes.

\section{Chapitre I}

\section{ALICE}

\section{$\underline{\text { Retour à la table des matières }}$}

Au moment où commence cette histoire, celle qui en fut l'héroïne n'était plus une toute jeune fille, mais, mariée, elle eût encore fait une très jeune femme. Petite, le regard vif, la bouche rieuse, elle parlait vite et beaucoup. Dès le premier contact, on était surpris et conquis. La surprise venait du flot de mots légers qu'elle jetait en cascade avec une gaîté de petite fille ; la conquête, de ses idées fermes sous les mots brillants. Des sots, parce qu'elle était étourdissante, l'ont prise pour une étourdie. C'était un cerveau très sûr, au service d'une âme dominatrice.

Elle se trouvait à Lille, dans la maison de sa mère absente, quand les Allemands arrivèrent dans cette ville, en octobre 1914. Après quelques semaines, elle étouffa et voulut aller prendre de l'air en France libre. Elle s'enquit vivement d'un passage vers la Hollande et partit. Elle n'a laissé nulle relation de ce voyage, qui dut être pittoresque. Ce qu'on connaît, c'est l'étrange aventure qui lui advint à Folkestone. Encore ai-je dû, pour reconstituer la scène qu'on va lire, me contenter de témoignages incertains, que d'autres contredisent. Le fond de l'histoire est vrai les détails ne sont que probables. Les évadés de France et de Belgique, très nombreux alors, qui prenaient passage à Flessingue pour l'Angleterre, étaient, à leur arrivée sur la terre britannique, soumis à un examen minutieux. On les faisait entrer, dès la sortie du paquebot, dans une salle entièrement occupée par une large et très longue table. Une dizaine d'officiers et de fonctionnaires anglais, assistés de se- 
crétaires belges, étaient assis d'un côté de cette table. De l'autre, les voyageurs défilaient, passant tour à tour devant chacun de ces hommes, qui leur posaient à voix basse, les uns graves comme des confesseurs, les autres souriant, des questions diverses et souvent indiscrètes.

Le médecin, si les réponses qu'on lui faisait ne le rassuraient pas, envoyait les gens dans la salle de visite. Le policier regardait de près les passeports. Un individu soupçonneux visitait les portefeuilles. Un autre demandait à chacun où il allait et pour quoi faire. Puis on arrivait devant des personnages plus aimables et qui cherchaient à plaire pour qu'on leur répondît bien. Ceux-là posaient mille questions : «D'où venez-vous ? Qu'avez-vous vu ? Que font les Allemands? Comment vit-on à Bruxelles? »

Quand ce fut le tour de la jeune fille de Lille, la foule qui la suivait se trouva bientôt bloquée. Au lieu de passer vite comme les autres et de céder son tour aux suivants, elle s'attardait.

- Vous venez de France ? lui avait-on dit. Que s'y passe-t-il ? Avez-vous quelque chose à nous dire sur l'armée occupante ?

Ce qu'elle avait à dire était sans doute intéressant, car les officiers voisins de son examinateur, quittant leur place, se rapprochèrent les uns des autres et braquèrent bientôt sur la jeune Française une impressionnante quantité de grands yeux bleus. Elle parlait à mi-voix, avec un calme parfait, mais un peu vite. Elle vit bientôt qu'ils ne la comprenaient pas entièrement. Alors elle continua sa déposition en anglais. Ils lui en surent gré et commencèrent à l'admirer beaucoup. L'un d'eux, étonné qu'elle connût certains détails que seuls des soldats ennemis avaient pu lui révéler, lui demanda son secret pour rendre ces gens bavards.

- Je parle leur langue, monsieur.

-Alors vous connaissez aussi l'allemand ?

Elle sourit, heureuse d'avoir conquis ces beaux gentlemen figés devant elle. Elle se garda, n'étant point vaine, d'ajouter qu'elle parlait aussi l'italien. Et sa déposition continua.

Cependant, les hommes et les femmes que cette causeuse faisait attendre commençaient à murmurer. Un officier, que les autres avaient appelé depuis un moment et qui paraissait leur chef, s'incline devant la jeune fille et lui dit : 
- Voulez-vous nous répéter votre nom, mademoiselle?

- Louise de Bettignies.

- Vous vous rendez en France ?

- Oui, près de ma mère.

- Où cela ?

- Je la crois en ce moment à Saint-Omer.

Les officiers se regardèrent. Saint-Omer était alors le siège du Grand Quartier Général britannique.

- Nous feriez-vous l'honneur, reprit l'officier, de retarder d'un jour votre embarquement pour la France, afin de nous accorder une autre conversation comme celle-ci ?

Elle rougit.

- Est-ce vraiment si nécessaire, messieurs ?

Ils insistèrent, et elle céda.

Dans la soirée, une automobile de ce service de l'Intelligence britannique, qu'en France nous appelons plus modestement le Service des Renseignements, déposait Louise de Bettignies à l'hôtel. Elle monta dans sa chambre, la tête en feu. Nos alliés venaient, à la suite d'une réception de la plus haute courtoisie, de lui demander une chose terrible.

- Louise de Bettignies. Un des nôtres, lui avait dit un officier général, va se rendre à Saint-Omer; il vous présentera, si vous le permettez, au maréchal French, qui vous confirmera notre requête : nous voudrions que vous fissiez désormais la navette entre Lille et nous, afin de nous rapporter régulièrement des renseignements comme ceux que vous venez de nous donner.

On demandait à cette évadée de retourner en prison ; à cette créature ardente, ivre de liberté, de se faire l'esclave d'un devoir dur, ingrat, sans grandeur apparente ; à cette fille de race de courir les routes comme une aventurière ; et, pour seule gloire, celle de se tenir bien droite, un matin gris, devant un peloton d'exécution.

Quoiqu'elle fût brave, elle frissonna. D'autres auraient refusé net. Elle promit de réfléchir et de prendre conseil. Et le lendemain, elle courait en France, impa- 
tiente de trouver auprès des siens le calme dont, après une telle secousse, elle avait besoin pour se déterminer en toute sagesse.

Mais qui donc était-elle, pour avoir fait sur nos alliés cette impression ? Sans m'attarder aux détails, je vais raconter à grands traits sa vie de jeune fille, toute simple et cependant tragique comme n'importe quelle vie humaine qu'on regarde bien.

Louise-Marie-Jeanne-Henriette de Bettignies, née le 15 juillet 1880, en la fête de saint Henri, était la septième enfant de Henri de Bettignies. Sa mère était une Mabille de Poncheville. Les Bettignies étaient de bonne noblesse et Louise, qui tenait à son nom, se flattait que le blason de ses ancêtres figurât avec honneur dans l'armorial du Saint-Empire. Originaires du Hainaut, les seigneurs de Bettignies avaient longtemps dépendu de la couronne de Charlemagne. L'arrièregrand-père de Louise, Maximilien-Joseph, avait épousé la fille d'un notable fabricant de porcelaine, Peterinck de la Gohelle. Son fils prit à Saint-Amand la suite d'une dynastie de faïenciers fameux, les Fauquet. Il fabriqua de la poterie de faïence comme on avait fait avant lui dans cette maison, mais s'essaya aussi, avec un beau succès, à produire de la porcelaine tendre. Pour cette industrie, qui demande un goût parfait et des soins délicats, il rétablit l'ancien mode de cuisson au bois, demanda des modèles à des artistes comme Clodion et confia la décoration des pièces à des peintres de talent. La famille connut alors, notamment au cours du Second Empire, des années de grande prospérité. Quand Henri, père de Louise, prit l'usine en 1865, elle était depuis vingt ans au lieu dit Le Moulin des Loups, dans le voisinage de la belle forêt de Saint-Amand, où les Bettignies prélevaient, sur les coupes leur appartenant, le bois nécessaire à leur industrie. En 1877, trois ans avant la naissance de sa dernière fille, Henri de Bettignies, succombant à des difficultés nombreuses, cessait la fabrication de la pâte tendre et cédait la maison.

Huit enfants à élever, car un fils encore était venu après Louise ; des ressources diminuées ; la mort du père survenant à l'heure d'établir la dernière fille, si impatiente de vivre : voilà bien des charges, bien des épreuves. Le destin, si sévère à ce foyer, n'allait-il pas frapper surtout la petite Louise ? Mme de Bettignies voulut armer cette enfant.

Elle la voyait d'une inlassable curiosité d'esprit. On lui avait accordé, pour couronner ses études, un long séjour en Angleterre et elle revenait, au moment où 
s'éteignait son père, de l'Université d'Oxford, d'où elle rapportait, après deux années d'études, un brevet qu'on conquiert plus habituellement en quatre ans. Ce n'était pas encore le temps où les filles apprenaient le latin. Elle regretta pourtant de s'être surtout adonnée là-bas aux sciences, et spécialement aux mathématiques ; et pendant quelques mois, elle s'exerça à Lille, sous la conduite d'un maître de l'Université, à déchiffrer la langue de Cicéron. Elle devait se remettre à cette étude beaucoup plus tard, en prison. En 1906, elle prit un parti courageux. « Je deviens difficile à marier », disait-elle ; ce qu'il fallait entendre de deux façons. Le sort est dur, dans l'âpre société où nous vivons, aux filles nobles sans fortune ; elle avait peu de chances de rencontrer un homme qui l'épousât pour son mérite. Mais elle craignait aussi de ne jamais rencontrer un parti dont elle voulût. Plus elle s'instruisait et meublait sa ferme intelligence, plus elle ressentait d'indifférence à l'égard du médiocre troupeau des hommes qu'on épouse. Elle voulait bien s'établir, mais d'abord aimer son mari et qu'il fût digne de son rêve, qui tous les jours grandissait. Elle résolut de se cultiver davantage, au risque de se vouer à une solitude sans espoir. Un homme peut bien dire que de telles jeunes filles sont à plaindre. La race est nombreuse de celles que nous ne mériterons jamais. Pour qu'une femme d'une certaine qualité s'appuyât confiante au bras d'un de nous, il faudrait qu'il lui fût encore supérieur. Et nous ne pesons pas lourd, qui que nous soyons, auprès des âmes féminines quand elles sont belles.

Louise de Bettignies, à vingt-six ans, s'en fut sous le ciel d'Italie, avide de connaissances nouvelles et d'une vue plus étendue du monde. Là-bas, elle s'instruirait, s'initierait à la langue de Dante, verrait d'autres hommes et d'autres choses. Et puis elle gagnerait pour la première fois quelque argent. C'était son indépendance qu'elle allait chercher dans la maison des Visconti, près de Milan. Pour se libérer, elle prenait du service. C'est la bonne recette ; car on ne s'affranchit jamais sur la terre : on change de maîtres,

Au contact de la haute société italienne, elle goûta des jouissances d'artiste et satisfit à ses goûts d'aristocrate, amie des hautes manières et des conversations raffinées. Un des traits de cette âme était l'ambition : nous la verrons occupée avec application aux soins du ménage et travaillant à ses toilettes comme la plus humble fille, mais elle voyait grand et entendait remplir sa vie. Comment? Elle l'ignorait encore, et cherchait. En attendant, elle se repaissait de beaucoup de choses, et des plus belles. Après l'Angleterre, après l'Italie, elle voulut connaître, non 
l'Allemagne, mais les pays de langue germanique. Il était écrit qu'elle serait grande selon son rêve et qu'un jour elle tomberait sous des coups allemands. Elle refusa de devenir la gouvernante des enfants de François-Ferdinand d'Autriche, comme si elle sentait que le nom de celui-là serait à l'origine des événements dont elle allait mourir. C'est en Pologne, près de Lemberg, chez le comte Mikiesky, qu'elle prit contact avec l'aristocratie autrichienne, fille comme elle du Saint-Empire. Elle y demeura un an, acquérant sur le langage, les mœurs, la psychologie, les travers germaniques, des connaissances qui lui seraient un jour précieuses. Dans cette maison et chez le prince Schwouzenberg-Worletz, en Bohême, où elle passa ensuite dix-huit mois de vie ardente et curieuse, elle se créa des relations dont une autre aurait tiré vanité. Mais l'orgueil n'a point de place dans une âme qu'habite l'ambition.

Hélas ! on est une femme et vient une heure où il faut pleurer. Toute cette histoire sera celle d'un coeur impétueux, que l'amour dévore : amour de Dieu un peu plus tard; amour de la Patrie plus tard encore et jusqu'au dernier souffle ; mais l'amour des hommes, d'un homme, un jour devait passer par là.

Pendant la guerre, alors qu'elle se dépensait avec ferveur pour le service des Alliés, un ami, la voyant avide de se sacrifier, prête à donner tout son sang, lui avait dit à brûle-pourpoint :

- Ne vous immolez pas ainsi ! Soyez prudente ! Vous feriez penser que vous agissez par dépit d'amour...

C'était à table. Chacun se tut. Et le soir, les convives, émus de l'incident, chuchotaient entre eux :

- Avez-vous vu comme ses yeux se sont mouillés ? Pauvre petite !

Voilà tout ce qu'on sait, ou presque, de ses amours humaines.

- Vous ne connaissez pas, vous, dit-elle un jour à l'une de ses compagnes de prison, la douceur d'avoir aimé...

Et elle mit sa main, qui brûlait, sur le bras frais de sa confidente.

On sait aussi par elle que sa foi religieuse faillit sombrer tout au début de sa vie de jeune fille. Elle eut alors, dans son âme blessée, des heures de révolte. Pour revenir aux pieuses délectations de son enfance, elle fit d'abord de graves lectures, puis, ce qui valait mieux, elle ouvrit son cœur, et le Dieu qui ne trompe jamais 
vint occuper une place encore chaude. Elle lisait beaucoup ; et, pareille à cette autre jeune fille de sa génération, Geneviève Hennet de Goutel, morte comme elle pour avoir follement aimé sa patrie, elle faisait ses délices du grand et terrible Pascal.

Physiquement, elle était solide. Son petit corps nerveux, elle l'avait dressé à tous les sports. Bonne cavalière, précise et vaillante au golf, nageuse hardie, marcheuse endurante et souple, elle se campait devant vous avec l'aplomb d'une femme maîtresse d'elle-même et des autres. Elle connaissait son charme et comptait sur lui. La grande beauté de cette fille d'Ève, c'était sa chevelure, soyeuse, opulente et brune sur un teint de blonde. Son visage fin, qui en paraissait parfois écrasé, prenait alors des airs de langueur et de lassitude. Puis elle s'animait: ses yeux, tantôt petits et malicieux, tantôt grands ouverts et dominateurs, on se sentait dévoré par eux. Par la ruse ou la force, elle conquérait, et, la prise faite, elle babillait comme un oiseau chante sa joie.

Comme tous les êtres de valeur, elle évitait le contact des gens médiocres. Dans un groupe, elle s'adressait aux autres et ne voyait pas ceux-là, qui lui en veulent encore. Non qu'elle fût dédaigneuse : elle adorait les petites gens et s'en faisait chérir. Mais, avide de voir, de sentir, d'entendre et de parler, les sots lui paraissaient des meubles inutiles.

Les officiers chargés par l'autorité britannique de faire l'examen des voyageurs arrivant à Folkestone n'ont pas dû voir passer beaucoup d'hommes ou de femmes de cette qualité. Ils ont tout de suite désiré, demandé, obtenu le concours de cellelà : c'est à leur honneur.

Évidemment, parmi les sentiments tumultueux dont elle sentit son cœur ravagé après leur requête, elle dut éprouver cette joie souveraine d'avoir été jugée, pour la première fois de sa vie, bonne à quelque chose. Car c'est ainsi : presque toutes les femmes, hors du mariage, sont des valeurs sans emploi. Du feu qui couve : voilà leur coeur. Ces Anglais venaient de souffler sur de la braise ardente. Et, pudique, elle croisa les bras sur sa poitrine pour étouffer la flamme prête à bondir. Car elle tenait farouchement à son honneur de femme; et l'aventure où on voulait la jeter lui faisait horreur par certains côtés. Elle résolut de mater ses craintes comme ses désirs, de laisser s'entre-dévorer ses passions contraires, et, pour décider, de consulter froidement son devoir. 
Après les premières effusions, joignant les mains devant sa mère qui était ivre de joie d'avoir retrouvé cette enfant perdue et commençait de bâtir des projets d'installation stable, elle lui demanda tout bas la permission de retourner à Lille. La pauvre femme crut défaillir.

- Si c'est ton devoir, ma petite, retourne là-bas. Mais prends conseil.

Cela dit, elle pleura. Aujourd'hui encore elle pleure. Qu'on ne les croie point, la mère et l'enfant, au-dessus de l'humanité. Elles ont agi avec grandeur, mais en tremblant, pauvres femmes souffrantes pareilles à toutes les autres.

Le conseil, c'est à Amiens que Louise de Bettignies alla le chercher. Là vivait son directeur spirituel, le P. Boulangé, jésuite notable, à qui elle s'était confiée peu d'années avant la guerre, alors qu'il résidait à Lille. Elle avait fait sa connaissance dans des conditions dont le souvenir l'amusait. Ce religieux, mort depuis, passait pour envoyer ses pénitentes au Carmel. «Non, merci ! » répondit-elle à ceux qui l'engageaient à l'aller voir. Et elle riait de bon cœur, car elle aimait la vie et ne songeait pas au cloître. Ce P. Boulangé était un bon colosse, d'âme tendre et de jugement droit. Il possédait cet avantage immense, aux yeux de ses fidèles, d'être entré tardivement dans les ordres. Docteur en droit, docteur ès lettres, il avait beaucoup vécu dans le monde avant de s'en retirer. L'expérience qu'il y avait acquise, il la mettait avec bonté au service des gens qui frappaient à sa porte. Celuilà écarté, Louise de Bettignies s'enquit d'un autre nom. Le prêtre qu'on lui signala était aussi un jésuite. Elle alla vers lui, dans la chapelle du collège Saint-Joseph de Lille. Mais elle trouva les abords de son confessionnal si chargés de monde, que, pressée ce jour-là, elle préféra s'agenouiller trois pas plus loin, aux pieds d'un ministre moins recherché. Celui-ci jugea sans doute qu'elle était intéressante, car, le sacrement donné, il engagea la conversation. Ainsi devaient faire les Anglais de Folkestone un peu plus tard. Quand on commençait à causer avec elle, on ne voulait plus qu'elle s'en allât.

- Vous n'avez pas de directeur ? lui demanda ce prêtre curieux.

- Non. On m'avait indiqué le Père ***, votre voisin : il a trop de monde. On m'a parlé aussi du P. Boulangé ; mais je n'en veux pas.

- Vraiment ! Et pourquoi ?

- Mais, parce que je ne me vois pas du tout en carmélite. 
- Mais qui vous a dit, mon enfant, que je vous enverrais au Carmel ?

Car c'était lui. Et quelques mois plus tard, émerveillé sans doute des ardeurs de ce cœur, il le poussait doucement vers le don total à Dieu. Au moment de la guerre, Louise de Bettignies était à la veille de quitter le monde et d'entrer dans cet ordre dont le nom seul la faisait bondir un peu plus tôt. Eût-elle fait une bonne carmélite ? Elle-même n'en était pas absolument sûre. Et la seule idée qu'elle pût vivre tranquillement derrière une grille donne à sourire à ceux qui la jugent seulement sur son entrain fou, son exubérance et son toupet sous la férule allemande. Le sagace Père Boulangé crut, en lui conseillant à Amiens d'écouter l'appel des Anglais, qu'il fallait en tout cas qu'elle se donnât : servante de Dieu dans le silence ou servante de la patrie parmi des aventures hardies, elle apaiserait sa soif d'aimer. Et tout son caractère la désignait, en attendant le cloître, pour la forme d'amour plus humaine qu'on lui proposait aujourd'hui.

Elle sortit de l'entrevue rassérénée ; et, présentée quelques jours plus tard au chef de l'armée britannique en France, elle lui déclara qu'elle était prête à servir, mais qu'encore voulait-elle prendre contact avec le grand quartier général français, Elle eut près d'Amiens, puis à Chantilly, diverses entrevues avec des officiers de notre deuxième bureau, celui qui, dans tous les états-majors, a dans ses attributions l'étude de l'ennemi. Elle fut frappée de la valeur des hommes avec qui on la mit en rapport. Sans vouloir offenser les Britanniques dont elle devait faire ses chefs, on peut bien dire qu'elle eût préféré s'enrôler sous nos couleurs : pour des raisons de sentiment d'abord; aussi pour la satisfaction de son intelligence. Avec nous, elle était comprise et comprenait au premier mot. La langue n'était pas en cause, puisqu'elle parlait l'anglais comme le français : mais à cet esprit lumineux, la pensée des gens de Folkestone devait toujours paraître un peu lente.

Nos alliés acceptaient d'ailleurs fort galamment qu'elle prît un service français. Elle opta pour eux par sagesse. S'ils ont des vues moins brillantes et rapides que nous, les Anglais sont plus précis en affaires. Alors que notre état-major offrait à la jeune fille de lui rembourser ses frais à sa convenance, eux lui proposèrent tout de suite une somme importante. Elle pensa qu'elle courrait au-devant de difficultés inextricables si l'argent lui manquait. Nous verrons plus tard avec quelle réserve elle usa des sommes mises à sa disposition. Encore voulait-elle n'avoir de ce côté nul souci. Dans l'intérêt de sa mission, elle préféra la formule anglaise. D'autre part, elle comprit à quel point elle était qualifiée pour aider nos alliés, qui 
faisaient la guerre en anglais contre des Allemands sur une terre française; connaissant les trois langues, elle se débrouillerait pour eux dans cette tour de Babel.

Son parti bien pris, elle connut avec plaisir qu'on attendait d'elle beaucoup plus qu'elle n'avait cru d'abord. Il ne s'agissait pas qu'elle apportât ses propres renseignements, mais qu'elle montât toute une machine, dont on lui expliqua les rouages ; elle étendrait sur la région de Lille un vaste réseau d'observateurs, concentrerait les renseignements qui lui viendraient ainsi et les ferait parvenir en Angleterre. Alors qu'elle était prête au rôle d'estafette, on lui demandait celui d'un chef. Il lui plut infiniment d'être chargée d'un haut emploi ; et, ayant embrassé sa mère, elle partit, douloureuse et fière, vers son destin.

Elle avait demandé au Père Boulangé, dans une suprême entrevue, des directions fermes pour la vie aventureuse où elle s'engageait. Car, dès son débarquement en France après l'interrogatoire de Folkestone, un incident qui eût brisé une âme moins ferme lui avait révélé dans quel monde effroyable elle allait entrer. Au lieu de se rendre directement d'Angleterre à Saint-Omer, elle avait eu la tentation, arrivée à Boulogne, d'y rendre visite à Mme Surmont, à qui elle apporterait des nouvelles de son mari, professeur à la Faculté de Médecine de Lille. Elle fut si bien accueillie dans cette maison amie qu'elle y resta deux jours. À l'état-major de Saint-Omer, où elle était attendue, on s'étonna d'abord, puis on prit peur et l'on conclut, comme à l'habitude dans ces milieux, que cette femme si bien documentée sur les Allemands n'avait sans doute apporté qu'un témoignage de fantaisie dicté par l'ennemi, dont elle était un agent. Et voilà la police secrète des Anglais, puis des Français, aux trousses de la pauvre fille. On arriva chez Mme Surmont pour y appréhender « l'espionne » et faire une perquisition en règle. L'oiseau était parti. On s'expliqua et l'affaire se termina correctement, Dieu merci ! Mais quel avertissement dès ce premier jour, et comme on comprend qu'elle ait eu besoin, avant de se jeter dans cette bagarre, du réconfort et des conseils d'un ami de son âme! Et puis il faudrait mentir, perdre à peu près tout contact avec la vérité : le pouvait-elle sans dommage pour son intégrité morale ? Elle serait contrainte à certaines libertés de langage ou d'allures, à des privautés dont d'avance s'épouvantait son honneur. De quelle splendide qualité dut être cet entretien entre le bon géant au visage calme, à l'âme sereine, soucieuse seulement de sagesse, et la jeune femme si petite pour un cœur gonflé de telles angoisses ! 
Elle reprit à Folkestone le bateau pour Flessinghe, passa à Terneuse, puis arriva par une triste journée de février 1915 à Philippine, dernier village hollandais contre la frontière belge. Une heure plus tard, elle avait trouvé un guide. Dans la nuit même, elle passait sous les fils de fer et prenait contact avec la terre belge en rampant sur elle, ses mains nerveuses enfoncées dans l'herbe glacée.

Le lendemain soir, à dix heures, elle sonnait à la porte de sa maison de la rue d'Isly, à Lille. Sa vieille bonne mit un peu de temps à se réveiller, puis à comprendre. Elle crut d'abord à une descente de quelque patrouille allemande. Quand, de la fenêtre, elle vit une silhouette de femme, elle cria :

- Mais qui êtes-vous ? Les rues sont consignées.

- Ouvrez toujours ! fit une voix rieuse.

- Mon Dieu ! c'est Mademoiselle !

Et comme une folle, elle courut à la porte. Ce soir-là, la maîtresse embrassa la servante. Dès les premières heures du lendemain, les distances furent rétablies. Louise de Bettignies aimait qu'on la servît. Il lui arrivait d'avaler à la cuisine un repas sommaire, quelquefois fait par elle-même : c'était la guerre ; mais, dans la salle à manger, elle entendait qu'on lui passât les plats. Elle tenait d'autant plus à certaines formules d'ordre et de discipline qu'elle était contrainte de vivre par ailleurs à l'aventure. Et son souci, dès ce jour, fut de courir bravement tous les risques qu'aimait son âme hardie, mais, la part faite au feu, de sauver le reste.

Nous allons la voir au travail. Elle s'y jeta rapidement, prit un nom de guerre, celui d'Alice Dubois, entra en contact, sans jamais laisser connaître qui elle était, avec ceux et celles qui pouvaient le mieux servir ses desseins, et se constitua tout de suite une parfaite équipe de collaborateurs, soit pour recueillir des renseignements ou pour les acheminer vers la Hollande. Mais elle vit bientôt qu'elle ne suffirait pas à sa tâche propre. Obligée d'aller sans cesse elle-même aux deux extrémités de sa ligne, depuis le front allemand jusqu'aux bureaux de Flessinghe ou de Folkestone, elle s'enquit d'un lieutenant. Un jour, dans une propriété voisine de Roubaix, à Mouveaux, eut lieu une entrevue entre elle et plusieurs notabilités de la région dont nous retrouverons les noms au cours de cette histoire. À cette entrevue assistait une jeune fille de tenue, modeste et prompte à rougir ; elle s'appelait Marie-Léonie Vanhoutte. 
Louise de Bettignies, qui ne la connaissait pas, l'interrogea, s'entendit avec elle, lui donna un jour pour réfléchir, et, quand elle revint, consentante, lui dit :

- Vous serez mon lieutenant et vous vous appellerez Charlotte. 
LA GUERRE DES FEMMES.

Histoire de Louise de Bettignies et de ses compagnes.

Chapitre II

CHARLOTTE

$\underline{\text { Retour à la table des matières }}$

J'ai voulu rendre visite à Marie-Léonie Vanhoutte dans l'importante maison de papeterie de Roubaix où chacun peut la voir aujourd'hui, doucement accueillante aux clients. J'ai trouvé une femme au regard droit, au parler net. Son teint vif révèle un sang pur. L'âme est très forte. Cette jeune fille, qui a partagé les épreuves de Louise de Bettignies, sera mon principal témoin. Sa compagne est morte ; elle, qui a survécu, m'a peut-être dit imparfaitement ce qu'elles ont fait l'une et l'autre, mais à ses réponses loyales, à la lumière de ses yeux devant certains souvenirs, j'ai senti quelles ardeurs les embrasaient toutes deux et quelles joies elles cherchaient dans leurs souffrances.

- Nous étions heureuses tout de même, dit-elle quelquefois en rougissant.

Aveu charmant, dont elle ne soupçonne pas la grandeur, quoiqu'elle en sache l'importance. Il importe, certes, de préférer la vie héroïque du temps de la guerre, malgré ses horreurs, aux heures médiocres qui ont suivi, n'apportant que du désenchantement à certaines natures d'hommes et de femmes. Une jeune fille qui s'est donnée tout entière aux autres, à tous les autres, pendant les années d'orage, est un peu heurtée par un air de médiocrité et d'égoïsme assez vil qu'il a bien fallu, la guerre finie, reconnaître à beaucoup de gens. Mon petit témoin s'en afflige, mais sans orgueil. Ceux qui ont vécu davantage et mieux sondé les cœurs savent 
qu'une telle douleur est un signe de race. L'humble fille qui allait servir aux côtés de Louise de Bettignies avait le cœur noble comme son chef : c'était aussi une aristocrate.

- Alice était très petite, me dit-elle souvent. Tant de force dans un corps si menu...

- Mais vous non plus, vous n'êtes pas grande.

Elle s'étonne. Le fait est qu'elle n'a pas la démarche d'une femmelette, mais un grand pas souple, comme ceux des soldats. Elle avance, nez et menton levés, l'œil ardent sous le lorgnon. On n'imagine pas ce que cette petite tête résolue a pu demander à ce corps mince et pas haut.

Quand arriva la guerre, Léonie Vanhoutte faisait depuis quelques semaines un stage à la Croix-Rouge. Dès le 2 août, elle travailla avec beaucoup d'autres à l'installation des ambulances. Toutes les femmes, toutes les jeunes filles offraient alors leurs services. Quelques-unes virent tomber leur zèle par la suite. Pendant plusieurs semaines, on s'empressa autour des premiers blessés français. On les gâtait ; c'était le bon temps. Puis commença l'invasion. À l'ambulance de la rue Pellaert, où elle était infirmière de salle, elle soigna encore quelque temps des Anglais et des Français. Arrivèrent les premiers blessés allemands; fallait-il se dévouer aussi pour ceux-là ? On lui demanda, comme à toutes ses compagnes, de rester pour veiller à la sauvegarde des intérêts de l'ambulance et ne pas abandonner la place aux infirmières ennemies. À Lille, Louise de Bettignies, au même moment, prenait le parti d'obéir à cette consigne. La petite Roubaisienne crut mieux faire en se retirant, mais elle garda deux objets précieux : son brassard et sa carte d'infirmière.

Nous sommes en octobre. Son frère, qui a cherché à fuir devant l'invasion, s'est trouvé bloqué à Frelinghien. Jours sinistres, où des milliers de civils, bons pour le service, couvraient les routes, pareils à d'immenses troupeaux poussiéreux sous le soleil, le regard vers l'ouest, les épaules ployées. Ils avaient peur, non de la guerre, mais qu'on les prît sans défense. Ils se hâtaient vers nos armées, pour se battre comme nous. Ils fuyaient, mais en braves. Ceux de Frelinghien ne reçurent pas les balles ennemies dans le dos. Une patrouille allemande apparut soudain au travers de leur route ; ils étaient pris. Le lamentable convoi dut rebrousser chemin. 
De ce jour, tous ceux d'entre eux qui avaient l'âme française et quelque force physique ne songèrent qu'à rejoindre la France libre, mais par où ?

Léonie Vanhoutte a entendu dire qu'on peut, en s'y prenant bien, gagner la Hollande. Son frère a vingt-huit ans ; les allées et venues d'un garçon de cet âge paraîtraient suspectes. Elle fera pour lui l'enquête nécessaire ; et, si l'aventure n'est pas folle, elle la dirigera.

Avec le brassard de la Croix-Rouge, on va partout. Elle quitte la maison de ses parents un matin à cinq heures, mais les rues sont consignées jusqu'à six heures. « Où allez-vous ? lui demande un Boche. - À la messe. - Il est trop tôt. - Laissezmoi passer tout de même. Je croyais qu'il était six heures. C'est ma montre qui avance. » L'Allemand regarde la figure si ouverte de cette petite menteuse, promène ses yeux sur le brassard, la montre, la carte d'infirmière. «Passez, dit-il ; schnell ?»

Voilà un mot allemand qu'elle comprend, un conseil qu'elle va suivre : vite à la frontière belge, vite à Mouscron, vite à Gand, où on doit lui donner le moyen de fuir en Hollande. Car elle est décidée à s'échapper avec son frère, à s'évader de ce bagne, elle aussi et très vite. Elle fait à pied soixante-dix kilomètres. À tous les postes allemands échelonnés sur la route, aux patrouilles volantes, elle montre sa carte et dit avec volubilité : « Je vais voir une tante malade au prochain village. Laissez-moi passer. Elle va mourir. » Les consignes n'étaient pas encore établies avec rigueur à cette époque. Cet aplomb, cette histoire de moribonde dans la bouche d'une infirmière déroutent les soldats, qui haussent l'épaule et laissent trotter la petite Française. À Gand, des amis sûrs lui donnent l'adresse de gens qui s'engagent, si elle revient bientôt avec son frère, à les faire passer par une voie sûre jusqu'en Hollande « Mon frère et moi seulement ? demande-t-elle. - D'autres, si vous voulez. - Combien ? - Pas plus de cinq en tout. - Moi comprise ? - Vous comprise. » Elle refait, en sens inverse, toujours par la grand'route, les soixantedix kilomètres. À Roubaix, où elle arrive harassée, mais si contente, elle trouve deux jeunes Belges et un Anglais qui la suivront. Elle leur fait promettre qu'arrivés de l'autre côté, ils rejoindront les armées combattantes. Ils ont tenu la promesse, les braves gens ; et deux ont été tués à l'ennemi : deux que le sort avait embusqués et qui se sont battus quand même. Avis à tant d'autres, qui vivent parce qu'ils ont été des lâches. Le pis est que de tels souvenirs ne les feront même pas rougir. 
Avec Léonie Vanhoutte, son frère et les trois autres, nous allons faire ce voyage de Roubaix vers la Hollande. Louise de Bettignies n'est plus là pour dire comment elle passait la frontière, ni ce qu'elle ressentait au long des durs chemins qu'elle a parcourus si souvent. Les premières impressions restent toujours les plus vives ; si elle n'était pas morte, la pauvre enfant, morte aux mains des Allemands, elle aimerait à nous conter, comme va faire son lieutenant, ses faux pas, ses naïvetés, ses terreurs et ses joies folles de débutante dans la carrière de bête traquée.

Le premier passage difficile est celui de France en Belgique. Car le régime n'est pas le même dans les deux pays et l'on ne circule pas comme on veut de l'un à l'autre. Les quatre hommes et la jeune fille sont partis chacun de son côté. Tous se rejoignent dans une rue de Tourcoing, au bout de laquelle est la barrière pour entrer dans Mouscron, ville belge. Sans cette barre de bois qui coupe la rue et qu'on soulève en la basculant quand se présente une voiture, on ne soupçonnerait pas que ces maisons qui se touchent, toutes pareilles, appartiennent à deux villes dont une seulement est française. Mais on ne va pas se présenter aux gardiens de ce poste important. La longue rue est bordée de petites maisons de briques sombres ; or, du côté belge et du nôtre, ces voies de faubourg sont comme des boyaux qui serpentent dans la campagne. Derrière les maisons basses sont des jardinets, puis la grande plaine, que sillonnent, au long des haies, des sentiers gris. Les voilà en file indienne, suivant ces pistes dans la verdure. On marche longtemps, longtemps, car les passages sont nombreux, mais bien gardés, et celle qui conduit J'expédition craint d'échouer aux premiers pas. Il fallut ce jour-là qu'elle descendit vers le sud-est jusqu'à Wattrelos. Là, elle savait une route mitoyenne. De telles routes font d'étranges frontières. Pour peu qu'un sujet du roi Albert titube un peu en sortant du café français qui, sur le trottoir d'en face, lui offre toutes sortes de boissons défendues dans son pays, il fait un pas en France, l'autre en Belgique, et à chaque élan vers la ligne droite, passe en se balançant d'un pays à l'autre. Au milieu de la chaussée, de distance en distance, des jalons : ce sont des pavés parmi les autres, mais beaucoup plus gros, comme ceux qui marquent, devant l'ancien portail de la Roquette, les cinq pieds de la guillotine. Les maisonnettes se regardent, et les commères aussi, qui jacassent aux portes. Pendant la guerre on avait mis du fil de fer barbelé un peu partout, mais pas devant les maisons. Quand celles-ci, comme il arrive en quelques endroits fameux et bien repérés, se font face, 
des sentinelles surveillent leurs habitants, petit monde plus sournois et turbulent que terrorisé.

Là, on n'avait pas attendu la guerre pour frauder et l'on s'était préparé, dans le dos des douaniers, à faire la nique aux Boches. Le problème, pour la petite Vanhoutte et sa troupe, est de traverser la chaussée tandis que l'Allemand qui fait les cent pas aura le dos tourné. Elle a pris des vêtements de paysanne, un petit châle, un tablier, un filet à la main. Eux, coiffés d'étonnantes casquettes, ont une bêche sur l'épaule ou un panier au bras. Ils ont pénétré par le jardin dans une maisonnette française et se tiennent silencieux dans la salle, le cœur battant. Elle se met sur le seuil avec l'un d'eux. À la minute propice, elle le conduit à la porte d'en face, qui s'ouvre. L'Allemand n'a rien vu : le tour est joué. Il faut revenir pour prendre le suivant. Quatre fois, elle fait ce voyage hasardeux, qu'un coup de fusil peut arrêter net. Quatre fois dans les deux sens. Au dernier tour, les yeux de la sentinelle l'inquiètent. Ce soldat est en éveil. Il regarde la petite maison peinte à la chaux, les volets verts, le toit bas; et la jeune fille, sous la porte, s'impatiente en tâchant que cela ne paraisse pas. Alors elle paie d'audace :

- Laissez-nous passer, murmure-t-elle. Nous avons un mot à dire en face...

- Schnell ! dit le Boche indulgent.

Mlle Vanhoutte assure, et je la crois, qu'elle se sentait légère et heureuse après de tels passages et qu'elle se serait bien mise à danser sur la route. Mais il ne s'agit pas de gambader : il faut marcher d'un bon pas, rattraper le temps perdu et rentrer dans Mouscron, où l'on doit prendre le train vicinal pour Courtrai. À la gare, on se met en queue d'une longue voiture, qu'un couloir traverse par le milieu ; aux deux bouts, des plates-formes. Le conducteur, moyennant une piécette, avertit les voyageurs, à la station suivante, qu'un policier boche est monté en tête et va visiter les passeports. Toute la bande descend à contre-voie, longe la voiture et remonte, le contrôleur passé, sur la plate-forme d'avant. Encore un danger écarté ! On est content, on trouve pendant cinq minutes qu'il n'y a rien de plus facile au monde que de gagner la Hollande à la barbe des Allemands.

À Courtrai, on descend à l'hôtel Bellevue : les patrons sont des gens sûrs, patriotes et serviables. On fait chez eux une bonne nuit et, le lendemain à la première heure, un grand bol de café dans l'estomac, on s'engage sur la route de Gand. Quarante-cinq kilomètres à abattre en un jour, car on est attendu le soir. Cette 
route, Louise de Bettignies et sa compagne l'ont suivie bien des fois. C'étaient neuf heures de marche. Elles partaient d'un bon pas, le cœur plein de courage. Avant chaque poste militaire, elles tâchaient de trouver une maison pas trop hostile, où l'on entrait pour se reposer un peu; il s'agissait de faire parler les bonnes gens, de recueillir quelques informations sur les Boches devant lesquels il faudrait passer, leurs habitudes, le moyen de leur filer dans les doigts. Si on les disait intraitables, il n'y avait qu'à prendre les sentiers derrière les maisons. À Harlebeke, la boutique où on s'arrêta ce jour-là était une pâtisserie, à droite avant l'entrée du bourg. Toute la bande y fut si bien accueillie que, par la suite, Léonie Vanhoutte ne manqua jamais d'y entrer, d'y manger un gâteau ou d'y boire un bol de lait, pour se donner du cœur et des jambes. Elle est droite, cette route de Courtrai à Gand ; on voit toujours au bout le même bouquet d'arbres qu'on n'atteint jamais. Sur la chaussée, pavée de gros grès, passent des convois de ravitaillement, qui soulèvent la poussière et vous cassent les oreilles. Les trois Français et l'Anglais qui vont en Hollande marchent devant la jeune femme ; la pelle sur l'épaule ou le panier au côté, à vingt mètres les uns des autres, ils jouent assez mal leur rôle de paysans. Le diable est d'empêcher les Français de porter le doigt à la coiffure pour saluer les passants. C'est un geste que ne font jamais les Flamands, et qui va trahir ces garçons : la jeune fille les a suppliés d'y faire attention. Et quand on ne leur donne pas un outil ou un paquet à porter, ils ont la manie, surtout ceux des carrières libérales, de déambuler les mains derrière le dos comme des penseurs. Pas facile à conduire, tous ces hommes. Et les petites bergères, qui sur tant de routes de France et de Belgique, le jour et la nuit, les ont guidés vers les champs où l'on se bat, vous diront toutes qu'elles faisaient là un métier dont elles restent fières, mais bien ingrat. Si elles n'avaient redouté, que l'ennemi ! Mais on ne mène pas des hommes comme des moutons, de pauvres hommes avec leurs manies, et si étourdis, quelquefois si poltrons. Nous avons tous eu peur à la guerre, même quand nous étions des braves: la question était de se dominer. Nous avons eu peur, mais pas devant des femmes. Ces petites ont vu des regards d'hommes angoissés. Léonie Vanhoutte et ses pareilles, surtout cette étonnante Louise Thuliez, qui passait ses nuits sur les routes à pousser vers le nord-est des troupeaux entiers de grands garçons de toutes les langues, française, anglaise, flamande, ces petites créatures, on petit leur prêter une âme audacieuse : c'était tout de même un cœur de femme qui habitait d'aussi frêles carcasses, un cœur fragile, prompt à s'émouvoir et qui, à la moindre alerte, eût volontiers trouvé le soutien d'une volonté mas- 
culine. Il est assez désagréable de penser que, si elles ont convoyé quelques héros, elles ont vu de trop près le pauvre cas qu'aux minutes de décision les femmes peuvent faire de beaucoup d'hommes.

Peu après Harlebeke, notre petite troupe est rattrapée par une charrette ; la jeune fille jette un regard pitoyable au paysan, qui s'arrête et, moyennant cinq francs par tête, la laisse monter et cueille au passage les quatre hommes. On arrive ainsi à Zulte, où il faut descendre. Les trois Français disent zut : cela s'imposait. L'Anglais sourit et comprend seulement que voilà toujours dix kilomètres avalés sans fatigue.

À la sortie du bourg, sur la droite, est un château dont les fossés sont pleins d'eau. Un général doit habiter là, avec tout son état-major. Au moment où nos fugitifs longent les douves que borde la chaussée, une limousine entre en trombe dans le beau pare, manque son virage et tombe à l'eau. Voilà mes quatre hommes et leur compagne qui s'accoudent sur le parapet et regardent patauger les Boches. Ce devait être assez drôle, car ils rient à belles dents tous les cinq. Un sousofficier les voit, court à eux : « Vous partir... Allons ! partir... » leur crie-t-il.

Ils ne demandent que cela. En route donc et vivent la France et l'Angleterre ! C'est incroyable comme on se sent courageux quand on a vu deux grands officiers allemands tout chamarrés barbotter dans la vase et se fâcher comme des sots.

On arrive, bien las, à Saint-Denis-Western. A l'auberge où on s'arrête un instant, Léonie Vanhoutte raconte à ses compagnons, pour les amuser, qu'en août 1914, les hordes germaines, qui déferlaient comme les vagues de la mer, agitaient les armes avec frénésie. On leur avait dit que Saint-Denis était aux portes de Paris. Voilà donc ce Saint-Denis et la grande ville toute proche ; et la guerre va finir. On rit un coup en traitant d'idiots tous ces gars-là. Puis les yeux se font graves : la jeune fille parle de l'aiguilleur qui, de son poste situé au passage à niveau qu'on va traverser dans un instant, notait tous les trains qui passaient, le nombre des voitures et ce qu'elles contenaient; et chaque jour son rapport partait pour les armées de l'Entente. Il fut dénoncé et fusillé... Fusillé ! Peut-elle dire ce mot, à cette heure, sans un frisson ? Elle se lève : «Allons, du courage, mes enfants. Vous quatre, je ne vous laisserai pas prendre. »

À l'entrée de Gand, le poste allemand est sous le large pont du chemin de fer. Léonie Vanhoutte, qui connaît déjà le truc de la boîte d'allumettes, en use avec 
succès. Tandis que la sentinelle examine ses papiers, elle laisse tomber la petite boîte, qui rend un son métallique. Le Boche comprend, la laisse passer, puis ramasse les allumettes et la monnaie. C'est dangereux, cette histoire-là. Quand le soldat ne veut pas comprendre, on l'entend grogner; il n'y a plus qu'à ramasser la boîte, comme si c'était par erreur qu'on l'avait laissée choir. Alors si les passeports sont louches, on risque gros. Comme ils le sont toujours, c'est chaque fois une minute tragique. On passe, on respire. Il arrivera qu'un jour on ne passera pas.

De Gand, Léonie Vanhoutte gardera toujours un aimable souvenir. Il faut que nous entrions derrière elle dans l'hôtellerie où, avec Louise de Bettignies, elle est si souvent descendue. C'est à l'enseigne de «La Ville d'Audenarde », chaussée de Courtrai. Ce soir, avec ses quatre hommes, elle y reçoit accueil pour la première fois. Tous les cinq pénètrent sans façon dans la grande salle du café, toute grouillante de civils et de soldats. Les clients les plus assidus, les plus bruyants, ceux qui consomment et paient le plus largement, ce sont les gens du ravitaillement. C'est toute la tourbe des profiteurs militaires et civils, bons buveurs et joyeux sires ; la guerre ne les a pas faits sanguinaires, mais sanguins. Ils regardent, de leurs petits yeux dans la graisse, les Belges vaquer à leurs affaires et comploter s'ils veulent. Leur souci est de tirer un gros parti des événements et qu'on leur fiche la paix. Léonie Vanhoutte joue des coudes sans trop d'émotion parmi ces gens-là. C'est dans les lieux les plus peuplés qu'on se cache le mieux. Et puis, la maison est si commode. C'est un bâtiment d'angle, avec trois entrées. On peut toujours filer si quelque policier paraît dans la place. La maîtresse de céans, qui connaît bien son monde, a vite fait de dire à l'un de ses enfants : "Va prévenir la dame qui est au coin, là-bas, pendant que je vais amuser ceux de la secrète. » Vous n'imaginez pas comme c'est utile d'avoir des enfants quand on est aubergiste et qu'on loge des patriotes. Dans cette maison, une fenêtre du premier étage donne sur des toits et ceux-ci communiquent avec la cour du voisin où l'on peut descendre tranquillement et sans bruit à la première alerte. Mais si c'est la nuit et qu'on laisse un lit défait, les gens de la police verront qu'un oiseau s'est envolé. Alors la patronne a décidé que ses deux garçons, des gamins de douze et quatorze ans, coucheraient dans le même lit et qu'au cas où se sauverait un client, l'un des gosses irait se couler dans les draps chauds du fugitif. 
En voilà une qui ne craint pas les responsabilités. Elle risque le poteau, pour elle et ses marmots. Je l'ai bien regardée tandis qu'essuyant des verres à son comptoir, elle avait quelque peine à dégager pour nous ses vieux souvenirs étouffés.

- Ah ! c'est mademoiselle Charlotte, dit-elle en reconnaissant, après huit ans, Léonie Vanhoutte. Quelles bonnes nouvelles?

Elle tend sa forte main à celle dont le nom de guerre était Charlotte, comme Alice était celui de Louise de Bettignies. Mais ici on ne disait pas Alice. La patronne avait trouvé un autre nom, qui allait à merveille à l'ardente jeune fille.

- Et Vite-Vite ? dit-elle, est-ce bien vrai, qu'elle est morte?

Elle nous parle tout bas de Vite-Vite. Les anecdotes reviennent lentement à sa mémoire. Je les recueille et je vous les conterai plus loin. Je voudrais savoir pourquoi la bonne femme s'est tant compromise pour cette Alice et cette Charlotte, dont elle ignorait tout, sinon qu'il était important de les cacher. Elle me répond par un haussement de ses épaules massives, et cela veut dire :

- Mon Dieu, je n'en sais rien. Je les voyais en danger, et si gentilles !

Elle regarde, avec de tendres yeux mouillés, celle qui a survécu.

- Venez voir votre chambre, dit-elle.

Nous y entrons avec émotion. C'est tout petit et propret. L'alcôve est sous l'escalier et l'on a mis la tête du lit du côté des marches, de sorte que si Louise de Bettignies, qui a logé là bien souvent, tentait de s'asseoir pour lire avant de s'endormir, elle était sûre de se heurter la tête à des arêtes de bois blanchies à la chaux. Des murs tapissés de papier clair, une petite fenêtre et des lambris vert d'eau. Du linoléum sous les pieds. Au-dessus de la chaise qui est au pied du lit, une gravure jaunie et un peu tachée représente Psyché offrant des présents à ses sœurs. La toilette est d'acajou et point grande, avec une glace ronde à bascule, dans laquelle la pauvre enfant se mirait pour donner à sa chevelure magnifique, en la tirant bien sur les tempes, des façons campagnardes.

Quand il a fallu quitter cette bonne hôtesse, j'ai serré sa main avec amitié et peut-être a-t-elle trouvé que c'étaient là bien des manières. Elle a été une héroïne sans trop le savoir. Tout au plus sourit-elle de ses yeux clairs à des souvenirs dont elle sent confusément qu'ils l'honorent, mais qui sont une petite chose dans son passé. La vie droite de certaines gens, surtout dans le peuple, est toute nourrie de 
menues vertus, auxquelles on n'a pas coutume de faire attention. Eux-mêmes rougiraient d'en tirer vanité. Un jour arrive où leur humble honnêteté prend des airs de grandeur : leur âme n'a pas changé, mais ils ont fait le bien, sans y penser, sur une scène plus grande et mieux éclairée. Ces braves gens qu'on ne voyait pas, un grand projecteur comme ceux que nous avons connus à la guerre, les a mis tout à coup dans la lumière.

Cependant Léonie Vanhoutte, ayant fait dîner ses quatre compagnons, pourvoit à leur logement pour la nuit. Elle ne les installe pas, cette fois, à l'hôtellerie, mais chez une autre femme dévouée, boulangère de son état ; puis elle se rend chez l'ami qui s'est chargé d'organiser l'étape décisive, de Gand à la frontière. Avec celui-ci, elle s'en va, toute fourbue, les jambes brisées, les pieds brûlants dans ses minces souliers de marche, reconnaître le poste de départ pour le lendemain. On prend rendez-vous. Tout est réglé. Alors elle peut gagner son lit, dire un bout de prière et souffler la bougie.

À l'aube, les cinq voyageurs s'empilèrent dans une grande voiture garnie de fourrage et on leur mit des bottes de paille en voûte autour du corps et sur la tête. Recommandation suprême : pas un geste, pas un cri, même si des policiers allemands à cheval, pris de zèle, sondent la marchandise et piquent dans la chair vive. Deux autres voitures sont chargées aussi de fourrage. On met l'une devant celle qui contient les fugitifs, et l'autre derrière. Et voilà le convoi en route. Ce sont des marchands de cochons qui portent de la paille à Bouchaute, dernier village avant la frontière, et qui ramèneront des porcs.

À chaque poste boche, on s'arrête. La première voiture a pris une forte avance. Les soldats la visitent, enfoncent la lance dans le fourrage ; puis le conducteur, qui est un habitué, entre au poste, bavarde, amuse son monde. La voiture suspecte, pendant ce temps, est arrivée. Elle se place un peu en avant de la première. Son conducteur, aussi un habitué, entre dans la maison, cause avec les Allemands. Puis on sort. Il présente la seconde voiture, celle qui a déjà été visitée, comme la sienne. L'autre cocher, qui est en règle, met en branle l'attelage de tête, entraînant des gens dont les cheveux sont ébourriffés dans la paille et qui étouffent, avec des fourmis dans les membres et de la poussière plein la bouche, plein le nez, plein la peau en sueur, mais qui sont si contents. 
Pas une fois dans la journée, les patrouilles, pourtant nombreuses sur cette route, ne piquèrent la fourche ou la lance dans le chargement de chair fraîche. Quand nul ennemi n'était signalé à l'horizon, on passait la tête, pour respirer un peu. Songez que ce voyage si inconfortable dura de neuf heures du matin à six heures du soir. Au début, en quittant Gand, on avait suivi une route majestueuse comme une allée de pare, bordée de peupliers hauts et touffus, route pavée comme toutes celles de ce pays; dans le char sans ressorts on sentait d'ailleurs les pavés inégaux, beaucoup plus qu'on n'admirait les grands arbres. Après l'alerte du poste d'Ertevelde, un moment de pause pour casser la croûte. Puis la route devient plus intime ; on passe parmi des jardins entourés de haies. Le pays est aussi plat, mais sans ces horizons, vastes comme la mer, qui donnent tant de majesté aux paysages flamands. On est enfermé dans des murailles vertes et, comme on a le cœur chargé d'angoisse, ce décor sans air est étouffant. La route se resserre encore. Voici les abords de Bouchaute. Il faut rentrer les têtes et faire silence sous le fourrage.

Vous pensez bien que ce village de la frontière est sévèrement gardé. Avant d'arriver au bourg, la route est coupée par la voie ferrée. C'est une ligne qui joint Anvers à Bruges et à Ostende. À la gare, placée tout contre le passage à niveau, est un gros poste de surveillance. Ne peuvent le franchir que les habitants de Bouchaute. Les trois voitures ne traverseront pas, bien entendu. Elles s'arrêtent à quelques mètres de la barrière et les conducteurs, sans rien dire, commencent à dételer. Là se trouve, à l'anode gauche de la route, avant la voie ferrée, une maison de briques. C'est une sorte d'auberge ou, comme on dit là-bas, un estaminet. Au-dessus de la porte, en lettres noires sur fond blanc sale, on lit le nom du propriétaire, que nous pouvons retenir : Edmond Dhollander. Ces gens-là vont recevoir les voyageurs cachés sous la paille et les feront passer en Hollande. Pour l'heure, avis est donné à mi-voix à la jeune fille et aux quatre hommes de se tenir cois dans leur cachette jusqu'à la pleine nuit.

Le moment venu, on les invite à descendre avec mille précautions, car, à vingt mètres, de l'autre côté de la barrière, des sentinelles aux aguets ont une consigne impitoyable : ici on fait feu sur les civils comme on tire un lapin. Un à un, les quatre et leur guide en jupons, en jupons bien chiffonnés, pénètrent dans la maison, dont toutes les lumières sont éteintes. Léonie Vanhoutte avoue qu'à cette minute elle a eu grand'peur. Dans l'ombre une grosse femme au parler barbare, trois 
hommes qui font penser à des brigands beaucoup plus qu'à des hôteliers, discutent un moment, puis on sert le café sur une table malpropre. C'est chaud ; cela ferait du bien si on savait mieux qui sont ces gens-là. Tout a coup la femme, qui n'avait parlé que flamand jusque-là, dit :

- Maintenant, coucher.

Elle les conduit au grenier par un escalier qu'on prendrait plutôt pour une échelle à poules. Au fond, deux cloisons grossières à angle droit : c'est une chambre dans un coin. Trois des hommes y sont poussés par l'hôtesse. Il y a là des bottes de paille. Ils se couchent : dix minutes plus tard, ils ronflaient comme des dieux. La jeune fille et son frère sont restés dans le grenier. Elle s'assied sur une malle, tout près du trou où débouche l'escalier. Lui s'étend à ses pieds. Elle ne dort pas. Il y a ici une odeur de saleté, qui dégoûte et révolte la pauvre enfant. Elle meurt de sommeil et de froid, mais se raidit. La paille sur laquelle dorment les autres ne la tente pas : assez de paille pour aujourd'hui.

Des pas dans l'escalier. Elle frisonne. C'est la femme, qui dit d'une voix lugubre

- Minuit. Faut descendre.

On les fait entrer dans une petite pièce au bas de l'escalier. Encore du café chaud, mais avec du pain gris, peu appétissant, qu'on trempe dans le jus. Deux Flamands sont assis à droite et à gauche de la cheminée. Ils se taisent et semblent soucieux. Puis la bonne femme tend la main : c'est l'heure de payer.

- Combien? demanda la jeune fille.

Avec ses doigts, elle montre que c'est vingt cinq francs par personne.

Pour vingt-cinq francs, on vous conduit de l'autre côté de la frontière : c'est la liberté à bon marché. Un des jeunes gens a l'idée d'offrir dix francs de plus.

- Ça jamais ! dit la femme. Nous, pas trafiquants.

Elle paraît indignée. Léonie Vanhoutte avait eu peur jusque-là, pas de la route à faire, mais de cette grosse femme dans la nuit et des visages moustachus, immobiles contre la cheminée. À ce cri honnête, elle reprend confiance et tend son bol pour qu'on lui serve encore du café.

- Ayez du courage, lui dit alors un des Flamands. Vous avez l'air effrayée. 
- Non, monsieur, plus du tout.

Au dehors, la lune s'était levée. Un des hôteliers, quittant sa chaise, alla lentement vers la porte, écouta un instant, puis rentra la tête dans la petite salle et dit sourdement

- Venez, c'est le moment.

Alors tout le monde sortit dans la cour, derrière la maison. L'homme qui avait parlé fit un signe d'adieu à la femme et, longeant le mur, disparut à l'angle du bâtiment. L'autre plaça les quatre jeunes gens en file indienne et donna ses instructions dans une langue impossible, mi-flamande, mi-française. Lui, se mettrait en tête ; la jeune fille fermerait la marche. On se serrerait très fort les uns contre les autres, de façon à ne faire qu'une ombre courte sous le clair de lune. Il ajouta, avec un geste impératif :

- Rien dire. Bien écouter pour obéir.

Puis il passa devant chacun, serra les mains et prononça des mots informes qui voulaient dire :

- Nous allons risquer notre vie pour sauver la vôtre.

Léonie Vanhoutte m'a déclaré qu'elle n'oublierait jamais cette minute solennelle, après laquelle, ayant levé le bras, l'homme entraîna sa petite troupe.

Si sévère que fût la consigne des sentinelles placées au passage à niveau, les soldats qu'on mettait là étaient des soldats comme les autres. À l'heure de la relève, ces garçons n'étaient pas disposés à attendre indéfiniment les camarades endormis dans le poste. Dans le jour, c'est la sentinelle montante qui vient libérer la descendante. La nuit, l'homme qui veille et trouve le temps long, quitte son poste et va secouer le dormeur qui le remplacera. Toutes les deux heures, le passage à niveau restait donc quelques instants sans gardien. Le secret des guides était de passer à ce moment avec leur troupe.

Cette nuit, l'affaire est aventureuse à cause de la lune. Le premier homme, celui qui est parti seul, est là, contre la barrière. Il se redresse : c'est le signal. On le voit courir en avant. Puis le long corps que font les cinq hommes et la femme chemine à sa suite en ondulant comme une chenille noire sur le sol blafard. Les guides ont mis aux pieds des sandales, et les fugitifs ont emmaillotté leurs souliers dans des chiffons. Sans bruit, la barrière est passée. On ne saurait croire comme 
c'est large, une voie ferrée, quand il faut la traverser ainsi. Tout de suite après, on quitte la route pour se jeter à droite dans des sentiers à travers champs. On marche longtemps. Soudain un chien aboie. Alors tout le monde se jette à plat ventre. C'est une minute terrible. Le guide est impatient d'avancer : on l'entend grogner. Au loin, on perçoit l'appel lugubre d'un grand-duc. On dirait un sifflet à roulette, mais dont la note serait plaintive. L'homme de tête, à qui nous donnerons désormais son nom d'Isidore, parce qu'il en a fait celui d'un héros, sait bien que ce grand-duc n'a pas de plumes et que le cri qui déchire ainsi la nuit sort du gosier de son compagnon, parti en avant. C'est un signal, auquel il faut se hâter de répondre en se présentant au passage reconnu. Le chien hurle toujours à la lune. L'homme décide, entre tant de dangers, de braver celui-là. On se relève. L'oiseau lointain continue, à intervalles réguliers, sa plainte. On court vers lui, laissant derrière soi la voix du chien, qui s'éteint peu à peu. L'herbe est mouillée, on trébuche dans les sillons : il faut marcher, marcher. On arrive enfin à vingt mètres d'un fil de fer. On se couche et l'on voit la barrière barbelée se dessiner sur le ciel clair.

Alors commence le passage. Le fil de fer qui semble si proche, il faut, pour arriver jusqu'à lui, traverser une sorte de ruisseau, l'un de ces petits canaux d'irrigation qui, dès la frontière, sont la marque de la Hollande. Le guide fait signe à toute l'équipe de demeurer là, à plat ventre, sans un mouvement. Puis il rampe avec le premier homme jusqu'au bord de l'eau. Il le charge sur son dos, descend dans la rivière, la traverse, mouillé jusqu'à la poitrine, et, ayant rejeté son paquet sur l'autre rive, fait un geste qui signifie: "Attendez là sans bouger. » On est trempé, mais on ne songe pas a se secouer comme un chien, ni à courir comme aux bains de mer pour la réaction : on se tient coi et l'on regarde avec effroi bouger les herbes qu'on prend pour des sentinelles. Cependant, les autres arrivent tour à tour et cela fait à la fin cinq paquets inertes qui sont tombés sur la berge. Au signal, on se remet en mouvement, rampant très bas, jusqu'aux fils de fer. Le guide s'est dressé à demi et a soulevé la barrière piquante ; en file indienne, on se glisse sous elle, non sans commettre la faute inévitable des débutants, qui est de se relever avant que tout le corps ait passé.

À ce moment, le guide a un conciliabule avec son compagnon, l'homme au cri d'oiseau, qui vient de surgir dans les herbes. Puis tous deux donnent, comme ils peuvent, en faisant de grands gestes, des explications à Léonie Vanhoutte. Ils font ensuite à tous les cinq un grand signe d'adieu et disent : 
- Allez !

Alors, les quatre hommes, précédés de la jeune fille, se mettent à courir droit devant eux. Ils trouvent, au bout de cent mètres, un petit ruisseau qu'on peut sauter, puis un grand talus. C'est bien ce que leur a dit le guide. Ce talus, c'est une digue des Pays-Bas. Ils croyaient trouver au haut une voie ferrée, comme il arrive en France ; c'est une route, avec des arbres ; ils la traversent et dégringolent de l'autre côté. Ils sont en Hollande, à l'abri de tout, même des balles perdues que pourrait lancer quelque sentinelle affolée. Alors le jeune Vanhoutte, qui s'est assis sur l'herbe glacée, comme tous les autres, se serre contre sa sœur et veut la remercier.

- Et si ces gens nous ont trompés ! dit-elle.

Elle n'osait croire que ce fût fini. La nuit était redevenue noire. Isidore avait recommandé qu'ils attendissent le petit jour. Alors ils verraient à leur droite un clocher, celui du bourg de Philippine et ce serait leur point de direction.

Anxieux, sans bouger, sans parler, sans dormir, presque sans penser, ils attendirent le soleil, Ils mouraient de froid. Quand l'horizon parut s'éclaircir un peu, ils se mirent en marche, avec des précautions et une timidité dont ils auraient eu honte de l'autre côté. Ils ne tremblaient pas ainsi sous la menace des Allemands. C'était de tenir en mains un bonheur si grand qui les effrayait. S'ils allaient le perdre !. Et justement, la jeune fille a cru tout à coup que tout cela n'était qu'un rêve voici des Boches, tout un poste, où elle est entrée sottement, comme une souris dans un piège.

Imaginez son émoi. Ils sont arrivés aux abords du village. Ils croient reconnaître un presbytère : elle sonne. Un homme en chemise paraît à là fenêtre, secoue la tête et se renferme. Alors elle avance un peu, disant aux camarades de l'attendre à ce tournant. Elle reconnaîtra les lieux et, si tout est sûr, viendra les chercher. Au coin d'une grande place plantée d'arbres, voici une belle maison. C'est la mairie avec ses deux écoles à chaque aile. À gauche un portail, d'où s'échappe un filet de lumière. La petite Française hésite un instant, puis pousse un peu la lourde porte qui grince.

Des soldats allemands sont là, les uns dormant, d'autres se chauffant les mains au poêle bien rouge ; l'un de ces derniers, qui a tout de suite aperçu l'intruse, la regarde, comme font tous les soldats du monde, en rigolant. 
- Vous, Allemands ? dit-elle, glacée de peur.

- Nicht, nicht!

Et il ajoute avec une large sourire :

- Vous, Belge ?

- Oui, traversé pour aller voir mon frère.

- Vous brave, beaucoup courage... Café ?

C'étaient de bons types de l'armée néerlandaise, des neutres très rassurants et pleins de pitié. Elle respire, court chercher ses compagnons et voilà toute la bande au poste qui se réchauffe, boit du jus bouillant, tandis que les soldats, essayant de lier conversation, gesticulent comme on pouvait faire à la tour de Babel.

Quand le jour est tout à fait venu et que s'ouvrent les maisons, l'un des soldats conduit la petite troupe de l'autre côté de la place, à l'auberge du Cygne, In den Swan. Là, on les reçoit avec humanité. On leur donne de l'eau chaude, du savon, des serviettes bien blanches. On allume un grand feu dans la salle claire qui se trouve à gauche de l'entrée ; tous ont les pieds trempés : ils les font fumer devant la flamme ; il y a là un divan, où les pauvres gens sont heureux de s'affaler et bientôt on leur apporte un vaste saladier rempli de moules fumantes. Philippine est le centre d'un important marché de moules. J'en ai mangé d'excellentes et fortement assaisonnées quand j'ai fait le pèlerinage des lieux qu'a parcourus ma petite héroïne. Elle a dû garder, elle aussi, un bon souvenir de l'auberge In den Swan, du jardinet si frais derrière la grande salle, de l'omelette au jambon et du zèle affairé de l'hôtesse. Mais il ne s'agit point de s'attarder. On se préoccupe de trouver une voiture pour Terneuse, d'où l'on gagnera Flessingue. Il y a quelques difficultés pour les passeports, mais ce sont des détails. On ne va pas échouer en Hollande et s'y faire interner, quand on a traversé heureusement plus de trente barrières allemandes. À Flessingue, aventure singulière, il faut attendre quatre jours son tour d'embarquement pour l'Angleterre : c'est que les gens qui viennent de Belgique et de France sont légion. Ils ont passé par où ils ont pu ; d'autres fraudeurs faisaient, toutes les nuits, à tous les passages de la frontière, le métier des frères Dhollander. L'histoire de Léonie Vanhoutte et de ses quatre compagnons n'est donc pas extraordinaire : c'est un coup de hardiesse entre mille. Le merveil- 
leux n'est pas que des jeunes filles comme elle et comme Louise de Bettignies aient passé une fois, c'est qu'elles aient recommencé.

Le quatrième jour, les jeunes gens s'embarquent et la petite Française, qui agite son mouchoir tandis que le navire s'éloigne lentement, ne sait pas encore ce qu'elle va faire. Son frère lui a conseillé de ne pas les suivre en France, où elle sera seule, sans foyer. Sa mission, qui était de le rendre à son devoir, est accomplie : qu'elle rentre auprès de ses parents. Flessingue est tout peuplé d'agents des divers belligérants. L'un d'eux, au service du gouvernement belge, incite vivement la jeune fille à rentrer en pays occupé. Il l'assure que l'expérience qu'elle vient d'acquérir va lui permettre de rendre à son pays des services. L'idée d'être utile lui agrée. Et, dix à douze jours plus tard, ayant trouvé un guide sûr, elle rentre à Bouchaute, mais par un nouveau chemin.

Cet autre passage est encore plus facile que le premier. Dans le langage des héros qui les ont utilisés, ces chemins dangereux s'appelaient des "tuyaux ». Il parait que le « tuyau » que je vais vous faire connaître était vraiment le plus sûr et le plus agréable de tous. Louise de Bettignies, qui n'a probablement jamais passé par le premier, a connu celui-là. La frontière hollandaise, à cet endroit, fait une boucle hors de la digue qui constitue, dans ces parages, sa bordure habituelle. On peut donc traverser cette digue et descendre son talus du côté belge, à la vue des Allemands, sans aucun risque. Il y a là, en pleine Belgique, un coin de terre et une maisonnette qui appartiennent à la Hollande. Du jardinet de cette maison au jardinet voisin, qui est belge, une haie à traverser. On l'a renforcée avec des fils de fer. Plus tard on devait y mettre un courant électrique. Mais les riverains ont mille ruses. Il y a l'étable à porcs contre la maison. Elle est basse et de son toit, facile à escalader, on saute la frontière comme on veut. Surtout on s'entend avec les Boches. Ceux d'ici ne sont pas des combattants au repos, mais des vieux de la Landsturm, qu'on a mis là à poste fixe et qui connaissent toutes les têtes du pays. Ainsi les inconnus ne passeront pas. Et c'est bien vrai que nul ne traverserait ce hameau sans guide. Mais justement on a des complices dans telle ou telle de ces maisons qui, au milieu de leurs vergers, font penser, avec leurs volets verts, aux bergeries de bois de nos enfants. Depuis que cantonnent là ces vieux territoriaux, les habitants ont sondé leurs cœurs, leurs reins, le creux de leurs mains ; une pièce à celuici, un sourire à celui-là ; et la sentinelle, au moment voulu, regardera d'un autre 
côté. Le jour où Léonie Vanhoutte passa, on lui dit, à peine entrée dans la maison belge la plus voisine de la frontière :

- Vite, habillez-vous. Il faut avoir fini de traverser tout le village avant cinq minutes.

On l'aide à se dévêtir. L'homme qui vient de lui parler fourre pêle-mêle tous les vêtements de la pauvre enfant dans son panier et file en avant. Tandis qu'elle s'attiffe en paysanne, une bonne femme lui réclame le prix du passage. On avait parlé de vingt-cinq francs : celle-ci lui en demande cinquante. Elle voudrait discuter. On lui commande, avec force, de payer. On lui met dans la main l'une des poignées d'un grand panier de linge. Une autre femme, vêtue comme elle, prend l'autre poignée. Et les voilà trottant par le pays. C'était la minute favorable, celle des sentinelles complices.

Elle arrive, après maintes aventures, à Gand, puis à Roubaix. Elle est toute chargée de lettres. Car, de Flessingue, elle a envoyé des nouvelles à tous les soldats, à tous les évacués, dont elle connaissait les familles. On lui a répondu. Elle distribue cela au retour. On se demande d'où tombent ces bouts de papier qu'on accueille en les bénissant. On n'aimait pas beaucoup alors, quoiqu'on les utilisât, les gens qui vivaient du trafic des lettres. Ce n'était pas le cas de cette petite, qui, spontanément et discrètement, apportait des nouvelles à ses amis, même à des inconnus, pour la seule joie de secourir un peu son prochain. Elle raconte des histoires fantastiques, n'importe lesquelles, pourvu que nul ne sache qu'elle a conduit des soldats là-bas et qu'elle en est revenue. On aime tout le monde dans ces grandes détresses communes et cependant on se méfie de tous, même des plus chers. Ainsi est faite l'humanité : il n'y a jamais de tendresse sans réserve. Ici, la tendresse était immense, spontanée ; la réserve était d'autant plus farouche. Le pire est qu'elle était justifiée.

Un peu plus tard, ayant trouvé trois jeunes hommes désireux d'aller se battre, elle décida de les emmener. Cette fois, elle recueillit comme elle put des renseignements sur les mouvements de troupes et les emplacements de batteries. Avec ce menu bagage et ses trois soldats, elle refit, à peu près dans les mêmes conditions et par la même voie, le grand voyage. Au retour, elle distribua encore des lettres et nul ne sut d'où elles venaient, sauf une femme de cœur appartenant à la haute société industrielle de Roubaix. Celle-ci lut tout de suite frappée des servi- 
ces que pourrait rendre une telle jeune fille. On venait de lui parler de Louise de Bettignies. Elle les présenta l'une à l'autre.

Après cette entrevue, que nous connaissons, Léonie Vanhoutte demanda quelques heures pour réfléchir. Elle alla trouver un homme de bon conseil, qui, la sachant de cœur droit, lui dît simplement : «Si vous hésitez, abstenez-vous. Si la tâche vous tente et que vous vous sentiez du courage, allez. - Et mes parents ? Ils ne conseilleront pas à leur fille de se sacrifier. C'est à vous de leur dire : je veux. » La mère opposa une vive résistance. Le père céda le premier : «Si c'est pour bien faire, mon enfant, je te permets. » Ils l'embrassèrent.

Aujourd'hui, tandis que je l'interroge sur l'impression que lui fit Alice ce premier jour, elle rassemble sans peine ses souvenirs et ne cache point que le regard vif, le parler net, le geste autoritaire de la petite personne qui allait être son chef lui firent une forte impression.

- Je sentis que j'avais devant moi une jeune fille capable de très grandes choses. Je fus dominée tout de suite. J'étais prête à la suivre partout.

Elle se tut, paraissant troublée.

- Ainsi, fis-je, elle vous a conquise...

Alors, bien qu'une larme mouillât ses yeux, elle sourit et sa voix se fit caressante pour me dire :

- Monsieur, elle était charmante. 


\section{LA GUERRE DES FEMMES.}

Histoire de Louise de Bettignies et de ses compagnes.

\section{Chapitre III}

\section{ALBERT}

\section{Retour à la table des matières}

- Tout un petit monde a vécu, travaillé, souffert, autour de Louise de Bettignies et pour elle. Quelques-uns ont su qu'ils étaient des patriotes : d'autres l'ont servie parce que, comme Léonie Vanhoutte, ils l'ont trouvée charmante.

- Il fallait bien la suivre, dit l'un d'eux. On ne savait rien lui refuser.

En Belgique et dans le nord de la France, on met le verbe savoir pour pouvoir. Celui que je viens de faire parler est un Flamand. Nous ferons connaissance, en passant, avec la plupart des autres, hommes ou femmes. Albert vaut une mention spéciale. Il s'appelait Albert, comme les deux jeunes filles se nommaient Alice et Charlotte : des noms de guerre. Dans la vie, c'était, c'est encore Victor Viaene, de Mouscron.

Pendant les premières semaines de l'occupation, il fit comme beaucoup d'autres, il se débrouilla. Habitué sans doute à passer en temps de paix du tabac belge en France, il eut l'idée d'aller acheter, pour le débiter à Roubaix et à Lille, du tabac de Hollande. Ayant rencontré à Gand un camarade qui connaissait les bons chemins, il lui conta son projet et tous deux se mirent en route.

- Alors, explique-t-il, on est parti visiter l'Hollande. On a promené deux jours là-bas, on a revenu. 
Quoi de plus simple ? D'autres passaient les lignes parce qu'ils étaient des héros : lui, pour subsister. Pas pour s'enrichir.

Un jour, à Lille, au café Royal, il était attablé avec je ne sais acheteur de ses cigares néerlandais, quand il remarqua près de lui deux messieurs bien mis qui discutaient. Albert a de longues oreilles. L'air mystérieux des compères le met en éveil : il écoute.

- Tout de même, finit par dire l'un des deux, c'est dommage qu'on ne puisse pas s'en aller par la Hollande.

Alors mon Flamand se pousse vers le personnage, le frappe d'un coup de coude amical, cligne un œil et lui glisse à mi-voix :

- Mi, je sais te conduire en Nollande, quand te veux.

L'homme bien mis le regarda de haut en bas et tourna le dos. Victor Viaene ne s'émut pas de ces façons. Elles étaient de règle en pareil lieu, en pareil temps, mais il sortit peu après, comptant bien que, si l'inconnu voulait vraiment s'évader, il le rejoindrait dans la rue. Ce qui eut lieu.

- Alors, c'est sérieux, ce que vous m'avez dit ? Vous me conduiriez en Hollande ?

- Pour sûr, mais tu dois payer, sais-tu.

- Combien ?

- Ça dépend si vous êtes tout seul ou avec des autres.

- Vous pourriez nous emmener à trois ?

Le bonhomme réfléchit un instant.

- Ce sera, dit-il enfin, quinze francs chaque, mais tu sais, tu paies seulement quand vous êtes arrivés.

Le marché fut conclu. Si les notables Lillois qui en ont été les bénéficiaires vivent encore et que ces lignes arrivent à leurs yeux, qu'ils envoient un mot cordial à ce Victor Viaene, 21 rue d'Herzeaux, à Mouscron. Le prix était de quinze francs, plus un peu d'amitié. Cette partie de la dette, il est encore temps de la payer. 
Lui-même, qui a sauvé tant d'ingrats, a toujours fait honneur à ses engagements. Il s'aperçut, la guerre finie, qu'il restait devoir vingt-sept francs à l'aubergiste Mélis, de Norderwysk, dans le pays à l'est d'Anvers. Il avait mangé et couché là plusieurs jours en 1915 ; puis, arrêté, relâché, surveillé, il cherchait depuis l'armistice une occasion de retrouver son créancier. Quand je lui proposai, dans l'été de 1923, de m'accompagner à travers la Belgique, il mit vingt-sept francs dans une enveloppe et me fit promettre qu'on passerait à Norderwysk.

- J'vas payer mes dettes, dit-il alors en se frottant les mains.

Ces Mélis, homme et femme, sont eux-mêmes de très honnêtes gens. Ils ont tous les deux logé, nourri, soigné, caché des quantités de patriotes. Tous ceux qui voulaient passer par Beersse et Baerle-Duc savaient qu'à cette étape ils seraient bien accueillis et aidés.

Ils ont revu Albert avec une joie dont le spectacle m'a ravi. Les vingt-sept francs, ils les ont refusés dans un bon rire. Et nous avons fait sous leur toit un repas rustique. L'hôtesse devait s'entendre à souhait avec Louise de Bettignies. Comme elle, c'était une femme petite et nerveuse : figure mince, un peu osseuse, mais si fine, avec une peau d'ivoire; lèvres fraîches, d'un charmant dessin ; des dents qui seraient une merveille s'il n'en manquait quelqu'une; un front et des sourcils intelligents, toujours en mouvement ; des yeux gris, pleins de flamme ; un petit nez droit, qu'elle lève bravement pour deux raisons : parce qu'elle veut sentir avidement, comme elle les voit, ceux qui lui parlent, et parce que ses cheveux cendrés, noués en un chignon bas, très lourd, pèsent sur sa nuque. Son mari, Joseph Mélis, est un grand garçon blond qui ne parle pas français plus qu'elle; mais tous deux causent, comme de vieux amis qui se retrouvent, avec Victor; leurs souvenirs arrivent en foule. Dans son jargon incroyable, Victor essaie de traduire pour moi le plus important. Il est question de celui-ci, de celui-là, de cet autre, qui ont passé, promettant qu'après la guerre ils écriraient. Aucun n'a donne signe de vie : c'est triste. Et celui qui est parti avec le pardessus tout neuf de Victor et qu'on avait longtemps, quoiqu'il n'eût pas d'argent, nourri, puis vêtu de bon cœur, pourquoi n'écrit-il pas ? Ils ne se plaignent point. C'était, si agréable de rendre service ! On sent que leurs âmes se réchauffaient à faire tout ce qu'il fallait pour la patrie et ses serviteurs. Alice, qui se sentait à l'aise chez ces gens courageux comme elle, avait promis à l'homme qu'elle demanderait pour lui une récompense française, et elle est morte... 
- Ça lui aurait fait du plaisir, à cet homme, me dit Victor en le regardant avec tendresse.

Et les yeux de tout ce monde se mettent à briller. Ils n'ont rien reçu pas un bout de, ruban, pas un bout de papier ils en ressentent un peu de peine. Rien que de l'ingratitude : c'est tout de même assez dur. Et, pour ma part, je voudrais bien que, là, le gouvernement français s'acquittât.

C'est par Léonie Vanhoutte que cet étonnant Victor entra dans le service de Louise de Bettignies. Un jour que Charlotte revenait de Hollande par le chemin de retour qu'elle avait utilisé la première fois, elle dut rester cachée plusieurs jours dans la maison belge que touchait la frontière. Elle avait facilement passé du jardinet hollandais à cette maison. Là, Emma, sa complice et son guide dans ce hameau, lui notifia que les troupes avaient été changées, que la consigne était féroce et qu'il n'y avait qu'à rester tranquille en attendant des jours meilleurs. Une belle nuit, un homme saute du toit de l'étable à porcs, tombe dans le jardin d'Emma et frappe à la porte, On ouvre. C'est Victor qui, lui aussi, arrive de Hollande et s'apprête à partir, avec son insouciance coutumière, pour Roubaix. Justement, les circonstances sont plus favorables. On va pouvoir, avant le petit jour, traverser le pays.

- Te viens avec ? dit-il à Charlotte.

Cet homme lui faisait peur, mais elle avait plus grand'peur de la route de Gand. D'avoir attendu là plusieurs jours, comme une captive, l'avait rendue nerveuse. Elle n'imaginait pas que, cette fois, elle pût passer seule. Elle accepta le bras de ce type étrange. Il se montra parfait. Des familiarités incroyables, et tout de même un grand respect.

- Vous avez venu avec moi comme un petit chien, Charlotte, lui dit-il aujourd'hui, assez fier de son ascendant.

Ascendant qu'il devait à sa droiture éclatante. Jamais je n'ai entendu parler un français aussi baroque que le sien. On le comprend à peine : il remplace tous les relatifs, que, dont, qui, quoi, par cui, qu'il prononce $\mathrm{Cu}$-i ; à presque tous les mots, il ajoute vé-ti ; on suppose que cela veut dire vois-tu ; en tout cas, cela embrouille tout ; il tutoie, bien entendu ; les mots qu'il ne connaît pas, il les fabrique ; et ceux qu'il sait appartiennent beaucoup plus souvent au patois de Mouscron qu'au français de Voltaire. Peut-être est-ce la surprise d'entendre dans une telle langue des 
paroles de sagesse qui a tant ému Léonie Vanhoutte. Elle a gardé un bon souvenir du voyage fait avec cet homme. Et quand, un peu plus tard, elle le sut en prison et qu'on pourrait le libérer moyennant trois cents marks, elle proposa à Alice d'acquérir, à ce prix, une recrue qui serait précieuse.

De ce jour, il servit fidèlement les deux jeunes filles.

- Moi et Nini, dit-il, on était comme deux moutons derrière Alice.

Car il vénère Léonie Vanhoutte et croirait manquer à la piété qu'il lui doit, s'il ne l'appelait maintenant de ce nom familier. Il dit quelquefois encore Charlotte, jamais Léonie, qui ne serait pas respectueux. Alors c'est Nini. Il y a une nuance. Tous ceux qui ont été des camarades de combat la sentiront.

Quand Alice le voyait revenir fourbu de la frontière et lui disait de repartir aussitôt, il lui arrivait de grogner un peu :

- J'irai pas.

- Si ! vous irez.

Elle le domptait, et il ne marchait pas : il courait.

Il est impayable quand il conte ses démêlés avec les Boches. Après ses trois Lillois, il avait transporté des tas de gens, toujours au même tarif. Un jour, à Assenède, un peu au sud de Bouchaute, il est aperçu et suspecté de loin par une patrouille ; il file dans les champs ; à la nuit, les Allemands retrouvent sa trace.

- J'ai couru, me dit-il, jusqu'à Terdonck. Je ne savons nin d'où que je courais. Ils ont bien tiré deux cents coups de fusil après mi.

On l'arrêta. Il eut la chance de n'être suspecté que de fraude de tabac. Ci, trois mois de prison, dont il ne fit qu'un tiers, Alice ayant, comme j'ai dit, payé la caution.

Il a rendu à Louise de Bettignies des services immenses. Pendant deux mois, il a fait, deux fois par semaine, à pied, le chemin de Bruxelles à la frontière hollandaise par Anvers. Toutes les missions dures, toutes les tâches ingrates, il les a acceptées, sans se plaindre, peinant et bavardant toujours, la tête pleine d'idées imprévues qu'il exprimait avec une cocasserie dont Alice se réjouissait follement,

- Eh ! oui, disait-elle quelquefois en rentrant, j'ai encore fait route au bras de Victor. 
Et elle riait de bon cœur. Elle l'aimait bien. Un jour, elle tenta de le convertir :

- Voyons, Victor, on peut nous fusiller tous les deux ; on peut tirer sur nous et nous tuer là, tout de suite. Moi, je suis prête. Vous devriez vous confesser.

- A confesse, mi ?

- Mais oui, Victor. Je serais si contente 1

- Non, Alice, mi, je n'ai rien à dire à confesse. Je n'ai jamais fait de mal à personne. Si tu as fait du mal, vas-y ; mi, j'y vas pas.

Elle vit qu'elle ne le sortirait pas de là.

Il avait d'ailleurs dit vrai et toute sa doctrine morale et sociale se résumait en ce devoir sacré : l'amour du prochain ; non seulement ne jamais lui faire de mal, mais le servir. Ce but-là, il y a, dans le plus bas peuple, des natures délicates qui le poursuivent sans un fléchissement. Pour lui, il écartait tout le reste.

- Mon bonheur, dit-il aujourd'hui, c'est de n'avoir jamais rentré dans un estaminet, de ne jamais avoir eu de camarades.

Pas de camarades : comme il est terrible, ce jugement d'un honnête homme sur les hommes ! Il leur veut du bien à tous et se fera tuer pour eux, s'il faut ; mais il les redoute. Il est bon, quoiqu'il les sache mauvais. Ce rustre est deux fois un sage.

Il a revu avec moi tous les vieux chemins, toutes les maisons où on l'accueillait alors. En passant devant celle d'Isidore, de cet homme qui, la première fois, a conduit Charlotte à la frontière, une plaque de marbre noir a frappé son regard et le mien.

Aan

Isidoor Van Vlaenderen

Door de Duitschers

Voor den kop Geschoten

den 12 septembre 1917

Het Vaderlandsch Verbond

Der gewezen Politieke Gevangenen. 
Cela signifie que le 12 septembre 1917 cet Isidore a été fusillé par les Allemands pour avoir servi sa patrie.

Un peu plus loin, en plein bourg de Bouchaute, une autre plaque semblable : c'est Léonie Rammeloo, fusillée le même jour. Cette Léonie, c'est la sœur de la « passeuse » Emma, dont nous parlions tout à l'heure. Pour désigner les passages de Bouchaute, on disait : le service d'Emma ; ou bien : celui des frères Dhollander, par quoi on entendait Edmond Dhollander et son beau-frère Isidore. Ainsi, dans chacun de ces deux services, il y a eu un martyr. On fusilla aussi le même jour une autre femme, Émilie Schatteman. Ces héros, vraiment obscurs et qu'on a fort de négliger, ont eu une fin très noble, Nous avons fait, avec Charlotte et Albert, - car c'est sous ces noms qu'ils sont connus là, elle et lui, - le tour des maisons où vivent dans la résignation les parents de ces morts. Edmond Dhollander et sa femme, cette fois, Léonie Vanhoutte ne les a pas trouvés terrifiants. Ils n'habitent plus la maison de brique au coin du passage à niveau, mais une ferme dans les champs. Pour y atteindre, on longe une digue que Charlotte a reconnue pour y avoir séjourné, par une nuit froide, près de trois heures, attendant le passeur. Dhollander l'avait laissée là, disant : « Je vais reconnaître le chemin. Attendez. » Il était surveillé, le chemin, et l'homme dut se terrer si longtemps qu'au retour il croyait bien ne plus trouver la jeune fille. Il savait par expérience que les « clients » qu'on fait attendre ainsi ont coutume de perdre la tète, et qu'ils se déplacent. Alors il n'y a aucun espoir de sauver la brebis égarée. Sa brebis, cette nuit-là, le bon pasteur l'aurait caressée, dans sa surprise de ne l'avoir pas perdue. C'est le cœur rempli de ce pieux souvenir qu'elle entra avec nous dans la maison de ceux qu'Alice appelait familièrement : « Nos maîtres ». On les nommait ainsi dans un sentiment où la terreur l'emportait sur l'amitié. Maintenant jour d'amitié, on oublie leurs façons rudes des nuits de guerre. Songez qu'un jour, Charlotte étant arrivée à Bouchaute à l'improviste avec Une mission si pressante qu'il fallait qu'on la passât tout de suite, Dhollander s'apprêtait à sortir avec elle, quand un homme, qui attendait son tour depuis plusieurs nuits, s'interposa et dit « Je passerai d'abord ; j'étais là avant elle. » Le Flamand lui ordonna de se taire. Comme il élevait encore la voix, Dhollander le jeta à terre, le bourra de coups et dit en s'essuyant les mains : « Je suis le maître ici. »Puis il conduisit la jeune fille en Hollande. 
Nous le voyons aujourd'hui, attablé dans sa grande salle claire. C'est un homme de soixante ans à peine, mince et bien bâti. Une bonne figure, où domine une moustache opulente, qui tombe à la gauloise. Sous une arcade sourcilière d'un dessin plein de noblesse et d'honnêteté, des yeux clairs, qui parlent seuls, car quels mots diraient les lèvres ? Il ne connaît que le flamand et notre interprète est trop ému pour nous être d'un secours quelconque. La femme n'a pas pris place avec nous autour de la table. Elle est assise dans un coin et nous dévisage, essayant de correspondre avec nous par Albert, qui ne trouve rien à dire et regarde tour à tour elle, lui et nous, comme un perdu. C'est une opulente personne, un type de Rubens qui remplit magnifiquement son corsage. Son regard est ouvert et tendre. Elle est sale, son mari aussi ; mais il y a tout de même de la fraîcheur sur leurs visages ; elle vient de leur santé morale, qui, du moins à cette minute, est débordante. Ils revivent devant nous, en silence, les grandes heures de leur humble vie. Ils en sont fiers, mais avec la modestie adorable des petites gens.

Que de choses tristes ils diraient, s'ils savaient faire remonter leurs souvenirs ! Elle raconte à Albert, qui nous la rapporte, l'histoire de cette femme, qu'on essaya de faire passer, et qui portait avec elle son enfant, un bébé de huit mois. Elle échoua. Il fallut rentrer au petit jour sans avoir pu approcher la frontière. Alors elle vit qu'elle ne portait plus qu'un enfant mort : elle l'avait, dans sa terreur, étouffé entre ses bras.

Voici que notre hôtesse se lève et va chercher, dans le tiroir d'une vieille commode, une liasse de papiers. Elle en sort l'image mortuaire où sont les portraits des trois fusillés : les deux femmes et cet Isidore, son frère, qu'on a tué quoiqu'il eût neuf enfants. Nous regardons avec compassion les pauvres visages, tirés de photographies maladroites, et nous quittons ces bonnes gens avec la pensée que, tout de même, parmi les centaines, peut-être le millier de gens qu'ils ont transportés du bagne à la terre libre, il aurait été bien qu'un ou deux, oui, un ou deux seulement, leur fissent savoir, après la guerre, qu'ils gardaient d'eux quelque souvenir.

Nous avons vu aussi la veuve d'Isidore. Elle travaille tant qu'elle peut, pour bien élever ses neuf petits. Elle est toute bouleversée par la visite que nous lui faisons ; et son temps, tandis que nous sommes assis en rond dans sa demeure, se passe à chercher la dernière lettre du fusillé. Dans les armoires, au fond des tiroirs 
des commodes, elle fouille en s'énervant un peu. On la sent honteuse de n'avoir pas mis en un lieu plus certain ce trésor. Elle sourit quand elle l'a enfin découvert :

- Vous voyez, dit-elle doucement, je l'avais trop bien caché.

C'est écrit en flamand. Il faudrait traduire. Alors, voyant mon embarras, cette pauvre femme me fait signe de garder la lettre.

- Elle dit que tu peux l'emporter, m'explique Albert. Tu rendras quand t'auras plus besoin.

Comme j'hésite, elle me rassure d'un bon regard. Et lui, mettant la lettre dans ma poche

- Elle a confiance, sais-tu.

Il faut rentrer à Bruxelles. On n'imagine pas comme c'est difficile d'interroger des hommes comme cet Albert. À un questionnaire en règle, il ne répondrait rien. Mais il est à côté du chauffeur. Sa tête travaille, tandis que nous courons sur les routes. Alors un souvenir vient à lui. Il se retourne à demi et, avec les mots qu'il trouve et qu'il farcit de cui et de vé-ti, il me conte une anecdote, me révèle un détail, un mot d'Alice, ou de Charlotte, ou de lui-même. J'apprends ainsi qu'au plus fort de son travail pour Louise de Bettignies, il se faisait passer pour agent d'assurances. C'est ce titre qui figurait sur ses cartes d'identité. Drôle d'idée ! Drôle d'assureur ! Et je pense que la police allemande ne devait tout de même pas être dupe d'une menterie pareille. Il lui arriva un jour une aventure assez mortifiante. C'était une heure après l'arrestation de Charlotte. Les policiers étaient encore dans la maison où ils avaient pris la pauvre fille. Albert sonne à la porte, ignorant que le malheur est venu sous ce toit., Une enfant de seize ans, qui lui ouvre, lui fait signe qu'il y a du danger. Alors, à haute voix, il explique dans son jargon qu'il faudrait tout de même payer la prime due : l'assureur voulait donner le change aux Allemands qui l'entendaient. Mais la maîtresse du logis, plus fine, crie à sa fille :

- Encore un mendiant! Dis-leur qu'on ne donne que le vendredi. Ils devraient le savoir !

Et on lui claqua la porte au nez.

Cette histoire-là, ce n'est pas lui qui la raconte, mais c'est parce qu'il ne s'en souvient pas ; car c'est un type sans rancune. 
À Bruxelles, Victor dut nous quitter pour rentrer à Mouscron. Je vis qu'il s'en allait mal satisfait. Je l'interrogeai. Il aurait voulu lire la lettre d'Isidore. Alors, à la terrasse du café de l'Espérance, près de la gare du Midi, nous nous attablâmes ; je sortis de mon portefeuille la pauvre enveloppe et la lui passai.

Au haut d'une très grande feuille de papier, l'homme qui se trempait jusqu'à la poitrine dans les ruisseaux de la frontière par les nuits glaciales de décembre et de janvier, le colosse qui portait, comme saint Christophe, des charges lourdes et sacrées sur ses épaules, avait dessiné comme un enfant une petite croix tremblante et mal équilibrée; et sur la croix, il avait tenté de mettre l'image du Christ, les bras étendus. Puis l'écriture naïve commençait

Chère femme et chers enfants,

Pour la toute dernière fois de ma vie, je viens, chère femme, vous souhaiter bonheur et prospérité avec mes enfants. J'espère qu'ils seront toujours envers la maman bons et obéissants...

Victor nous traduisait cela comme il pouvait. Il lisait :

- Ma bonne femme, je ne veux nin t'écrire une triste lettre. Tu as déjà de la tristesse assez. Fais pour mi des prières. Toutes mes affaires sont pour ti et les enfants. Mon costume de velours, c'est pour Edmond.

À ce moment, l'interprète cessa de parler. Il lisait pour lui le texte flamand. Je le vis, pâlir, puis ses joues tremblèrent tandis que de son gros pouce de travailleur, bordé de noir, il suivait l'ondulation des lignes.

- Que dit-il ? risquai-je.

Alors, d'une voix saccadée, il voulut nous expliquer ; mais les mots venaient mal et je compris seulement ceux-ci :

- Il dit que demain il va vir el bon Dieu, ici en haut...

Et Victor lève des yeux pleins d'angoisse vers le ciel pâle de Bruxelles. 
Il eut d'ailleurs bientôt fait d'avaler son émotion et c'est en riant de tout son honnête visage qu'il nous quitta.

- Mi, dit-il, j'aime encore mieux qu'on ne m'a pas fusillé !

Il apprécie la vie, ce digne garçon, bien qu'elle ne lui soit pas douce. C'est un résigné et c'est charmant d'user d'un tel homme quand on le fait avec honneur. D'avoir servi, suivi comme un chien fidèle Alice et Charlotte, il n'a gardé nulle rancœur. De ces deux-là, il eût accepté des coups de bâton. Mais une âme simple qui se donne ainsi, qui croit, à cause de sa bonté foncière, à la bonté des autres, qui se fait, dans son esclavage accepté, une idée haute de tous les maîtres, il ne faut pas qu'on la scandalise. Victor, comme tous les petits, est facilement indigné des fautes des grands et leurs vices lui font horreur. Il obéit, il baisse la tête, mais il juge. Il voit agir ceux qui commandent et la colère monte en lui. Un tel homme, ne vous étonnez pas si le bon moyen de le trouver à Mouscron à ses heures de loisir et le dimanche, c'est d'aller voir à la maison des socialistes. Ce patriote qui avait d'avance accepté la mort pour les bourgeois ses maîtres, qui s'était à plein cœur sacrifié à la société, c'est-à-dire aux riches aussi bien qu'aux pauvres, il aurait fallu que les gens bien habillés fussent aussi beaux que lui pour qu'il n'allât pas au camp des révoltés. C'est un révolutionnaire peu dangereux, mais ils sont nombreux ainsi et grossissent l'armée des destructeurs. C'est dommage. En tout cas celui-là, j'ai pris plaisir à connaître son âme enfantine et je pense avec délectation que peut-être il a gardé de son compagnon de pèlerinage un souvenir amical. 


\section{LA GUERRE DES FEMMES.}

Histoire de Louise de Bettignies et de ses compagnes.

\section{Chapitre IV}

\section{AU TRAVAIL}

$\underline{\text { Retour à la table des matières }}$

« Un soir du début de la guerre, nous étions réunis à Audenarde, petite ville belge, dans notre salon de famille. Il faisait gris sur les murs et dans nos âmes. Alors que tous nos amis avaient leurs fils, leurs frères, leurs maris sous les armes, nous étions au complet chez nous. Mon père, entouré de ses six filles, semblait accablé. - Moi, disait-il, je n'ai personne à donner à la patrie. - Nous nous redressâmes, toutes pâles ; car nous nous sentions souffletées. Et tout de suite, relevant le gant, nous jurâmes que nous servirions. » C'est ainsi que Mlle Madeleine Doutreligne et ses sœurs décidèrent qu'elles feraient la guerre. Elles ont tenu parole et nous les retrouverons parmi les condamnées à mort qui furent les compagnes de misère de Louise de Bettignies.

Elle aussi, la petite Française, enviait les hommes. Elle a voulu se battre, pas comme nous, mais autant que nous. Et le service dont elle venait de recevoir la charge, elle l'organisa dès son arrivée à Lille avec l'entrain d'un bon soldat.

Nous la verrons courir les routes sans une plainte, toujours, rieuse et décidée, narguant l'ennemi, charmant les gens dont elle avait besoin, épouvantant à plaisir les poltrons; vraiment il semblait qu'elle rayonnât, et tel homme sévère a pu craindre qu'elle n'eût la folie de la croix. Elle avait seulement accepté de tomber 
au champ d'honneur, « de donner, disait-elle, sa petite vie qui ne valait que quelques sous ». Mais d'abord elle entendait agir ardemment pour être utile, et sans doute estimait-elle, comme tout bon guerrier, que le premier devoir devant l'ennemi n'est pas de mourir, mais de tuer pour la patrie. Elle a tué des milliers d'Allemands, non de sa main, mais en dirigeant de sa tête fine nos coups aux bons endroits. Elle l'a fait méthodiquement dès le premier jour, et d'abord en choisissant à la perfection son personnel, ce qui est la première vertu d'un chef.

Les renseignements qu'elle avait mission de recueillir étaient de deux sortes. Pour les uns, des observateurs modestes mais appliqués suffisaient. D'autres demandaient le concours d'esprits avisés, maîtres de leur curiosité. Elle mit le plus grand soin à choisir des hommes sûrs, habitant auprès des ponts de chemins de fer, des passages à niveau, des carrefours importants ; ceux-là devaient seulement enregistrer le nombre des trains ou des convois, celui des voitures dans chaque train, avec toutes les indications pouvant éclairer sur la nature du chargement. Un exemple, pour qu'on comprenne l'utilité de tels renseignements. En avril et mai 1918, nous avons connu exactement le nombre et la contenance des trains de blessés que l'ennemi ramenait du mont Kemmel. Déjà nous savions combien de divisions avaient été successivement engagées sur ce charnier; les chiffres qui nous furent données par d'humbles agents comme ceux de Louise de Bettignies nous révélèrent qu'il ne restait à peu près aucun homme valide dans les unités remplacées. Alors nous comprîmes que cette affaire, dure pour nous, équivalait pour l'Allemand à un désastre. La nouvelle, portée à nos troupes, souleva leur moral, et Foch fit sauter avec plaisir de son échiquier quelques pions qui le gênaient.

Ainsi, chaque soir, tandis que roulaient les trains, deux yeux français demeuraient collés à la vitre de telle petite maison de briques près de la voie. Dans la pièce voisine, bien close pour que la lumière éclairant son papier n'apparût pas au dehors, une femme ou un enfant, inscrivait une barre à chaque coup que l'observateur frappait du pied sur le parquet. À l'aube, on faisait les additions. De ce côté-ci du front, nos femmes et nos enfants pouvaient dormir. Sur notre ligne, des sentinelles les couvraient ; et d'autres veilleurs épiaient l'ennemi dans le dos, inscrivant chacun de ses pas dans la nuit.

Pas un des veilleurs de Louise de Bettignies n'a trahi ; pas un n'a été pris. C'est qu'elle les avait bien choisis et presque toujours elle-même. Elle ne s'adressait qu'à des hommes qu'on lui avait signalés comme honorables. Elle allait de préfé- 
rence aux pères de famille. Si leur maison était bien tenue, les enfants propres, elle entrait en confiance. Elle trouva parmi le personnel du chemin de fer des agents modestes, dont elle obtint un dévouement admirable. Quelques-uns refusaient d'être rétribués. D'autres recevaient pour leur travail, qui était dur, un salaire. Cela ne changeait guère la qualité de leur sacrifice. Ils ne servaient pas pour de l'argent ; mais, contraints de travailler pour vivre, Ils s'enorgueillissaient à bon droit que leur travail fût noble et dangereux.

L'autre catégorie d'observateurs était plus difficile à recruter. Alice Dubois entra peu à peu en contact avec les quelques personnalités habitant le voisinage du front, qui pouvaient la renseigner le plus parfaitement sur les mouvements de l'ennemi et ses desseins. C'étaient des hommes ou des femmes occupant une situation sociale importante, ayant des loisirs et la faculté de circuler. À Santes, Mme Paul Bernard ; Mlle Marie-Thérèse L'Hermitte et son père, à Haubourdin ; Mme Destombes-Lutin et son mari, à Frelinghien ; M. Milon, à Helemmes ; d'autres encore, qu'elle avait attachés au succès de son œuvre, étaient pour elle des antennes vivantes, qui suçaient les nouvelles, puis se repliaient sur Lille pour les lui apporter. On venait à la ville deux fois par semaine et spécialement le mercredi, jour de bourse ou de marché. Elle demandait à de tels informateurs les renseignements les plus variés, les plus abondants. Dans une maison amie ou dans son petit cabinet de travail de la rue d'Isly, elle recevait les rapports écrits ou verbaux de ces agents de qualité. Emplacements de batteries d'artillerie, importance et nature des approvisionnements en munitions, travaux de mines ou autres, relèves de troupes, propos de soldats ou d'officiers au salon ou à l'office ; déductions de toutes sortes faites sur place d'après les observations quotidiennes; tout était pris, recueilli et s'en allait en Angleterre.

On inscrivait cela sur de minces feuilles de papier du Japon. Les plus habiles calligraphes arrivaient, avec une plume à dessin très fine et de l'encre de Chine, à établir des manuscrits qu'on ne pouvait lire qu'à la loupe. Alice recevait ces rapports et rédigeait les siens. Quand elle avait couru toute la journée, reçu ou visité des agents, passé de tous côtés des consignes et qu'elle rentrait fourbue, elle consacrait une partie de la nuit à faire courir sur du papier sa petite plume, qu'un ardent ami de sa mémoire conserve et m'a montrée. Dans ses rapports, elle multipliait les détails, sachant que rien ne serait indifférent à ceux qui là-bas déchiffreraient ce flot de nouvelles, petites et grandes. Elle travaillait de préférence dans la 
deuxième partie de la nuit, au lever du jour, seul moment où elle pût se mettre à son bureau sans lumière et avec quelque chance de n'être pas interrompue par une perquisition. Tout ne lui semblait pas bon à écrire. Et ses agents comme ellemême ont souvent inscrit, non sur du papier, mais dans leur mémoire, des chiffres ou des mots qu'on ne voulait pas risquer de laisser voir à l'ennemi. Quand Louise de Bettignies fut arrêtée, deux dames de Mouscron qui venaient de recevoir l'autorisation de passer en Suisse se chargèrent de faire parvenir la triste nouvelle à ses amis de France et à ses parents. On leur confia, en outre, divers renseignements pour notre état-major. Et tandis qu'elles roulaient dans des trains allemands, au milieu de voyageurs hostiles, elles racontent qu'elles se donnaient du courage en s'invitant l'une l'autre à dire le chapelet : aussitôt leurs lèvres remuaient, récitant dévotement la leçon qu'on leur avait apprise et qu'elles craignaient de ne point rapporter à la perfection aux officiers français de la frontière. Alice, vite familiarisée avec les mots, les choses, les chiffres et les noms propres, avait toujours dans la tête de quoi noircir des pages entières. Quand elle passait en Hollande, elle écrivait parfois son rapport de l'autre côté des fils de fer. S'il fallait qu'elle confiât son message à un courrier, il lui arrivait d'aller le rédiger dans un coin perdu de la Flandre, sous quelque toit au milieu des bois, où elle était assurée qu'on ne la dérangerait pas.

Il y aurait mille choses à conter sur le mode de transcription des rapports. À la fin de la guerre, on était arrivé à inscrire trois mille mots sur une pellicule grande comme un verre de lunette. L'inscription était invisible et la transparence de la pellicule absolue. On collait cela sur son lorgnon et l'on passait. À Folkestone, il n'y avait plus qu'à faire apparaître l'écriture et à la projeter sur un écran. On imagina même de coller de ces pellicules chargées de nouvelles sur les photographies des cartes d'identité. On avait la joie de voir les Allemands y apposer leurs cachets. Un jour vint où ceux-ci, méfiants, exigèrent des photographies mates sur les passeports.

Ayant assuré son service à Lille, Louise de Bettignies se tourna vers une personnalité de Tourcoing qui devait lui rendre d'éminents services. M. Lenfant, commissaire de police dans cette ville, avait pris, dès les premières menaces d'invasion, diverses initiatives hardies qui témoignaient d'un zèle peu commun pour le bien public. Sans liaison directe avec les armées de l'Entente, il s'était acharné, usant de moyens de fortune, à renseigner nos états-majors. Avec un notable indus- 
triel, M. Louis Sion, dont la maison, toute proche de la frontière belge, se prêtait aux conciliabules secrets, il avait organisé tout un service de renseignements. Au début, les automobiles de M. Sion furent mises à contribution ; puis, quand il fallut cacher les voitures, celui-ci donna son salon, où Louise de Bettignies devait plus tard passer bien des soirées émouvantes; il offrit enfin que son fils Étienne se chargeât de transporter des courriers à Tournai, à Gand ou à Bruxelles. Malgré leur zèle, qui était grand, M. Lenfant et ses amis éprouvaient quelque peine à faire parvenir régulièrement leurs informations. Ils les communiquaient comme ils pouvaient à d'autres services avec qui le hasard les mettait en contact ; mais l'immense force dont la situation officielle de M. Lenfant lui permettait de disposer était, somme toute, à peu près sans emploi. C'est alors que la personne avisée qui, un peu plus tard, devait faire entrer Léonie Vanhoutte dans le même service, Mme Paul Prouvost-Masurel, convia ensemble M. Lenfant et Louise de Bettignies dans sa propriété de Mouveaux. Cet homme réfléchi, au visage doux, mais sous lequel on sentait une grande fermeté de caractère et de pensée, fut tout de suite conquis par l'extraordinaire jeune fille et celle-ci sympathisa d'autant plus avec lui que, l'ayant, suivant sa coutume, interrogé familièrement, dès les premiers mots, sur sa vie particulière, elle apprit que quatre enfants grandissaient dans sa maison.

À Mouscron Alice fit appel à M. et Mme de Geyter. Lui, qui possède dans cette ville un laboratoire de chimie industrielle, offrit à la jeune Française de traduire ou de photographier ses notes ou les cartes et autres documents qu'elle voudrait bien lui confier. Il centralisa lui-même les renseignements émanant de toute la région avoisinant sa ville, et fit des rapports nombreux, pleins de faits et aussi d'observations personnelles. Quant à Mme de Geyter, elle prit bravement l'emploi de courrier, et se mit à seconder Alice en courant pour elle sur les routes de Bruxelles, ou de Gand, ou de Tournai.

Telle fut, dans ses grandes lignes, l'organisation locale de Louise de Bettignies dès les tout premiers jours. On pense bien que, pour faire converger chez elle avec une absolue régularité des documents émanant de sources ni nombreuses, elle dut user de mille précautions et montrer beaucoup de sagesse et de fermeté dans ses consignes. Elle eut des déboires : tous les dévouements ne lui demeurèrent pas fidèles ; des amis du début prirent peur ; d'autres, la jugeant imprudente, rompirent avec elle sans élégance. Ces défections la faisaient souffrir et la contrai- 
gnaient, comme Pénélope, à recommencer sans cesse les mêmes points sur son métier.

Et ce n'était qu'une partie de son service, la moins dure. L'autre consistait à acheminer les courriers vers la Hollande. Mais pour quoi faire ? Et vraiment les renseignements fournis valaient-ils la peine que nous allons voir qu'elle se donna ? Il est assez difficile d'entrer dans des précisions, mais voici un fait qui est plein de sens. Un jour, un des amis dévoués d'Alice est pris de doute sur l'importance de sa mission. Il ne conteste pas qu'elle ait une voie pour faire parvenir les documents aux Alliés, mais il ne peut croire qu'elle aille elle-même si facilement en Angleterre; et ce major de l'armée britannique qu'elle désigne sous le nom familier de l'Oncle Edouard, il commence à craindre qu'il n'ait jamais existé que dans l'imagination de l'étourdissante jeune fille. Alors, au bas d'un des rapports que celle-ci va porter là-bas, il glisse ces mots : «Si vraiment Alice en personne remet le présent rapport à un officier de l'armée britannique à Folkestone, je prie ce dernier, pour m'en donner un témoignage incontestable, de faire envoyer des ordres pour que le nouveau dépôt de munitions que les Allemands viennent d'installer près de la gare de Tourcoing, à l'endroit indiqué sur le plan ci-annexé, soit bombardé au premier jour, entre minuit et une heure du matin. » Quarante-huit heures plus tard, une explosion formidable ébranlait la gare et ses abords ; et, comme saint Thomas, l'incrédule, ayant vu, entendu et touché, revint à la foi. Quand Alice fit, peu après, irruption dans sa maison, elle lui dit en riant aux éclats : «Eh bien, avez-vous confiance maintenant? » Il la prit dans ses bras, émerveillé de la revoir si vite et victorieuse.

À ce seul fait, on jugera combien l'ennemi a pu pâtir de ses avis répétés et toujours si précis et sûrs. Pendant les quatre mois de mai à août 1915, toutes les batteries allemandes de la région de Lille furent par trois fois totalement détruites. Songez qu'ayant établi, avec le concours dévoué du docteur $\mathrm{D}^{* * *}$, de Lille, une sorte de plan directeur de tout son secteur d'action, plan quadrillé et numéroté, elle emporta tranquillement un double de ce plan à travers la Belgique et la Hollande et le mit entre les mains des Britanniques, à qui, dès ce jour, elle put avec deux chiffres seulement, faire connaître n'importe quel emplacement de batterie.

La voici donc maîtresse d'un personnel d'élite, qui la renseigne. Il s'agit maintenant qu'un autre personnel coure les routes, passe les barrières, assure, à la barbe des sentinelles allemandes, le transport régulier de ses dépêches. Il faut choisir des 
messagers hommes ou femmes, et des lieux de relai, auberges ou maisons amies. Nul de ces agents ne doit connaître ceux qui dirigent le service. Chacun a une tâche limitée, qu'il accomplit sans savoir d'où viennent ni où vont les plis. À tous, il faut fournir des pièces d'identité ou des passeports. Si l'un d'eux, par poltronnerie ou parce qu'il est vraiment plus raisonnable qu'il se terre, vient à manquer un jour, il faut avoir pourvu à ce cas et que le rapport arrive quand même à destination : d'où nécessité de faire passer à plusieurs exemplaires et par des voies différentes les communications importantes. Aux divers points de la frontière, il faut des passeurs, dont le dévouement soit certain. La liaison entre tout ce monde, c'est elle-même qui l'assure, avec son lieutenant Charlotte et le fidèle Albert. La plupart des petits agents reçoivent une rétribution, et c'est justice. Encore faut-il qu'elle leur soit régulièrement versée. Comme c'est commode, alors qu'à toute minute on est exposé à être fouillé, de revenir de Hollande avec des milliers de francs sur soi, et de se promener sur la ligne pour distribuer cet argent par petites sommes à de pauvres diables qui gagnent, à risquer leur vie, quelque dix francs par jour !

Il lui arrivait d'être très lasse, mais elle ne le montrait pas volontiers. Si, venant de Tournai ou de Bruxelles, elle sonnait à la porte de Mme Sion ou de Mme de Geyter, c'était habituellement à la fin de l'après-midi, après une journée épuisante. Elle bavardait jusqu'à l'heure du dîner et montait alors dans sa chambre, disant qu'elle allait faire un peu de toilette. On l'attendait longtemps, quelquefois en s'impatientant un peu. Puis on voyait descendre, non plus la voyageuse hardie de tout à l'heure, mais une jeune femme en toilette du soir, parée, coiffée, le visage frais, les épaules découvertes. Elle semblait ravie de rompre pour une heure avec sa vie aventureuse et de redevenir une femme du monde, coquette et confortable.

Ces jours-là, elle se couchait tard, ayant beaucoup parlé ; car il lui plaisait qu'on lui fît la cour et qu'on la gâtât un peu ; son cœur, qu'elle mettait au long des jours et des nuits à de si rudes épreuves, aimait les caresses. Au lendemain de telles soirées, il lui arrivait de faire la grasse matinée. On venait alors bavarder avec elle auprès de son lit. Elle était charmante, encadrée de ses deux nattes qu'elle étalait avec une joie d'enfant sur le beau linge de son hôtesse, ses nattes lourdes, de cette chaude couleur que prennent à trente ans les cheveux des petites filles blondes ; deux noeuds écarlates étaient au bout, et ses mains fines les tapotaient 
ou bien mettaient de l'ordre dans les dentelles dont elle avait couvert avec une volupté d'artiste sa poitrine et ses bras. Elle appréciait, en effet, la belle lingerie, et toutes les parures des femmes. « Montrez-moi votre garde-robe ! » disait-elle gentiment à ses nouvelles amies, dès qu'elle avait pénétré chez elles. Cette guerrière, qu'on s'attendait à voir parler et gesticuler en amazone, était une vraie femme, de l'espèce la plus fine.

Ses toilettes de travail étaient sobres : tailleur gris, tailleur noir ; chapeau de crin noir qu'elle pliait et cachait au fond d'un sac s'il fallait paraître en cheveux devant les postes allemands. Elle restait coquette, même sous des vêtements de fille du peuple, car elle tenait à plaire; tandis qu'on regardait son visage ou sa silhouette, on ne songeait pas aux papiers dans son panier ou dans sa sacoche. Quand Charlotte l'accompagnait, elles faisaient les premiers kilomètres en se donnant le bras; elles marchaient ainsi d'un meilleur pas. Alice tirait son chapelet et récitait une dizaine ou deux, et la jeune Roubaisienne répondait à mi-voix. Vous représentez-vous le mouvement de ces petites, courant légères au bord des routes ? Des gens les ont rencontrées, qui ont à peine détourné la tête. S'ils avaient su quel souffle animait ces images précieuses, ils les auraient fixées avec avidité dans leur souvenir ; mais les passants ne savent jamais. Nous frôlons sans cesse des trésors que nos yeux ne voient pas.

La grande affaire pour ces jeunes filles n'était point d'entraîner leurs corps à des étapes de trente et quarante kilomètres. Nerveuses et solides toutes les deux, elles étaient prêtes aux pires fatigues. Mais il s'agissait qu'on les laissât passer. Le plus agréable était de traverser les barrières sans être vues. C'était quelquefois possible. Pour échapper au regard d'une sentinelle, il n'est que de la distraire. Il arrivait à Alice de commander à des gamins, pour quelques sous, d'aller se battre devant le poste. Les deux petits hommes avançaient au bon endroit, s'injuriaient, se défiaient, puis se jetaient l'un sur l'autre et roulaient ensemble sous les jambes de l'Allemand. Tandis que celui-ci, paternel, se penchait sur eux, la jeune fille se glissait derrière son dos.

Un jour, faisait route dans la voiture d'un négociant des environs de Mouscron, M. Ernest Lamote, elle descendit quelques centaines de mètres avant un poste difficile. Son compagnon continua, puis arrêta son cheval devant la sentinelle, sauta sur le trottoir, chercha son passeport et fit mine de ne pas le trouver. Il fouillait dans ses poches, ouvrait et refermait son portefeuille, passait de sa culotte 
à son gilet. Un homme en veston porte sur lui quatorze poches, et ce Lamote avait par surcroît un manteau ce jour-là. L'Allemand, le voyant faire, plissait le front. Il finit par le pousser vers ses chefs, dans la maison.

- Attendez, lui dit Lamote au milieu du couloir, je crois que le voilà. Regardez si c'est bien cela.

Il retint ainsi l'homme quelque temps. Car ce passeport suspect, il importait de l'examiner avec soin et de confronter le portrait et son porteur. Pendant ce temps, une jeune fille passait d'un bon pas souple sur le trottoir d'en face, et le tour était joué.

Puisque je tiens ce Lamote, voici une autre aventure qui lui advint avec Alice. À la sortie d'Herzeaux, qui est un bourg voisin de Mouscron, sur la route de Tournai, il fallait passer devant une maisonnette où les Allemands avaient installé un poste de police secrète. Parmi les agents placés là était une femme généralement habillée de drap vert et portant des chapeaux de même couleur et ridicules. On l'avait baptisée la grenouille. Et rien n'est drôle comme d'entendre les gens du pays vous parler encore de cette sorcière, qu'ils appellent à leur façon la grenoule. Cette femme, qui fourrait ses dix doigts dans la chevelure des passantes et poussait les suspectes dans son antre pour les déshabiller, terrorisait la population féminine de la région. On la savait de mœurs ignobles et cela rendait plus écœurant le contact de ses mains crochues. Un matin, Lamote, passant avec Alice, est prié de descendre et de montrer son porte-feuille. La grenouille y trouve un chiffon de papier portant quelques chiffres avec ce mot : Péronne. Elle interroge le malheureux garçon, qui, ne sachant plus du tout ce que peuvent signifier ces nombres mystérieux avec ce nom de ville, reste coi.

- On va vous fouiller, lui dit la femme.

L'affaire était mauvaise, moins pour lui que pour sa compagne, dont le passeport était en règle, mais qui n'avait nul désir qu'on visitât ses vêtements. Lamote se souvint tout à coup que, passant au Pecq, localité voisine de Tournai, il avait relevé sur une affiche l'annonce d'une adjudication de fourrages. Il en avait noté les mises à prix, avec le nom d'un des herbages, la prairie dite de Péronne. La grenoule voulu qu'on y allât voir sur-le-champ. Une automobile conduisit l'homme avec deux agents devant l'affiche. On confronta les chiffres : ils concordaient. Quand Lamote revint, il trouva son cheval à l'attache, Alice conversant familiè- 
rement avec la grenouille, et, dans le caisson béant et bousculé de sa voiture, un magnifique saucisson, scié d'un bout à l'autre en tranches minces comme du papier. La grenouille, au lieu d'ouvrir le sac à main de Louise de Bettignies, où elle aurait trouvé de quoi la faire fusiller tout de suite, avait soupçonné et tailladé cette pièce de charcuterie. Les voyageurs partirent, et la jeune fille mit, en riant aux larmes, ses dents gourmandes dans les tranches fines que l'Allemande avait coupées pour elle.

Il fallait posséder, pour circuler à loisir de tous côtés, deux sortes de pièces : la carte d'identité., que tout habitant des territoires occupés devait pouvoir exhiber à toute heure du jour ou de la nuit ; et, pour aller d'une ville à l'autre, un passeport. Alice se procura des cartes d'identité nombreuses : à Lille, à Mouscron, à Gand, à Tournai, à Bruxelles. Elle les mettait toutes ensemble dans son sac avec une incroyable insouciance et montrait aux Boches celle qui convenait.

- Ils sont stupides, disait-elle. Avec n'importe quel papier qu'on leur plante sous le nez, et du toupet, on passe.

Quand elle posait pour ses photographies d'identité, elle remuait les yeux, le nez, faisait des grimaces. Puis elle collait avec joie sa figure sans regard et sans traits sur la petite carte, et la montrait, triomphante, à toute réquisition. Il lui est arrivé à Bruxelles d'être arrêtée plusieurs fois dans la même journée. Tout passant pouvait être interpellé par un agent en civil qui demandait à voir la carte. Elle riait, sortait son portrait :

- Je suis jolie là-dessus ! disait-elle au Boche.

Eu si l'homme paraissait ombrageux, elle lui racontait en bon allemand quelque histoire drôle, qui le désarmait.

Les Français et les Belges poussaient fort loin l'art de fabriquer des pièces d'identité. Le docteur Béal, de Lille, que Louise de Bettignies fit passer en Hollande, fut très surpris de recevoir des mains de Léonie Vanhoutte, avant son départ, tout un dossier admirable, comprenant une carte d'identité, un passeport, un extrait de casier judiciaire, le tout timbré, paraphé et portant, en bonne place et certifiée exacte par la kommandantur, la photographie du voyageur. Une maison excellait dans cette industrie. On l'appelait couramment la fabrique de pièces d'identité de Bruxelles. À Mouscron, M. de Geyter était aussi devenu très habile 
dans l'art délicat de faire les cartes, et sa femme dans celui de les présenter à la signature des Allemands à la kommandantur.

Quant aux passeports, qui valaient d'ordinaire pour un seul voyage, l'autorité occupante ne les délivrait qu'à bon escient et si l'on avait pour se déplacer des raisons contrôlables. Alice et Charlotte imaginèrent des ruses diverses. L'une d'elles se déclara marchande de fromages. Elle obtint d'une maison de Lille des ordres pour faire à Bruxelles et à Laeken des achats importants. On assure qu'un jour un wagon tout chargé de ce produit parfumé fut envoyé par ses soins en gare de Lille. Il est plus probable qu'elle se bornait volontairement à des démarches sans succès. Elle apprit toutefois le langage de son nouveau métier, s'enquit des prix et des habitudes professionnelles. Elle acheta un jour à Bruxelles, puis débita à Mouscron, deux wagons de lait ; une autre fois, un wagon de carbure : c'était, assure-t-on, une occasion, en tout cas un alibi ; elle devint ensuite institutrice, couturière et lingère. Charlotte fut successivement marchande de dentelles et de produits alimentaires, puis couturière ; dans ce dernier état, l'ambition la saisit ; elle déclara qu'elle irait prendre à Tournai, pour se hausser dans son art, des leçons de coupe. D'où nécessité de voyages fréquents, avec un passeport permanent. Ce sauf-conduit, valable un mois, puis renouvelé, la mit longtemps à l'abri de tout souci. Elle avait loué, dans le petit village belge d'Etaimpuis, une chambrette dans une maison dont la façade était à six mètres de la frontière. Avec une carte d'identité fabriquée, Mlle Charlotte Lameron devenait ainsi citoyenne d'Etaimpuis et le problème du passage de France en Belgique était résolu. Pour le passeport vers Tournai, elle s'en fut à la kommandantur de Pecq. L'officier de service, un petit blond, frisé comme un caniche, lui déclara qu'elle était bien sotte d'aller prendre à son âge des leçons de coupe.

- Mais c'est pour gagner ma vie, lui dit-elle.

- Je regrette, madame. Refusé !

Elle partit et, dans la rue, se prit à pleurer. Aujourd'hui elle se demande vraiment pourquoi ces larmes, dans une si mince aventure. Elles vinrent d'ailleurs à point, car le secrétaire du jeune capitaine, pris de pitié, la suivit et, au premier tournant, l'aborda, lui disant :

- À deux heures, vous reviendrez. Moi, je vous donnerai le passeport. Ne le dites pas au commandant, surtout ! 
C'était un assez vieux bonhomme, dont la compassion paraissait sincère. Elle hésita. « Si je vais là, pensait-elle, on m'arrêtera. C'est un piège. » La curiosité fut la plus forte. L'homme avait préparé la pièce et la lui remit. Elle voulut le remercier et tira sa bourse.

- Non, non, dit l'Allemand. Partez, courez, finish !

La voilà donc autorisée à se rendre régulièrement à Tournai. De son côté, Alice a raconté qu'elle allait donner des leçons de littérature à des jeunes filles de Bruxelles. Elle a obtenu, elle aussi, un passeport. Toutes deux s'abonnent au chemin de fer et sont en règle.

Passer est bien, mais il faut passer avec des plis. Et l'on peut se faire prendre et fusiller, mais on ne doit pas laisser tomber aux mains de J'ennemi ce qu'on porte. Au début, Alice dissimulait son courrier dans le talon de son soulier. Elle y renonça vite, ayant appris que les Allemands savaient l'art de bien dépecer une chaussure. Un matin, elle eut grand'peur. On l'avait arrêtée la veille au soir près de Selzat, avec Charlotte. Elles avaient vainement essayé ce jour-là de passer la frontière, puis, l'affaire manquée, de trouver un gîte pour la nuit. À dix heures du soir, une patrouille les croise. On les conduit au poste. Elles racontent qu'elles sont en promenade, ce que les Allemands ont peine à croire, car elles portent des cartes d'identité de Gand et l'on est à cinq heures de marche de cette ville. Le courrier d'Alice est en partie dans son sac, le reste dans son soulier ; celui de Charlotte, dans une tablette de chocolat. Elles entrent dans une sorte de bureau, posent sur la table, l'une son sac, l'autre son paquet de chocolat, et se prêtent à la fouilleuse, qui ne trouve rien sur elles. On s'excuse et on leur offre un logement pour la nuit. Ravies, elles se couchent dans des chambres confortables et la téméraire Alice n'hésite pas à mettre ses souliers à la porte. Au réveil, plus de chaussures. On les lui avait prises, mais point pour les fouiller. Les Allemands, qui gardaient quelque doute sur l'innocence des deux captives, voulaient, en les déchaussant, les empêcher de s'évader dans la nuit. Elles durent promettre d'aller se présenter à la kommandantur de Gand, ce qu'elles firent le plus simplement du monde, puis elles s'en furent, du même pas naturel, vers la Hollande.

On imaginait mille cachettes : les manches de parapluies; les bougies allumées dans les lanternes des voitures, la nuit ; les poignées des sacs et des valises. On glissait de minces feuilles le long des baleines de corset ou dans les ourlets des 
jupes. Mais tout cela fut vite impraticable. Alice, pour sa part, préféra presque toujours tenir le pli dans son gant ou dans son sac, prête à s'en défaire à la première alerte. Il arrivait à elle et à ses agents de le tenir à la main, la nuit, enroulé dans du fil noir. En cas d'alerte, on jetait la petite boule et l'on gardait entre ses doigts l'extrémité du fil. Si le danger passait, on repêchait l'objet précieux. Quand elle prenait le parti de cacher quelque chose sur elle, ses précautions étaient telles que, soumise à la plus indiscrète visite, elle n'aurait pas livré son secret. Elle réussit à creuser les lacets de ses souliers et à y introduire des plis ; elle en mit aussi dans le cordonnet serrant ses cheveux. Elle fit mieux : ayant tordu une feuille de papier, elle se fabriqua ainsi du fil à repriser et raccommoda ses bas avec des documents secrets.

C'était sur son aplomb devant l'ennemi qu'elle comptait surtout. En principe, elle voyageait avec des paquets nombreux, si nombreux qu'au départ de Bruxelles il fallait toujours qu'un chasseur de l'hôtel l'accompagnât, les bras chargés, jusqu'à la gare ; ainsi elle occupait les fouilleuses, faisait du zèle, ouvrait elle-même ses colis, défaisait les ficelles, bavardait, s'amusait et se tirait d'affaire.

- Et encore ça, madame, que vous alliez oublier.

- Non, disait l'Allemande. Finish.

Alors, triomphante une fois de plus, Alice soufflait à l'oreille de Charlotte :

- Décidément, ils sont trop bêtes !

Au retour de Bruxelles, elle aimait à rapporter des journaux de Paris ou La Libre Belgique, qui paraissait alors clandestinement. Elle distribuait ces feuilles à ses amis de Lille, de Roubaix ou de Tourcoing. C'était un peu de joie qu'elle leur donnait et de l'aliment pour leur foi. En mai et juin 1915, les raisins de serre qu'on cultive volontiers en Belgique s'écoulaient malaisément et à bas prix. Alice en achetait beaucoup et l'un des garçons de l'hôtel Saint-Jean, Gustave Gailly, qui est aujourd'hui propriétaire d'une brasserie à l'enseigne de la Marne, chaussée d'Ixelles, à Bruxelles, les plaçait dans des caissettes, sur un matelas de journaux défendus. Il mettait aussi pour elle des gâteaux dans des boîtes à double fond. En route, elle mangeait les gâteaux et le raisin. Et ses amis, quand elle arrivait, dévoraient les nouvelles. 
Elle et Charlotte glissaient quelquefois leur courrier entre les pages d'un catalogue de magasin. Un jour, en gare de Tournai, Charlotte laissa tomber un de ces catalogues. Un Allemand zélé le ramassa, courut derrière elle et le lui remit avec des façons gracieuses, quoique essoufflées.

De telles alertes n'étaient pas rares. Charlotte dut un jour offrir tous ses vêtements à la visite, alors que le pli était dans la boule de laine de son tricot. Albert, arrêté un soir, commença spontanément, et pour cause, de se déshabiller. Il venait d'enlever sa cravate et de la poser sur une table, quand on lui cria brutalement de lever les bras. On le fouilla sans merci.

- Mi, dit-il aujourd'hui, je pensais tout le temps au courrier dins m' cravate. Et j'avais chaud...

Il reprit sa cravate et ne la mit pas à son cou, mais dans sa poche, puis s'en fut boire un grand verre de rhum, qui ne le soûla pas.

En gare d'Anvers, Alice fut un jour signalée par un contrôleur allemand et remise à une sentinelle pour être conduite au poste, un peu plus loin. Cette fois, elle était bien prise et ce qu'elle portait sur elle devait la perdre. Elle eut l'audace de proposer au soldat un beau louis de vingt francs tout brillant. Il hésitait. Elle se fit si caressante que, cupidité ou pitié, il la laissa partir.

Ses amis s'alarmaient de la voir quelquefois trop audacieuse. Elle voulait que le sacrifice de sa vie, puisqu'il était fait, fût profitable au plus grand nombre possible de ceux qui souffraient du joug allemand; et, bien que sa consigne fût de ne pas compromettre par trop de zèle son service d'État, elle passait en Hollande des hommes, des femmes, des jeunes gens ; et, à chaque voyage, elle portait en France ou en rapportait des cartes postales et des lettres. De tels chargements pouvaient la rendre suspecte. Elle cousait dans la doublure de sa jaquette tout un matelas de papiers qui lui faisaient un dos peu élégant, mais elle n'en avait cure et passait. Au retour, elle apportait toutes sortes d'objets encombrants. Elle revint un jour de Hollande avec une cinquantaine de ballonnets, dont elle se servit longtemps, par les vents favorables, pour aviser les, Britanniques de son prochain départ, ou de son retour heureux, ou leur annoncer un courrier important. Elle rapporta une fois de la mélinite, mais sans plaisir.

- Je ne suis pas une anarchiste, disait-elle en riant, et je n'aime pas ces histoires-là. 
Elle remit son colis à l'homme qu'on lui avait désigné et ne s'en occupa plus.

« Je me rappelle, m'écrit un officier supérieur de notre armée, qui la rencontra deux fois à Folkestone et qui a gardé d'elle un souvenir impérissable, je me rappelle sa joie en recevant le détecteur tant attendu par le poste de réception de T.S.F. de la région qu'elle habitait. » Elle passa cette fois sous les fils de fer chargée de ce détecteur, des lettres et cartes habituelles, de l'argent nécessaire à son service, de notes pour les agents et, sans doute, comme à l'habitude, d'un chapeau dans son sac et d'un châle sur sa tête, à moins que le châle ne fût dans le sac et ses beaux cheveux sous le chapeau.

Ses rapports avec Charlotte étaient d'une simplicité délicieuse. Elle voulait que cette petite la tutoyât.

- Minou, disait-elle, appelle-moi Alice : je serai si contente !

Et Minou refusait, parce qu'elle sentait en cette charmante aristocrate les deux instincts qui la faisaient noble : l'amour sans mesure du prochain, mais aussi le goût de régner. On ne tutoie pas la reine : on la sert et on la chérit.

On lui fait à l'occasion des remontrances. Et si Alice a de fausses cartes d'identité pour dérouter l'ennemi, Charlotte la gronde un peu de toujours porter sur elle sa médaille d'enfant de Marie, et aussi de garder à son doigt une chevalière où sont gravées les armes de sa maison.

- Bah ! répond-elle, je sais bien que je sauterai un jour. Mais j'aurai rendu des services. Hâtons-nous, Charlotte, et faisons beaucoup de choses avant d'être prises.

Un jour, Charlotte tomba malade. Après de trop longues marches dans la poussière, la fièvre l'avait prise à Gand, à cette hôtellerie de La Ville d'Audenarde que nous connaissons bien. Le médecin avait diagnostiqué une angine infectieuse. Il avertit l'aubergiste et sa femme que cette enfant mourrait peut-être sous leur toit. Ils la soignèrent comme leur fille. Alice, qui était alors en Hollande, revint à point pour la ramener, toute pâle et chancelante à Roubaix.

Mais on n'a pas le droit d'être malade à la guerre, et, cet incident passé, les deux petites Françaises reprirent avec allégresse leurs courses vivifiantes par les grandes routes et les champs.

- J'aime la vie primitive, disait sans cesse Alice. 
Oui, cette créature raffinée était au-dessus de la civilisation : elle en connaissait et en goûtait les finesses, mais son âme, assoiffée de grandeur, y étouffait. Il fallait à ses poumons l'air du large. Tout enfant, elle aimait les promenades solitaires. En Bohême, elle faisait de longues courses à cheval, laissant la bête marcher à l'aventure. De tels êtres sont heureux sur les chemins et plus heureux s'ils s'y sentent en danger.

Sur la route de Courtrai à Gand, à Mascheleim, il est une auberge que Louise de Bettignies aimait entre toutes. Elle est à l'enseigne du Prinskardinal. Les gens qui la tiennent sont propres et bienveillants. Quand ils voyaient arriver chez eux, perçant la foule des voituriers allemands, cette jeune femme si vivante et rieuse, ils la saluaient de bonne grâce et disaient tout bas : « Encore une petite qui fait du commerce. Elle se débrouille, elle a raison. » On la poussait à droite, dans un petit salon suivi d'une chambrette dont la fenêtre basse donnait sur un jardin tout fleuri. D'une enjambée, sans sauter, Alice se serait trouvée, en cas d'alerte, dans le jardin, puis dans les champs. Les draps étaient de belle toile et sentaient bon. Elle prenait là un vrai repos. À l'aube, vers cinq heures, elle se levait, se faisait servir des œufs, du jambon, des fruits. Elle remettait à l'aubergiste cinq francs pour le dîner de la veille, cinq francs pour la nuit, deux francs pour le repas matinal, et tirait de son sac des bonbons pour la vieille mère du bonhomme. C'est avec de telles gentillesses qu'elle se faisait adorer.

Elle sortait ordinairement de là en caraco blanc. Les femmes du Nord portent volontiers ces sortes de camisoles et rien n'amusait plus Alice que de s'en attifer. Quand il fallait se déguiser ainsi, elle entrait en joie et cherchait les façons les plus drôles pour amuser Charlotte et se donner à elle-même du courage, car la gaîté fortifie.

Mais elle rétablissait vivement sa tenue à la moindre alerte. Un jour, une sentinelle lui refusa le passage. Elle rebroussa chemin, se débarrassa de ses atours de paysanne et redevint citadine. Au moment de tenter une seconde fois l'aventure, elle vit sortir d'une propriété bordant la route un personnage important qu'accompagnait un officier d'ordonnance. C'était Ruprecht de Bavière. Elle alla bravement vers lui :

- Altesse, dit-elle, me reconnaissez-vous ? Je vous ai battu au bridge, il y a cing ans. 
L'altesse s'arrêta, rassembla ses souvenirs, puis, saluant l'amie de ses hôtes de Bohême, se mit galamment à son service.

- Ces gens-là, reprit-elle, font des difficultés pour me laisser passer. Vous seriez si bon de leur dire que je suis pressée...

Et elle lui sourit gentiment. Elle emportait ce soir-là vers la Hollande les emplacements d'une quantité notable des batteries de ce Ruprecht.

C'étaient chaque jour des émotions de ce genre, qui ajoutaient à la fatigue des muscles celle de nerfs ; mais elle veillait à cela comme à tout. Quand elle s'attablait à l'auberge, elle voulait un bon repas, qui lui donnât des forces ; jamais de bière, quoique, fille du Nord, elle l'aimât ; mais du vin, comme les, soldats français. Puis elle partait, ne sachant jamais si elle trouverait quelque véhicule pour épargner ses pauvres jambes. Plusieurs fois, elle s'étendit dans l'une de ces voitures à moules qu'on voit sur les routes de Flandre : ce sont de grosses poches de bois, dont la panse tombe jusqu'au sol ; on doit être cahoté là-dedans, et les moules, comme les noyaux de pêche, font des matelats peu estimés.

À quoi pensait-elle par tous ces chemins ? À son service d'abord, aux braves gens qui la secondaient, comme cet huissier de la mairie de Roubaix, Platel, qui recueillait chaque jour et transmettait à Charlotte les renseignements militaires les plus divers, pris à la bonne source, sur le bureau du général commandant la région ; ou à des amis sûrs, comme le docteur Dupureur et M. Desmul, de Gand, où M. Nopenaire, où Mme Bogaers, de Tilbourg ; elle pensait à ceux aussi qui l'ignoraient et dont elle entendait, en se dévouant secrètement, abréger la souffrance. Elle savait qu'elle absente, $M$. Lenfant la remplaçait à Lille et concentrait les renseignements, puis les acheminait vers le Nord. Car, dans tout ce service si bien réglé, les grands postes étaient doublés et par des hommes ou des femmes d'un dévouement et d'une intelligence à toute épreuve. L'admirable est qu'au même moment où Louise de Bettignies et sa petite équipe bravaient la mort et accomplissaient des prodiges, d'autres comme Firmin Dubar, René Wibaux, Mlle Nollet, la sœur Louise, le pharmacien Willot et sa femme, l'abbé Pinte, couraient, chacun à sa façon, des risques pareils, et accomplissaient pour l'amour de la patrie de grandes actions silencieuses. Il est triste d'ailleurs que le silence ait continué, la guerre finie, de planer sur ces hautes figures. Je le romps pour une entre les autres, 
dont l'image m'a charmé, comme ses yeux vivants savaient ensorceler qui la voyait, mais je voudrais que mon exemple fût suivi.

Elle pensait à son service, à la France, à son grand amour aussi : au Dieu qu'elle irait un jour adorer à son aise au fond d'un Carmel. Elle emportait souvent avec elle un petit livre : c'étaient les exercices de saint Ignace, ou ceux de sainte Thérèse ou de saint Jean de la Croix. Et si, de Bruxelles, elle avait le temps de courir jusqu'au faubourg d'Anderlecht, elle sonnait à la porte de ses bonnes amies, les Carmélites. La Prieure, issue d'une des plus nobles familles de France, recevait avec bonté cette servante de la Patrie qu'elle voyait courir au martyre avec l'allégresse des chrétiennes des premiers âges. Au retour, Louise disait quelquefois ses impressions avec la volubilité d'une enfant de la route, devenue primesautière et un peu gamine.

- J'ai vu, disait-elle, la maîtresse des novices. Elle ne me plaît pas du tout. Mais je le dirai à la Mère Prieure, et on la changera.

Elle faisait alors son geste de la main, que connaissaient bien tous ses amis : un geste vertical et tranchant, qui disait : je veux, je coupe, et voilà.

Mais voici l'heure de nous recueillir. Je vous l'ai montrée à Lille, puis sur la route de Gand ou de Bruxelles. Nous allons maintenant aborder avec elle les postes de la frontière. Beaucoup de gens ont passé de Belgique en Hollande, qui n'ont peut-être pas trouvé l'aventure si émouvante. C'est que, tout au début, certains passages étaient faciles. Elle-même a longtemps traversé par Saint-Nicolas et La Clinge. Là, on suivait sans gros risques une route mal gardée et droite, au bout de laquelle des soldats cupides prélevaient un droit de cinq francs par évadé. On assure que ces Allemands peu ombrageux ont laissé passer des voitures chargées de monde, et que Belges, Français, Anglais se présentèrent là, certains jours, en caravanes de cent personnes. Ceux qui vivaient de ce commerce trahissaient à bon compte : ils se rattrapaient d'ailleurs sur la quantité et l'opération n'était mauvaise que pour leurs maîtres. Par contre, nous savons que le passage par Bouchaute, qui demeura toujours l'un des plus faciles, ne se faisait point sans risques. Et jamais Louise de Bettignies, qui se rendit certainement de quinze à vingt fois en Hollande et qui traversa donc de trente à quarante fois les zones dangereuses, n'a sauté la frontière, quoiqu'elle fût brave comme pas une, sans une émotion violente. Songez que les Allemands avaient placé au-dessus de certaines plaines, que leur im- 
mensité faisait difficiles à garder, des projecteurs d'une grande puissance. Tout autour, des sentinelles, le fusil armé, le doigt prêt à presser sur la gâchette, promenaient leurs regards sur la terre blafarde. Qu'un point noir remuât sous les rayons de ces phares et les balles crépitaient. Au matin, on relevait des civils morts, des femmes, des enfants. Car il y avait toujours des gens avides de passer quand même, et Louise de Bettignies comme les autres. Pour n'être point vue, elle se glissait exactement sous les lampes, en vêtements clairs. Elle avait calculé que c'était leur ombre qui dénonçait les victimes. Plus les pauvres gens s'éloignaient des projecteurs, plus s'étirait la bande noire qui les trahissait. Mais allez donc raisonner dans des moments pareils! En se portant, pour être moins vue, dans la zone la plus lumineuse, elle témoignait d'une hardiesse souveraine et broyait en elle tous les instincts et toutes les terreurs qui habitent le cœur des femmes.

Elle essaya quelque temps d'aborder la Hollande par une région boisée à l'est de Turnhout. Là, les sentinelles n'ayant ni vue, ni champ de tir, il aurait fallu les multiplier à l'excès, et les Allemands les avaient remplacées par des mines, des pièges et des fils de fer électrifiés au ras du sol. Elle marchait quand même, ne craignant rien, pas même la solitude, que le mystère des bois rend si terrifiante. C'est qu'elle avait une volonté de fer, que trahissaient sa parole martelée, son geste vif, le Mouvement hardi de sa fête et son beau regard, si doux pour attirer, si impérieux quand elle avait décidé. Le cardinal Charost, alors évêque de Lille, et dont l'attitude héroïque en face de l'occupant est restée légendaire, connaissait bien Louise de Bettignies. Il n'en parle aujourd'hui qu'avec attendrissement. Ce qu'il admirait le plus en cette noble fille, c'était son audace. " Elle était bondissante ", répète-t-il volontiers. On eût dit que des forces bouillonnaient en elles , toujours prêtes à gonfler son âme, à soulever son corps léger. Elle bondissait, mais avec quel art ! Ceux qui l'ont accompagnée sur les routes et parmi les dangers ont remarqué sa démarche si souple, à la fois rapide et prudente. Elle passait avec une adresse extraordinaire, sans remuer un caillou ni une branche. Il lui arrivait de rentrer à Lille toute déchirée et boueuse. Mais elle savait comme le moindre bruit se prolonge et va se répercutant dans la nuit; et si le fantôme courait à travers tout, rampant sur le sol et maculant ses vêtements, c'était un fantôme silencieux, qui ne réveillait, ni les échos, ni les chiens hurleurs, ni les fusils. Un jour, elle, s'était aventurée dans les bois, à l'aube. À deux cents mètres devant elle, une femme et un homme se dirigeaient aussi, un gros sac à la main, vers la Hollande. 
Elle résolut de demeurer à distance, car elle devait à son service d'être circonspecte, mais elle garderait le contact pour secourir à l'occasion ces apprentis. Tout à coup, elle vit jaillir une immense flamme, puis fut renversée par un souffle chaud dans un grand vacarme. Les pauvres gens qu'elle suivait, ayant heurté une mine, venaient de sauter. La petite Française se releva ; elle alla vers le lieu de la catastrophe, aperçut les débris affreux des deux corps et continua sa route au milieu des pièges ; mais tous ses membres tremblaient.

- Je ne vous souhaite pas, dit-elle un plus tard à Charlotte, de voir une chose pareille. J'aime mieux passer sous les yeux des sentinelles. Le danger ne m'effraie pas, ruais je veux le voir.

Et quand on lui demandait si elle avait jamais eu peur.

- Oui, répondait-elle. Comme tout le monde. Même, une fois, j'ai eu très peur, une peur folle ; mais c'était après le danger. Avant, c'est défendu.

Un des chemins qu'elle utilisa le plus souvent est celui de Beersse. Au nord de ce village est un canal, que les Allemands gardaient alors sévèrement. Quand on l'avait franchi, on gagnait la Hollande en deux heures de marche prudente dans la nuit ; encore fallait-il passer ce canal.

Le plus simple était de s'entendre avec des gens du pays. L'un d'eux, Alphonse Verstapen, rendit à Louise de Bettignies d'immenses services, avec le dévouement d'un héros. Il habitait une maisonnette sur la rive nord, c'est-à-dire du côté de la Hollande, en bordure du chemin de halage. Prévenu par Albert, qui, pour se faufiler partout, connaissait des méthodes fantaisistes que nous ne chercherons pas à comprendre, cet Alphonse traversait le pont avec sa femme ou une voisine, se rendant au bourg. Là, il rencontrait Alice, à qui la paysanne prêtait son tablier, son châle, ses sabots. Alphonse repassait le canal avec sa nouvelle compagne en saluant familièrement de la main la sentinelle. Et la Flamande authentique rentrait un peu plus tard, après la relève.

Mais Alphonse n'était pas toujours là.. Cet homme, qui se serait fait tuer pour Alice et eût, a son appel, abandonné tous les autres, passait des quantités de gens et les conduisait jusqu'en Hollande. Il fit si bien qu'on dut le contraindre un jour, sa tête étant mise à prix, à rester de l'autre côté, où les alliés utilisèrent ses intelligents services. Il est aujourd'hui gravement malade; c'est un invalide de guerre, qu'il faut saluer avec respect. Quand il lui manquait, Alice, jamais démontée, pas- 
sait quand même. J'ai vu le canal ; il est sale et sinistre j'ai frissonné en apprenant par Charlotte que Louise de Bettignies, quand elle devait traverser par Beersse, s'habillait d'un costume de bain, d'une culotte de laine noire et d'une jupe très simple. Pour passer dans les fourrés et les bois, elle relevait la jupe et enjambait les obstacles en riant, heureuse de montrer à son amie qu'elle était leste et sautait comme un chat. Et la nuit, si elles prenaient toutes deux le frais au long du canal, devant la maison d'Alphonse, elle regardait l'eau froide et disait :

- Pas sympathique, cette rivière ; mais quand il faudra, on s'y jettera et on la passera. N'est-ce pas, Minou?

Minou, qui ne sait pas nager, répondait qu'on pourrait essayer d'abord de recourir au boulanger, à ce boulanger d'en face qui avait plusieurs fois permis qu'on fit de son pétrin une barque pour les évasions.

J'ai dit combien elle aimait et savait choisir les maisons propres. Du côté de Beersse, le long du canal, c'était presque toujours chez de pauvres gens très débraillés qu'elle se cachait, prenait ses repas et demeurait la nuit. J'ai vu quelquesunes des femmes qui habitent aujourd'hui dans ces parages. Elles m'ont reçu dans leur toilette du matin; et j'ai surtout remarqué qu'une d'elles avait mis ses pieds nus et sans blancheur dans des souliers Richelieu éculés et délacés. L'entrevue avait lieu au dehors, dans une boue noire comme de l'encre. Des pieds sales dans des sabots n'ont jamais scandalisé personne. Ceux de cette femme m'ont effaré. Louise de Bettignies a dû, dans ce coin-là, frayer avec des ivrognes, mettre ses coudes sur des tables poisseuses, respirer un air âcre, entendre des jurons que, plus heureux, je n'aurais pas compris. Car elle s'était vite familiarisée avec le flamand, qu'elle parlait bravement avec tous ces gens-là. Elle était très vexée quand on lui disait, pour la taquiner, qu'au Carmel elle ne pourrait peut-être pas donner chaque matin beaucoup de temps à son tub et à sa toilette; car elle aimait l'eau froide, l'eau qui vivifie, Elle acceptait pourtant le contact de gens malpropres, soit qu'elle se sentît heureuse chez eux, à cause des solides vertus qu'elle apercevait sous la crasse de plusieurs d'entre eux, soit que la joie de souffrir pour la patrie la soulevât.

Ce monde de fraudeurs a le langage et les moeurs rudes. Alphonse Verstapen, nature d'élite, qu'elle admirait, eût fait peur à toute autre moins vaillante. Il disait, en l'entraînant vers le langer : «Si je descends un homme, cela ne vous regarde 
pas. Suivez-moi. » Et, quand il fallait passer un ruisseau, il la soulevait comme une feuille et la pressait contre lui de ses bras robustes. C'était la nuit et le désert : elle ne tremblait pas.

Les fils de fer passés, elle se rendait vivement à Flessingue, où elle rejoignait, le représentant des autorités britanniques: c'était M. Courboin, de Bruxelles, qu'elle désigna longtemps sous le nom de M. Beemans, puis sous le sobriquet de tante Anna. Elle lui remettait son courrier, recevait des instructions, reprenait le chemin de la Belgique et de la France captives. Elle alla quatre ou cinq fois à Folkestone, jamais à Londres. Elle fit deux voyages en France. À Flessingue et en Angleterre, on l'accueillait comme une petite fée, à cause du charme que dégageait sa personne avenante et brave et pour les services éminents qu'elle rendait. Les Anglais ont employé beaucoup de monde en pays occupé : on apprendra peutêtre avec surprise que deux cent vingt-neuf agents des services britanniques, hommes ou femmes, ont été fusillés par les Allemands. C'est dire quelles tentatives variées et répétées nos alliés ont faites pour connaître l'ennemi, ses mouvements et ses desseins. Toutes ne furent pas heureuses. On a pu leur reprocher, comme aux Belges et à nous-mêmes, d'avoir parfois utilisé des amateurs, qui, dépourvus d'expérience, se laissaient prendre au premier piège et nuisaient par des maladresses à la cause pour laquelle ils mouraient d'ailleurs bravement.

Le service d'Alice Dubois, non seulement ne fut pas un service d'amateur, mais, au témoignage de l'état-major britannique, il ne fut dépassé par aucune autre organisation durant toute la guerre, pour la qualité, le nombre et la richesse des documents et des renseignements fournis. Nos alliés sont tenus encore à une grande réserve et les dossiers où sont amassées les preuves de l'activité de Louise de Bettignies et du profit qu'en a tiré l'Entente ne seront ouverts aux chercheurs que beaucoup plus tard, quand on pourra, sans dommage pour eux, laisser connaître les noms de certains agents qui survivent. Nous verrons du moins, à la fin de ce livre, de quelle majesté il plut à nos alliés d'entourer les funérailles de cette jeune fille, quand leurs soldats, arrivant en Allemagne, découvrirent son nom sur une croix de bois blanc. Et j'ai recueilli moi-même l'avis de son chef en Hollande, qui m'a dit: «Les services que Louise de Bettignies a rendus sont inestimables. Nous avons connu par elle, avec une précision, une rapidité et une régularité 
qu'aucune autre organisation n'a dépassées, tous les mouvements de l'ennemi, les emplacements exacts de toutes ses batteries, et les mille détails particuliers que nos états-majors demandaient à tout propos. Peut-être, au cours de la guerre, l'expérience ayant perfectionné les méthodes, un ou deux autres services ont-ils égalé le sien. Aucun ne l'a jamais surpassé. Ici, monsieur, nous avions pour cette jeune Française une admiration presque religieuse. Nous l'adorions. »

Il faut se rendre compte de la force surhumaine qu'elle a dû déployer pour fournir deux fois par semaine des rapports si touffus qu'il fallait chaque fois plusieurs jours aux officiers de. Folkestone pour les déchiffrer et les classer. Son service a été le plus fructueux et le moins cher. Elle travaillait comme une fourmi, courant sans cesse, ne payant leurs services qu'à d'honnêtes gens. Dès qu'un agent haussait ses prix, elle entrait en défiance, et pour cause, les bons patriotes étant d'accord pour ne pas battre monnaie de leur zèle. Oui, elle travaillait dans la joie, mais à fond, et j'imagine combien devaient la scandaliser ces jeunes hommes, si légers, qu'elle ou Charlotte amenaient à Flessingue et qui, à peine en terre libre, les quittaient pour aller se vautrer dans de mauvais lieux. Car elles ont tout subi, ces pauvres petites même cette injure de voir courir à des plaisirs malpropres de grands garçons qu'elles étaient pourtant si fières de conduire à l'honneur.

Quand on l'avait bien fêtée chez les Anglais ou à Flessingue, elle rentrait en France toute transfigurée ; à Bruxelles, où elle retrouvait Charlotte, elle prenait le bras de cette petite et lui disait :

- Ah ! Minou, nous pouvons être heureuses. Nous nous donnons du mal, mais nous sommes utiles. J'en suis sûre maintenant : ils me l'ont dit si gentiment...

Pressée par le major Cameron, de Folkestone, celui qu'elle appelait l'oncle Edouard, elle décida, au mois d'août 1915, d'étendre vers le sud-est le réseau de ses agents. Elle alla un jour à Valenciennes, y vit quelques personnes et jeta les bases d'une organisation pareille à celle que dirigeait pour elle M. Lenfant dans la région de Lille et de Tourcoing. Elle songea aussi à pousser jusqu'à Mézières.

J'ai voulu savoir si cette fille ardente, à voir ainsi grandir son rôle, ne s'était pas un peu grisée. Tous les témoignages la montrent plus ferme, plus maîtresse d'elle-même de mois en mois. Elle restait rieuse et grave, comme toujours ; peutêtre moins rieuse et plus grave. Une fois seulement, elle vit tomber sa gaîté ; et son front s'assombrit. 
C'était en France libre, lors du second et dernier séjour qu'elle y fit, dans les premiers jours de septembre 1915. Elle avait senti le besoin de revoir les siens et d'aller demander du courage au Père Boulengé. Le 9 septembre, elle était au Portel, auprès de sa sœur, la comtesse d'Argœuves. Elle la quittait le lendemain, un vendredi, pour se rendre à Amiens, puis elle courait à Paris, où elle embrassait sa plus jeune sœur et l'un de ses frères ; elle arrivait enfin le dimanche matin à ParisPlage, où habitait alors sa mère : « Je veux vous voir tous une dernière fois, lui dit-elle tristement, car je sens que c'est fini. Ils vont me fusiller. » 


\section{LA GUERRE DES FEMMES.}

Histoire de Louise de Bettignies et de ses compagnes.

\section{Chapitre V}

\section{DANS LA SOURICIÈRE}

$\underline{\text { Retour à la table des matières }}$

Le 23 septembre 1915, une charrette légère s'arrêtait boulevard de Metz, à Roubaix, devant la maison de Léonie Vanhoutte. Deux hommes en descendaient : c'étaient le commissaire de police Lenfant et M. Sion, qui venaient prier la jeune fille de se rendre tout de suite en Hollande pour y transporter un courrier urgent. Elle refusa d'abord. Les Allemands l'avaient trop évidemment surveillée à son dernier voyage. Elle se sentait suspecte et ne trouvait pas raisonnable qu'on la remît aussitôt en route. Les visiteurs insistèrent. Alice était alors en France. Il fallait pour le pli à transporter un courrier sûr et rapide.

- Il faut au moins que vous alliez jusqu'à Bruxelles.

- Bien, j'irai ! dit-elle.

Le lendemain, à quatre heures du matin, elle quitte la maison de ses parents. L'air âpre des nuits de septembre lui fouette le visage et colle sa jupe à ses genoux. Elle avance, courbée en deux, le cœur inquiet. Elle tient en grelottant son livre de messe dans ses deux mains. Précaution inutile aucune patrouille ne l'arrêta ce matin-là. Il a une heure et, demie de marche pour atteindre la halte du chemin de fer qui conduit à Tournai. Elle presse le pas et pourtant manque le premier 
train. C'est la déroute qui commence. Elle prend le suivant, ne trouve pas à Tournai l'homme à qui elle devait confier un premier courrier et, contrariée de cette mésaventure où elle voit un présage, elle arrive à Bruxelles un peu avant midi. Elle est là, dans le flot des voyageurs qui ont dévalé ensemble sur le quai et qui courent vers la sortie. Ses yeux cherchent quelqu'un. Dans le hall, un peu à l'écart, un homme parait indifférent; en vérité. il dévisage tant qu'il peut ces gens qui passent. Dès qu'il a rencontré le regard de Charlotte, il disparaît. C'est Albert, elle l'a vu: la voilà un peu rassurée. Alors commence le manège habituel. Elle va à petits pas vers la cathédrale Sainte-Gudule et s'y met en prière sous la chaire, la grande chaire de bois sculpté où sont figurés autour du premier homme et de la première femme tous les animaux du paradis terrestre. Un quart d'heure plus tard, Albert, errant sous les hautes voûtes, passe devant elle, puis se retire lentement. Elle le suit à quelque distance. À l'arrêt du tramway, non loin de là, ils ne retrouvent ensemble, montent dans la même voiture, sur la même plate-forme, mais sans se parler, sans se connaître. À la porte de Namur, il faut descendre pour prendre une correspondance. À ce moment, Albert, devant qui passe Charlotte, lui glisse un mot : Aduatiques.

Les Aduatiques sont l'une des tribus barbares qui défendirent contre César le sol où vit aujourd'hui le peuple belge. Albert se moque un peu de ces gens-là, mais on a donné leur nom à une rue qui avoisine le monument du Cinquantenaire, et dans cette rue, au numéro 64, est une maison où Charlotte sait maintenant qu'elle peut sonner sans crainte. Pour l'heure, la mission d'Albert est terminée : il se perd dans la foule.

À chaque voyage, Charlotte était ainsi avisée du lieu où elle devait se rendre : c'était tantôt l'hôtel Saint-Jean, tantôt celui de l'Espérance, plus souvent la maison où elle va frapper aujourd'hui.

C'était une sorte de pension de famille que des Pères Jésuites avaient recommandée à Louise de Bettignies. On les y a reçues toutes deux plusieurs fois au cours de cet été de 1915. Comme elles se trouvaient rarement ensemble à Bruxelles, elles y occupaient tour à tour la même chambre. Toutes les maisons de cette charmante capitale de la Belgique se ressemblent. En façade, une porte et une fenêtre seulement. Quand on ouvre, on a devant soi un haut escalier, droit comme une échelle et d'une blancheur éclatante. Sur les murs, les marches, la rampe, qu'ils soient peints au ripolin ou qu'il s'y mêle, dans les maisons cossues, du vrai 
marbre tout brillant, une vaste fenêtre laisse passer la lumière à flots. Le tapis, rue des Aduatiques, était de linoléum avec de larges plaques de cuivre au bord des marches. Au haut à gauche, à l'entrée du palier du premier étage qui donne accès aux chambres, est une petite porte - c'est là qu'ont habité nos deux jeunes filles.

Les pensionnaires disposaient du salon, qui est en façade au rez-de-chaussée, et prenaient leurs repas dans une salle à manger derrière ce salon. Alice et Charlotte, qui ne tenaient pas outre mesure au contact de ces indifférents, vivaient plus volontiers avec la famille de leur hôtesse, au sous-sol. À vrai dire, ces sous-sols de Bruxelles sont presque à ras de terre. Dans celui-là, la pièce de devant, très étroite mais assez longue, est éclairée par une large fenêtre. Une table de travail rectangulaire occupe ce salon intime presque en entier et le soleil la chauffe et l'égaie. Si on lève le nez, on voit les chevilles des passants, celles des passantes aussi, et c'est quelquefois agréable, pas toujours. C'est là que vivaient les dames Pandelaers, la mère et les deux filles. L'aînée est aujourd'hui mariée et n'habite plus la maison ; c'est la cadette, type parfait de la petite Bruxelloise appétissante et délurée, pleine de charme et d'aplomb, qui m'a fait, au dernier printemps, en l'absence de sa mère, les honneurs de la maison. Nous étions accoudés, Charlotte, elle et moi, dans ce sous-sol, autour de la grande table, et la jeune fille, dont les yeux noirs jetaient des feux sur l'émouvante pensionnaire de 1915 qu'elle n'espérait plus revoir, nous parlait de « Mademoiselle Alice ».

- Elle a fait de longs séjours ici, nous dit-elle. On la gâtait. Elle était si jolie !...

Cet avis d'une enfant qui avait quatorze ans au début de la guerre et qui appartient à une génération si étrange, si difficile à satisfaire, m'enchanta ; et je lui dis :

- Vraiment, vous la trouviez jolie?

- Très. Je ne sais comment vous expliquer, monsieur, mais je ne cessais de la regarder. Elle n'était pas « chic », mais distinguée à un degré incroyable.

- Quel âge lui donniez-vous?

- Oh ! elle « faisait » vingt-sept ou vingt-huit ans. Je l'appelais, à part moi, l'aristocrate, quoiqu'elle fût Mlle Dubois. C'était surtout à cause d'une certaine jupe noire à plis qu'elle portait avec majesté et qui, je l'avoue, m'émerveillait. Ses 
cheveux cendrés aussi me faisaient impression. C'était une personne calme, un peu nonchalante.

- Vraiment ?

Oui, monsieur. Sans doute était-elle fatiguée quand elle s'arrêtait ici. Elle aimait qu'on la servît. Un jour, un pensionnaire, au petit déjeuner du matin, dut lui verser goutte à goutte le café dans sa tasse, tandis qu'elle y battait un jaune d'oeuf. Il a bien fallu qu'il s'exécutât : on ne pouvait rien lui refuser ; mais il s'arrangea les jours suivants pour ne plus paraître à la salle à manger en même temps qu'elle. Nous achetions pour elle beaucoup de fruits. Souvent, elle passait à la cuisine et nous aidait. Ou bien, elle travaillait dans cette pièce, faisant un petit savonnage, puis repassant son linge fin, s'arrangeant une robe, une chemisette. Nous avions chez nous, depuis deux mois, au moment de l'arrestation de Mlle Charlotte, deux Françaises, dont une était modiste et lui faisait des chapeaux. Elle les essayait avec une joie d'enfant ; et elle parlait, parlait.

- Vous doutiez-vous de ce qu'elle faisait?

- Du tout. Elle ne cachait pu sa haine contre les Allemands. Mais elle se souciait beaucoup plus de toilette que d'autre chose. Elle était si amusante quand elle avait fait un bel achat ! Une fois, au Mont des Arts, elle avait trouvé une blouse en tulle. Je m'en souviens encore.

- Avec de petits nœuds violets ? demanda Charlotte.

- Celle-là, justement. Vous rappelez-vous comme elle était fière de son achat? Elle l'essayait, nous l'essayait, la remettait sur elle et passait devant cette glace. Vous vous souvenez maintenant? Elle ne l'avait payée que cinquante francs. Moi, je trouvais que c'était cher alors. Elle m'éblouissait. Je crois bien qu'elle ne l'a jamais portée, sa jolie blouse.

Il semble vraiment que, sur cette toute jeune fille, Louise de Bettignies ait exercé une séduction totale. C'est un honneur que de charmer les âmes enfantines. Quand ils rendent compte, ces êtres frais, de leurs émerveillements, ils s'attachent à des détails sans beaucoup de prix ; ils ne savent pas eux-mêmes ce qui les a conquis et vous disent que c'est un bout de ruban, quand c'est un regard avec une âme au fond. 
- Moi, dit celle-ci, j'aimais surtout son tailleur noir bordé d'un galon de soie. Elle tenait toujours sa jaquette ouverte. Avec son grand chapeau de tagal, elle avait une allure magnifique.

Quand, le 24 septembre, vers midi, Léonie Vanhoutte sonna à la porte de cette maison, ce fut cette toute jeune fille qui lui ouvrit.

- Il y a deux lettres pour vous, lui dit-elle tout bas dès l'entrée.

La voyageuse pâlit.

- J'en étais sûre, pensa-t-elle. Je suis prise.

Elle jeta un regard angoissé sur la première. C'était une carte postale de Louise de Bettignies adressée de Hollande à Mme Pandelaers, mais évidemment écrite pour Charlotte. Des mots vagues sur sa santé et celle de je ne sais plus quelle tante révélèrent à la jeune Française que tout allait bien là-bas et qu'Alice s'apprêtait à rentrer. L'autre lettre était plus mystérieuse. La suscription était d'une écriture inconnue. La nouvelle venue monta droit à sa chambre et, toute tremblante, fit sauter l'enveloppe. Elle lut ceci : Venez au plus tôt, ce soir ou demain vers huit heures, au Lion belge. Journal à la main. Il s'agit d'Alice.

C'était signé : Alexandre et Joseph.

Elle n'eut pas une seconde d'hésitation. Cette lettre était de la police, qui lui tendait un piège. Elle ignorait ce que pouvait signifier la signature de Joseph. Quant à Alexandre, c'était le nom d'un individu dont Alice projetait depuis peu d'utiliser les services pour le passage des courriers en Hollande. On était en pourparlers avec lui : rien de plus. Sans doute cet homme, arrêté, avait-il révélé aux policiers les noms d'Alice et de Charlotte. Que faire ? Léonie Vanhoutte est de celles qui, aux heures de grande émotion, gardent sang-froid et appétit. Elle alla prendre des forces à table. À deux heures, Albert vint aux ordres. Elle lui remit l'exemplaire de son courrier destiné au passage de Turnhout et reçut de lui un pli minuscule, venu de Hollande pour Tourcoing. Comme il la voyait inquiète, il l'interrogea. Alors elle lui montra la lettre.

- Mon impression, dit-elle, c'est que c'est boche.

Il lut, relut le papier, le retourna, le froissa dans ses doigts, puis le rendit à la jeune fille en haussant les épaules. 
- Te vois toujours des Boches tout partout, lui dit-il. Non, non, c'est bon, ça 1 Tu peux aller, sais-tu.

Journée d'angoisse. L'insouciance du bonhomme l'avait un peu rassurée, mais son cœur se contractait, quoi qu'elle voulût penser. Elle erra une heure ou deux dans Bruxelles, cherchant à s'étourdir. Quand elle revint rue des Aduatiques, une femme l'attendait. C'était Julia, qui faisait le courrier entre Gand et Bruxelles. Elle venait chercher le double du pli qu'avait emporté Albert. Tandis que le premier exemplaire passerait par Turnhout, celui qu'elle allait recevoir s'en irait par Gand vers Bouchaute. À Julia aussi la lettre mystérieuse fut montrée.

- Moi, j'irais, dit cette femme. Voulez-vous que je vienne avec vous ?

Tous s'accordaient ingénument pour la pousser dans la souricière.

- Non, j'irai seule. Et puis je n'ai plus peur, tenez !

Le fait est que c'est d'un pas ferme que, la nuit venue, elle se dirigea vers la gare du Nord. Albert l'accompagnait. Il la quitta sur la place et attendit. Le Lion Belge est une petite brasserie foute proche de la gare. C'était plein de monde et très éclairé. Un journal à la main, la jeune fille entra bravement et passa entre les tables, regardant autour d'elle. A gauche de la porte, contre la devanture vitrée, deux civils étaient attablés. L'un d'eux se leva, fit un pas derrière elle. Vivement, elle se retourna l'homme la salua et lui dit à mi-voix :

- Mademoiselle Charlotte, sans doute ? Vous voudrez bien excuser Alexandre, qui se sent surveillé et qui a eu peur, en venant ici, de se faire arrêter. Mais je viens de sa part et vous pouvez parler.

Il souriait. C'était un grand garçon, brun, solide, le visage rasé, l'œil extraordinairement vif : un œil terrible. Comme une petite bête fascinée, la jeune fille le suivit à sa table, s'assit auprès de lui, reçut un salut de l'autre homme, refusa la bière que ces galants lui offraient et, bien certaine à cette minute d'être entre les mains de deux policiers qui l'abattraient d'un coup de revolver si elle tentait de fuir, elle fortifia son âme pour la lutte qui s'engageait.

- Alexandre est prêt, lui dit l'homme, qui avait pris un parfait accent belge. Je travaille avec lui. Avez-vous une mission tout de suite?

Elle répondit qu'en effet elle voulait passer en Hollande. 
- Si c'est pour transporter un courrier, nous pouvons nous en charger.

- Quel courrier ? Je veux passer, moi, voilà tout.

- Et Alice ?

- C'est une amie. Il n'est pas question d'elle. Il s'agit que je passe.

- Pour quoi faire ?

- Pour m'en aller. J'ai mon fiancé de l'autre côté. Combien prenez-vous pour un passage?

Elle plaça la conversation sur ce terrain et s'y tint si bien que son interlocuteur l'y suivit d'assez bonne grâce. À la fin, celui-ci paraissait croire qu'en effet sa prise n'était pas si fameuse. Elle avait, au cours de l'après-midi, prévu bien des choses. Elle put lui montrer la photographie du fiancé et lui confier, pour la faire passer moyennant trois francs, une lettre insignifiante. Elle-même, tant la conversation prenait un tour confiant et peu dangereux, jugea un moment ses craintes excessives. Peut-être cet homme était-il vraiment envoyé par Alexandre. Tout à coup, ses yeux rencontrèrent ceux de la patronne de l'établissement, assise à la caisse, sur son haut tabouret. Cette femme la regardait avec une expression de pitié qui la jeta dans l'épouvante.

La brebis était bien dans les griffes du loup : une inconnue compatissante lui en faisait l'atroce aveu. Alors elle continua son jeu, avouant, pour sauver tout le reste, qu'elle était une amoureuse avide de s'échapper vers le bonheur.

Il y avait un monde fou dans cette maison, qui empestait la bière et le tabac. Des civils et des soldats se bousculaient au comptoir, parlant haut, riant fort, ne se doutant guère qu'à cette petite table, contre la porte, un drame se jouait entre une jeune femme et deux bandits.

Elle avait la tête cassée. La sentant à bout de forces, ils firent comme les chats qui ont pris une souris : ils ouvrirent les pattes. Elle crut qu'elle était libre.

- Demain matin, à onze heures, lui dirent-ils, venez chez Alexandre, rue des Tanneurs. Nous déciderons là si nous pouvons vous faire passer.

Sur la place, elle fit signe à Albert de ne pas l'aborder. Ils sautèrent, sans se parler, dans le même tramway. Un soldat monta à la marche et se tint, silencieux, auprès d'eux, qui se tournaient le dos. Le monument du cinquantenaire est au mi- 
lieu d'espaces immenses. Ayant erré là quelque temps l'un et l'autre, ils finirent par se rencontrer sur le même banc. La nuit était épaisse.

- Attention, on nous épie, dit Charlotte.

Il voulut la rassurer.

- Non, dit-elle, je suis prise, Je sens partout leurs regards. C'est affreux, cette impression que des yeux pèsent sur vous.

Comment, ainsi angoissée, prit-elle le parti de rentrer rue des Aduatiques ? Elle assure qu'elle se croyait hors de danger jusqu'au rendez-vous du lendemain à onze heures. À celui-là, elle n'irait pas. Mais pour aviser dès le petit jour, il fallait reprendre des forces et d'abord faire une bonne nuit. Elle se sentait brisée. Elle congédia Albert. Les dames Pandelaers lui avaient remis une clef. Elle rentra sans bruit et se déshabilla. Après avoir placé dans un vide-poches le pli compromettant que lui avait remis Victor, elle prit le parti plus raisonnable de le fixer à un cordon blanc qu'elle noua autour de sa taille, sous sa chemise, puis elle se coucha et bientôt s'endormit.

À cinq heures, trois hommes, revolver au poing, faisaient irruption dans sa chambre. Comme ils l'éclaboussaient avec leurs lampes électriques braquées sur elle, elle fit un geste du bras sur les yeux.

- Pas un mouvement, ou je tire ! lui cria un des individus.

Elle abaissa les bras et attendit.

- Autorité allemande, reprit le policier ; on vous arrête.

C'était l'homme de la veille : elle reconnaissait sa voix. Il prit la peine, pour justifier son agression, de sortir sa médaille et de la faire briller sous le feu de sa lampe. Puis, tandis qu'il se chargeait de surveiller la prisonnière, il fit signe aux autres de commencer leur travail. Ils fouillèrent partout. Deux autres les rejoignirent. Ils étaient quatre, qui regardaient sous le lit, derrière les tableaux, dans les rideaux, ouvrant et secouant le parapluie. Ils prirent un à un tous les vêtements de la jeune fille, sa robe, son linge. Ils retournèrent ses bas ; l'un d'eux y fourra sa lampe: ils n'étaient pas de soie ni transparents. Un gros bonhomme demeura longtemps aux prises avec le corset de la pauvrette, qui en rit encore. Dans sa valise, ils jetèrent pêle-mêle, au fur et à mesure qu'ils les avaient examinés et palpés, tous les objets lui appartenant, sa montre, sa chaînette, son tour de cou, ses objets 
de toilette, même ses épingles à cheveux, sans lesquelles elle eut un peu plus tard quelque mal à se coiffer.

Dans la maison, les pensionnaires dormaient, mais on devine l'émoi de l'hôtesse. Son premier soin avait été de porter dans la boîte à ordures, au fond de la cour, une lettre arrivée la veille au soir à l'adresse de Charlotte. Comme il pleuvait à seaux, la malheureuse femme rentra le dos trempé. Quand les policiers l'appelèrent pour avoir de la lumière, elle comprit son imprudence. Si, la voyant mouillée, ils l'avaient interrogée, elle était perdue, elle aussi. Elle demanda timidement, tout en allumant la lampe, si elle pouvait apporter une tasse de café à la prisonnière.

- Non, lui répondit-on brutalement. Allez vous-en.

L'armoire était pleine d'objets appartenant à Louise de Bettignies. La pauvre Charlotte regardait cette armoire avec angoisse. Ils parurent n'y rien trouver de suspect. C'étaient des vêtements de femme : ils ne s'enquirent pas de leur propriétaire. La jeune fille conclut qu'ils n'étaient point sur la piste d'une autre victime avec elle et ne se souciaient pas d'Alice. Tout de même, quand ils eurent fermé le meuble, elle respira. Ce qu'ils cherchaient tous les quatre, c'était ce petit morceau de papier du Japon qu'elle sentait à ce moment sur son corps et qu'elle avait failli, hier soir, laisser à leur vue. Avec ce bout de chiffon tout menu, on conduit une fraîche jeune fille au poteau. Ils sont avides de cette preuve, les bourreaux. Oseront-ils la lui ravir ? Vont-ils faire monter une de leurs fouilleuses, dont les yeux sont impudiques et les caresses ignobles ? Ils l'ont forcée à se lever. Comme elle ne porte point de linge à la mode, mais une chemise qui couvre sa poitrine et ses, bras, elle accepte de rester là devant eux tous, à demi assise au bord de son lit, les bras croisés ; mais il fait froid et elle tremble.

- Vous avez peur? lui dit le chef de la bande.

- Pas de vous, mais j'ai froid.

- Eh bien, habillez-vous.

- Devant tous ces hommes ? Y pensez-vous

Alors un des Allemands part d'un gros rire et lui dit en mauvais français :

- On est mariés. On a des vemmes. On sait ce que c'est. 
Cette goujaterie la mit en colère. Elle protesta avec la dernière violence ; et, s'étant recouchée, déclara qu'elle ne s'habillerait qu'en présence de la maîtresse de maison ou d'une de ses filles.

- Bien, dit le chef. Les autres vont se retirer et la dame va monter. Mais il faut qu'un de nous reste. Ce sera moi. Je m'en excuse.

La fermeté de sa victime l'avait presque rendu poli.

Tandis qu'elle s'habillait, son hôtesse, effondrée sur une chaise, sanglotait. À de pareilles minutes, on joue sa vie. Il s'agissait pour cette femme de n'être pas retenue comme complice. Elle était réellement terrorisée, mais se souciait encore plus de le paraître. Elle parlait, parlait, semblant accabler la pensionnaire qui lui valait une aventure pareille. En réalité, elle occupait le policier, tandis que la pauvre enfant serrait tranquillement son corset, écrasant contre sa taille le petit papier de mort. Un seul mot imprudent échappa à la pleureuse : elle dit qu'elle ne connaissait rien de cette jeune fille, que tout au plus savait-elle qu'une ou deux fois elle s'était rendue à Anvers... Charlotte craignit à cette minute une trahison. Mais les yeux des deux femmes s'étant rencontrés, l'accord se fit entre elles contre l'ennemi, et, dans la chambrette que l'aube commençait à emplir de pâleur, on n'en tendit plus rien que la pluie battant les vitres.

Quand elle fut prête, l'Allemand lui fit signe de quitter la chambre devant lui. Elle jeta un dernier regard sur le lit de fer avec ses boules de cuivre, sur les tables et les commodes d'acajou verni, l'armoire de noyer, les lourdes chaises de velours cramoisi : objets déjà familiers, au milieu desquels « Mademoiselle » avait vécu et qu'elles aimaient toutes deux. On l'arrachait à cette minute à tout son passé, peutêtre pour toujours. Ces meubles étaient les derniers témoins de sa liberté ; elle pleura en les quittant.

J'ai dit que l'escalier était raide. La sensation de le descendre avec cet homme dans le dos lui parut horrible.

- Pas si vite ! lui cria-t-il en arrivant auprès de la porte.

Là, il passa devant elle, fit un signe dans la rue et attendit. La pluie cessait à ce moment. Deux des policiers parurent et conduisirent la prisonnière au fond d'une des deux voitures qui ronflaient à quelques pas de la maison. En montant auprès d'elle, le chef de la bande dit à un autre qui n'avait pas paru dans la chambre 
- Je l'ai ! Ça va bien.

Et, s'étant assis lourdement, il se frotta les mains.

- Vous pouvez être fier, en effet, lui dit la jeune fille, que tant de grossièreté rendait moqueuse.

- Pas d'embarras, vous ! lui cria-t-il. On vous tient bien, et la police allemande sait ce que vous avez fait.

- Où me conduisez-vous ?

- Où je veux.

Alors elle rentra dans sa coquille, mais lui aussi. Elle n'en demandait pas davantage. Il essaya un peu plus tard de reprendre la conversation, lui conseillant d'être sincère à l'instruction et d'avouer. Elle haussa les épaules. Toutes les femmes d'un peu de tête ont eu l'instinct, même en péril de mort, de parler à ces genslà de haut en bas, comme à des chiens.

La voiture pénétra sous une voûte au milieu de hautes murailles. C'était la prison de Saint-Gilles. Cette construction coquette et propre, on devine au premier regard son emploi, car elle ressemble à souhait à tous les donjons de carton-pâte des reconstitutions historiques et à ceux des décors d'opéra-comique. Dans la cour est un pimpant escalier de pierre, qui donne accès à un vestibule orné de balustres gothiques et de colonnes de granit de la plus aimable rondeur. Là, c'est le seuil de quelque université qu'on croirait franchir. Léonie Vanhoutte ne vit pas ces détails, mais seulement un registre qu'on mit sous ses yeux au greffe. Elle y inscrivit son nom, son vrai nom, celui que portait la carte d'identité qu'un des hommes avait trouvée dans sa chambre. Elle pensa ensuite qu'elle n'aurait pas dû se coucher elle-même sur ce livre d'infamie. C'est un Livre d'Or aujourd'hui. En doutait-elle ? La vérité est qu'elle arriva à Saint-Gilles hébétée, n'en pouvant plus. Ses nerfs, tendus à l'excès depuis deux heures, se relâchaient.

Mais voici qu'on ouvre une haute grille de fer, et la jeune fille, encadrée de deux soldats, est poussée dans un couloir long et clair, richement dallé de noir et de blanc, au bout duquel une autre grille est manœuvrée à grand bruit de clefs par un gardien. Elle voit alors qu'elle se trouve dans une vaste rotonde inondée de lumière. Cette rotonde forme carrefour et cinq galeries, comme les branches d'une étoile, s'ouvrent autour d'elle. On fait encore grincer une grille pour entrer dans la 
première de ces galeries, à gauche. Là aussi, le sol est de pierre noire et blanche, mais la voûte s'élève à une hauteur bien plus grande que dans l'autre couloir. De chaque côté de cette galerie, longue de quatre-vingts mètres, les murs éblouissants sont tachés de portes brunes. Ils s'élancent si hardiment, ces murs, qu'on a pu mettre, bien au-dessus de celles du rez-de-chaussée, une autre série de portes, puis une autre encore plus haut. Et le long de ces deux étages de trous de pigeonnier courent des passerelles de fer, qui sont légères et ne brisent pas la ligne de l'édifice. La prisonnière, entre les deux Allemands, marche d'un pied décidé sur la pierre, et leurs pas, dans ce lieu désert, font un bruit sonore. À droite, voici qu'une porte est ouverte. Curieuse, la jeune fille se dispose à y jeter en passant un regard, quand ses deux compagnons s'arrêtent, l'y poussent et donnent un tour de clé. Elle est dans sa cellule.

Debout, le dos à la lourde porte qu'on vient de fermer, elle regarde avec stupeur autour d'elle. Les murs, dit la notice offerte aux visiteurs, sont « couleur pierre de France, avec filets rouges aux angles ». Elle considère tour à tour ces murs trop beaux, le parquet de chêne à petites lames entre-croisées, le plafond haut, la fenêtre confortable qui laisse entrer l'air et la lumière à flots. La pièce mesure quatre mètres de la porte à la fenêtre et sa largeur est de deux mètres cinquante. À droite, un lit plié en deux laisse voir de bonnes couvertures ; il est surmonté d'une planchette d'une irréprochable propreté, qui sert de table. Une chaise est là. Elle n'y prend pas place. Non, elle ne s'asseoira pas. Il ne faut pas accepter les politesses de ces gens-là, mais se raidir. Et d'abord, où est-elle ? Les prisons ne sont pas faites ainsi. Elles s'attendait à un trou noir, une cave avec de la paille dans un coin, une cruche, des rats... Au fait, avait-elle jamais imaginé ce que pourrait être vraiment un cachot où on la mettrait? Alors une pensée horrible envahit son pauvre cerveau. Non, cet endroit n'est pas une prison. On l'a enterrée vivante dans une maison de fous. Elle eut peur, à cette minute, affreusement peur. Elle tourna la tête de tous côtés, cherchant du secours. à droite de la porte, une manette de fer frappa ses yeux. Elle la poussa d'un coup nerveux : un timbre puissant résonna dans le couloir. Elle attendit, le cœur haletant... Des pas feutrés... Ce n'est donc pas un soldat? Alors un gardien? Un gardien de déments ? Au milieu de la porte est un guichet qui se rabat brusquement. Une tête parait.

- Que voulez-vous?

- Savoir où je suis, monsieur. 


\section{- En prison.}

Et le guichet se referma avec violence. Alors elle alla vers la chaise, s'y laissa choir, mit les coudes sur ses genoux et la tête dans ses deux mains ; puis elle pleura comme une enfant.

Quand elle eut bien mouillé tout son visage et ses mains fiévreuses, et jusqu'à ses bras que brûlaient les larmes, elle alla vers une étagère où elle apercevait un essuie-mains. Car on lui avait ravi le matin son mouchoir avec tout le reste.

- Non, pensait-elle en tamponnant sa figure décomposée, je ne dois pas me laisser aller ainsi. Quand on a fait son devoir, on ne pleure pas.

Il fallait se ressaisir et, pour sortir des mains de ces gens-là, garder sa force. Elle examina sa prison et se mit à l'arpenter. Les mains derrière le dos, cinq pas vers la porte, cinq pas vers la fenêtre, elle alla et vint ; c'était un commencement. Elle a fait ce manège à Saint-Gilles pendant sept mois, à Siegburg pendant deux ans et demi, Il lui arrive encore aujourd'hui, si elle est seule, de mettre ses bras derrière elle et, la tête en avant, de compter cinq pas, puis de se retourner comme un soldat de garde ou comme une bête captive.

Si viriles que fussent ses résolutions, elle sentit tout en marchant que l'angoisse allait encore l'envahir. C'est alors qu'ayant levé les yeux, elle vit au-dessus du lit un crucifix de bois clair. Elle ne put s'empêcher de lui sourire.

- Je ne suis pas seule, murmura-t-elle.

Et elle s'agenouilla. Mais, cette fois, elle ne pria pas, car une horrible pensée envahit tout à coup son esprit : elle se souvint du document qu'elle gardait imprudemment sur elle et qui allait la perdre. Vite elle se dévêtit pour le retrouver sous son corset.

Mais voici du bruit. Le guichet s'ouvre et se rabat à l'intérieur, formant tablette. Sur cette tablette, une grosse main pose une tranche de pain gris. Comme elle est empêtrée dans sa jupe qui va tomber et qu'elle tarde à s'emparer de l'objet, la main envoie celui-ci d'une tape sur le parquet et referme le guichet.

Alors elle prit le temps de fouiller sous ses vêtements ; elle détacha de sa ceinture le cordon qu'elle y avait noué la veille, en retira le pli de papier fin, le roula dans ses doigts, le mâcha bien et l'avala. Elle rajusta ensuite sa toilette, s'empara du pain qui gisait à terre, le regarda avec gourmandise, puis s'assit et le mangea 
jusqu'au bout. La ration était grosse : c'était celle de la journée entière. Elle apprit par la suite à en faire trois parts, une pour chaque repas.

Au cours de l'après-midi, on lui proposa divers objets qu'elle accepta : du papier à lettres, un peu de chocolat. Quand le cantinier rendit compte au greffe des achats de cette «nouvelle », on lui révéla qu'elle n'avait pas de dépôt d'argent. Il courut réclamer sa marchandise ; le chocolat était mangé, et, sur le papier à lettres, une grande écriture courait déjà. Elle expliquait, dans une longue épître au directeur de la prison, qu'elle était innocente et demandait à être interrogée et confrontée tout de suite avec qui on voudrait, afin qu'on pût aussitôt la libérer.

Le directeur était alors un Allemand débonnaire. Quelques gardiens étaient Belges. Quand, dans les jours, puis les semaines et les mois qui suivirent, l'un de ceux-ci entrait dans la cellule pour le service, la jeune fille échangeait avec lui quelques mots. Elle se hâtait de rire pendant cette minute précieuse. Quelquefois, un gardien s'étonnait :

- Vous savez rire ici ? disait-il.

Et elle répondait doucement :

- Je n'ai pas de mouchoir, je ne peux pas pleurer.

C'était vrai. Il faut bien renoncer à la douceur des larmes quand on n'a que le revers de sa main pour les sécher et pas un bout de chiffon pour tamponner ses yeux. On l'a laissée sept mois sans mouchoir et sans linge de corps. Ses bas, sa chemise, les autres objets de lingerie qu'elle portait sur elle en arrivant à la prison, elle n'a pas pu les changer une seule fois au cours de sa détention. Elle faisait des savonnages le soir et tâchait que cela séchât vite, près de la fenêtre s'il faisait beau, ou sur les conduits du chauffage central en hiver. Il fallait des précautions pour ne pas déchirer ces pauvres choses, qui s'usaient à la fin. Songez à la paire de bas portée pendant si longtemps! Elle se souvient encore avec tendresse du petit tailleur gris dont elle demeura vêtue pendant toute la prévention, de sa chemisette de soie verte qui, à la fin de l'instruction, était en lambeaux, enfin du chapeau bleu à plume bleue dont elle s'était coiffée sous les yeux du policier, rue des Aduatiques, et qu'elle garda avec tant de sollicitude dans sa cellule, pour être belle le jour du procès. 
On la laissa trois jours à ses réflexions avant de l'interroger. Enfin un gardien accompagné d'un soldat, baïonnette au canon, vint la prendre dans sa cellule. Elle parcourut en sens inverse le chemin du premier jour. Au long de la galerie, puis du couloir, elle eut le temps de se donner du courage. Cette marche faite d'un bon pas anima son sang. Avant la dernière grille, au lieu de tourner à gauche vers le greffe, on la fit entrer à droite dans une grande salle rectangulaire, lambrissée et meublée de bois clair : c'était le prétoire. Deux ou trois individus étaient attablés autour d'un vaste bureau. Parmi eux, la jeune fille reconnut tout de suite celui qui l'avait arrêtée. Mais il était, l'autre jour, entièrement rasé, et maintenant il portait une forte moustache noire. Il la regardait, narquois.

- La barbe pousse vite en Allemagne, lui dit-elle.

Cette entrée en matière mit tout le monde de bonne humeur. On lui fit d'abord préciser son identité. Elle donna l'adresse d'Etaimpuis, pour qu'on n'inquiétât pas ses parents. L'instructeur parut se contenter facilement de ses dires. Il lui présenta le portrait d'homme qu'elle avait montré au Lion Belge.

- Qui est-ce ? lui demanda-t-il.

- C'est Paul Hoffmann.

Ce nom était celui d'un soldat français qu'elle avait conduit à la frontière trois mois plus tôt et dont elle savait déjà qu'il s'était fait tuer en arrivant au front.

- C'est votre fiancé ?

- Parfaitement. Il habite 14, rue Française, à Paris. Je voulais la rejoindre. Quel mal à cela?

- Nous savons que vous deviez faire passer la frontière à des jeunes gens.

- Non, vous ne le savez pas.

- Dites leurs noms.

- Ça, jamais !

- Allons ! vous êtes une menteuse, mais on saura vous faire parler. Emmenezla!

Au moment de se retirer, elle aperçut sa valise dans un coin du prétoire, derrière la table des policiers. Son pauvre sac, que des bandits, trois jours plus tôt, 
avaient bourré, y entassant ses effets à coups de poing, elle l'eût serré dans ses bras si on le lui eût rendu alors !

- Me laisserez-vous au moins y prendre un peu de linge ? demanda-t-elle.

Ils ricanèrent.

- Alors, monsieur, je vous en prie, donnez-moi les portraits de mes parents.

Les larmes lui montaient aux yeux. L'un des hommes prit la valise, la déposa sur la table et, l'ayant fouillée, en retira une pochette, d'où il sortit des photographies. Tous les trois se penchèrent sur ces reliques avec sévérité.

- Des espions, ces gens-là ! dit l'un deux.

- Non, monsieur. Rendez-moi ces portraits. Vous n'en ferez rien. Et moi, je serai si heureuse !

- Mais nous ne voulons pas que vous soyez heureuse. Vous n'êtes qu'une espionne. Allez-vous-en !

- Alors, monsieur, mon chapelet, que je vois dans sa gaine, là ? Voulez-vous ?

L'homme prit dans sa main l'objet menu, le soupesa, puis, ayant ouvert la gaine, parut hésiter.

À ce moment, s'il avait regardé la jeune fille, il eût compris qu'avec cette petite chose, c'était elle-même qu'il tenait, à demi morte, dans ses doigts. Elle avait senti tout à coup son sang affluer à son visage, puis se retirer, la laissant blanche comme de la cire d'autel. Le couvercle de l'étui avait chu sur la table, son ouverture vers elle, et elle y avait vu une tache grisâtre : c'était la notice secrète rapportée de son dernier voyage en Hollande, avec l'indication des consignes, des mots de passe et du chiffre. De quoi la perdre et vingt autres avec elle.

L'homme ramassa le fragile chapeau de cuir, fragile et si lourd. Il en coiffa nonchalamment l'étui ; puis, incapable d'un geste généreux sans grossièreté, il rendit à la prisonnière son chapelet en le jetant si brutalement sur la table qu'il alla ricocher contre un mur avant de s'abattre sur le sol. Elle se rua sur lui comme une bête affamée sur sa proie et, la tête en feu, s'en fut à sa cellule.

Là, elle embrassa avec amour la chère petite chose. Elles étaient un talisman, ces cinq dizaines et cette croix. Jusqu'ici, elle l'avait cru pour une raison sainte : elle en était sûre maintenant, pas seulement avec son cœur, avec ses yeux. Le mo- 
tif sacré de sa foi, c'était qu'un jour une mère, dont elle avait sauvé le fils en le passant en Hollande, lui avait donné ce chapelet, disant : «Gardez-le bien ; je veux qu'il vous porte bonheur ! » Un geste de gratitude, c'est un miracle de Dieu sur la terre. Il faut faire mille fois le bien pour sentir une seule fois sur son front la caresse qui remercie. La bénédiction de cette mère venait encore de la couvrir. Elle comprit que les promesses de la reconnaissance, Dieu les tient, parce qu'il les aime.

De ce premier interrogatoire, elle conclut que ces gens n'avaient rien contre elle. Et c'était vrai, mais le résultat fut qu'on la garda longtemps. On perquisitionnait rue des Aduatiques ; on cuisinait Alexandre, qui était pris en effet, et dont s'occupait le parquet d'Anvers; on recherchait Alice Dubois, mais sans rien soupçonner d'elle, et l'on partait sur de fausses pistes. Toutes les Dubois de Bruxelles furent passées au crible et Louise de Bettignies, qui le sut un peu plus tard, s'en amusa bien.

Un jour, la police vint s'emparer de tout ce que contenait l'armoire de noyer de la rue des Aduatiques, où nous savons qu'Alice, suivant sa coutume, avait laissé mille choses. Peu après, un agent rapportait le tout, y compris une sorte de sacvalise. Lee Pandelaers, supposant bien que tôt ou tard on viendrait leur redemander ces objets, se gardèrent d'y toucher. Ils firent bien, car, un matin, un policier vint ouvrir la valise, en perça la doublure et en tira un mince rouleau de papier du Japon. Il le brandit, triomphant, devant la jeune fille qui l'avait introduit dans la chambre et lui dit :

- Je vais emmener votre maman. Cette fois, vous pouvez l'embrasser un bon coup. Parce que, crrr... son affaire est claire.

L'enfant était terrorisée. Quand il eut bien joui de son émoi, il consentit à la rassurer.

- Allons ! dit-il, ne pleurez pas. Ce papier, c'est moi qui l'avais mis là il y a huit jours.

Si les Pandelaers, fouillant dans cette valise, y avaient trouvé un pareil pli, ils l'auraient sans doute détruit pour sauver leur locataire. On les eût alors arrêtés comme complices, mais de qui ?

Tous ces policiers allemands n'en savaient rien. 
Un peu plus tard, l'homme chargé de l'instruction vint prendre Charlotte dans sa cellule.

- Mettez votre chapeau, dit-il, nous allons faire un tour en ville.

- Avec vous?

- Oui, tous les deux. Si vous êtes sage, je vous emmènerai chez le pâtissier.

- Que voulez-vous dire ?

- Allons, venez. Dépêchez-vous.

Elle s'habilla et sortit, toute surprise. Quand ils eurent franchi la voûte et passé devant la sentinelle de garde, elle fut si étourdie de se trouver à l'air libre sur le pavé de Bruxelles qu'elle porta sur son compagnon des yeux brillants qui voulaient dire : Je suis libre, n'est-ce pas ?

Il répondit en tirant de sa poche un revolver. Il le tint un moment au creux de sa main, le regardant avec complaisance.

- Il est chargé, dit-il. Si vous faites un pas pour m'échapper, je vous abats.

Il était une heure. Pendant tout l'après-midi, il arpenta les divers quartiers de Bruxelles, cette jeune fille à son côté. Il la fit entrer avec lui dans la plupart des cafés importants de la ville. Ils longèrent les trottoirs les plus fréquentés, se faufilant quelquefois avec peine dans la foule, car Bruxelles était alors une ville que la tourbe allemande animait fort. Quand il craignait de la perdre parmi tant de gens qui allaient et venaient, il passait sa main sous le bras de la pauvre enfant ou pinçait familièrement entre ses gros doigts le drap de sa jaquette. Ces contacts l'auraient fait crier si elle eût osé. Cependant, elle regardait avec convoitise tous les passants libres, les passants qui prenaient pour des amoureux à la promenade ce chat et cette souris.

Ils rentrèrent à sept heures. Il l'avait inutilement fatiguée et angoissée. Son espoir qu'elle fût rencontrée et saluée par quelque complice était stupide. Les hommes et les femmes «du service » qu'elle eût croisés n'auraient pas bronché, pas remué un œil : elle en était sûre. Et ce n'est pas de peur qu'elle trembla au long de ce calvaire, mais de rage et de dégoût.

- Que cet homme, dit-elle volontiers aujourd'hui, ne paraisse jamais devant mes yeux ! Je le reconnaîtrais entre mille et je crois que je lui sauterais à la gorge. 
Le dépit de ne rien trouver contre elle exaspéra ses bourreaux au lieu de les adoucir. On l'avait mise au plus dur régime, celui du grand secret. Elle n'avait pas le droit de paraître à la chapelle. L'aumônier allemand qui la visitait lui déplaisait nettement. Elle avait refusé de se confesser à cet ennemi, car elle considérait les policiers dont elle était la proie comme capables de tout, même de revêtir une soutane pour lui arracher des aveux. Il lui apportait la communion chaque semaine et prenait négligemment les saintes espèces dans la poche de sa culotte, comme on en tire sa tabatière. Mais il y avait, l'homme parti, la petite croix sur le mur, et elle sentait, dans son corps enchaîné, le Dieu qui libère.

Après quelques semaines de ce régime, elle fut transférée à Anvers. Le panier à salade, le wagon cellulaire ne lui ont pas laissé de souvenir offensant. C'est une fille de bonne humeur, habituée à trouver sa paix en elle. En face de soi-même on n'est pas seul, si on sait converser avec son âme. C'est une grande compagnie que ce souffle de Dieu qui habite en nous. Elle l'emportait entre les hautes cloisons du wagon d'infamie. Libre, elle eût par la portière vu courir les plaines flamandes ; prisonnière, elle regardait les manèges patients d'une araignée, ou pensait que nul au monde ne lui ravirait la douceur d'être une bonne servante de sa patrie.

Une amère surprise l'attendait dans sa nouvelle geôle. Des religieuses belges y assuraient le service. La supérieure, dont il me coûte de médire, dit à l'arrivante :

- Pourquoi êtes-vous ici ?

- Parce que j'ai voulu passer la frontière.

- Toute seule, sans vos parents? Alors vous avez couru les routes, les auberges pendant la nuit?

- Mais oui.

- Eh bien ! c'est honteux, mademoiselle.

- Mais...

- Ne répondez pas ! Vous êtes une prisonnière.

Les autres sœurs ne comprirent pas davantage quel trésor le destin leur confiait. Elles traitèrent cette captive comme elles avaient coutume de faire, priant Dieu de lui pardonner, mais sans pitié humaine. 
Elle trouva dans sa cellule, plus petite que celle de Bruxelles et toute grise, un livre de prières rempli d'appels au repentir. Elle le lut, puis le relut, songeant aux femmes déchues qui l'avaient, feuilleté avant elle. Auprès de leur détresse, la sienne lui semblait facile à porter.

Seule, une petite sœur, la plus jeune, regardait quelquefois la jeune Française avec tendresse ; elle lui apporta un jour en cachette un petit pain de Belgique, avec du jambon et une poire.

À l'instruction, Charlotte garda son système de défense. Hors ce qu'elle avait dit au Lion Belge, elle niait tout. Un matin, on la confronta avec Alexandre. Ils se regardèrent longtemps et jurèrent qu'ils ne se connaissaient pas. Le piquant, c'est qu'ils disaient vrai. Ils en savaient sans doute assez long l'un sur l'autre pour donner aux Allemands, d'un seul mot imprudent, la joie de les envoyer tous les deux au poteau. Mais ils ne s'étaient jamais vus.

Que Charlotte se tût, rien d'étonnant. Mais l'homme fut d'un mutisme farouche, qui aurait arraché des larmes d'admiration à sa complice.

Les policiers écumaient. L'un d'eux, pris de rage, s'avança vers le pauvre diable, le secoua tant qu'il put de ses deux bras, puis le roua de coups.

- Direz-vous encore que vous ne la connaissez pas ? répétait-il, le front en sueur.

- Je ne la connais pas, disait l'homme.

- Mais laissez-le ! suppliait la jeune fille.

- Si vous le défendez, vous, c'est que vous êtes sa complice...

Après quelques semaines, las de recommencer des interrogatoires et des confrontations sans issue, ces gens comprirent qu'il fallait abandonner la partie. Un jour, vers midi, on pria la petite Française de se tenir prête pour l'audience du lendemain. L'instructeur, étant battu, se fit aimable pour lui dire qu'elle s'en tirerait avec trois mois de prison pour tentative de passage de frontière.

Elle édifia, en déjeunant, mille projets. Ses trois mois étaient presque faits, en prévention. On allait donc la libérer...

À trois heures, une sœur entra dans sa cellule.

- On vous demande au greffe, dit-elle. 
Contrairement à l'usage, deux soldats, baïonnette au canon, l'encadrèrent dans les couloirs. Ses genoux se mirent à trembler. L'instructeur l'accueillit avec la gravité des mauvais jours. Il tenait devant lui et regardait attentivement un document collé sur un carton de grande taille. Il se leva tout à coup, tourna d'un geste dramatique le carton vers la prisonnière et lui dit en la perçant de son regard :

- Connaissez-vous cette personne ?

La jeune fille regarda bien la photographie qu'on lui montrait, rassembla toutes ses forces pour contenir le sang qui courait d'un trait vers son cœur, et dit nettement :

- Non, je ne connais pas cette personne.

C'était Louise de Bettignies.

- Bien, fit l'homme. Vous pouvez aller mettre votre chapeau. Vous serez ce soir à Bruxelles.

Alors elle vit qu'elle était perdue. 
LA GUERRE DES FEMMES.

Histoire de Louise de Bettignies et de ses compagnes.

\section{Chapitre VI}

\section{POUR AVOIR RI}

$\underline{\text { Retour à la table des matières }}$

Louise de Bettignies, revenant de France quelques jours après l'arrestation de Charlotte, apprit à Bruxelles, sans doute par le fidèle Victor, le malheur et la menace qui fondaient sur elle. Elle rapportait des instructions nouvelles, qui accroissaient l'importance de son service, et pour lesquelles le zèle sans limite de la petite Vanhoutte lui serait indispensable. Non seulement cet admirable lieutenant lui manquait, mais il faudrait, au moins pendant quelques semaines, qu'elle se fit ellemême très prudente et qu'elle mit en mouvement le moins de monde possible. La consigne du silence s'imposait. Conclusion : elle multiplia son effort personnel et décida qu'elle ferait elle-même les courses vers la frontière, interdites à Charlotte arrêtée, et à tous les autres, suspectés.

Elle songea aussi que le passage en Hollande finirait par devenir impossible. Elle s'entendit donc à Roubaix avec l'abbé Pinte, qui recevait tranquillement, à la barbe des Allemands, des sans-fil de tous les belligérants, et lui demanda s'il accepterait de recueillir et de lui transmettre des télégrammes chiffrés de l'état-major britannique. 
Ses dispositions prises de ce côté, elle alla un jour faire une promenade dans les champs en compagnie de ses amis de Geyter et reconnut avec eux, non loin de Mouscron, un terrain où il lui sembla que des aviateurs anglais pourraient facilement déposer des pigeons. Elle tira de son sac un appareil photographique et prit des vues de ce coin de campagne, avec la briqueterie et, un peu plus loin, la cheminée d'usine, qui seraient des points de repère pour l'aviateur. Alors elle annonça qu'elle irait indiquer cet emplacement à l'oncle Edouard et que, pour les détails d'exécution, ils seraient transmis chaque fois par sans-fil au moyen d'un chiffre qu'elle rapporterait de Folkestone.

Là-dessus, elle s'en fut en Hollande, une fois de plus. À son retour, elle annonça la descente du premier pigeon pour le dimanche suivant. Des draps furent étendus sur l'herbe à l'heure convenue : il est permis, en vérité, à chacun de faire sécher du linge. Et le soir, au couchant, un avion laissa tomber, suspendue à un parachute léger, une cage d'aluminium contenant une petite bête flegmatique et grave à souhait pour sa mission patriotique. Le médecin d'un bourg voisin passait justement par là dans sa carriole : il allait raccrocher une jambe cassée. N'étant pas dans l'affaire, il jugea que, cette bête suspecte, il fallait la porter aux autorités. Ce qui fut fait.

Louise de Bettignies et ses amis eurent un mouvement de mauvaise humeur. Mais elle avait pris ses dispositions pour que la tentative, si elle avortait, fût renouvelée un peu plus tard. Les Anglais diraient par sans-fil leur jour et. leur heure. M. de Geyter, flânant dans la région, recruterait des volontaires pour capter le pigeon, prendre son étui, le lui apporter à Mouscron et l'aller attacher ensuite à l'oiseau, chargé d'un pli chiffré. Tout étant ainsi réglé pour que le dur service par la route fût doublé d'un service aérien, Alice repartit, porteuse d'un courrier sans doute important pour l'Angleterre.

Elle alla, en effet, jusqu'à Folkestone et en revint presque aussitôt. La mission qu'elle rapportait devait être pressante, car, ayant fait la route de la frontière à Tournai du, matin au soir, elle estima qu'elle ne pouvait pas attendre au lendemain pour continuer vers la France et prit le parti, à dix heures, de s'engager à pied sur la route de Lille. À la, sortie de Tournai, avant de passer la barrière de Froyennes, qu'on appelait aussi le poste de Mamour, du nom d'un pâtissier dont la maison avoisinait celle du corps de garde, elle prit peur. Elle sentit que, si elle poursuivait seule, la fatigue et l'émotion auraient raison de ses forces. Alors elle regretta le 
bras de la petite Charlotte et même celui de Victor, qui, pour l'heure, avait ordre de ne plus faire l'assureur ni le mendiant aux portes, et de se terrer. Parmi les maisons proches de Mamour, se trouvait celle d'un ouvrier peintre, chez qui elle se souvint qu'elle avait reçu plusieurs fois bon accueil. C'était un de ces asiles où l'on entrait avant de passer devant un poste difficile : on y laissait les objets suspects, ceux qui démentiraient la fausse identité. Là échouèrent quelques chapeaux et les souliers fins, et les gants, et le parapluie de celle qui allait se présenter aux Allemands, quelques pas plus loin, muée en villageoise. Oserait-elle sonner chez de telles gens par cette nuit noire ? Elle hésita, puis tira la petite poignée de fer, tapa à la porte discrètement et plus fort. Une femme entr'ouvrit la fenêtre. Après quelques chuchottements, Louise de Bettignies fut introduite. L'homme était couché. Irrésistible comme toujours, elle le décida à s'habiller en hâte et à faire route avec elle jusqu'à Mouscron. De là, elle se rendrait seule à Roubaix, puis à Lille.

Je voudrais pouvoir rapporter les confidences de Louise de Bettignies sur cette promenade nocturne ; elles seraient savoureuses. J'ai reçu celles d'Henri Bauduin, le brave homme qui fut son guide. Elle ne lui laissa rien ignorer du péril qu'il courait avec elle. Sans lui révéler le but d'un tel voyage, elle lui confia cependant, tandis qu'elle pesait sur son bras et marchait bon train, qu'elle arrivait droit d'Angleterre et qu'à Anvers elle avait dû passer l'Escaut dans une barque, afin d'éviter le questionnaire des policiers au débarcadère régulier. Elle avait laissé dans la maison de cet homme un chapeau de velours noir et un parapluie, dont se défit à regret le ménage, quand, après de longs mois, on sut son arrestation, Elle fit route avec un grand châle, dont elle se couvrit bientôt la tête, car, si vivement qu'elle marchât, le froid de cette nuit d'octobre finit par la saisir. Elle fût d'une extrême gaité tout au long de la route et l'homme crut sentir qu'elle voulait ainsi lui rendre la corvée plus légère. Il eut grand'peur en arrivant à Herzeaux, non loin de Mouscron. Une patrouille surgit là, au tournant d'un chemin. Un officier s'en détacha et, les ayant sommés de s'arrêter, les interpella en français :

- Qu'est-ce que vous faites là, vous deux ? Vos papiers ?

Elle lui répondit en allemand sur un ton de parfaite insouciance. Il répliqua doucement dans la même langue, puis se retira avec ses hommes.

- Que lui avez-vous dit ? demanda Bauduin, tandis qu'elle abandonnait son bras, sur lequel elle s'était un instant appuyée comme une amante. 
- Moi, que nous venions de nous amuser ensemble au Café du Petit-Paris. Cet imbécile l'a cru. Maintenant, faisons vite.

Et, tremblante, elle acheva au pas de course cette périlleuse randonnée. À une heure, elle frappait à la porte d'Ernest Lamote, qui la reçut avec son compagnon et les coucha chez lui tous les deux,

Son hôte, quoiqu'il la trouvât imprudente, ne pouvait que s'incliner devant une femme pareille. Il accepta, au moment où elle prit congé de lui dans la matinée, de lui chercher un passeport pour retourner à Tournai le plus tôt possible. Et elle courut à Lille.

Nous la retrouvons à Mouscron le lendemain, qui est un vendredi. Elle apporte à M. de Geyter du courrier à copier. Une partie doit partir tout de suite par une voie qu'elle indique. Elle-même emportera mercredi prochain le reste et ce qu'elle aura réuni d'ici là. Elle passe une partie de l'après-midi avec la servante, la fidèle Flore : ensemble elles fabriquent un grand sac de toile, avec une poignée de cuir, pour aller aux provisions. Dans l'épais ourlet qui borde son ouverture, elles glissent un courrier. Alice a jugé que ce n'était pas bien d'abîmer les yeux des Anglais et, cette fois, le texte sera en caractères lisibles. C'est donc un papier de grand format qui part avec le sac. On bourre celui-ci de légumes, et une jeune femme, dont les traits sont un peu fins pour une maraîchère, vient le prendre Celle-ci, dont je ne sais rien, sinon qu'elle est religieuse aujourd'hui, faisait aussi de grandes choses au péril de sa vie : une de plus. La guerre des femmes a été noble et douloureuse comme la nôtre. Il est temps que nous ayons la galanterie de conduire par la main dans l'histoire celles qui l'ont faite.

Le samedi et le dimanche, Louise de Bettignies est à Lille. Elle y voit divers agents et passe quelques heures paisibles dans la maison de Mme Feron-Vrau. Celle-ci a gardé le souvenir de cette dernière visite. Elle gronda un peu l'ardente jeune fille, qui se flattait d'avoir échangé en tramway des propos assez vifs avec un officier. L'Allemand, en se séparant d'elle, avait voulu faire la paix. Il lui tendait la main : devant tous les voyageurs, elle la lui avait refusée.

- Vous n'êtes pas raisonnable, Louise. Ces gens-là vous inquiéteront.

- Ils me font horreur ! répondait-elle; et je n'ai pas peur d'eux, car ils sont sans esprit. 
Elle paraissait contente, cet après-midi-là. Son service, à la suite des deux voyages qu'elle avait faits coup sur coup à Flessingue et à Folkestone, sr réorganisait. Et malgré l'ombre que projetait sur son destin la capture de Charlotte, elle espérait que son dévouement serait précieux aux alliés de la France.

- Alors, lui disait son amie, faites grande attention. Ne vous laissez pas prendre au moment où vous allez être le plus utile !

- Soyez tranquille ! ripostait-elle en riant.

Et l'on parlait d'autre chose.

Le lundi, vers deux heures, elle était à Mouscron. Elle sonna tranquillement à la grand'porte de ses amis de Geyter. Le maître de céans la reçut fort mal, pour deux raisons. La première était assurément que de se glisser discrètement à la tombée du jour par la porte de derrière eût été plus sage que d'user à la face du soleil des grandes entrées. Mais une autre affaire mettait M. de Geyter de méchante humeur. M. Lenfant lui avait apporté l'avant-veille, le samedi, un télégramme chiffré de l'abbé Pinte. Et, depuis quarante-huit heures, il essayait en vain de mettre en ordre les signes de ce sans-fil mystérieux. C'était Alice qui avait fourni la clef : cette clé ne valait rien, Alice non plus !

La jeune fille monte dans son laboratoire, s'assit auprès de lui, le remit sur la bonne voie et s'en fut, mais cette fois par une échelle qui donnait, par-dessus le mur du jardin, chez les voisins.

M. de Geyter dut interrompre la lecture de sa dépêche pour préparer le courrier qu'Alice emporterait le surlendemain à l'aube. Il avait été convenu que ce courrier serait remis à Ernest Lamote, qui le transmettrait à la jeune fille. Car il ne fallait pas que celle-ci sonnât encore à la maison de la rue de la Station. On l'y voyait trop depuis quelques jours : l'intérêt du service demandait qu'elle se cachât davantage.

Ce que fit Louise de Bettignies après cette réception un peu fraîche, dont $\mathrm{M}$. de Geyter ne parle aujourd'hui qu'en frémissant, mais pas contre elle, nul ne saurait le dire au juste. Le certain, c'est que le lendemain soir elle rencontra dans une rue de Lille Mme Féron-Vrau. Celle-ci l'accompagna jusqu'à l'embarcadère du tramway électrique, dit Mongy, qui devait la conduire à Tourcoing. De là elle se rendrait à Mouscron, puis, par Tournai, en Hollande et peut-être en Angleterre. 
Elles causaient ardemment toutes deux et le temps passait, sans qu'y songeât la voyageuse. Quand elles arrivèrent place du Théâtre, elles virent que le tramway s'ébranlait. Louise de Bettignies dut courir, puis sauter sur le marchepied.

- Surtout, pas d'imprudence ! lui avait jeté dans l'oreille son amie, en l'embrassant.

Et Mme Feron-Vrau sentit des larmes monter à ses yeux, tandis qu'elle regardait cette petite, légère et gaie comme une enfant, s'engouffrer dans la longue voiture jaune qui la conduisait vers l'inconnu.

Alice n'osant pas retourner chez $\mathrm{M}$. de Geyter, passa cette nuit-là dans la chambre qu'avait louée Charlotte à Etaimpuis.

C'était vraiment jouer d'audace. Songez que les Allemands tenaient depuis un mois la petite Vanhoutte dans leurs griffes et que celle-ci, pour qu'on n'allât pas tourmenter ses parents à Roubaix, avait donné à l'instructeur l'adresse d'Etaimpuis. Songez que la mère Carlier, propriétaire de cette maisonnette, était déjà surprise et inquiète de ne voir qu'à intervalles trop espacés sa locataire. Elle fut interloquée quand une autre se présenta, disant :

- Je suis l'amie de Mlle Charlotte. J'occuperai sa chambre cette nuit, voulezvous?

Si les Allemands avaient senti, après leur exploit de la rue des Aduatiques, que la prise était bonne, ils auraient, serré de près la maison d'Etaimpuis et possédé la mère Carlier : alors Louise de Bettignies ne serait pas sortie libre de la chambre où elle dormit cette nuit-là.

Elle dut passer au foyer de la bonne femme une soirée pleine de douceur. C'est un de ces intérieurs où règnent l'ordre et la propreté, chers aux Flamands courageux et à leurs voisins de la France du Nord. Le toit de tuile est très bas et, derrière la maison peinte en blanc, est une courette payée de briques, suivie d'un potager menu et propret, à la mesure de la demeure si discrète. Le roi de ces petites maisons, celui qu'on soigne, qu'on astique pour qu'il brille et qu'on entoure de chaises en rond, c'est le poêle de fonte où chante la soupe. La bonne femme, courte et bien ronde, reçut avec bonté celle inconnue. Elle ne lui cacha point que Mlle Charlotte lui semblait une étrange marchande de dentelles.

- Et vous, mademoiselle, vous vendez aussi de la dentelle? 
- Non, du fromage. Il faut bien vivre.

- Je suis sûre que ce n'était pas votre métier avant la guerre, dit la malicieuse commère.

Et elles rirent de bon cœur. Puis la bonne hôtesse mit le couvert dans la cuisine et les deux femmes, la jeune et la vieille, soupèrent religieusement d'un potage bien fumant et d'une forte omelette au lard. Puis elles se saluèrent et montèrent dans les chambres. À six heures, quand la mère Carlier se leva, sa voyageuse était partie.

Cependant M. Lamote avait eu de la peine à trouver un passeport. Alice avait prescrit qu'il la conduirait en voiture à Tournai ce matin-là, mais elle avait exigé qu'il eût une autre voyageuse avec lui. Elles se sentirait ainsi plus à l'aise pour passer les barrages. Lamote, ayant appris que Mlle Seynaeve d'Herzeaux, avait obtenu un sauf-conduit pour se rendre à la première communion d'une nièce à Tournai, fit demander à cette jeune fille de le lui prêter pour la matinée du mercredi. Il le rendrait à midi, après en avoir usé pour sa fille. Le passeport fut prêté. Restait à trouver une passagère, Mlle Lamote n'ayant mille intention d'accompagner son père ce jour-là. On songea à Mlle Marguerite Le François, qui cherchait en effet une occasion d'aller acheter à Tournai quelques objets et qui accepta. Mais cette jeune fille n'avait pas de sauf-conduit.

- Qu'à cela ne tienne! lui fut-il répondu. Vous prendrez celui de Mlle Seynaeve.

Le mercredi matin, tandis qu'il attelait sa jument, Ernest Lamote songeait, non sans mélancolie, qu'il avait un seul passeport pour ses deux voyageuses et que sans doute Mlle Alice ne serait pas contente. Mais il la savait débrouillarde et pensa qu'une fois de plus elle se tirerait d'affaire. L'imprudence qui devait la perdre, ce n'est donc pas elle, si hardie, qui l'avait commise. Tout de même son audace, parce qu'elle était contagieuse, avait commandé le malheur dont elle allait mourir.

- Bah ! elle en a vu d'autres, pensait son guide.

Et il partit vers Herzeaux, où les parents de Marguerite Le François possèdent, face à l'église, une de ces belles demeures qu'habitent avec dignité et bonhomie les fastueux bourgeois des petites villes. La jeune fille, qui devait avoir vingt ans 
alors, était élancée, fraîche et d'un grand charme. Cette promenade l'enchantait. Elle fut d'un bond dans le haut cabriolet de M. Lamote. La caisse de cette voiture, infiniment légère, était de chêne verni. Alice l'aimait pour ses bons ressorts, ses roues fines aux jantes de caoutchouc, son coffre sous la banquette où l'on cachait une valise, un parapluie, une fourrure et mille choses. Peut-être appréciait-elle aussi que cette charrette fût un peu archaïque, semblable à tant d'autres qu'elle avait caressées de son regard sur de belles estampes coloriées. La jument de M. Lamote était aussi une bête élégante, digne des maîtres de la gravure anglaise. Mais il ne faut pas que nous parlions d'Alice. Mlle Le François ignore tout ce qui se prépare. Elle ne sait pas que sous la banquette où elle a pris place se trouve, en effet, la valise de Louise de Bettignies, ni que, dissimulé dans une couture de sa casquette, près de la visière, son compagnon porte un pli secret pour les armées de l'Entente, ni qu'un peu plus loin une admirable jeune fille va monter, qui ne dira pas son vrai nom.

Il était sept heures ; on venait de passer, à la sortie d'Herzeaux, devant la maison. de la grenouille, et c'était une joie pour la toute jeune fille et son guide de parler de cette fouilleuse détestée, sur laquelle on avait toujours des histoires atroces et qui faisaient rire quand même. Tout à coup, à un tournant, une jeune femme apparut, qui marchait d'un pas pressé dans la même direction que le cabriolet. Quand on fut à sa hauteur, elle se tourna vers Ernest Lamote et lui fit un signe. Il s'arrêta en grognant un peu.

- Vous allez loin ? dit-elle.

- À Tournai.

- Puis-je monter ? J'y vais aussi.

On se serra pour lui faire place : l'homme à droite, la petite Le François au milieu, Louise de Bettignies à gauche.

Elle engagea gentiment la conversation, se disant couturière. Elle allait à la ville, pourtant lointaine, chercher du travail. Sa jeune compagne de route prit grand plaisir à l'écouter. Naturellement il ne fut question que de toilettes. Et le complice, qui entendait cela, eût souri dans sa moustache, mais l'histoire du passeport le tourmentait. 
- Ah ! fit tout à coup l'inconnue, j'ai oublié mon sauf-conduit. Comment faire?

Elle attendait que Lamote lui annonçât qu'il en avait un sur lui, par hasard. Il fut bien obligé de se taire. Alors Marguerite Le François, charitable, dit à sa voisine :

- Mademoiselle, si vous voulez le mien, je n'irai pas à Tournai, voilà tout.

- Non, Mademoiselle, ne vous sacrifiez pas ainsi. Nous passerons toutes les deux avec le même ; j'en fais mon affaire.

Tout de même son cœur se serra un peu. Ce poste de Froyennes aux portes de Tournai, lui avait fait peur l'autre soir. Elle comptait être en règle pour le traverser ce matin. À la grâce de Dieu !

La pluie s'était mise à tomber. On s'arrêta pour relever la capote. On était secoué doucement, mais bien secoué tout de même, sur cette route aux pavés durs. Et le ciel était bas. Ces petites chaussées flamandes tournent sans cesse, à droite, puis à gauche, et presque toujours brusquement, parmi des champs unis qu'elles couperaient si facilement. De Mouscron à Tournai, les gens du pays comptent cinquante-quatre virages : ce serait fatigant pour les yeux, si le paysage n'était plat et toujours pareil. On voit à l'horizon des quantités de clochers tristes. Les champs étaient peuplés alors de soldats et de civils occupés à récolter la betterave ou à préparer l'ensemencement du blé. Mais voici qu'on passe au long de l'établissement des Frères de Passy-Froyennes. C'était alors un hôpital. À gauche est un somptueux et vaste cimetière allemand. Le silence se fait dans la voiture tandis qu'on traverse peu après la voie ferrée. À partir de cette minute, on sait qu'il n'y a plus de route transversale ni de sentier par où l'on pourrait se dérober en cas de danger. Il faut aller droit vers le passage qu'on sait dangereux.

Alors, d'un geste nonchalant, Ernest Lamote tire de sa casquette le pli minuscule dont il était convenu qu'il garderait la charge jusqu'à cette minute. Il le passe à Louise de Bettignies qui le glisse entre sa bague et son doigt. Et voici qu'apparaît le groupe de maisons au milieu duquel est la barrière allemande.

Imaginez qu'une grand'route plantée d'arbres au milieu de champs se resserre tout à coup en un court boyau bordé de bâtisses sombres. Après cent mètres, la chaussée redevient large, deux fois plus large qu'avant l'ingrat passage. Là-bas des 
ormes séculaires, sur quatre rangées à droite et quatre à gauche, couvrent le sol, si proche et si lointain, d'une ombre douce, qui fait envie. On pense, en abordant les premières maisons, qu'il fera bon un peu plus bas, sous les branches lourdes. Mais passera-t-on ?

La consigne est dure. C'est qu'on est, de ce côté-ci, dans la zone des armées, où n'entre pas qui veut et dont on ne sort pas non plus à sa fantaisie. La barrière franchie, c'est le domaine du gouverneur général de Belgique. Là, on respire. Les mœurs y sont plus douces et, s'il y a des routes fraîches, on peut en jouir.

Il faut passer. Le cabriolet s'arrête à droite, à l'auberge du Palais-Royal. L'homme et les deux jeunes femmes sautent à terre. Il y a là des voitures qui stationnent et toute une foule de gens affairés, de soldats, de gamins courant et se faufilant entre les groupes. Tandis que Lamote dételle et se prépare à remiser sa charrette, puis à se mêler, dans l'auberge, aux autres voituriers autour du poêle, Louise de Bettignies avise un gosse, glisse quelques mots à son oreille et s'en va d'un pas ferme, au bras de sa compagne, dans la direction du poste allemand, qui est à gauche, à l'enseigne du Canon d'Or, juste avant la pâtisserie Mamour. Mais à vingt mètres de la sentinelle, on la voit quitter le bras de la petite Le François, qui poursuit seule vers le danger, son passeport à la main. Alice, ayant obliqué à droite, va chercher un refuge dans une sorte de courette triangulaire, formée par une maison en retrait et le pignon de la suivante. Elle suit de cet abri le manège de son conducteur, affairé là-bas autour de la jument, et lui sourit. Mais voici que le bambin de tout à l'heure vient frôler ses jupes. La main derrière le dos, il s'appuie contre elle et regarde avec un vit intérêt les gens qui passent. Dans la petite main est un papier, que des doigts fins saisissent ; et la petite main reste ouverte pour qu'y tombe une piécette. L'enfant s'en va, en gambadant, gagner sa vie ailleurs. Et Marguerite Le François, qui est là-bas sous les arbres, attend qu'avec le passeport de Mlle Seynaeve, qui est un si parfait talisman, sa nouvelle amie la couturière franchisse le poste à son tour. L'admirable est que le jeu réussit à point. Le soldat allemand trouva le papier aussi valable la seconde fois que la première, et nos deux amies rieuses, s'ébattent maintenant, comme deux oiseaux échappés, sous les ombrages, La candeur de ces croquemitaines si faciles à berner les amuse. Le passeport à cette époque ne comportait pas de photographie. Alors on se tirait facilement d'affaire avec un peu d'aplomb. C'est égal, il fait meilleur au pied de ces gros arbres que là-bas entre les maisons. 
Tandis qu'elles musent et babillent, deux hommes, deux civils qui venaient de Tournai, les regardent, s'arrêtent, s'étonnent de leur joie un peu gamine, puis les abordent

- Vos papiers?

- Mais nous les avons montrés là, dit vivement Louise de Bettignies.

- Faites voir tout de même.

Alors elle perdit la tête.

- D'abord qui êtes-vous ? demanda-t-elle.

L'un des deux tira sa médaille et dit d'une voix dure :

- Autorité allemande. Si vous avez des passeports, je veux les voir.

Alice tendit le sauf-conduit. Il se tourna vers l'autre jeune fille

- Et vous?

Marguerite Le François fit semblant de le chercher dans son sac. Elle tremblait comme une feuille.

- C'est bon. Au poste toutes les deux.

Dès cette minute, comme s'ils connaissaient l'immense valeur de leur proie, dont en fait ils ne savaient rien, ils se conduisirent vis-à-vis de Louise de Bettignies comme des brutes.

On les ramène au poste ; on les pousse dans le couloir étroit de l'auberge ; à droite est une petite salle, où se tient un gradé ; les agents en civil qui les ont arrêtées font constater qu'elles n'ont qu'un passeport pour deux.

- C'est bien, dit le policier. Je préviens Tournai. Gardez-les.

Et tandis qu'il. décroche le téléphone, elles sont ramenées dans le couloir exigu, qu'elles traversent pour entrer dans la grande salle de l'auberge.

Cet estaminet du Canon d'Or a retrouvé, après la guerre, ses anciens maîtres, et dans la salle du poste, alors encombrée d'une table chargée de papiers et des fils embrouillés du téléphone, un enfant de douze ans en tablier noir apprend aujourd'hui ses leçons avec une application charmante. À peine lève-t-il la tête, tandis que ses parents m'expliquent que, s'ils ont abandonné la maison dont les Boches 
devaient faire un si cruel usage, c'est qu'ils ont fui dès les premiers jours de l'invasion, fui dans l'affolement, à cause de ce petit dont on leur disait que les barbares allaient couper le poignet.

Nous entrons avec ces braves gens dans la grande salle qui servait de corps de garde et où furent poussées les deux jeunes filles. On était allé chercher au Palais Royal le pauvre Lamote, qui ne s'attendait pas à pareille aventure et qui aujourd'hui reconstitue pour nous dans tous leurs détails les scènes tragiques qui allaient suivre. Cette salle donne sur la rue. Quand on est adossé aux fenêtres, le long desquelles courent des banquettes devant des tables, on a en face de soi un vaste comptoir et, à gauche, une porte vitrée donnant sur une autre pièce, plus petite, mais très claire. On fit asseoir Lamote près d'une fenêtre ; Marguerite Le François fut placée entre le comptoir et la cloison de la petite salle, et l'on introduisit Louise de Bettignies dans cette autre salle.

Des soldats faisaient leur toilette. L'un d'eux, nu à mi-corps, se lavait dans un baquet à moins d'un mètre de la petite Le François. Il dressa tout à coup la tête et, montrant du doigt Louise de Bettignies à travers la porte vitrée, il cria d'une voix rauque :

- C'est une criminelle. Recardez-la.

Elle était en train d'avaler le chiffon de papier de sa bague.

Alors arrivèrent le policier Rotselaer et, derrière lui, la grenouille. Cette ignoble femme, qu'on voyait partout à Mouscron, il fallait qu'elle fût de service à Tournai ce jour-là ! Elle courut droit à Marguerite Le François :

- Déshabillez-vous 1

- Ici ? demanda la pauvre enfant, qui regardait avec effroi tous ces hommes à leur toilette.

Quand elle eut défait son corsage, puis desserré sa jupe, elle défaillit. Ces gens plongèrent alors le verre à dents tout maculé d'un des hommes dans un broc et donnèrent à boire de l'eau sale à cette petite. La crise dura longtemps, dix minutes, peut-être plus. La grenouille fut sans pitié, fit tomber tous les vêtements de sa victime et, l'ayant fouillée, la laissa là pour passer dans l'autre pièce, où sa tâche fut plus dure. 
Car Louise de Bettignies, qui parlait la langue de cette femme, ne mâcha pas ses mots et se défendit. Elle était la moins forte : elle dut céder. Elle ne livra point les cinq ou six pièces d'identité, toutes différentes, qu'elle portait sur elle. Mais on les lui prit avec rage, en l'injuriant. Et, mise en goût, la drôlesse qui promenait ses mains sur elle fut sans merci, n'épargna pas un centimètre de son linge, ne lui fit grâce d'aucune curiosité.

Pendant ce temps, Rotselaer, chef de la police de Tournai et fort important personnage, cuisinait Lamote. C'était un petit homme tout noir et nerveux, avec une courte moustache et des yeux perçants. On le disait juif, et de Francfort. On disait aussi qu'il avait longtemps habité Anvers. Ce garçon, habituellement correct dans son langage et vêtu avec soin, veston bien coupé, chapeau mou, ne ressemblait aux autres Allemands que par la grossièreté de ses colères. Il comprit, dès les premiers mots de Lamote, que l'une des femmes était innocente. Il n'eut pas un instant l'idée que l'homme fût lui-même coupable, et il accepta si bien l'histoire de la couturière rencontrée en chemin qu'il ne songea même pas à faire visiter le cabriolet.

- Allons ! tout ce monde-là en voiture ! dit-il à la fin.

Et dans une torpedo à six places, Louise de Bettignies fut jetée au fond, un gendarme à son côté ; devant elle, Lamote et Marguerite Le François ; sur le siège, Rotselaer et un chauffeur. Au départ, il se tourna vers les prisonniers et leur dit, dans son meilleur français :

- Pas un mot, vous trois. Vous êtes au secret et surveillés !

La grenouille suivait avec d'autres policiers dans une deuxième voiture. 1

On arriva en quelques minutes aux bureaux de la police secrète, à Tournai, près de la gare. Les Allemands avaient réquisitionné pour cet usage une belle maison, très bourgeoisement habitée aujourd'hui. En façade sur la rue est une salle à manger claire et vaste, qu'orne une imposante cheminée de bois sculpté. Les policiers ont mis là une table qui couvre presque toute la superficie de l'immense piè-

1 Les souvenirs de Mlle Le François et ceux de M. Lamote ne concordent pas entièrement, il y a donc deux versions, avec des différences assez sensibles, de cette scène de l'arrestation. J'ai donné l'une qui me paraît probable. J'indiquerai l'autre dans une édition ultérieure, car je le crois alors utile à la sincérité, que je veux de ce récit. 
ce. Tout autour sont des civils qui fument ou des Allemandes, jeunes et vieilles, qui tapent sur des machines. Sur la table, un désordre fou, des magazines, des cendriers tout maculés, des dossiers et les chapeaux de ces messieurs. On va interroger séparément les prisonniers, mais d'abord celle qu'ils appellent déjà l'espionne. On éloigne les deux autres. Elle est assise près de la cheminée, toute pâle, les mains sur les genoux, et elle attend, tandis que ses bourreaux parlementent à voix basse et que les dactylographes la dévisagent sournoisement par-dessus leurs machines. Tout à coup, ses yeux rencontrent ceux de Lamote, qu'on a mis là-bas, dans un petit salon séparé de la salle à manger par un large couloir. Les portes sont restées ouvertes, Dieu merci ! et cet homme, sous le regard de qui la grenouille vient de faire chauffer une tasse de lait et d'y verser une poudre jaune qu'elle délaie maintenant avec amour, fait comprendre à Alice, d'un geste des doigts à sa bouche, qu'elle fera bien tout à l'heure de serrer les dents.

- Vous devez être bien lasse ! dit alors une voix pitoyable. Buvez cela.

Et Louise de Bettignies voit que l'Allemande lui présente en minaudant un bol de lait.

- Merci, madame. Je n'ai pas soif.

Elle insiste. Refus poli, puis refus net. Alors Rotselaer s'en mêla :

- Allons, vous, pas d'histoires ! Avalez, ou dites pourquoi.

Elle se garda bien de répondre à cet homme, qui surveillait ses dents. Elle les tint serrées et quand ils essayèrent de lui ouvrir la elle fit d'un geste brusque rouler la tasse sur le parquet.

Le pli était bien caché : ils comprirent que celui-là, à moins de la tuer et d'ouvrir son estomac tout de suite, ils ne l'auraient pas.

Alors ils décidèrent, sans plus la questionner, de la retenir et de l'enfermer ; puis, désarmés par l'innocence vraiment éclatante de l'autre jeune fille, dont l'émoi et la douleur faisaient peine à voir, ils la confièrent à son compagnon d'infortune et donnèrent à celui-ci un sauf-conduit pour qu'il rentrât au plus vite à Mouscron dans son cabriolet et ramenât la pauvre enfant à ses parents. 
LA GUERRE DES FEMMES.

Histoire de Louise de Bettignies et de ses compagnes.

\section{Chapitre VII}

\section{LE MANTEAU ÉCOSSAIS}

$\underline{\text { Retour à la table des matières }}$

C'est seulement le soir, vers quatre heures, que la redoutable nouvelle arriva jusqu'aux oreilles de Mme de Geyter, à Mouscron ; elle et son mari, dès cette minute, pouvaient trembler. Ils ne surent, ce jour-là, que le fait brutal de l'arrestation, sans un détail. Ernest Lamote, qui ne se souciait point qu'on le vit chez eux, leur avait fait passer par un jeune garçon un avertissement laconique. Il était d'ailleurs trop affairé chez lui pour sortir. La valise et le parapluie de Louise de Bettignies, il s'agissait de les brûler et d'en disperser les cendres. Il le fit en maugréant contre les Boches, mais tout de même avec la satisfaction d'avoir été deux fois servi par le destin. Le matin, au lieu de confier tout de suite la valise à un gamin qui eût suivi les jeunes filles et qui, pris, eût trahi son « client » et mis en pièces, sans y penser, l'histoire de la couturière inconnue cueillie sur la route, il était entré, sa jument dételée, dans la salle encombrée de l'estaminet du Palais-Royal, oublieux de sa consigne. Heureuse faute ! L'autre faute bénie, le policier Rotselaer l'avait commise en omettant d'aller fouiner sous la banquette du cabriolet. Jamais Ernest Lamote ne devait être inquiété par la suite. Y comptait-il alors ? Il savait du moins que pas un mot qui pût le compromettre ne sortirait des lèvres de la prisonnière. 
Dans la maison de la rue de la Station, ou comprit tout de suite qu'on aurait la visite des policiers : on se mit en mesure de les recevoir sans dommage. Il s'agissait de faire disparaître tout ce qui compromettrait la prisonnière, ou les maîtres de céans, ou des tiers. Mme de Geyfer imagina aussi de bouleverser la disposition des meubles, afin que la maison fût méconnaissable. et pour rendre les confrontations incohérentes. Chose incroyable, c'est seulement le lendemain, vers deux heures et demie de l'après midi, que les policiers arrivèrent à Mouscron. Leur forte voiture courait à vive allure à travers les rues silencieuses. C'était une torpédo poussiéreuse, au fond de laquelle les passants purent voir, blottie dans un grand manteau de lainage écossais, une jeune femme d'une grande pâleur.

Au 132 de la rue de la Station, l'automobile stoppa.

M. et Mme de Geyter étaient à la cuisine avec leur bonne, occupés à préparer des conserves de carottes.

- On sonne, Flore ! Allez vite ouvrir !

Flore courut, puis revint :

- Vite, madame, monsieur ! Ce sont les Boches.

Les patrons de la pauvre fille s'avancèrent lentement à la rencontre de l'ennemi. Et Flore, qui était retournée vers la porte, parut de nouveau, disant d'une voix qu'étouffait l'angoisse :

- Mademoiselle est avec ! Mon Dieu ! Qu'est-ce qu'on va faire ?

On entre dans la maison de M. de Geyter par une porte cochère, qui donne accès à un large et haut couloir voûté, conduisant au jardin. Au milieu de ce passage, à gauche, on monte trois marches de marbre noir et l'on pénètre par une porte vitrée dans le vestibule. C'est là que les deux groupes se rencontrèrent. Mme de Geyter, son mari et leur bonne avaient pris le temps de se ressaisir, tandis que les autres descendaient de voiture, attendaient une deuxième torpédo chargée de policiers subalternes et se groupaient pour leur entrée. Flore avait même trouvé moyen de courir au buffet et de verser du cognac dans deux verres, qu'e1le tendit à ses patrons. Mme de Geyter ayant pu, seule, avaler ce cordial à la dérobée, la servante ne voulut pas que le second verre se perdît et n'en fit qu'une gorgée. Mais voici que, sonnant de l'éperon sur les marches de pierre, le Kreischef s'avance, suivi du petit Rotselaer en civil. Ce dernier, quoique il s'efface respectueusement 
devant le général, sait que, des deux, c'est lui qui, à cette place, à cette heure, est le maître. Le commandant du district apporte ici le prestige de son rang, de sa fonction ; mais l'homme de métier, celui qui va manœuvrer tous ces gens-là tambour battant, c'est Rotselaer. Et, tout de suite, il parle haut :

- Vous connaissez cette femme ? dit-il brusquement.

Et il fait passer devant lui la petite Louise de Bettignies, qui a gravi à sa suite, entourée de deux argousins, ces marches familières où ses pieds légers ont si souvent couru.

Alors, à la grande surprise de Mme de Geyter et de son mari, la jeune fille, dont le visage était livide et les yeux si cernés qu'elle semblait un fantôme, prit les devants et, penchée vers eux, leur dit avec volubilité :

- N'est-ce pas, madame, que je suis une évacuée de Neuve-Église et que je travaille chez vous tous les jours, depuis six mois, comme couturière... N'est-ce pas, madame, que c'est vrai ?

Il y avait une supplication si énergique dans son regard qui s'était animé tout à coup, mais aussi tant de douleur sur tout son visage, que vingt-quatre heures de contact avec des hommes brutaux avaient déjà décomposé, que Mme de Geyter crut qu'elle n'aurait jamais la force de renier cette malheureuse enfant. Il le fallait, cependant, pour tous et pour elle-même.

- Non, mademoiselle, ce que vous dites n'est pas vrai. Je ne vous connais pas.

Louise de Bettignies recula et passa sa main devant son visage avec épouvante.

- Et vous, monsieur ? dit Rotselaer se tournant vers le mari.

- Moi, je ne connais pas cette personne.

Le général, avisant la vieille Flore, lui demanda :

- Et vous, l'avez-vous déjà, vue ?

- Jamais, monsieur, dit-elle avec toute la force qui lui restait.

Quelle minute tragique ! Dans toute l'histoire que je conte ici, Louise de Bettignies n'a commis nulle défaillance. Et cependant, elle voulait donner à l'ennemi, ce jour-là, une indication qui aurait perdu un homme et une femme parmi les plus 
zélés serviteurs des Alliés. Qui devinera comment elle avait conçu sa défense, pour violer à ce point la consigne qu'elle-même avait fixée ? On avait pris sur elle, avec le passeport de Juliette Seynaev et une carte d'identité à son nom de Louise de Bettignies, une autre carte avec le nom d'Alice Dubois et l'adresse de la rue de la Station. Peut-être avait-elle cru, aux premiers mots de l'interrogatoire de Tournai, qu'elle serait relâchée tout de suite si tous, à Mouscron, s'accordaient pour reconnaître en elle une couturière travaillant à la journée. Ayant risqué, dans une minute de faiblesse trop excusable, ce mensonge sommaire, elle essayait de s'y tenir et criait son jeu aux de Geyter pour qu'ils y fissent écho. Ceux-ci, longtemps stylés par elle-même, qui avait toujours dit qu'en cas de malheur la seule politique serait de s'ignorer les uns les autres, même contre l'évidence, eurent en l'entendant un mouvement d'effroi. Ils oublièrent toute pitié : il le fallait. Elle et lui et la vieille servante répondirent à son mensonge par un autre, le seul bon. Car on se perd rarement en niant, et l'on sauve tous les autres. La seule façon de ne trahir personne est de répéter toujours : je ne sais rien, je ne connais pas cette figure, je n'ai rien vu, je ne comprends pas ce que vous dites. Avec cela, on montre bien à l'ennemi qu'on le trompe et c'est de quoi l'exaspérer, mais on ne lui livre rien, ni personne, pas même soi. Louise de Bettignies disait vrai : il faut nier.

Et savez-vous ce qu'elle fit quand elle comprit que ceux-là avaient raison contre elle ? Elle céda, se donna tort au-dedans d'elle-même, mais ne le fit point paraître, car leur complicité eût alors éclaté.

- Vous mentez, dit-elle, parce que vous avez peur. C'est bien, je ne dirai plus rien.

Et, redevenue crâneuse et belle comme dans ses plus grands jours, elle se planta si droit devant les Allemands qui épiaient chacun de ses gestes, que Rotselaer, pris de fureur, la prit par les deux bras et la secoua violemment, lui criant au visage :

- Mais, menteuse, avouez donc ! Avouez ! Mais avouez ! Ah ! la menteuse !

Le kreischef mit fin à la scène, qui devenait atroce, en faisant signe au policier d'interroger M. de Geyter dans le petit salon, qui était la première pièce à gauche dans le vestibule ; lui-même entra avec Mme de Geyter dans le grand salon, faisant suite au petit et donnant comme lui sur la rue. Louise de Bettignies fut consignée et gardée à vue dans le couloir. Quoique moins grossier que son acolyte, le 
kreischef trouva plaisant de poser un revolver sur le guéridon qui séparait son fauteuil de celui de Mme de Geyter. Celle-ci refusa de parler devant ce vilain objet. Il céda, mit l'arme dans sa poche, mais, goujat quand même, installa sa cravache sur la table. L'interrogatoire ne donna rien.

- Nous allons fusiller cette espionne, disait-il. Et vous aurez le même sort si vous ne dites pas la vérité. Avouez, c'est votre intérêt.

Quand ils virent, chacun dans son salon, qu'ils ne tireraient rien du mari ni de la femme, ils gagnèrent le vestibule et, avisant l'escalier qui en occupait tout le fond, ils firent signe que la perquisition allait commencer et qu'on visiterait d'abord les étages. En revoyant Louise de Bettignies si douloureuse, Mme de Geyter fit une prière à Rotselaer, qui était le plus près d'elle :

- Monsieur, puis-je offrir quelque chose à cette jeune fille ?

- Elle vous intéresse donc ? riposta-t-il sèchement.

Il n'attendit pas la réplique et fit monter tout le monde. Au haut de l'escalier, il se ravisa et dit à sa prisonnière :

- Avez-vous soif ? Que voulez-vous?

- Un peu de cognac et d'eau, répondit-elle tristement.

Mme de Geyter descendit alors, mais pas seulement pour chercher à boire. Elle avait bien autre chose en tête.

Il faut savoir qu'un bon mois plus tôt, le 8 septembre, elle venait de prendre à Tournai le train pour Mouscron, quand l'ordre fut donné à tous les voyageurs de descendre pour la visite. Elle avait des raisons de croire que c'était elle qu'on visait, et comme elle portait un grand manteau de laine, beige d'un côté, écossais bleu et vert de l'autre, qui la désignerait tout de suite aux fouilleurs, elle abandonna ce manteau dans le compartiment, avec un paquet de gâteaux secs dans une poche, se mêla sur le quai à la foule et, tandis qu'on cherchait la dame au vêtement voyant, réussit à quitter la gare et à s'esquiver. Elle portait un courrier important et c'était une fameuse proie que les Allemands perdaient là ; mais, depuis ce jour, elle demeurait inquiète. Les policiers avaient certainement trouvé le manteau et, sur lui, l'adresse du fournisseur à Lille. Les gâteaux aussi, elle les avait achetés chez un pâtissier qui la connaissait à Tournai et qui, peut-être, sans penser à mal, la trahirait. 
Or, c'est, ce vêtement sur le dos que Louise de Bettignies venait d'entrer dans sa maison. Les policiers de Tournai l'avaient jeté au départ sur les épaules de la jeune fille, et celle-ci, pour monter avec eux dans les chambres, venait de le déposer sur une banquette du vestibule. Mme de Geyter s'en empara vivement, constata que l'adresse du vendeur était toujours là, alla chercher un couteau dans la salle à manger, coupa le morceau de ganse portant la marque en lettres d'or, puis prépara un grog et le monta au premier étage.

Louise, ayant bu, lui dit :

- Madame, vous ne me connaissez pas, mais vous êtes généreuse. Cette boisson m'a fait du bien.

Elle paraissait alors affreusement triste. On avait visité la chambre de $\mathrm{M}$, et de Mme de Goyter, à droite, Rien de suspect. Au fond, deux portes. Celle de droite ouvrait sur une chambre d'amis, qu'avait quelquefois occupée, Léonie Vanhoutte, quelquefois aussi Louise de Bettignies. On y resta longtemps. Le mobilier de ces confortables demeures belges ne ressemble pas à celui des appartements au ripolin de nos maisons, qu'on fait, sous prétexte d'hygiène, pareilles à des hôpitaux. Là, les tapis épais, les rideaux doubles et triples, les meubles de velours ou de soie couverts de coussins, d'ouvrages de dentelles, les toilettes chargées de nappes et de voiles brodés, les lourdes et somptueuses garnitures de cheminées, les lustres, les candélabres, les tableaux sur les murs, les grands christs d'ivoire sur fond de velours cramoisi dans des cadres de Venise, la literie de plume avec d'admirables couvre-pieds, purs chefs-d'œuvre, sur des édredons gonflés comme des ballons, tout ce luxe parfaitement confortable et solide des bonnes habitations d'autrefois règne encore, et sans dommage pour la santé : car tout cela est blanchi, épousseté, entretenu, caressé avec amour tous les jours que Dieu fait, par des mains expertes et courageuses. Mais allez donc perquisitionner dans ce monde d'objets entassés ! Surtout si la maîtresse de maison, qui a prévu la perquisition, a mis exprès du désordre partout, jetant des vêtements sur le lit, vidant les armoires sur les chaises.

- Madame, je ne voudrais pas être votre mari, lui dit sévèrement le kreischef.

Et elle jubile. Les gens qui fouillent, il faut les dégoûter en faisant du fouillis avant eux. Ils sortirent de cette petite chambre dégoûtés.

Une autre porte, également au fond, ouvrait sur la chambre de Flore. Et, dans cette chambre, était un escalier pour atteindre au grenier. Rotselaer monta là-haut 
avec la servante, se fit allumer une bougie, défit consciencieusement des rouleaux de papier peint qui traînaient dans un coin et descendit en grognant.

Cependant, Mme de Geyter était devenue pâle comme une morte. Ils avaient, elle et son mari, passé une partie de la nuit à détruire des quantité de lettres, de papiers, de documents de toutes sortes. Et elle se souvenait avec terreur, au moment où les Allemands allaient y pénétrer, que la chambre de Louise de Bettignies était encore pleine des effets de la jeune fille, même de sa correspondance, et peut-être de pièces secrètes. Ils avaient pensé à tout cette nuit, sauf à cela, qui était le plus grave. Elle sentit que ses genoux lui manquaient et crut qu'elle allait défaillir.

En revenant des pièces du fond vers l'escalier, on trouvait deux portes à droite. La première était celle de cette chambre, où chaque objet trahirait la pauvre captive et ses hôtes. Mme de Geyter, rassemblant toutes ses forces, mit la main sur la poignée de la serrure et dit au krieschef :

- Entrez-vous ici, maintenant?

Rotselaer, que sa visite au grenier avait agacé, intervint :

- Non, dit-il, nous perdons notre temps avec cette menteuse. Elle a menti dans la première chambre, menti dans la seconde. Pour l'entendre mentir aussi dans les autres, autant nous en aller tout de suite, Descendons.

Et comme sa victime n'obtempérait pas assez vite, il la poussa vers l'escalier.

- Eh bien, qu'attendez-vous pour obéir ? lui cria-t-il.

Pendant que ces scènes se déroulaient dans le corps principal de la maison, $\mathrm{M}$. de Gryter vivait un peu plus loin d'horribles minutes. Deux hommes avaient reçu mission de le garder dans la cuisine. Il s'était mis d'abord à gratter des carottes. Cette occupation paraissait le rendre sympathique à ses gardiens, Il s'arrêta cependant, s'allongea sur sa chaise et fit mine de s'assoupir. En réalité, il écoutait avec anxiété les allées et venues de trois ou quatre individus qui perquisitionnaient au-dessus de sa tête dans son laboratoire. À la fin, n'y tenant plus, il décida d'y aller voir. L'un de ses gardiens, à son exemple, s'était assis, puis assoupi ; il dormait maintenant la bouche ouverte ; l'autre avait entrebâillé la porte du jardin et regardait au dehors. M. de Geyter se leva et fit à pas feutrés quelques allées et venues. Le soldat se retourna, parut hésiter, puis, portant les mains à son ventre, 
fit comprendre d'une grimace qu'il serait bien aise qu'on lui indiquât un lieu d'apaisement.

- Par ici, mon ami, lui dit avec la plus généreuse obligeance le maître du logis.

Il le regarda. partir et s'enfermer, puis passa doucement dans un couloir, monta au premier étage, où il entendit les cris de Rotselaer et les réponses sèches de Louise de Bettignies, se glissa dans là salle de bains et par là dans son bureau qu'une cloison vitrée séparait du laboratoire. Ces deux pièces formaient l'étage d'un petit corps de bâtiment bâti sur le jardin ; au rez-de-chaussée était la cuisine avec ses dépendances. De son bureau, M. de Geyter vit avec effroi qu'on pillait grossièrement ses instruments de travail. Des hommes étaient occupés à démonter pièce à pièce ses microscopes. Des ampoules, des cornues, des vases, des ballons de verre gisaient à terre, brisés pour la plupart, Un individu regardait un à un, par transparence, puis rejetait pêle-mêle les tubes contenant des ferments en culture. Un autre empochait, pour le service de la grande Allemagne, des capsules de platine. Celui-là connaissait la valeur d'un tel métal : un spécialiste, sans doute. Le propriétaire dont on saccageait ainsi les richesses ouvrit la porte pour bien voir son malheur. À sa droite, contre la cloison en façade sur le jardin, était une longue table toute chargée d'objets en désordre. Du lieu où se trouvait M. de Geyter en entrant dans la pièce, il était séparé de cette table par la largeur d'une porte : porte vitrée ouvrant sur une passerelle métallique, marche supérieure d'un léger escalier de fer descendant dans les herbes. Pour que le vent de la porte ne frappât point l'opérateur au travail, on avait abrité la table par une planche verticale. Sur cette planche, droit devant son nez, M. de Geyter aperçut, pendues à un clou, trois ardoises. Au même moment, le policier qui paraissait conduire la bande vit aussi ces ardoises. Il alla vers elles, les saisit ensemble brutalement et les arracha. C'étaient de ces tablettes de carton qu'on donne aux écoliers : elles sont percées d'un trou qui s'agrandit à l'usage. L'une d'elles, sans doute, était vieille. Le fait est que, sous le choc, elle acheva de se déchirer et tomba. te policier ne s'aperçut pas qu'il n'en tenait que deux dans sa main. Il alla les regarder sous le gaz, car le jour commençait à baisser. Les chiffres et les signes dont elles étaient couvertes l'intriguèrent sans doute : il se retira vers le fond de la pièce, où un bec plus fort était placé plus bas. Il perdait sa peine, car c'étaient là des calculs, sans doute savants, mais innocents. L'autre ardoise, celle qui gisait à terre, contenait le texte en clair du sans-fil que, le lundi, Louise de Bettignies avait aidé M. de Geyter à déchiffrer. C'était 
l'indication du jour, de l'heure et du lieu où tomberaient les prochains pigeons. Comment, ayant détruit et brûlé tant de choses, avait-il laissé là cette ardoise ? Bien qu'il se crut à ce moment près de devenir fou, il se conduisit comme un sage. Négligemment, il entr'ouvrit la porte sur la passerelle. L'air frais qui entra tout à coup aurait dû alarmer tous ces Allemands ; ils étaient bien trop affairés, trop nombreux aussi, et les mouvements suspects de cet homme, chacun les attribua sans doute aux camarades. Il eut ainsi tout le loisir de pousser du pied, avec mille précautions, le morceau de carton noir. Il eut la chance qu'au lieu de rester accroché à la passerelle, il passa entre les barreaux et s'en alla tomber avec un bruit sourd dans l'herbe folle au pied de la cuisine. Il referma doucement la porte et s'en alla. Quand il en parle aujourd'hui, il pâlit encore.

Au moment où, las de cette perquisition manquée, le kreischef allait se retirer avec tous ses hommes et sa proie, Rotselaer se frappa le front et dit à son chef :

- Ah ! mais ce n'est pas tout. Donnez-moi encore une minute. Il y a le manteau. Et prenant le vêtement de laine qui traînait toujours sur un meuble du vestibule, il courut le montrer à la servante dans la cuisine.

- Flore, dit-il, vous connaissez ce manteau, n'est-ce pas?

- Non, monsieur.

- Voyons, regardez-le de près. Est-ce que madame ne voyage pas quelquefois?

- Non, monsieur.

- Elle ne va jamais à Tournai ?

- Non.

- Souvenez-vous bien ! Et puis, est-ce qu'elle ne rapporte pas quelquefois des gâteaux ? Allons, Flore, soyez sincère !

- Jamais, monsieur ! D'abord, on fait toute la pâtisserie ici.

- Vous savez donc faire des gâteaux ?

- Oui.

- Eh bien, je reviendrai et vous m'en donnerez à manger. 
Puis il sourit à la vieille servante, regagna le vestibule et mit avec soin et déférence le vêtement mystérieux sur les épaules de Louise de Bettignies.

Quand, la lourde porte cochère s'étant refermée, M. et Mme de Geyter se trouvèrent seuls dans leur maison silencieuse, ils s'en furent rejoindre leur bonne à la cuisine et, sans un mot, se remirent, assis en rond autour de la table, à laver des carottes.

Les policiers allèrent interroger rapidement quelques voisins, les Rasson, les Coulon, les Dubois, puis Rotselaer revint chez les de Geyter, espérant les surprendre.

Ils avaient chacun la main dans un bocal à demi plein de racines appétissantes et bien grattées.

- Toujours des conserves ? leur dit-il.

M. de Geyter le regarda par-dessus ses lunettes et lui répondit :

Oui, monsieur, et de carottes. 
LA GUERRE DES FEMMES.

Histoire de Louise de Bettignies et de ses compagnes.

\section{Chapitre VIII \\ LE POLICIER GOLDSMITH}

$\underline{\text { Retour à la table des matières }}$

En entrant au greffe de la prison de Saint-Gilles, quelques jours plus tard, Louise de Bettignies considéra avec curiosité un tableau de marbre noir portant cette inscription :

QUELQUE GRANDS QUE SOIENT LES MALHEURS QUE VOS FAUTES VOUS ONT ATTIRÉS NE VOUS ABANDONNEZ PAS AU DÉSESPOIR. OUVREZ VOS CEURS AU REPENTIR, VOTRE COURAGE RENAÎTRA, VOS SOUFFRANCES S'APAISERONT, VOUS REDEVIENDREZ DIGNES D'ESTIME ET VOUS MÉRITEBEZ LE PARDON DES HOMMES ET LA CLÉMENCE DE DIEU.

Elle apportait dans cette demeure une âme presque sereine. L'heure des premières révoltes était passée : il s'agissait maintenant de bien jouer le jeu. Tant que durerait la prévention, tout son effort porterait contre l'instructeur. Plus tard, si on ne l'envoyait pas à la mort, elle aviserait. Elle apprécia le régime de Saint-Gilles. Sans doute s'appliqua-t-elle, pour demeurer forte, à faire les exercices de gymnastique rythmée qui sont signalés aux détenus de cette prison, dans chaque cellule, par dix figures avec des légendes. On pense en frémissant que des spécialistes du cambriolage ont peut-être acquis là une souplesse nouvelle pour récidiver. Elle 
s'entraînait, quant à elle, en vue de l'évasion. Dès le premier jour, elle monta sur sa petite chaise, se haussa de son mieux et détacha du mur le crucifix, qu'elle voulait sous son regard. Quand ses gardiens entraient dans sa cellule, pendant le long séjour qu'elle fit à Bruxelles, ils pouvaient voir l'image du Christ sur sa table, près de sa main.

Au début, l'instructeur, qui n'était pas un juge de carrière, mais un bas policier, et s'appelait Goldsmith, la traita avec certains égards. Cet individu, d'une grossièreté révoltante dans ses mauvais jours, se montrait parfois aimable avec affectation, presque câlin. Le rang de la nouvelle détenue l'incitait au respect : tous les Allemands rectifient d'instinct la position et se font humbles devant quiconque porte la particule. Louise de Bettignies, plus fine que ce finaud, usa de son prestige, et prit, aux premières passes, un ascendant certain sur lui. Mais elle niait tout, même l'évidence, avec une effronterie où il sentait tant de mépris pour son intelligence, qu'un jour il se jeta sur elle et la frappa. Dès lors, ce fut entre elle et lui une lutte implacable. La grenouille avait trouvé sur elle, au Canon d'or, une lettre dont personne n'a jamais voulu dire, même au procès, ce qu'elle contenait. Il est probable qu'elle était sans grande importance. Tout au plus trahissait-elle que la jeune fille, au moment de son arrestation, connaissait des moyens de passage vers la Hollande. Louise de Bettignies avait eu le toupet de dire à Rotselaer que, cette lettre, c'étaient ses policiers qui la lui avaient mise dans les mains pour la compromettre. Elle répétait la même chose, ou d'autres de même force, à Goldsmith. Celui-ci entrait alors dans des fureurs dont la jeune fille jouissait sans réserve. Sur quoi, mis à bout, il se levait et la bousculait, le rouge aux yeux,

Ne pouvant rien tirer d'elle et leurs perquisitions n'ayant pas abouti, ils la laissèrent près d'un mois dans sa cellule sans l'interroger. Ce qui les agaçait était de ne rien connaître de l'autre Dubois, car Louise de Bettignies, c'était tantôt Alice et tantôt Marie Dubois. Pour cette Marie, ils se donnèrent un mal fou. Ils n'ont même jamais su si Alice était bien celle qu'ils tenaient. Dans un livre de l'avocat Sadi Kirschen, du barreau de Bruxelles, où sont rapportés les souvenirs d'audience d'un grand nombre de procès de patriotes belges devant les conseils de guerre allemands, on voit que le 4 ou le 5 mai 1916, plus de six mois après l'arrestation de Louise de Bettignies, ils demandaient encore au détenu Lefèvre, qu'ils devaient fusiller quelques jours plus tard, s'il n'avait pas parmi ses noms de guerre celui d'Alice ou celui de Dubois. Un jour vint où ils s'avisèrent que les deux Alice, celle 
de la rue des Aduatiques et celle de la carte d'identité saisie à Froyennes, étaient peut-être une seule personne. Alors ils firent venir Charlotte à Bruxelles.

Ils avaient dans l'intervalle interrogé Gustave, le garçon de l'hôtel Saint-Jean, mais comme des gens qui sont près du but et ne s'en doutent pas. Ils font songer à ce jeu de cache-tampon où l'on tape avec des pincettes quand le chercheur brûle. Personne n'était là pour leur crier que la piste était bonne. Après les réponses évasives ou narquoises de cet homme plus malin qu'eux, ils se retirèrent. Ils avaient dit à Gustave : "Nous avons capturé une petite bonne femme qui est bien entêtée ; elle ne veut pas avouer, quoique nous ayons contre elle des preuves accablantes. Elle venait souvent dîner chez vous. Nous savons tout : avouez le reste. » Gustave cherchait avec application dans sa mémoire et paraissait désolé de n'y rien trouver.

Quand ils décidèrent de confronter les deux jeunes filles, ils ne savaient à peu près rien de l'une ni de l'autre, sinon qu'elles faisaient sans doute de l'espionnage ou du recrutement en Belgique et qu'elles obéissaient à des chefs, mais lesquels ? Le fil leur manquait.

Un jour, Louise de Bettignies vit entrer brusquement Goldsmith dans sa cellule, suivi d'une mince jeune fille qui se cachait derrière lui, pâle et toute tremblante. C'était la petite Vanhoutte. Toutes d'eux, d'abord épouvantées, cherchèrent du secours en elles-mêmes. Leur cœur qui battait à se rompre, elles le matèrent d'un seul coup. Il resta deux petits corps d'acier et, dans chacun, une volonté,

- Vous la connaissez, celle-là ? dit Goldsmith à Alice, en poussant Charlotte au-devant d'elle.

- Moi ? non, répondit-elle sèchement.

- Vraiment non ? fit-il en ricanant.

Elle dévisagea sa compagne avec attention, d'un regard dur.

- Non, vraiment, dit-elle ; je ne la connais pas du tout.

Alors il frappa du pied et devint rouge.

- Mais vous sortez toutes les deux de la même boîte ?

À voix douce, pour qu'il comprît mieux qu'il venait de s'exprimer comme une brute, elle répliqua : 
- Monsieur Goldsmith, je ne sais pas de quoi vous voulez parler.

- Et vous, cria-t-il à Léonie Vanhoutte, vous qui n'êtes pas une insolente, convenez que vous la connaissez.

- Moi, monsieur ? Je n'ai jamais vu cette figure-là !

Il l'emmena, furieux. Dans le couloir, elle l'entendit maugréer :

- Je ne suis pourtant pas un apprenti ! Je ne vais pas me laisser battre par ces deux bouts de femmes...

Il fit une nouvelle tentative le lendemain. Les ayant appelées toutes les deux au prétoire, il les y laissa seules un instant, espérant qu'elles se trahiraient. Il les observa en vain derrière une porte : elles se regardaient froidement comme des statues.

Leurs yeux avaient tout de même pris le temps de s'envoyer une caresse et c'est le cœur en joie qu'elles se séparèrent. C'étaient encore les bons jours : ceux où elles tenaient, en niant ou en se taisant, l'adversaire à leur merci. Alors elles se savaient fortes. La confiance que chacune avait dans l'autre les soutenait. Et, pour la tendresse, l'éclair d'un regard avait suffi : elles emportèrent ce matin-là du feu et de la lumière en elles pour de longs mois.

Un soir, on déposa un deuxième lit dans la cellule d'Alice. Son premier mouvement fut de s'attrister : elle avait pris goût à sa solitude. Quand elle vit arriver la compagne qu'on lui donnait, elle eut pitié de cette femme. Celle-ci, qui avait été condamnée deux mois plus tôt à dix ans de détention dans l'affaire de Miss Cawell, semblait être retenue à Saint-Gilles pour un complément d'information. Elle passa ses premières journées assise, la tête dans ses mains, silencieuse et prostrée. Elle faisait peine à voir, et sa compagne, dont le cœur était plus fort, essaya de la consoler. Peu à peu, les deux femmes se lièrent ; la nouvelle venue parut s'apprivoiser ; elle parla un peu, fit à Louise de Bettignies des confidences qui l'émurent et, à son tour, interrogea cette jeune fille si maternelle. Tous les jours on venait chercher plusieurs fois la malheureuse femme pour des interrogatoires qui n'en finissaient pas. Elle en revenait chaque fois avec un désespoir nouveau; tantôt elle se jetait sur sa chaise et sanglotait, ou bien elle s'enfermait dans un silence sauvage ; et tantôt elle arrivait comme une furie, lançant des imprécations contre Goldsmith, qui, criait-elle, l'avait battue. 
Un jour, elle dit à Louise de Bettignies :

- Vous savez qu'il y a une femme au grand secret dans la cellule contre la nôtre. On a dû l'y mettre ce matin. J'ai vu l'écriteau.

C'était exact. Charlotte était maintenant la voisine d'Alice. Et sur la porte de l'une et de l'autre, les Allemands avaient écrit : Gefâhrlich Person (Personne dangereuse).

- Vous connaissez son nom ? demanda Alice.

- Je crois que c'est la Française qu'on a confrontée avec vous plusieurs fois.

- Comment savez-vous tout cela?

- Mais, ma pauvre petite, je ne suis pas une prévenue, moi ; je suis une condamnée, et une ancienne ; je connais tout le monde ici, et quand je bavarde, on me répond. Si vous, avez des commissions pour le dehors, je suis prête à m'en charger ; et aussi pour des détenues, si vous en connaissez.

Louise de Bettignies, qui s'était ouverte peu à peu en l'entendant, se referma brusquement.

- Je ne connais aucune détenue, dit-elle.

La femme Ladrière, c'était son nom, ne dit pas un mot de plus ce jour-là.

Le lendemain, elles se regardaient toutes deux, lasses et tristes.

- Si nous essayions, dit la femme, de parler avec nos voisines ?

Le long du mur, du côté de la fenêtre, à vingt centimètres au-dessus du parquet, couraient deux minces tuyaux de fonte, peints en gris clair. Ils venaient de la cellule de droite et passaient dans celle de gauche : c'étaient les conduits du chauffage central, En s'agenouillant sur le sol, en portant les lèvres sur l'un des tuyaux tout contre la cloison, puis en y mettant l'oreille, on pouvait tour à tour parler à sa voisine ou l'écouter. Louise de Bettignies vit sa compagne se baisser, puis essayer de prendre contact avec la prisonnière de gauche, qui n'était pas Charlotte. Point de réponse ; la cellule était vide, sans doute. La jeune femme passa du côté droit, donna sur la fonte trois coups secs, et attendit. Bien ne bougea. Après un deuxième appel, elle crut percevoir qu'on déplaçait une chaise. Alors, les yeux brillants, elle tourna la tête vers Alice, qui vint à elle et s'agenouilla aussi sur le sol. Troisième appel. Haletantes, elles collèrent l'oreille sur le tuyau toutes les deux. Et, 
très lointains, voici que trois petits coups arrivèrent jusqu'à elles, trois chocs émouvants qui ébranlèrent le cœur de la sensible Alice. Alors, n'y tenant plus, elle écarta l'autre, comme peuvent se bousculer des enfants.

- Laissez-moi, disait-elle ; je vais lui parler.

Puis, le visage plaqué sur la cloison, tout bas, tout bas, mais en y mettant cependant tout ce que l'émotion lui laissait de souffle, elle appela

- Minou ! Minou ! c'est moi.

Minou ne répondit pas. Plus raisonnable ce jour-là que son chef, elle fit la morte : c'était la consigne. Et Louise de Bettignies se releva, déçue et prête à pleurer.

- Mais qui donc appeliez-vous ainsi ?

- Eh ! bien. Je vais vous le dire, fit Alice, dont la force de, résistance était épuisée.

Et elle livra la vérité à cette femme, qui l'écoutait avec gourmandise, lui pressant les mains et pleurant avec elle,

Quand Louise eut fini sa confession, l'autre eut une sorte d'étourdissement, dont elle se remit d'ailleurs aussitôt. Alors elle poussa d'un coup sec le signal d'appel, disant.

- Il faut que je voie le médecin tout de suite. Je me sens mal.

Un gardien l'emmena. Elle se fit conduire au prétoire et, courant presque, elle arriva devant Goldsmith, à qui elle répéta d'un trait ce que venait de lui dire la petite Française.

- C'est bien, dit l'Allemand en se frottant les mains. Mais vous savez que je veux un écrit d'elle. Arrangez-vous.

Cette femme, dont le nom de fille était Louise Tellier, avait accepté, en échange de certains adoucissements à sa peine, de faire l'ignoble métier de « mouton ». Les journaux ont parlé d'elle quand, après l'armistice, lasse de traîner des jours affreux, elle prit, un beau matin, le parti de s'empoisonner.

D'autres, beaucoup d'autres, hommes et femmes, ont trahi comme elle. Ainsi de presque tous les mercenaires : ils se vendent aux amis d'abord, et puis à l'en- 
nemi. Le deuxième marché n'est pas toujours le plus immoral : c'est commercialement le seul honnête, car il est fait entre fripons mais qui le savent.

Les Allemands ont utilisé pour ce métier des Français et des Belges. Si basses que soient les âmes de ces gens qui ont vendu leurs compatriotes et les ont envoyée au poteau, ceux qui tiraient la ficelle étaient plus abjects. Les premiers étaient des couards. On leur disait qu'ils avaient un seul moyen de n'être pas fusillés, celui-là. Affolés devant la mort, ils acceptaient de lui livrer, pour sauver leur vilaine peau, des vies nobles. Rien, pas même la hideuse peur, n'excuse un tel crime, et si je connaissais les noms et adresses de quelques-uns de ceux qui ont fait cela et qui se terrent maintenant en Hollande, en Suisse, en Allemagne, je les afficherais ici et nous leur cracherions au visage. Mais les Allemands, qui ont joué avec cette matière sacrée qu'est le cœur humain, comment les mépriser assez ? Ils n'ont pas de psychologie, dit-on ils connaissaient au moins celle des lâches et, vils entre tous, ils l'exploitaient.

Ce qui se passa ensuite entre Alice et cette femme, on ne le saura jamais. Elles sont mortes l'une et l'autre. Léonie Vanhoutte a pu recueillir, dans des conversations hachées de prison, les confidences dont j'ai tiré ce qu'on a lu. La scène à travers le mur hantait douloureusement le souvenir de toutes les deux. Pour le reste, nous verrons que Louise de Bettignies commit l'imprudence de confier à l'ignoble femme quelques lignes de sa main destinées à Charlotte. Elle ne dit pas un mot du « service ». Aucun nom ne lui échappa, sauf on ne comprend pas pourquoi, celui d'un agent qu'elle avait à peine utilisé, le voiturier De Saever : il fut arrêté sur-le-champ. Elle parla surtout de Charlotte, s'inquiétant de son état, suppliant la messagère si charitable d'encourager leur voisine à nier jusqu'au bout.

Son travail fini, on retira le « mouton » pour l'envoyer à d'autres besognes. Et Goldsmith fit comparaître Louise de Bettignies.

- Direz-vous encore, lui cria-t-il dès son entrée, que vous ne connaissez pas cette Vanhoutte? Vous lui avez écrit.

- Moi ? pas vrai ! répondit-elle avec force.

- Et cela, qu'est-ce que c'est ?

Il levait vers la lumière une feuille de papier où apparaissaient en transparence des caractères tracés au jus de citron. 
- Vous lui donnez des conseils de prudence, à votre amie. Bonne idée ! Mais il n'aurait pas fallu laisser traîner ce papier-là.

Il avait, comme d'habitude, son revolver chargé sur la table. Il le prit dans sa main, le soupesa et dit froidement :

- Douze balles dans la peau, mademoiselle Dubois ; c'est tout ce que vous valez.

La jeune fille haussa les épaules. On lui présenta un indicateur de chemins de fer trouvé dans la valise de Charlotte, rue des Aduatiques. Sur l'une des pages, une rectification à l'horaire avait été portée de la main d'Alice.

- Et cela, dit-il, ce n'est peut-être pas votre écriture ?

Ce qu'elle répondit et comment se poursuivit l'interrogatoire, on ne le trouverait qu'au dossier de l'instruction, que je n'ai pas eu sous les yeux. Et ce serait la version allemande, qui est suspecte. Ce qu'on sait, c'est qu'à la suite d'une scène dont la violence dut être extrême, Louise de Bettignies convint qu'elle connaissait en effet Léonie Vanhoutte.

Cinq minutes plus tard, le magistrat, ayant fait rentrer Alice dans sa cellule, s'amusait à torturer Charlotte. Il avait souvent auprès de lui, notamment ce jour-là, un secrétaire qui parlait admirablement le français. Cet homme se flattait d'avoir été pendant six ans le représentant d'une importante marque d'automobiles et de cycles à Lille. Il citait la maison et ajoutait :

- À moi, au moins, vous devriez répondre. Je ne suis pas contre les Français. Traitez-moi comme un compatriote.

- Ah ! non, taisez-vous ! lui disait la jeune fille excédée.

Goldsmith n'avait jamais paru si aimable. Il se montra tour à tour flatteur, compatissant, jovial. Elle le voyait mentir avec un cynisme qui l'eût exaspérée ; mais son jeu était par ailleurs si savant, si souple, qu'elle-même y prenait plaisir. Que risquait-elle ? Sa réponse était toujours prête. Elle niait, puis niait encore.

À elle aussi, il montra le papier aux caractères transparents. Il le fit brutalement, en coup de théâtre. Elle ne broncha pas. Il essaya de l'émouvoir avec l'inscription sur l'indicateur. Pas de réponse.

Il se leva comme un fou. 
- Mais avouez donc que vous la connaissez !

- Non! Non et non!

- Bien, dit-il. Garde, ouvrez la porte !

Alors Louise, pâle comme une morte, entra dans le prétoire et, les mains jointes, le regard vers la petite Vanhoutte :

- J'ai avoué que nous nous connaissions ! s'écria-t-elle. Pauvre petite, pardonnez-moi ! Tout à nous deux maintenant !

Et elles se jetèrent dans les bras l'une de l'autre en sanglotant.

Les Allemands en savaient assez. Ils les séparèrent brutalement.

Une seule fois, ils les remirent en présence mais elles puisaient à se regarder l'une l'autre une force qui les rendait invincibles. Alors Goldsmith prit le parti de les interroger séparément, disant à chacune que l'autre avait fait des aveux. Elles tinrent bon, et c'est très remarquable. Songez que Miss Cawell, dès le premier interrogatoire, ajouta foi aux propos de son instructeur, qui se vantait de posséder la liste de tous ses complices. Cette honnête femme tenait la sincérité pour une vertu, en prison comme ailleurs. Elle donna des noms, des adresses, et ceux mêmes qu'on ne lui demandait pas. Elle perdit, par excès d'honneur devant des félons, de braves gens qu'on n'eût pas songé à inquiéter, Louise de Bettignies et Léonie Vanhoutte, dont l'intelligence et le caractère étaient hors de pair, eurent tout au plus quelques menues faiblesses.

- J'ai avoué de très petites choses, qu'on me disait qu'Alice avait avouées, confesse aujourd'hui la survivante.

Et c'est exact. Elle a dit, par exemple, qu'elle avait copié, à la prière d'Alice, des rapports peu importants et les avait apportés à Bruxelles. Elle risquait ainsi de perdre Louise de Bettignies et elle-même. Mais le misérable qui avait mis un «mouton » dans la cellule d'Alice avait, pour obtenir cet aveu, commis un autre crime. Reprenant la lettre écrite au jus de citron, il osa en donner à Charlotte une lecture fausse. Il fit croire à cette pauvre petite que sa compagne lui écrivait : «J'ai avoué que nous portions des rapports et que vous en avez transcrit. Dites cela, et rien de plus. Mais dites comme moi. » Elle nia tout de même. Alors cet Allemand fit une vilaine chose : « Je vais faire arrêter, lui dit-il, vos vieux parents. Eux, me diront la vérité. » Elle eut pitié de son père, de sa mère. Elle eut peur 
surtout que ceux-ci, sans défense contre tous ces policiers, ne fissent, sans y prendre garde, connaître des complices. Elle hésitait encore.

- Mais puisque Alice vous écrit d'avouer ! lui cria-t-il.

Elle céda.

De ce jour, il ne cessa de répéter à Charlotte que cette Bettignies la chargeait sans cesse pour se sauver elle-même.

- Vous avez été bien sotte, ajoutait-il, de la suivre comme un caniche. Tirezvous d'elle!

À Alice, il rapportait complaisamment les aveux de la pauvre enfant. Il voulait les dresser l'une contre l'autre et les pousser au dégoût, puis au désespoir, peutêtre aux dénonciations. Il perdait sa peine : Charlotte était triste, et Louise de Bettignies, quand elle arrivait au prétoire, jetait des flammes. Elle et Goldsmith étaient comme feu et eau ; agressifs et têtus tous les deux, ils se battaient avec une sorte de volupté, mais lui pour la perdre, elle pour sauver tous ceux dont elle tenait la vie dans sa main.

La noblesse de ces deux femmes, c'est d'avoir tout subordonné, sans une défaillance, au souci de rester seules en cause. Il eût été mieux pour elles-mêmes qu'elles ne fissent jamais l'aveu qu'elles se connaissaient. Était-ce possible ? Il fallut, en tout cas, deux félonies pour les y contraindre.

Cependant, Charlotte tremblait d'avoir perdu l'amitié de son admirable petit chef. Elle eût voulu lui parler, au moins la voir et rencontrer ses yeux. Elle réussit un jour, puis une autre fois, à apercevoir sa silhouette.

Au bout de chacune des longues galeries de près de quatre-vingts mètres où débouchent les cellules de Saint-Gilles, se trouve un étroit couloir aboutissant à une rotonde dallée, de dix mètres environ de diamètre, très éclairée par le haut et bordée de vingt-quatre petites portes vitrées de bleu. À travers le bleu foncé de ces vingt-quatre vitres, on aperçoit autant de jardinets, en forme de tranches de tarte. De hauts murs de briques séparent toutes ces tranches ; au fond est une grille comme celle des fauves dans les ménageries ; on a vue par delà sur des plants de choux, puis sur le mur qui clôt la prison ou sur un autre, cachant le préau de la galerie voisine. Les préaux, c'est ainsi qu'on nomme ces cellules triangulaires à ciel ouvert, sont fleuris l'été et proprement entretenus toute l'année. Un massif, 
que les prisonniers français appelaient « quart de brie », en occupe le sol presque entier, laissant juste une piste le long des deux murs et de la grille. Chaque jour, les prisonniers sont conduits dans un de ces étroits jardins pendant une heure. On règle les entrées et les sorties de telle sorte qu'ils ne puissent pas communiquer entre eux. On les enferme et, du centre de la rotonde, un seul gardien surveille tous ces êtres bleus qui déambulent sur fond bleu. C'est une heure de détente, presque de bonheur. On regarde les fleurs à ses pieds, et le ciel libre sur sa tête. Par la grille du fond, on arrive, si la sentinelle qui se promène dans les choux n'est pas enragée, à communiquer avec les voisins. Les Allemands, qui le savent, veillent d'ailleurs à ne pas mettre côte à côte certains détenus. Pour repaître ses yeux de Louise de Bettignies, Charlotte se plaçait à côté de la rotonde contre la porte vitrée, en s'effaçant de son mieux. Ainsi le gardien ne pouvait guère la voir, et elle demeurait là de longues minutes chaque jour, au lieu de faire la promenade, pourtant si nécessaire.

Deux fois elle eut l'émotion de voir déboucher du couloir son amie. La pauvre Alice avançait tristement, puis se dirigeait vers l'une des portes bleues, qui s'ouvrait et se refermait sur elle. Cette vision bouleversait la petite curieuse. Sa « Mademoiselle »si pimpante, si délurée, était-ce ce fantôme penché, qui se traînait sur les dalles silencieuses ?

Comment lui parler ? Bien qu'elle se tînt en garde, depuis l'histoire de la femme Ladrière, contre les voisines suspectes, elle entreprit, mais sans succès, de lier conversation autour d'elle par les tuyaux de chauffage. C'était pourtant ainsi qu'elle avait conversé bien des fois, tout au début de sa première instruction, avec Gabrielle Petit. Maintenant elle était loin de cette admirable patriote belge, dont le procès aurait lieu dans quelques jours ; loin aussi d'Alice, qu'on ne laissait pas à sa portée ; Louise Thuliez était partie en Allemagne depuis longtemps. Et le temps passait. L'hiver était venu. La prison était chauffée, certes, mais nos deux prévenues portaient toujours les vêtements et le linge du jour de leur arrestation. Et point de fil ni d'aiguille pour réparer ou rapiécer. Les corsages se perçaient aux coudes. Et les bas étaient pleins de trous, les chaussures aussi. On ne les interrogeait plus, ces messieurs étant à la recherche ingrate du chef de leurs mystérieuses prisonnières. Pas un instant ces psychologues ne pensèrent qu'ils tenaient celle qui avait tout conduit. Ils ne doutaient pas qu'elle eût abordé, sinon traversé la frontière et transporté du courrier. Ils arrivèrent tant bien que mal à reconstituer quel- 
ques-unes des étapes de son service, mais sans certitude, sans preuves pour arrêter les complices. Un jour vint où il fallut bien clore l'instruction : ils avaient de quoi faire fusiller les deux captives, mais ils les tenaient pour des comparses, et c'est de fort mauvaise humeur qu'ils signèrent leur renvoi devant le conseil de guerre.

Le matin du 3 mars, elles étaient toutes deux dans le préau et se tenaient contre la vitre de couleur, regardant vers le couloir d'accès. La plupart des détenues faisaient comme elles. On savait dans la prison que Gabrielle Petit avait été jugée la veille et personne ne connaissait encore le verdict. On espérait la voir à la promenade : c'était son heure. Elle arriva en effet. Elle marchait de son grand pas fier. C'était une belle fille, pleine de sang. Elle saisit elle-même la poignée d'une des petites portes et disparut dans son jardinet comme dans une trappe. Les autres quittèrent leur observatoire et elles reprenaient avec mélancolie la promenade coutumière sur les étroites pistes en triangle, quand un chant semblable à un cri emplit le ciel :

\section{Salut ! ô mon dernier matin!}

On dut secourir une détenue qui, à ces mots, était tombée sur le sol, défaillante. D'autres s'agenouillèrent. Gabrielle Petit, comme un oiseau chante le printemps, annonçait à ses sœurs qu'elle allait mourir. 
LA GUERRE DES FEMMES.

Histoire de Louise de Bettignies et de ses compagnes.

Chapitre IX

L’AUDITEUR STOËBER

$\underline{\text { Retour à la table des matières }}$

Les Allemands, pendant la guerre, confiaient à des magistrats de carrière l'instruction des petites affaires. Pour les crimes, ils jugeaient que la police secrète, dite police criminelle, leur rendrait des services plus sûrs ; et c'est ainsi que Louise de Bettignies fut livrée pendant ses cinq mois de prévention au policier Goldsmith, comme Miss Cawell l'avait été au policier Henry Pinkhof. Ce dernier, pour avoir habité longtemps Paris, où il vendait, dit-on, des parapluies, connaissait non seulement notre langue, mais nos manières, nos gestes, les mots que nous faisons. Goldsmith aussi ; car ces gens-là appartenaient, comme ils s'en flattaient, à « la même boîte » : c'étaient de misérables agents d'espionnage. Ainsi une noble fille de notre sang dut subir la double disgrâce d'être injuriée en français et par un espion. Pendant l'occupation, le parler de chez nous était un refuge. On chérissait ses sons familiers, sous lesquels on échangeait des pensées fraternelles, et l'on se scandalisait comme d'un sacrilège si le maître proférait sa pensée hostile avec des mots amis. Quant aux espions, leur nom faisait horreur aux âmes délicates. Notre langue, si riche, n'a malheureusement qu'un mot pour désigner les bas agents 
qu'on utilise en les méprisant et certains héros farouches qui vont chez l'ennemi pour lui voler ses secrets. Ces derniers font plus que d'exposer leur liberté et leur vie : ils acceptent d'être suspectés jusque dans leur honneur. Il faut les honorer d'autant plus, quand on les a discernés. Pour Louise de Bettignies, pour Léonie Vanhoutte, la question ne se posait point. Jamais elles n'ont été voir les Allemands chez eux. Elles n'acceptaient pas qu'ils fussent chez nous; elles répondaient à leurs coups par d'autres coups, à la force par la ruse. Elles allaient crier aux combattants : "Voilà ce rue font, ce que disent, ce que préparent ces maudits. Défendez-vous et comptez sur nous, qui paraissons soumises et qui les haïssons. » Elles n'espionnaient pas : elles faisaient la guerre. Alors on peut soupçonner leur mépris pour les beaux garçons, forts en couleur, en muscles, qui les malmenaient en prison ou à l'audience. C'étaient, pour ces combattantes, des embusqués.

M. le conseiller Stoëber mérite une place de choix dans la galerie de ces personnages antipathiques. Je parlerai de lui sans fiel. On va lire le récit de la séance. du Conseil de guerre séant à Bruxelles le 16 mars 1916. Après quoi, chacun pensera ce qu'il voudra de l'homme qui survit quelque part en Allemagne, la conscience chargée des durs souvenirs que je vais rappeler.

Alice et Charlotte, qu'on n'interrogeait plus depuis huit jours, sentaient que l'heure du jugement était venue. Elles s'y préparaient en ranimant leurs âmes et en parant avec un soin coquet leurs petites personnes amaigries. Chacune possédait un pauvre col de lingerie, pour mettre une, note fraîche sur sa jaquette usée ; ce col, elles l'avaient lavé, puis étendu sous le matelas. Alice était occupée, le soir du 15 mars, à le caresser après l'avoir mis à son cou, quoiqu'elle n'eût point de glace pour se mirer, quand un gardien vint l'avertir qu'on la traduirait le lendemain devant ses juges.

On les tira de leur cellule au début de la matinée, vers sept ou huit heures. Si vous demandez à Charlotte de préciser, elle vous répondra qu'en prison elle n'avait point de montre, ni, aux environs, de cloches bavardes pour régler sa vie à la cadence des êtres libres. On les fit monter séparément dans la même voiture cellulaire. Louise de Bettignies y fut introduite la première. Charlotte, qui aperçut de loin sa compagne, la trouva gaie ; elle avait l'air de partir à la promenade. Où les menait-on ? Non seulement elles l'ignoraient, mais la petite Vanhoutte ne le savait pas encore quand, faisant avec elle à Bruxelles le pèlerinage des lieux où 
elle avait souffert, je la priai, au cours du dernier été, de me conduire à la salle d'audience. Nous nous rendîmes ensemble au Palais de Justice.

- J'ai été jugée, dit-elle à un gardien, à la salle du Sénat. Peut-on nous la montrer?

- Mais ce n'est pas ici, mademoiselle. C'est rue de la Loi, au Palais de la Chambre des Représentants.

Elle rougit de son ignorance ; et moi j'ai trouvé cela charmant.

Le conseiller Stoëber avait imaginé de faire juger les procès politiques dans la salle des séances du Sénat : c'était un cadre majestueux pour la justice allemande ; et, pour ce petit juge vaniteux, une tribune sonore.

Alice et Charlotte, extraites du panier à salade, montèrent lentement côte à côte un escalier de pierre aux lignes monumentales mais paresseuses. Sur ces marches basses, un tapis de haute laine rouge était couché ; les pieds froids de ces petites en savouraient la caresse au travers de leurs chaussures percées. Ce luxe officiel les amusait, les réchauffait aussi. À mi-hauteur est un large palier, avec une banquette de velours pourpre. On les y fit asseoir un instant. Bien qu'un soldat les séparât avec sa baïonnette au bout du fusil, elles tentèrent d'échanger quelques mots. Louise, contrainte brutalement an silence, coula vers son amie un regard malicieux et, mettant deux doigts à ses lèvres, lui envoya, avec son baiser, du courage pour le reste du jour.

On les fit alors pénétrer dans la salle. Imaginez l'impression que dut leur faire cet hémicycle vaste, silencieux et vide, où leurs pas mêmes, sur les tapis lourds, étaient sans bruit. Louise, plus curieuse, promena ses yeux sur les tribunes et le haut plafond vitré, tandis que Léonie Vanhoutte se laissait conduire dans la travée centrale et, s'engageant dans le quatrième rang des fauteuils à droite, allait occuper l'un d'eux. À ses côtés, les deux soldats chargés d'elle s'enfonçaient béatement dans d'amples sièges de sénateurs belges. Car le banc des accusés, dans ce singulier tribunal, c'étaient des chaises curules aux proportions imposantes; sur leur fond grenat, de grands lions jaunes étalaient des formes tourmentées. Les soldats qui s'asseyaient alors sur le lion belge se prenaient pour des vainqueurs : ce lion-là monte maintenant avec assez de majesté la garde sur le Rhin. Louise de Bettignies prit place avec ses deux soldats de l'autre côté : elle allait à elle seule représenter pour le tribunal toute la gauche de l'assemblée. À droite, d'autres ac- 
cusés vinrent s'asseoir, à grande distance les uns des autres, autour de Charlotte et derrière elle. Les deux jeunes filles les virent entrer avec curiosité. Ce fut d'abord le voiturier De Saever, gaillard solide, de ceux dont on dit familièrement qu'ils sort bien balancés, avec des bras longs et souples et le poing lourd; son visage débonnaire, qu'adoucissait encore une longue moustache grisonnante et soyeuse, se durcit dès l'entrée à la vue de Louise de Bettignies. Puis un pauvre homme entra, la mine hébétée : celui-là, on dut le pousser comme un aveugle jusqu'à sa place. Cbarlotte vit arriver ensuite et salua au passage Alexandre, avec qui on l'avait confrontée à Anvers. Et la dernière victime fut introduite : une vieille femme impotente et prostrée. En tout, six accusés, cinq à droite, une à gauche. Au-dessus des fauteuils de droite s'ouvrait une vaste tribune réservée alors au gouverneur von Bissing. Celui-ci, qui devait assister pendant plusieurs heures aux débats, ne vit bien qu'un visage, et ce fut celui de Louise de Bettignies. Les longs regards qu'échangèrent cet homme et cette petite, on envie Dieu d'avoir connu quel feu courait en ceux qui montaient, quelle gêne en ceux qui descendaient.

Le Tribunal fit une entrée théâtrale. Devant les accusés debout et les soldats au port d'arme, une trentaine de personnages pomponnés, astiqués, casqués, gantés et décorés se placèrent, les uns derrière une grande table au pied de la tribune ; d'autres, simples invités. un peu plus loin. Tout ce monde resta longtemps debout, échangeant des saluts, des redressements de la tête et du corps, des chocs de talons, des exclamations gutturales, des sourires à pleines dents. Louise de Bettignies mourait d'envie de faire asseoir ces lourdauds, dont les politesses devenaient fatigantes. Les juges posèrent enfin leurs casques sur la table, leurs gants blancs auprès des casques et leurs corps sanglés dans les fauteuils. Un général présidait : c'était un homme de cinquante-cinq ans, moustachu et grisonnant, qui ne comprenait que l'allemand et, ne parlait peut-être aucune langue, car il ne pipa moi de l'audience. Il ne s'était d'ailleurs pas mis au centre de la table, mais à la droite d'un personnage plus jeune, M. le conseiller Stoëber.

Dans les tribunaux de guerre allemands, un homme seul interroge les accusés, dirige les débats, conduit l'affaire à sa guise, parle, crie, tempête, malmène ceux qu'il veut perdre, sauve qui lui plaît, joue à la fois tous les rôles et fait la loi aux juges, qui ne sont que des jurés, même au président, qui n'est qu'un soliveau : c'est le commissaire du gouvernement, qu'on appelle chez eux M. l'auditeur. 
À Bruxelles, depuis l'affaire Cawell, les fonctions d'auditeur étaient occupées par Stoëber, homme terrible, qu'on eût dit fait sur mesure pour un tel rôle. Un comédien chargé de représenter à la scène l'accusateur devant un conseil de guerre allemand prendrait d'instinct le visage de cet homme et ferait tous ses gestes. Il arrivait de ce qu'il appelait « le front », c'est-à-dire des tribunaux divisionnaires ; il est important de savoir que de tels hommes, qui envoient les autres à la mort, sont d'ordinaire assez petits devant elle. Nous verrons ce, qu'il faut penser de Stoëber, auditeur : Stoëber, soldat allemand, est une triste chiffe et c'est un soldat français qui le lui dit. Dame! c'était un beau garçon. Grand, svelte, plein de sang, les joues dures et roses coupées par une belle moustache sur des dents éclatantes,, il se bichonnait avec des soins de femme et sa raie tombait par derrière dans son faux col avec une rectitude très honorable pour son coiffeur. Sa voix forte, qui eût pu mettre en mouvement tout un bataillon, il la lançait, en s'écoutant, contre des jeunes filles. Il a dit un jour à l'avocat Sadi Kirschen, de Bruxelles : «Si vous me malmenez plus tard dans vos écrits, où que je serai, J'userai du droit de réponse, et je rectifierai. » Me Kirschen a publié chez Rossel, à Bruxelles, en 1919, un ouvrage où il a parlé librement de cet ogre, et l'ogre s'est gardé de répondre ${ }^{2}$. Ils étaient fous d'orgueil tandis qu'ils se croyaient les maîtres. Ils sont, à l'heure présente, assoiffés de revanche ; ils se terrent, avant de tenter un nouveau crime. Que leur importe ce que nous disons d'eux, s'ils rêvent de nous mettre un bâillon sur la bouche! Il faut, pour demeurer en état de défense, que nous nous souvenions toujours ; et je bénis mes petites héroïnes, parce qu'elles sont belles, de m'avoir fourni une histoire attachante pour rappeler aux étourdis que nous sommes le danger d'hier et celui de demain. Stoëber parlait un français correct ; il martelait ses mots et les accompagnait de regards foudroyants. Pour ce qu'attendaient de lui les Allemands, c'était un excellent magistrat, d'une intelligence suffisante et d'une âpreté peu commune dans la discussion ; mais l'âme était basse et l'esprit vulgaire. Pour l'œuvre infâme qu'a été le meurtre de Miss Cawell, il fallait un garçon sans scrupules : Stoëber a accepté et rempli la tâche avec un empressement qui me donne le droit, parce que je suis un honnête homme, de le mépriser. Et sur la délicatesse de ce cœur allemand, une anecdote vous fixera. Un Belge, agent d'assurances, était poursuivi pour espionnage dans l'affaire Parenté et consorts, jugée au Sénat

2 Devant les Conseils de guerre allemands, 1 vol. 8 francs. 
du 2 au 6 mai 1916. L'accusé était un vieillard, homme simple et correct, assez durement traité par la vie et qui méritait respect et pitié.

- Puisque vous êtes assureur, lui cria Stoëber en pleine audience, je pense que vous avez pris soin de contracter vous-même une assurance sur la vie.

L'accusé restant muet, l'auditeur se frotta les mains et ajouta, avec un rire avantageux :

- Pas assuré ? Vous avez eu tort, mon ami, car nous allons vous fusiller.

Ces mots-là jugent un homme, et une race.

Le 16 mars, Stoëber interrogea d'abord les comparses. Alexandre et sa mère répondirent en flamand. Stoëber posait les questions en allemand, afin d'être entendu par les juges. Un interprète les répétait dans la langue des accusés, puis traduisait pour Stoëber la réponse, et celui-ci prenait souvent plaisir à la répéter à son tour, afin de secouer de sa voix d'acier les militaires somnolents qu'avait un peu hébétés le ronron du soldat interprète et des pauvres gens à la barre.

Quand ce fut le tour du brave homme dont j'ai dit qu'il était entré dans la salle en titubant comme un aveugle, ni Stoëber ni l'interprète n'en purent tirer un mot. Celui-là avait pris le parti de faire la bête ; quoique la nature le prédisposât à ce rôle, il jeta Louise de Bettignies dans l'émerveillement ; elle savait par expérience qu'il fallait être bien fin pour nier sans défaillance ; peut-être était-il stupide et roué tout à la fois, le pauvre homme ; il devait s'en tirer ce jour-là, mais pour tomber un peu plus tard. Je vous dirai sa navrante histoire tout à l'heure.

Voici le tour du voiturier De Saever. Celui-là se croyait une victime de Louise de Bettignies. C'est contre le «mouton », la femme Ladrière, qu'il aurait pu tourner sa colère, contre les policiers allemands aussi. Car ces derniers ont usé contre lui de moyens infâmes. Ils l'ont grisé le jour de son arrestation pour le faire parler. Et j'ai des raisons de croire qu'ils ont commis un autre crime. Louise de Bettignies avait probablement confié à la femme Ladrière, en même temps que la lettre au jus de citron destinée à Charlotte, une lettre pour De Saever. Ce n'est pas cette lettre qu'ils ont montrée au pauvre homme, mais une autre, fabriquée de leurs mains. Ils ont eu l'idée baroque de la signer : Comtesse de Bettignies, et, la tendant à cet homme, ils lui ont dit : «Voilà qui vous apprendra à vous fier à des comtesses. Vous serez fusillé par la faute de celle-là. » Jamais ma petite héroïne 
n'a signé ni ne s'est fait appeler comtesse. Seuls des Allemands, fabriquant un faux, ont pu imaginer une chose pareille. La lettre que De Saever a vue et qui devait l'indisposer si fort contre Alice, ce n'est pas elle qui l'avait écrite. Le brave homme a gardé quelque rancune contre la mémoire de Louise de Bettignies ; ellemême, avant de mourir, a souvent pensé avec douleur qu'elle avait compromis cet homme par une imprudence. Mais on faisait, en présence de l'ennemi, assaut de générosité ; et quoi qu'eussent tenté les Allemands pour inciter De Saever à dénoncer la jeune fille et à la perdre, il ne dit pas un mot contre elle à l'instruction ni à l'audience.

Il avait pourtant la langue bien pendue et le verbe haut.

- Vous n'avez pas le droit, cria-t-il à Stoëber, de me condamner sur des interrogatoires que j'ai subis en état d'ivresse.

Et quand le policier qui avait instruit son affaire leva la main pour prêter serment,

- Ne jurez donc pas, lui jeta-t-il à la face, puisque vous allez mentir !

On dut renvoyer à sa place sans avoir rien tiré de lui cet accusé trop irascible et bavard.

- Vanhoutte, approchez!

C'est l'interrogatoire de Charlotte qui va commencer. Elle est conduite par ses deux soldats devant la table des juges. On a placé là une chaise, où on la prie de s'asseoir. Elle n'a pas peur et ses réponses sont prêtes. Mais on tarde à lui adresser la parole, et Stoëber fait des gestes en regardant du côté gauche de la salle. Que se passe-t-il ? Elle tourne vivement la tête et voit qu'on emmène Louise de Bettignies. Tout à l'heure, elle-même sera écartée tandis qu'on interrogera sa compagne. Même à cette audience publique, elles demeurent au secret.

Je ne rapporterai pas l'interrogatoire des deux jeunes filles. Il faudrait en demander le texte aux Allemands, et c'est ce que je n'ai point tenté de faire. Léonie Vanhoutte n'a pas de souvenirs précis. Elle a seulement l'impression que les façons de Stoëber, au lieu d'intimider les prévenus, les excitaient, el qu'elle-même, après les ripostes violentes du Flamand De Saever, se sentait prête à sauter à la tête de ses juges. L'auditeur, d'abord poli, en vint rapidement aux violences.

Vous mentez ! lui disait-il. Tant pis pour vous ! On vous fusillera. 
Il se livrait à des variations sur ce thème délicat, lui répétant qu'elle était bonne à mettre au mur et qu'on la ferait bien taire avec douze balles dans la peau.

- Vous rendez-vous compte, lui avait-il demandé d'abord, de la gravité de l'accusation qui pèse sur vous ?

- Je connais la valeur de mes actes, répondait-elle. J'ai conscience d'avoir été une Française irréprochable.

- Vous êtes une espionne.

- Prouvez-le.

Ils firent alors donner lecture de ses aveux à l'instruction. Elle se défendait à belles dents, n'admettant pas qu'on en fît état, parce qu'on les lui avait arrachés en la menaçant d'arrêter ses parents. Goldsmith, appelé en témoignage, fit d'elle un tableau perfide, la représentant comme une rouée dont on ne se méfiait pas au début, à cause de sa douceur.

- Et elle n'a pas de cœur, ajoutait-il. Vous pouvez aujourd'hui lui dire que vous allez arrêter son père et sa mère. Vous verrez qu'elle vous tiendra tête.

C'était vrai. Bien ne l'eût fait fléchir à cette minute, pas même, sa piété envers ceux qui là-bas, à Roubaix, priaient dans l'angoisse pour que Dieu la leur gardât. Elle avait alors la tête toute bourdonnante des paroles qu'à travers la paroi de sa cellule elle avait échangées quelques jours plus tôt avec Gabrielle Petit.

- Mais non, lui avait dit cette fille extraordinaire, je n'ai pas peur. Ils m'ont condamnée à mort et vont me tuer. Je ne tremble pas en y pensant. Ce sera si vite fait, ma petite ! Songez ! Je n'aurai même pas le temps de réfléchir... Si j'étais un soldat à la guerre, il faudrait mourir aussi, et ce serait plus long. Et puis, c'est pour ma Belgique...

Léonie Vanhoutte ajoutait à sa force, qui était grande, celle que la petite Belge, prête à mourir pour son pays, lui avait passée en lui parlant à genoux par les conduits de chauffage de la prison. C'est ainsi que ces jeunes femmes, s'entraînant l'une l'autre vers les cimes, dominaient leurs bourreaux.

- C'était beau tout de même, notre procès, dit quelquefois encore Charlotte en joignant les mains. 
Et j'ai eu beaucoup de mal, quand j'ai visité le Sénat avec elle, à l'arracher des tribunes d'où nous dominions cet hémicycle plein de ses plus ardents souvenirs. Oui, c'était beau de sentir en soi une grande âme ! Ce jour-là, bien qu'il fût à tout propos question de sa mort, elle vivait. Il y a des gens qui ne vivront jamais.

Elle se rendit compte, l'interrogatoire fini, que Stoëber ne la manquerait pas. Cet homme, qui parlait ici en maître, voulait qu'on la fusillât et le voulait bien. Si elle était brave, elle aimait aussi la vie ; et le tour de ses pensées, quand elle se retrouva dans son grand fauteuil entre deux soldats, eût été mélancolique si, tout de suite, ses yeux, son cœur, tout son être n'avaient été divertis, au sens où l'entendait Pascal, par le plus admirable spectacle.

Louise de Bettignies, frêle et gracieuse dans ses vêtements usés, s'avançait à la barre. Stoëber lui demandait son nom, ses prénoms ; et l'interprète s'apprêtait à répéter en français la question, quand, se tournant vers ce subalterne, elle lui imposa silence :

- Ne prenez pas tant de peine, dit-elle, j'ai compris.

Et elle répondit en français.

- Parlez allemand, puisque vous le pouvez, lui dit Stoëber. Nous irons plus vite.

- Non, monsieur, je suis Française. Vous avez un interprète ; usez-en, mais qu'il ne me trahisse pas : je surveillerai ses traductions.

Charlotte n'en entendit pas davantage. On la fit disparaître.

À ce début, Stoëber sentit que la partie serait dure. Il alla tout de suite au fait et lut à Alice la déposition de Charlotte à l'instruction. À quoi elle répondit :

- C'est une déposition sans valeur, que l'instructeur a obtenue par des moyens déloyaux.

On appela aussitôt Goldsmith à la barre. Il fit le bon apôtre, assura que Charlotte, excédée de la tyrannie exercée sur elle par cette jeune aristocrate, avait préféré se montrer sincère et avouer ; qu'au surplus Alice était insupportable et d'un mysticisme religieux exaspérant, même pour sa compagne.

- Cette jeune fille et moi, répliqua-t-elle, nous ne sommes pas des complices. Je la connais : voilà tond. J'ai trahi mon amitié pour elle dans une lettre écrite au 
jus de citron, que vous m'avez arrachée par un procédé infâme ; je l'ai embrassée devant vous le jour où vous nous avez confrontées. C'est mon amie : vous savez cela, et vous ne saurez pas autre chose.

Comme Goldsmith ricanait et que Stoëber tenait en mains la lettre fatale, elle s'écria :

- Lisez cette lettre ; lisez-la devant les juges ils verront que j'avais pitié de cette petite en prison. Est-il défendu d'avoir de la compassion pour une innocente à la torture?

- Vous lui recommandiez de se taire...

- Et je le lui dirais encore si, contre tout droit, vous ne l'aviez écartée d'ici. Je sais pourquoi vous n'avez pas voulu me laisser entendre sa déposition ni qu'elle connaisse la mienne : c'est qu'on a mis un mensonge entre nous deux...

Et elle regardait la lettre. Elle sentait, quoiqu'elle ne le sût pas encore, que ces misérables avaient commis avec ce papier une félonie.

- Lisez cette lettre, répétait-elle.

- Le tribunal la connaît, répondit Stoëber, et elle vous accable. Vous commandiez à votre complice de faire silence : c'est que vous aviez quelque chose à cacher.

- J'ai tout à vous cacher. Vous êtes l'ennemi.

- Vous êtes une espionne,

- Ne dites pas ce mot devant l'homme qui est là, fit-elle en regardant Goldsmith avec dégoût.

Sa vigueur excitait Stoëber. Ce triste individu, peu accoutumé à de pareilles ripostes féminines, devait avouer plus tard à l'avocat Kirschen, qui m'a rapporté le propos, que cette petite Française lui avait paru une fière créature, d'une noblesse peu commune. Pour l'heure, il la tenait entre ses griffes; et, pour la perdre, la pousser à des mots compromettants, peut-être à des aveux, il s'acharnait à l'exaspérer, en l'insultant.

Je ne connais que des bribes de ce duel entre elle et cet homme : ce sont des mots rapportés par elle-même, çà et là, dans des propos de prison. Elle fut surtout frappée des façons grossières de Goldsmith et de Stoëber et, par contraste, de 
l'apathie des cinq officiers dormeurs qui recevaient tour à tour en plein nez ou dans la joue, sans qu'en fût troublée leur respiration pesante, les éclats de voix des deux parties.

J'ai sous les yeux un carnet appartenant à une autre patriote admirable, la princesse Marie de Croy, et j'y lis ces mots de la main d'Alice : Louise de Bettignies, condamnée à mort à Bruxelles, le 16 mars1916, pour avoir refusé de parler.

Elle sentait bien, la brave petite, que son obstination à ne rien révéler à ses juges la perdrait, mais resterait son plus haut titre de gloire.

Stoëber la tortura pendant une longue heure sans tirer d'elle un mot qui servit ses desseins. Elle réalisa ce prodige de rester seule en cause quoiqu'elle eût plus de cinquante complices. Elle a donné, elles ont donné toutes les deux, la vivante et la morte, cet exemple magnifique de tout souffrir sans une défaillance, et pas seulement du cœur ou de la volonté, sans une défaite de leurs intelligences féminines.

- Le mal que je vous fais en sauvant tous ceux que vous cherchez, leur cria-telle, vous voudrez que je le paie de ma vie. Eh bien, tuez-moi, mais vous ne me ferez pas parler !

Et elle levait le menton, son menton volontaire mais si fin et, puisqu'elle était femme, fait pour les caresses. Son front du moins connaîtrait celles de la gloire, et c'était de quoi, dès cette heure, la griser d'un beau plaisir.

On s'étonnera cependant que tous ces policiers retors n'aient rien découvert alors ni par la suite de l'organisation si parfaite et si large qu'avait montée cette jeune fille. Ils avaient établi pour le procès une sorte de schéma du service d'Alice ; cette pièce, retrouvée par les Anglais après l'armistice, révéla qu'ils eu connaissaient toutes les étapes et les ramifications depuis Lille jusqu'à la frontière ; mais ils n'avaient pas de preuves. Et, une fois de plus, c'est un vice de leur esprit qui les mettait en état d'infériorité : partis d'une hypothèse fausse, ils n'eurent pas un seul jour l'idée de s'en dégager. Ils ne croyaient point, nous le savons déjà, qu'Alice fût le chef d'une aussi vaste organisation ; ils voulaient, ce qui est plus grave, trouver ce chef à Courtrai ; et non seulement ils s'usaient à chercher le bout du fil de ce côté, mais pour rien au monde ils ne l'eussent ramassé ailleurs. Au Sénat, Stoëber, qui le tenait dans sa main, eût été fiché de s'en apercevoir. 
Sur les dépositions de Rotselaer, de la grenouille, du policier qui avait arrêté Charlotte et de celui qui, un jour, l'avait promenée dans Bruxelles; sur les confrontations angoissantes entre les deux jeunes filles; sur la lecture des documents accusateurs, au premier rang desquels figurait une lettre anonyme, évidemment accablante et précise, mais fabriquée par les Allemands, qui avaient assemblé là toutes leurs hypothèses; sur le mépris hautain de Louise après une telle lecture, sur les mille autres incidents de cette audience tragique dont notre curiosité demanderait à tout connaître, je ne sais rien d'assez certain pour en faire état ici.

Songez que Stoëber avait fait interdire l'accès du Sénat à tout le monde, même aux Allemands. Un petit nombre d'officiers se tenaient sur des chaises, derrière les juges : c'étaient des privilégiés, des amis sûrs, qu'on voulait régaler d'un spectacle rare. Hors ces personnages, au nombre d'une vingtaine, et von Bissing, tout seul dans son avant-scène, il n'y avait dans la vaste salle que le tribunal et les six accusés avec une poignée de soldats pour les garder.

J'allais oublier les avocats, ou l'avocat. Dans la plupart des procès, notamment dans celui, grave entre tous, de Miss Cawell, on admettait que les prévenus fussent assistés par des défendeurs belges. Des personnalités éminentes du barreau de Bruxelles réussirent à se faire agréer par les plus ombrageux auditeurs et remplirent, avec zèle et piété, l'ingrate mission de plaider des causes sans espoir devant des tribunaux sans justice. Notez que, dans ce cas, les avocats n'avaient pas le droit de communiquer avec leurs clients avant ni pendant l'audience. On ne leur montrait aucun dossier. Ils arrivaient au procès les mains et la tête vides, pas le cœur : car c'était un cri de pitié qu'ils venaient jeter. La comtesse Jeanne de Belleville raconte qu'en entrant dans la salle du Sénat où elle devait être condamnée à mort avec Miss Cawell, elle reçut d'un civil debout parmi quelques autres groupés près du tribunal un salut qu'elle se garda de lui rendre. Cet homme la dévisagea tout au long des débats avec un intérêt dont elle était prête à s'offenser, quand elle connut par hasard qu'un avocat belge la défendrait ; c'était lui qui la dévorait des yeux : il étudiait sa cliente et se documentait comme il pouvait pour sa plaidoirie. Louise de Bettignies, Léonie Vanhoutte et ceux qui furent jugés avec elles n'eurent pas la consolation d'être assistés par de tels défenseurs. Sans doute Stoëber ne voulait-il point de témoinsdans cette affaire, qu'il sentait grave et qu'il faudrait bâcler sans une preuve, sans un nom. Il ne doutait pas qu'une au moins des deux 
jeunes filles fût une ennemie redoutable : on fusillerait celle-là, et l'autre si on pouvait. Mais ces histoires n'ont rien à voir avec la justice : il écarta les avocats.

Il est probable qu'un Allemand, peut-être plusieurs Allemands furent chargés d'office de dire quelques mots de défense. Qui le saura jamais ? Car Louise de Bettignies, qui entendait la langue de ces gens-là, si elle s'est aperçue qu'on plaidait, pour elle, n'en à jamais parlé. Quant à Léonie Vanhoutte et à De Saever, ils n'ont rien remarqué de semblable. Cet officier, ces officiers, qui se sont peut-être levés tout à coup et ont dit trois mots, étaient-ce un greffier, un témoin, un accusateur, un juge ? Je suppose, quant à moi, qu'un simulacre d'appel à la pitié a été fait par quelque figurant. Je suppose ; je ne sais pas.

L'audience, ouverte vers neuf heures du matin, avait été interrompue à midi pour le repas des officiers. Ces messieurs firent sans doute bonne chère, car leurs oreilles étaient rouges et leurs paupières lourdes quand ils revinrent. Aux accusés et à leurs gardiens on avait apporté la même gamelle. C'était encore le temps où l'Allemagne pouvait nourrir ses soldats. Louise de Bettignies fit avec joie la dînette sur son pupitre cossu de sénateur. Elle amusa Charlotte et tous les autres en leur montrant, avec des gestes gamins, qu'elle se régalait: depuis cinq mois, elle n'avait pas connu pareille fête ! Peu à peu, réchauffés par le repas, voilà que tous ces prisonniers oublient leur infortune et s'animent, chuchotent, bavardent, puis s'interpellent de la droite à la gauche. Les soldats, qui sont bien assis, trouvent le temps bon et inclinent à l'indulgence. Ils vont être débordés par ces écoliers indisciplinés, quand un huissier, d'une voix de tonnerre, annonce le tribunal et rétablit l'ordre.

La deuxième suspension d'audience eut lieu vers quatre heures : celle-là fut plus émouvante. La cause entendue, le tribunal se retirait pour permettre à l'auditeur de rédiger ses conclusions avec l'indication de la peine qu'il demanderait pour chaque accusé. Les juges restèrent absents une demi-heure. Les prévenus, las de cette dure journée, le cœur plein d'angoisse, ne disaient mot, ne bougeaient plus : c'étaient des fantômes dans les grands fauteuils. Seule Louise de Bettignies, l'âme en feu pour avoir lutté de toutes ses forces contre Stoëber, résistait à la mélancolie et s'agitait sur son siège. Ayant levé la tète, elle vit au-dessus de la tribune et du fauteuil du président de vastes panneaux décoratifs, dûs à Jacques de Laising ; et son visage, d'abord attentif, s'illumina, puis s'épanouit. 
- Voyez donc, dit-elle à l'un des soldats qui la gardaient, voyez ce qu'ils font là-haut.

Elle lui montrait Dumouriez et ses soldats se ruant, sous le drapeau tricolore, à la poursuite de hordes autrichiennes.

Et, lui souriant doucement, elle ajoutait :

- Ne trouvez-vous pas qu'elle est jolie, cette fresque ? Et celui-là, au milieu, qui est-ce donc?

- Ish weiss nicht, disait l'autre.

- Moi je sais. Regardez bien : c'est Louis XIV. Comme il est beau !

Sa contemplation dura longtemps; et Charlotte s'émerveillait de la voir si curieuse, si ardente à dégrossir son soldat. Celui-ci ricanait, le nez en l'air, et ne comprenait pas quelle précieuse leçon d'histoire lui donnait cette petite.

Quand le tribunal rentra, un grand silence se fit. Tout le monde étant debout, au port d'armes, accusés, soldats, juges, Stoëber donna lecture en allemand, et l'interprète en flamand pour les uns, en français pour les autres, des peines requises contre les cinq accusés.

Pour Louise de Bettignies, la mort.

Pour Léonie Vanhoutte, la mort.

Pour Georges De Saever, la mort.

Pour chacun des trois autres, les deux hommes et la femme, la prison.

La lecture finie, tous s'assirent, et les condamnés furent sèchement appelés, suivant l'usage, pour leur suprême requête.

Alors on vit approcher de la barre la petite Bettignies. Son assurance paraissait tombée. Elle parla doucement et en langue allemande, afin que Charlotte ne l'entendît point.

- Messieurs, dit-elle, je vous demande de ne pas fusiller mon amie ; elle est jeune et j'implore votre pitié pour elle ; moi, je veux bien mourir.

Elle ajouta, montrant de la main le Flamand hébété qui de toute l'audience n'avait dit mot : 
- Je voudrais aussi que vous rendiez à la liberté ce pauvre homme, qui n'a rien fait et ne comprend pas pourquoi il est ici. Songez qu'il a neuf enfants : ces petits ont besoin de lui.

Les Allemands libérèrent, en effet, celui-là. Mais on revient à ses premières amours et, fraudeur et passeur d'hommes, il reprit, à peine relâché, son aventureux métier. Un soir de 1917, tandis qu'il se dirigeait vers la Hollande avec un groupe de cinq ou six personnes, il fut tué d'un coup de feu par une patrouille. On fit, après Alice, avancer Charlotte. Elle ignorait ce qu'avait dit sa compagne.

- J'accepte ma condamnation, déclara-t-elle, et vous pouvez me fusiller ; mas je vous demande avant de mourir, et vous ne pouvez pas me la refuser, la grâce de Louise de Bettignies.

On les fit sortir. Quelques minutes plus tard, elles avaient la permission de s'embrasser et de déambuler côte à côte dans un grand vestibule, en attendant que la voiture cellulaire vint les reprendre. Premières minutes d'effusion après six mois de détention, au soir d'une journée qu'elles croyaient la dernière de leur vie ! Léonie Vanhoutte en parle encore avec des larmes dans les yeux.

- Mais non, lui disait Louise, ils ne nous tueront pas.

Et elle souriait.

- Alors, disait Charlotte, ils vont nous envoyer en Allemagne...

Alice, à cette pensée, entrait dans l'épouvante. Elle prenait le bras de sa compagne et le serrait très fort, disant :

- Ne pensons pas à cela. Jouissons du présent. Tu es là, Minou, et je suis près de toi.

Mais il faut partir. On les conduit vers l'entrée et voilà qu'au lieu du fourgon d'infamie qui les avait amenées ici le matin, les Allemands font une voiture découverte, une sorte de grande victoria. Louise et la petite Vanhoutte prennent place dans le fond. En face, sur la banquette, s'asseoient De Saever et un soldat allemand. Sur le siège, près du cocher, monte un autre soldat. Et la voiture s'ébranle, fait un beau virage dans la cour d'honneur, puis s'engage dans la rue. On était à la mi-mars. Cinq heures sonnaient et un soleil pâle caressait doucement les visages. Louise, les yeux rayonnants, regarda sa compagne, puis se leva à demi et, heurtant d'une tape amicale le dos de celui qui menait l'équipage, lui dit : 
- Voilà six mois que nous n'avons pas pris l'air, cocher. Nous avons envie de faire une belle promenade. Vous seriez si gentil de ne pas nous conduire tout droit à la prison !

Le cocher regarda le premier soldat, puis l'autre : ils acquiescèrent. Et par les belles avenues de Bruxelles, ce soir-là, passa lentement une étrange charrette de suppliciés, où l'on ne cessait de jaser, de rire et de se caresser les mains, que pour sourire aux passants et discrètement, car il ne fallait point faire de scandale, leur envoyer des saluts.

Il fallut bien rentrer à Saint-Gilles. On y accueillit les prisonnières avec une compassion dont elles furent touchées. Quoiqu'on n'ait que faire de la pitié de ses bourreaux, tel est le pouvoir d'un regard attristé, d'une parole dite en tremblant, d'un geste caressant, qu'elles ressentirent de la tendresse pour ces gardiens qui chuchotaient en les entourant : "Pauvres âmes ! on vous a donc condamnées ! Demandez ce que vous voulez! Nous désirons vous faire plaisir, chères âmes. » Car elles n'étaient plus que des âmes et sans doute avaient-elles pris leur parti de passer déjà pour des mortes. Mais ces gens allaient un peu vite. Il est très allemand de tenir pour négligeables des corps qu'on n'a pas encore tués.

Elles prièrent qu'on les laissât ensemble un peu de temps : on les autorisa à faire une promenade de deux heures dans une grande galerie haute comme une nef de cathédrale. Alice s'accrocha au bras de Charlotte comme au temps des longues étapes sur les routes flamandes; elles allèrent et vinrent, tantôt babillant comme des pensionnaires à la sortie, tantôt silencieuses pour mieux goûter l'ivresse de telles minutes.

Quand on vint leur dire que le temps était venu de rentrer dans les cellules, Louise prit son plus beau regard pour demander qu'on lui permît de garder sa compagne avec elle toute la nuit. Le directeur, qui n'était pas un mauvais homme, fit répondre qu'il ne pouvait malheureusement pas accorder cette faveur. Elles en pleurèrent toutes les deux.

- Mais c'est la preuve, chuchota l'un des gardiens, qu'on ne vous fusillera pas demain matin. Dormez donc en paix.

On leur laissa de la lumière. Léonie Vanhoutte écrivit longtemps, longtemps, puis se coucha, Louise de Bettignies, puisqu'elle aurait au moins la journée du lendemain pour se préparer à mourir, céda au sommeil. Son chapelet à la main, 
elle s'endormit, comme une enfant que le grand air et les jeux violents auraient brisée. 
LA GUERRE DES FEMMES.

Histoire de Louise de Bettignies et de ses compagnes.

Chapitre X

EN ALLEMAGNE

$\underline{\text { Retour à la table des matières }}$

On les fit sortir de leurs cellules le lendemain matin à neuf heures. En arrivant sur le perron devant lequel stationnait la voiture cellulaire qui devait les conduire à la Kommandantur, Charlotte aperçut un groupe de gardiens belges dont les mines paraissaient joviales. Le cœur battant, elle quêta une parole de ces braves gens. « Il y a du bon ! » chuchota l'un d'eux, qui accompagna ce propos d'un clin d'œil familier. On arriva vite dans la sinistre maison de la rue de Berlaimont où tant de malheureux ont appris qu'ils seraient fusillés. Dans une petite pièce, où elles se rencontrèrent avec les quatre autres accusés, elles virent entrer Stoëber, une serviette sous le bras. Il la posa lentement sur la table, en tira une feuille de papier qu'il porta à bonne distance de sa vue, puis il prit le temps de jeter un regard circulaire sur ses victimes. Quand un homme se lève ainsi au soir d'une journée d'examen et va lire les noms de quelques nouveaux bacheliers, il sait quelle angoisse étreint ses auditeurs et qu'il va en jeter beaucoup dans la désolation : il fait vite. Stoëber s'attardait. Chacun de ceux qui étaient là retenait son souffle, les yeux sur cette feuille chargée de secrets horribles ou sauveurs. Il commença enfin :

- Louise de Bettignies. Peine requise : la mort. Peine prononcée : la mort. 
Il leva les yeux par-dessus son papier : elle ne sourcillait pas. Elle attendait la suite, et, son sort réglé, s'inquiétait avec passion de celui de sa compagne.

- Léonie Vanhoutte. Peine requise : la mort. Peine prononcée : quinze ans de travaux forcés.

Stoëber sourit. Sans égards pour De Saever, qui était assez pressé de savoir ce qu'on ferait de lui, il ouvrit une parenthèse et, s'adressant aux deux jeunes filles :

- Nous savons, dit-il, en Allemagne, rendre hommage à l'héroïsme. Le tribunal a diminué la peine de Vanhoutte et M. le Gouverneur général, qui était à l'audience, va sans doute examiner le dossier de Bettignies avec indulgence.

- Et les autres ? demanda Louise, à qui la générosité de cet homme ne causait nulle émotion, mais qui s'inquiétait pour les pauvres gens haletants auprès d'elle.

- De Saever, reprit Stoëber. Peine requise la mort. Peine prononcée : quinze ans de travaux forcés.

Il annonça ensuite des peines légères Pour Alexandre et sa mère, et l'acquittement de celui dont, la veille, Alice avait demandé la grâce. Puis, ayant montré à tous sa mine satisfaite et ses dents de carnassier, il disparut.

J'ai sous les yeux trois lettres qu'écrivit Louise de Bettignies le surlendemain 19 mars. Quoiqu'on eût fusillé Miss Cawell dans la nuit même du jugement, Alice savait sans doute qu'on la laisserait vivre encore quelques jours. Ainsi, Gabrielle Petit, condamnée le 2 mars, ne devait-elle être exécutée que le 1er avril. Louise, qui avait la permission de faire avec Charlotte de longues promenades au préau, donna ces journées de répit à l'examen réfléchi de son procès ; elle interrogea sa compagne, puis rentra en elle-même, fortifia son âme, et, alors seulement, écrivit.

Sa première lettre fut pour Stoëber, à qui elle fit part de son indignation contre Goldsmith : « J'ai appris hier, écrit-elle, et cela confirme ma déclaration au conseil de guerre, que M. le commissaire Goldsmith a employé un moyen déshonnête pour forcer Mlle Vanhoutte à faire la déposition que vous connaissez. M. Goldsmith a montré à Mlle Vanhoutte quelques-uns des papiers composant la lettre que je lui ai écrite avec le jus de citron, et lui a dit: " Je vais vous lire la lettre d'Alice. » Il lui a lu une lettre truquée et fausse... Elle continue longtemps ainsi, avec la verve de ses meilleurs jours : «J'ai entendu, le 1er février, ajoute-t-elle, comment M. Goldsmith voulait forcer Mlle Vanhoutte à faire une déposition 
contre un prêtre ; j'ai entendu la pression qu'il faisait contre cette pauvre jeune fille. Le 17 février, je le lui ai reproché ; je lui ai dit que je porterais plainte. Je lui ai dit qu'il commettait une infamie, qu'il m'attaquait parce que j'étais catholique, que j'étais fatiguée de ses insultes, que mon honneur m'était cher et que je ne permettrais pas que le nom de mon père et de mes frères fût entaché par les dépositions qu'il me prêtait. » Elle conclut en demandant la grâce et la mise en liberté immédiate de Mlle Vanhoutte et de Georges De Saever, dont elle ne savait même pas exactement le nom, puisque, dans cette lettre et dans la suivante, elle l'appelait M. Devraes.

Et voici la deuxième lettre, adressée à von Bissing :

Prison de Saint-Gilles, no 24.

Bruxelles, 19 mars 1916.

À Son Excellence M. le Gouverneur de la Belgique, Général von Bissing.

Excellence,

Je viens vous demander la grâce de Mlle Vanhoutte et de M. Georges Devraes, condamnés tous deux à, quinze anss de détention par le tribual de guerre du 16 mars.

J'ai mis M. le Conseiller Stoëber au courant des incidents de notre instruction et des moyens indélicats employés par M. le commissaire Goldsmith, moyens qui ont amené de fausses dépositions et la condamnation de ces deux personnes.

Mlle Vanhoutte et M. Devraes ont noblement supporté la fausse accusation portée contre eux ; ils ont fait quatre et six mois de prison, victimes de procédés déshonnêtes, et je viens vous prier, Excellence, de leur faire grâce et leur accorder la mise en liberté.

Je suis condamnée à mort ; étant donné que par mon silence j'ai aidé les personnes responsables à se mettre à l'abri ; étant donné que j'ai refusé de dénoncer qui que ce soit, même pour me justifier, je reconnais avoir mérité la sentence de mort et ma condamnation est juste.

J'ai agi en tout honneur et en toute liberté et crois avoir fait mon devoir.

Je mourrai contente, Excellence, si j'apprends que vous avez agréé ma demande et mis Mlle Vanhoutte et M. Devraes en liberté; d'avance je 
vous remercie de ce que vous ferez pour eux et vous prie de croire, Excellence, à l'assurance de mes sentiments distingués.

\section{LOUISE DE BETTIGNIES.}

« Je mourrai contente... » Elle a tracé cela de sa petite écriture intelligente et ferme, écriture d'une honnêteté touchant à la candeur, et qu'on sent, sous ses gaucheries apparentes, conduite d'une main volontaire. Elle veut la grâce de sa compagne. Et, parlant à von Bissing, à cet ennemi, elle ne peut se contraindre à implorer ; elle prescrit, puis, séductrice, sourit un peu... « Je mourrai contente, Excellence. » Pauvre petite ! Elle écrivait ces mots légers, les larmes au bord des yeux.

Elle fit ensuite ses adieux à la Mère Prieure du Carmel d'Anderlecht, dans une lettre toute simple, écrite au crayon comme les deux autres, et qu'a pieusement conservée sa destinataire. En voici les principaux passages :

Prison de Saint-Gilles, Bruxelles, le 19 mars 1916.

Ma Révérende Mère,

Je viens d'être condamnée à mort par le conseil de guerre. J'aurais été désireuse de vous voir, Ma Mère, avant le grand voyage. Il ne m'est pas permis d'aller à Anderlecht, et puisqu'il vous est aussi impossible de sortir, je viens vous prier de vouloir me déléguer quelqu'un qui pourra me transmettre vos derniers conseils et votre bénédiction. Je serais heureuse d'avoir un scapulaire du Mont-Carmel ayant touché le manteau de sainte Thérèse. Puis-je espérer aussi recevoir l'assurance d'une petite prière de toute la communauté?

Vous savez, Ma Mère, combien j'ai besoin d'aide et d'intercession près du Bon Dieu pour obtenir sa Miséricorde. Ma vie n'a pas été exempte de fautes et je n'ai pas été un modèle de douceur et d'abnégation. Depuis que je suis solitaire, j'ai eu le temps de repasser ma vie ; que de misères j'y ai découvertes ! J'ai honte de moi-même et du mauvais emploi que j'ai fait de mon temps et de ma santé, de mes facultés et de ma liberté; ces cinq mois de prison ont été cinq mois de retraite, de prières et d'étude. 
Avec saint Jean-de-la-Croix, j'ai essayé de monter la Montagne du Carmel ; l'Écriture Sainte m'est devenue chère, et j'ai fait quelques progrès en latin.

La solitude ne m'a pas pesé ; j'ai seulement un peu souffert du manque d'air frais ; en réalité, j'ai découvert que ce temps de prison était un excellent noviciat.

La décision du conseil de guerre n'est pas discutable. J'accepte ma condamnation avec courage. Lors de mon opération, j'ai envisagé la mort avec calme et sans effroi ; j'y joins aujourd'hui un sentiment de joie et de fierté, car j'ai refusé de dénoncer qui que ce soit et j'espère que ceux que j'ai sauvés par mon silence m'en sauront gré et m'en remercieront par une bonne prière. J'avoue que je préfère la rigueur de ma condamnation au déshonneur de m'être disculpée en dénonçant des personnes qui ont fait leur devoir envers leur pays.

Je vous écris fort à la décousu, Ma Mère, étant encore sous l'émotion du verdict; je suis toute brisée et sans forces. Demain je serai mieux; je recevrai le Bon Dieu et me préparerai à l'aller voir au Ciel. Je voudrais que ces derniers jours ne soient qu'un acte d'amour de Dieu et de complet abandon à Sa volonté. N'est-ce pas le moment de vivre la prière d'oblation de la Petite Sœur Thérèse ? Cette chère petite Sœur me tient compagnie, ainsi que le souvenir de Mère Isabelle; ajoutez-y le Christ, et vous connaîtrez, Ma Mère, mes amis de cellule.

À Dieu, Ma Mère, veuillez me pardonner les écarts et fautes dont j'ai pu me rendre coupable. Une bonne prière, s'il vous plaît, pour celle qui avait espéré se dire votre fille affectueuse et respectueuse.

\section{LOUISE DE BETTIGNIES.}

Une prière pour ma pauvre Maman! Que Dieu l'aide à supporter son épreuve!

Le 23, on lui apprit que von Bissing avait signé sa grâce et qu'elle allait être envoyée en Allemagne en détention perpétuelle.

Ce dernier mot la fit sourire.

- En détention jusqu'à la victoire de la France, dit-elle.

Mais, revoyant Charlotte, qui, le jour même, lui annonçait son départ pour l'autre rive du Rhin, elle lui jeta à l'oreille en l'embrassant : 
- Nous nous reverrons là-bas ; mais je vous plains et moi aussi ; j'ai peur de ce qui nous attend chez ces gens-là.

- Peur de quoi ?

- De tout. Je sens que je n'en reviendrai pas.

Si les Allemands n'ont pas percé de balles son corps charmant, ce n'est pas qu'ils aient eu pitié : ils avaient besoin qu'elle vécût, pour la confronter avec ceux de son service qui tomberaient dans leurs mains. Ils l'ont tuée tout de même. Au lieu de la conduire au poteau d'exécution, ils ont mis deux ans à la faire mourir. Le 21 avril 1918, abreuvée de souffrances sans nom, sentant venir la mort, une horrible mort en prison, elle écrivait à la Supérieure du Carmel : « Oui, j'ai cette faiblesse de vouloir repousser la Croix offerte et de regretter de n'avoir pas été fusillée... »

Elle resta encore un mois à Saint-Gilles. Les dames du Carmel purent lui envoyer deux ou trois fois des gâteries par des sœurs ; la visite de ces petites tourières lui apportait un peu de distraction. Un jour, une d'elles lui apprit la mort du Père Boulangé. Elle écrivit aussitôt à la Mère Prieure : «Oui, le Père a été bon, disait-elle ; il a travaillé à ma formation intellectuelle et morale, toujours très patient pour ma volonté récalcitrante et traitant avec indulgence mes lubies et bizarreries de caractère... Sa bonté avait eu raison de mon indépendance farouche, comme il l'appelait... » Et se souvenant de leur dernière entrevue à Amiens, peu de jours avant son arrestation, elle ajoutait : « Il craignait de ne plus me revoir et, en pleurant, il me bénit ! Mon pauvre Père, comme je vais prier pour lui ! »

Le Jeudi saint, on vint l'avertir dans sa cellule qu'une dame la demandait au parloir. Était-ce Mme Féron-Vrau, dont elle espérait ardemment la visite, ou la servante de la rue d'Isly, Hélène, qui devait aussi venir à Bruxelles ? Elle fut d'abord un peu déçue de se trouver en présence d'une inconnue.

- Je suis Française, dit la visiteuse, et j'ai obtenu de venir vous apporter le salut et les consolations d'une compatriote.

- Est-ce vrai ? fit la malheureuse enfant, toute bouleversée. Vous êtes bonne, madame...

Elle l'aurait embrassée, sans les barreaux. Au Carmel, elle acceptait ces barreaux, qui lui faisaient horreur ici. Tandis que la sentinelle regardait d'un autre 
côté, la visiteuse tira de son corsage et mit dans la main de Louise un mince bouquet à nos trois couleurs. La pauvre petite n'aurait pas reçu avec plus d'émotion le billet d'un fiancé, Elle pleura et dit en tremblant :

- Merci, madame. Vous ne saurez jamais quel bonheur vous venez de m'apporter.

Mme Louis Robiliart, c'était son nom, employa de son mieux le quart d'heure qu'elle avait le droit de passer avec la prisonnière. Elle lui annonça que toute une caisse remplie de douceurs venait d'être remise par elle à ses geôliers, qui avaient promis de la faire porter dans sa cellule.

- Dites-leur bien en sortant, madame, que c'est pour le 24. Ici je ne suis pas Louise de Bettignies : je suis ce numéro-là. Et revenez, voulez-vous ? Revenez dans huit jours.

Le lendemain, Vendredi saint, à trois heures de l'après-midi, elle partait brusquement pour l'Allemagne. On lui avait donné dans la matinée l'ordre de se tenir prête pour le jour même.

« J'ignore ma destination, écrivit-elle aussitôt aux Carmélites. Je ferai aujourd'hui une nouvelle station sur le chemin du sacrifice. Ce départ précipité m'attriste un peu. J'avais désiré passer les fêtes de Pâques en pays ami, et surtout voir Mme Féron et Hélène... Je n'ai qu'à me soumettre. Ce Vendredi saint est bien le jour entre tous où nous ne saurions refuser à Jésus mourant un sacrifice... »

Nous allons la précéder dans cette geôle de Siegburg, qui sera son tombeau. Elle y est morte pour avoir tenu tête à ses bourreaux et servi sa patrie contre eux avec J'exaltation d'une amoureuse. Le drame qui devait la conduire à l'immolation totale s'est dérouté dans un cadre et parmi des personnages qu'il faut que nous connaissions. Léonie Vanhoutte et ses compagnes vont nous faire visiter sa prison. Nous verrons comment, tandis que nous nous battions, de nobles femmes savaient aussi souffrir et plus que nous. Les unes, moins robustes ou, comme Louise de Bettignies, pour avoir abusé des puissances de leur âme et de leur corps, sont tombées à ce champ d'honneur ; d'autres, qui ont survécu, ont été déchaînées à la fin par la révolution allemande. Elles étaient trois cents dans cette forteresse, qui toutes avaient, ont encore, en Belgique et en France, des parents, des amis ; ce que je vais conter, ces milliers de gens le savent et ils me pardonne- 
ront de le redire. Quant à tous les autres, ils ajouteront foi, j'espère, à un récit que tant de témoins vont contrôler.

Léonie Vanhoutte, à sa sortie de Saint-Gilles, le 24 mars, avait été conduite à la gare du Nord. Là, on la fit monter dans un compartiment de troisième classe. Un officier et un soldat l'escortaient, l'un et l'autre humains et bien élevés. Le voyage se serait passé sans encombre, si des civils n'avaient dévisagé avec arrogance cette captive, qui ne parlait point leur langue. Tandis que le train franchissait le pont sur le Rhin, l'un d'eux lui dit :

- Avouez que c'est grand et beau. Vous n'avez rien de pareil en France.

- Oui, ce fleuve est beau, répondit-elle ; mais vous ne le garderez pas toujours.

- Ah ! taisez-vous ! crièrent tous ces Allemands, hommes et femmes, dont il faut convenir que l'émoi était justifié.

L'officier qui conduisait la jeune Française cherchait à apaiser tout ce monde, quand, du compartiment voisin, surgit un petit lieutenant, sorte de blanc-bec, dont la colère avait teinté les joues de rose.

- Taisez-vous ! fit-il, en jetant des feux sur la prisonnière.

Comme il agitait sa cravache, elle se dressa devant lui avec l'aplomb d'un petit coq.

- De quoi vous mêlez-vous ? osa-t-elle lui dire. Est-ce donc vous qui êtes chargé de moi ?

Ce foudre de guerre fit aussitôt sortir tous les civils du compartiment, et, debout dans le couloir, se mit à invectiver la jeune Française.

- Vous allez en Allemagne, lui disait-il, et vous y resterez; vous y mourrez on vous mettra dans des cachots sans manger vous pourrirez là-dedans. C'est comme cela que nous traitons les espions chez nous !

- Non, répondait-elle avec douceur ; les Français ont la vie dure et vous ne me ferez pas mourir ainsi.

La pauvre enfant, sous ce flot d'injures, ne ressentait nulle émotion, car une grande idée l'occupait tout entière. On lui avait remis l'argent pris sur elle le jour de son arrestation. Elle n'en ferait rien en prison et voulait le dépenser en voyage. 
Son gardien, l'officier timide, avait accepté de la conduire au wagon-restaurant ; et de ce repas en tête à tête avec son geôlier elle se faisait une fête, comme une petite fille de dîner avec sa poupée. Après les violences de son bouillant camarade, l'officier si galant n'osa plus maintenir sa promesse. Par contre, il accepta de conduire sa prisonnière à travers les rues de Cologne, où l'on devait s'arrêter plusieurs heures. Elle visita la ville avec lui et fit, dans une brasserie, dans une charcuterie, dans une confiserie, des dépenses folles : un verre de bière, un grand saucisson, des bonbons de chocolat, Le soir, vers dix heures, le train arriva dans la petite gare de Siegburg. Il faisait noir.

- Voulez-vous prendre le tramway ? lui demanda son cavalier ; nous pouvons faire la route à pied, mais elle est longue.

- Combien?

- Une demi-heure de marche.

- Une demi-heure de liberté, dit-elle. Marchons !

Le soldat se chargea de sa petite valise, Il se tenait à sa gauche. C'était un homme simple, qui connaissait un petit nombre de mots français.

- C'est malheureux, disait-il. En prison, une jeune fille...

À sa droite, l'officier s'efforçait de la distraire. Ils marchèrent trois quarts d'heure, battant le sol de leurs talons, respirant à pleine gorge l'air froid de ce ciel sans lune. Devant un mur sinistre, le trio s'arrêta,

C'est la prison. Un bruit de grosses clefs fait courir un frisson dans le dos de la jeune fille. Un visage d'homme apparaît. Quelques mots ,allemands ; des gestes Je surprise ; puis un rugissement du portier, qui peste, sacre et claque la porte au nez des intrus : ils avaient amené cette jeune fille dans la prison des hommes...

Méprise bénie, qui prolongea de trois minutes, pour Léonie Vanhoutte, l'illusion de la liberté. Quand l'autre porte s'ouvrit, une gardienne mit le nez dans l'entrebâillement ; elle parlementa, trouvant qu'il était bien tard pour une entrée, puis fit attendre la jeune fille et ses gardiens dans un vestibule entre deux grilles. Un instant après, la directrice arrivait. Elle échangea quelques mots avec l'officier, le congédia, puis, ayant dédaigneusement toisé sa nouvelle pensionnaire, dit à la geôlière : 
- Conduisez-la dans sa cellule.

Cette directrice était une jolie femme, grande et distinguée. Quelques détenues seulement l'ont détestée ; la plupart lui ont su gré d'être bien élevée : c'est rare en Allemagne, plus rare en prison. Fille d'un professeur notoire, veuve d'un ingénieur peu heureux en affaires, cette Frau Ruge gagnait sa vie en Angleterre à la déclaration de guerre. Protégée en haut lieu, elle obtint la direction de cette prison de Siegburg, poste important. Elle a certainement eu pour Louise de Bettignies, quand elle la vit près de mourir, des égards ; mais sa part de responsabilité dans cette mort reste lourde ; et je comprends le sentiment de Léonie Vanhoutte, qui ne l'aimait pas.

Cependant la petite Roubaisienne s'en allait, par les longs couloirs mornes, vers sa cellule. Sa gardienne lui avait enjoint de ne point marcher sur les dalles cirées, mais de raser les murs, le long desquels courait un sentier de pierre grise. Distraite, la pauvre fille mit une ou deux fois, le pied sur le sol défendu ; l'autre femme la poussait alors, comme on bouscule un chien qui s'est aventuré sur le gazon. À ce détail, la prisonnière mesura sa déchéance. Elle pensa qu'elle aussi, la fière, la charmante Alice, on la renverrait dans l'ornière. « Jamais ma petite princesse, se dit-elle, ne supportera qu'on la traite ainsi. » Le plus amer était que la fraulein, sans doute une fille de rien, peut-être une criminelle assagie, se dandinait, en traînant les pieds, au milieu de l'allée. On arriva à la cellule. Grosse serrure, difficile à manœuvrer. Une porte massive s'entr'ouvre. La jeune fille n'a pas le temps d'y entrer elle-même : on l'y pousse ; et la lourde machine se referme. Elle est dans un trou noir.

Debout, sans un mouvement, elle écoute battre son cœur, puis demande :

- Il n'y a personne ici ?

Pas de réponse. L'écho de sa voix lui révèle que la cage est petite. Elle voudrait en faire le tour, mais elle n'ose. Son imagination s'égare ; elle veut du secours et frappe, frappe si fort que la directrice en personne accourt, ouvre, lui rappelle qu'elle est une criminelle et lui accorde cependant vingt minutes de lumière et sa valise. Elle peut alors examiner le lieu où on l'a mise. C'est plus petit et plus gris qu'à Saint-Gilles, avec un mobilier plus grossier. Elle en prendrait son parti, mais le lit la dégoûte. Il est constitué par des planches sur lesquelles on a mis une paillasse en trois parties : trois galettes carrées, plates, dures et sales. Il y a vingt 
ans qu'on n'a pas lavé cette literie sur laquelle ont couché des centaines de criminelles de droit commun. Charlotte prend dans sa valise des essuie-mains, qu'elle étale sur la litière.

- Vous ne serez pas toujours si difficile, lui dit la belle Allemande en haussant les épaules.

- Mais ce lit est dégoûtant, madame.

- Il est assez propre pour vous.

Le crime de cette femme élégante qui faisait dans ces murs sordides, certains frais de toilette et, parce qu'elle voulait conquérir l'attention des prisonnières d'un certain rang social, savait témoigner à celles-là, tout en restant leur geôlière, le respect dû a des femmes héroïques, son crime est d'avoir traité les autres avec mépris et sans humanité. Elle était Allemande d'abord et son patriotisme en eût imposé ; mais elle était de sa race, en même temps que de sa patrie ; race dure aux faibles et, suivant, une vieille loi humaine, oppressive dans la mesure de sa servilité.

Charlotte dormit à poings fermés, ce qui est une façon d'échapper à ses chaînes. Le matin, une fraulein vint la chercher pour la présenter à la Hausmutter, grosse femme avec une voix de portefaix. On voyait au haut de la tête en boule de cette mégère un chignon pareil à une pelote de ficelle ; là-dessus se balançait un bonnet blanc, gonflé et ballottant, que les détenues appelaient son chou-fleur. De cet aérostat tombaient deux rubans de soie bleu tendre qui se rejoignaient en un large nœud posé sur sa poitrine comme sur une table. Elle voulait qu'on la désignât sous son titre allemand de Hausmutter ; ou bien il fallait prononcer tout au long Madame la mère de la maison, ce que les prisonnières faisaient avec une joie folle, en minaudant ; par derrière, on disait la belle-mère.

- Fenez au bain ! cria-t-elle à la nouvelle venue, en la dévisageant comme une galeuse.

Alors la petite Vanhoutte, comme toutes ses compagnes, jeunes ou vieilles, filles du plus haut ou du plus humble monde et les religieuses mêmes, dut se dévêtir, puis se laisser frotter et savonner des cheveux aux pieds par deux criminelles allemandes, tandis que la Hausmutter, assise près de la baignoire, les deux 
poings sur ses jambes écartées, donnait audience, laissant entrer là qui voulait, comme au moulin.

On fit un paquet des vêtements et du linge de la « nouvelle » et on lui tendit ses effets de prisonnière : chemise, dure, bas de coton bleu et blanc, robe de bure, grand fichu croisé sur la poitrine, et tablier. Aux pieds, chaussures massives de soldats et, pour sortir, des sabots. Sur ta tête, les deux nattes en couronne. Peu de temps après l'arrivée de Léonie Vanhoutte, les détenues politiques furent autorisées à garder leurs effets personnels. Elle préféra, et plusieurs autres avec elle, dont Louise Thuliez, rester sous la livrée. qui ne leur paraissait pas infamante. Le fichu Marie-Antoinette était seyant. Quelques-unes, riches d'une chevelure opulente, sentaient que leurs nattes lourdes encerclaient à ravir leurs visages amincis. Un dimanche, la directrice renvoya dans sa cellule Léonie Vanhoutte qui se rendait à la messe avec des frisons. Une autre fois, elle et d'autres s'avisèrent de raccourcir de deux doigts leurs jupes de drap brun.

- C'est la mode, ma chère.

- Vous croyez?

Et les pauvres petites, dans leur trou noir, firent marcher les ciseaux, le cœur battant.

La Hausmutter, le lendemain, jeta des yeux féroces sur les chevilles des petites espiègles, qui, pour expliquer qu'elles avaient sans doute grandi dans la nuit ou attaché leurs jupes un peu haut par mégarde, prirent des mines d'enfants dociles. La grosse femme hurla et tourna les talons.

Après le bain du premier jour, on passe au secrétariat. Là, en attendant d'être interrogée, il faut se tenir debout, le nez au mur ; et, si plusieurs prisonnières ont été introduites, elles doivent se placer à cinq mètres les unes des autres. La directrice est attablée près d'une secrétaire, qui appelle :

\section{- Fanhoutte!}

Charlotte avance d'un pas vers son interlocutrice. Alors celle-ci se lève, le corps rejeté en arrière, et fait un geste de son bras tendu, comme pour écarter la peste. Quand la pauvre petite, dont le cœur se gonfle de se sentir si méprisée, s'est remise à bonne distance, on lui demande durement son nom, ses prénoms, son âge, tout son état civil et l'adresse de ses parents. 
- Maintenant, dit l'Allemande, vous allez signer.

La jeune Française se porte vers la table. La secrétaire, comme épouvantée, se rejette au fond de sa chaise et dit :

- Reculez! Reculez!

Elle s'assure que la pauvre fille a pris du large, pose le papier au bord de la table, très loin, puis tend la plume, de ses doigts allongés comme des pincettes.

Quand Léonie Vanhoutte parle aujourd'hui de cette scène ridicule, elle prend une moue amusante.

- Ça, dit-elle, c'était vexant.

Elle se chargea d'ailleurs de le manifester à ces dames.

- Vous ne devriez pas avoir peur de moi ! fit-elle. Pendant la guerre, on enferme les braves gens ; et ce sont les autres qui les gardent.

- Was ist ! Was ist ! s'écria la secrétaire, tout hébétée.

Et la directrice, hautaine, ajouta :

- Vous faites la fière et il n'y a pas de quoi vous devriez penser à votre déchéance, avec un costume pareil !

Son costume, elle l'a aimé. Et c'est charmant de voir Louise Thuliez, qui a rapporté le sien d'Allemagne, le déplier avec soin et, si l'on se montre un peu curieux et qu'on insiste, s'en parer en souriant.

À la tête des deux prisons, celle des hommes et celle des femmes, régnait un individu grossier, herr Dürr. Ce personnage, dont je n'ai pas réussi à savoir s'il avait perdu sa jambe à la guerre ou par accident, on eût peut-être respecté son infirmité, mais l'homme était abject. Nous verrons Louise de Bettignies aux prises avec lui. Il terrorisait toute la prison, geôlières et détenues. Quand, à la promenade dans la cour, il avait fait une apparition, les prisonnières, moqueuses, attendaient qu'il eût le dos tourné pour se mettre à boiter comme lui. Deux dents de rongeur au milieu d'une petite bouche en goulot, une bouche suceuse, lui donnaient un air faux. Ses yeux clignotants y aidaient, surtout l'un d'eux qui regardait toujours en l'air. Cet homme avait mission de faire souffrir, et il y réussit, d'admirables femmes, dont il faudrait plusieurs livres comme celui-ci pour honorer la noblesse, le charme, les vertus. Je voudrais pouvoir les faire venir toutes devant ceux qui me 
liront, et qu'on apprît de moi de quel culte elles sont dignes. Je ne connais pourtant qu'un petit nombre d'elles et je sais peu de choses de chacune; assez pour avoir reconnu en presque toutes cette hauteur d'âme par où les êtres de boue que nous sommes se replacent au rang qu'a voulu Dieu pour nous. Le premier visage frais qu'aperçut Léonie Vanhoutte à Siegburg fut celui de la petite Marie Albert. Elles étaient deux sœurs, condamnées à mort, puis graciées et jetées là pour toute la guerre.

- Faites attention, lui dit cette enfant de vingt ans. Ne dites pas un mot imprudent ici tous ces gens-là sont faux.

- Mais vous-même, mademoiselle, qu'avez-vous fait ?

- Chut ! je vous le dirai quand la paix sera signée.

Elle disparut, ayant donné gentiment à la nouvelle venue un conseil de sagesse et le témoignage d'une fermeté d'esprit peu commune. J'ai sous les yeux une lettre que sa sœur Jeanne, héroïque comme elle, a bien voulu m'adresser de Liège, où elles vivent paisiblement de leur travail. «Quand les Allemands, m'écrit-elle, interrogèrent ma sœur Marie, lui disant qu'elle était devant la justice, elle les interrompit et leur dit qu'il n'y avait pas de justice allemande, qu'ils étaient les plus forts et se conduisaient en maîtres, pas en juges... La grâce d'en haut et notre fierté de Belges nous aidèrent à entendre le verdict avec sang-froid. Sur vingt accusés, onze furent condamnés à mort, dont nous deux. Neuf, dont une femme, étaient fusillés le lendemain au lever du jour. »

Deux autres sœurs, les demoiselles Doutreligne, d'Audenarde, se souviennent surtout, si on les interroge sur Siegburg, de l'amitié qui unissait toutes ces captives. « Dès notre entrée en prison, où nous arrivions sans vivres, écrit-elle, Louise de Bettignies, qui avait échangé quelques mots avec moi à la promenade, nous fit passer une petite caisse, remplie de biscuits, de boîtes de conserve, de lait, de cacao. » Et Léonie Vanhoutte m'a souvent dit que la grande affaire de toutes ces déshéritées qui mouraient de faim était de reconnaître celles qui n'avaient point reçu de colis et s'en cachaient ; alors on se cotisait pour leur envoyer des gâteries. On tenait à jour dans les cellules le registre des dates de fêtes et des anniversaires, on brodait en cachette, avec de la soie volée, des fleurs ou sa signature des bouts de chiffon pris l'Allemagne et l'on échangeait, avec une joie inconnue des gens heureux, des politesses. Quand arrivaient des caisses de France avec du beurre, du 
chocolat, des biscuits faits de bonne farine, on les montrait aux fraulein amaigries. Tandis que ces Allemandes jetaient des yeux ronds sur ces richesses en disant: « Das ist shôn! das ist schôn! » on leur demandait avec une sympathie larmoyante : «Et vous avez encore beaucoup aminci depuis la dernière fois ? " C'est une consolation, quand on s'anémie en prison, de voir dépérir davantage ses geôlières. Dans les notes que m'a envoyées Mlle Madeleine Doutreligne, il n'y a pas un mot de plainte, et si elle rappelle le temps héroïque où ses sœurs et elle servaient la patrie comme des hommes, elle le fait avec des mots charmants. Elle conte, par exemple, comment elle obtint son premier passeport pour Bruges, où il s'agissait d'aller prendre des renseignements pour les passer en Hollande. Elle s'est faite dentellière pour la circonstance. «Une amie complaisante nous donne, écrit-elle, de fausses quittances ; nous fabriquons des lettres d'ouvrières de Bruges réclamant notre inspection et nous nous présentons, ma sœur et moi, à la Kommandantur : Que voulez-vous ? me dit-on. - Un sauf-conduit pour Bruges. - Nein ! hurle un officier. - Pleure! me dit alors ma sœur en me poussant le coude. Et me voilà qui éclate en sanglots. Nous avons fait pitié à ce bourru, qui a établi le passeport et nous l'a remis en nous consolant. » Et l'on rencontre encore des femmes qui médisent du mensonge ! Les hommes, assez forts pour être francs, s'abaissent quand ils mentent. Pour elles, qui n'ont pas d'autre défense, c'est un art sacré. Et ce don des larmes, que valent auprès de lui nos grosses malices masculines ? Ces deux petites, dont les aventures héroïques et touchantes vaudraient qu'on les contât dans tout un livre, ont passé leur captivité, comme Jeanne et Marie Albert, à sourire à leurs compagnes, à offrir aux oubliées de menus cadeaux, à faire des niches à leurs gardiennes, à entretenir dans les autres âmes et dans les leurs la bonne humeur, fille et génératrice du vrai courage.

Vais-je énumérer toutes ces prisonnières ? Je commettrais des omissions et je ne voudrais contrister personne. Quelques-unes vont être mêlées à la tragique histoire de Louise de Bettignies : nous les nommerons alors. J'en vais citer plusieurs autres, afin de donner un aspect vivant à cette prison, où l'on avait assemblé des victimes très diverses entre elles, quoique sur un point elles fussent pareilles : elles ressemblaient toutes à cette pauvre femme de Verviers, Mme Ramet, qu'on avait jetée là avec ses deux filles, Claire et Louise, après avoir fusillé son fils Alphonse. Elle-même, brisée de douleur, devait mourir dans sa cellule le 12 avril 1917 ; pendant la veillée de Noël 1916, les prisonnières choristes de là chapelle 
donnaient un concert à leurs compagnes ; on les avait placées au carrefour des deux grandes galeries constituant la prison, et les portes de toutes les cellules étaient ouvertes ; Mme Ramet, comme les autres, droite au seuil de son caveau, écoutait les chants, non loin d'elle, la princesse de Croy observait cet extraordinaire spectacle. Les voix plaintives s'étiraient tristement dans les voûtes froides ; et le long des balcons de fer, sur le fond noir des portes alignées, des silhouettes immobiles recevaient d'en bas une lumière incertaine qui leur donnait des tons de cadavres. C'était le temps où le Kaiser venait de lancer d'insolentes propositions de paix, premier signe, quoi qu'il en dît, de la lassitude allemande.

- Croyez-vous, demanda timidement la vieille Mme Ramet à la princesse de Croy, que la paix soit prochaine?

- Non, madame. La paix viendra plus tard. Ayez patience...

- Mais je ne veux pas de leur paix ! riposta la moribonde, toute tremblante.

Elle expliqua, en s'essoufflant, qu'elle mourrait contente dans sa prison parce qu'elle savait bien qu'un jour ses filles seraient délivrées par la victoire. On a écrit des livres et mis des drames au théâtre pour rappeler la basse aventure d'une Mata-Hari ; à Siegburg se déroulaient chaque jour des scènes qui conduiraient sans effort à l'immortalité les écrivains capables de les raconter simplement.

Des familles entières étaient internées là. Mme Denoël, de Hasselt en Belgique, s'y trouvait avec ses quatre filles : Julienne, Stéphanie, Raymonde et Jeanne. L'aînée avait vingt-six ans, la dernière dix-neuf. Une autre, Mme Boizard, Française, était seule à Siegburg mais les Allemands avaient fusillé son mari condamné à mort, puis gracié et interné son fils aîné, et condamné son second fils à trois ans de forteresse ; le troisième était prisonnier de guerre. Bien d'autres pleuraient dans leur cachot un mari ou un fils fusillés. De toutes jeunes filles, appartenant aux classes sociales les plus diverses, apportaient leur grâce et leur gaîté dans ce tombeau : parmi elles, Marguerite Nollet, coupable d'avoir collaboré à Roubaix avec l'abbé Pinte et le ménage Willot pour rédiger, à l'aide de renseignements recueillis par sans-fil, un journal clandestin fameux, L'Oiseau de France; il y avait aussi Hélène Javaux, dont le père avait été fusillé, laissant neuf enfants ; et Germaine Firquin, Marguerite Bellot, Lily Maindiau, Eva Montfort, la petite Kerf ; j'en passe, et de plus jeunes. Quelques détenues portaient sur la tête, au lieu de la natte réglementaire, un bonnet pour cacher leurs cheveux courts : à ce signe 
seulement on reconnaissait au début les religieuses : mère Marie-Louisa et mère Marie de Loyola, des Dames de Saint-André ; la sœur Irma, de la Providence, la sœur Louise, des Filles de la Charité ; mère Augustine, des Ursulines de Lierre ; et cette sœur Victoire, qu'on ne vit là qu'en passant : on lui avait infligé trois mois de détention pour avoir dit un jour sans bienveillance : « Ça sent l'Allemand, ici. » Un peu plus tard, les sœurs, comme les autres détenues, eurent la permission de garder leur costume. Parmi les plus notables figures assemblées là, il faut encore nommer Mlle L'Hotellier, de Valenciennes ; et, bien que je lui aie presque promis de ne pas le faire, je dirai aussi le nom de la comtesse Jeanne de Belleville, condamnée à mort avec Miss Cawell et Louise Thuliez et qui passa toute sa captivité, comme la princesse de Croy, sa voisine et son amie, à user, pour adoucir le sort de ses compagnes, de l'ascendant que son titre et son nom lui donnaient sur la vaniteuse frau Ruge.

Toutes ces femmes, jeunes ou vieilles, riches ou pauvres, ont vécu dans ces murs noirs des jours horribles. J'ai dit leur vaillance et comme elles ont su trouver en elles-mêmes des ressources pour s'entr'aider en souriant. Ainsi, parce que nous l'avons supportée d'un grand cœur, des gens de l'arrière ont cru que la vie du front était douce. Si ces femmes n'ont pas, la paix venue, crié sur les toits leurs souffrances, c'est à l'honneur de leur discrétion : je n'ai pas leurs raisons pour me taire.

Dans un article que la Revue des Deux Mondes a publié le 1er août 1919, Louise Thuliez parle de ses compagnes mortes à Siegburg. « L'une, dit-elle, Léonie Macaire, de Saint-Quentin, fut contrainte d'épandre par seaux, sur le jardin, tout un tonneau de vidanges. Il faisait un froid vif : on était à la fin d'octobre. L'odeur infecte respirée depuis le matin l'empoisonnait : on lui imposa de continuer le travail jusqu'au soir. Elle se coucha peu après et ne se releva plus. » De Lucienne Dethier, de Monthermé (Ardennes), qui vomissait constamment le sang et qu'on employait cependant aux durs travaux d'une briqueterie voisine, Louise Thuliez nous dit : « Une nuit que je la veillais, elle eut une hémorragie si violente que je crus sa dernière heure arrivée. Elle vomissait le sang à flots, et ce ne fut qu'au cinquième torchon plein de sang que je pus obtenir enfin qu'une surveillante allât chercher du secours. » Elle mourut quelques jours après. Il y avait d'ailleurs un médecin à Siegburg, mais c'était un monstre, qui renvoyait grossièrement les malades sans avoir seulement tourné la tête vers elles. Il prenait leurs noms et criait, aux premiers mots que balbutiaient les pauvres femmes pour dire leur mal : 
«C'est bon. Sortez. » De là le sobriquet de docteur Sortez, sous lequel il était connu. Les détenues apprenaient dans la journée qu'il avait prescrit au hasard de l'aspirine, de l'éther ou rien du tout. Quand on obtenait d'entrer au lazaret, c'était souvent pour y mourir.

Le soir, on fermait les cellules, qui, sous aucun prétexte, ne pouvaient être ouvertes avant le réveil. Comme il n'y avait pas de pétrole pour les lampes, la nuit et l'ennui commençaient en hiver à trois heures et demie, Il était dès lors impossible de travailler, et, le calorifère étant éteint faute de charbon, on mourait de froid. Vers cinq heures, une fraulein entre-bâillait la porte ; on lui tendait dans l'obscurité son écuelle, où tombait d'une grosse louche une ration d'eau chaude mal colorée. On pouvait après cela souffrir, crier, frapper sur les murs ; on pouvait mourir : la porte ne s'ouvrait plus. Des prisonnières ont craché le sang ; d'autres, Souffrant de crises de foie, ont pu hurler la nuit entière, suppliant qu'on leur donnât quelque soulagement : les voisines joignaient les mains et pleuraient, impuissantes et brisées d'émotion. Des enfants sont venus au monde à Siegburg : on trouvait le matin ces nouveau-nés tragiques dans la cellule de leur mère. Frau Ruge veillait ellemême à J'accomplissement de la consigne inhumaine. Le 28 septembre 1917, un dépôt de munitions voisin des deux prisons sauta. Le vacarme fut épouvantable, et dura longtemps. À chaque explosion, à chaque lueur nouvelle, les captives pensaient que c'était la prison même qui s'effondrait et brillait. Toutes, même les plus raisonnables, se mirent à pousser des cris aigus, se brisant les poignets contre les portes. Ces appels déchirants augmentaient l'horreur du tumulte, car chacune croyait que sa voisine hurlait dans les flammes. Quand on ouvrit le lendemain, on trouva presque tous les tabourets en pièces et quelques prisonnières encore évanouies. Frau Ruge dira peut-être pour sa défense qu'elle fit rassurer quelques détenues proches de son bureau : elle a donc volontairement laissé les autres à leur cauchemar. C'était elle qui disait en ricanant, si on réclamait un peu de ouate pour un pansement : «Allez donc la chercher en Angleterre. »C'est elle enfin qui porte la responsabilité de certaines scènes atroces dont Léonie Vanhoutte fut le témoin et l'une des victimes lors d'une épidémie de typhus.

Presque tous les dimanches, deux ou trois prisonnières, prises de syncope à la chapelle, s'effondraient sur leurs bancs; on les prenait alors par la tête et les pieds ; en allait les jeter dans leurs cellules, puis on donnait un tour de clé. Si les autres se plaignaient pour ces malheureuses laissées à demi mortes à l'abandon, on 
leur imposait silence. Des geôlières au parler gras criaient : «Das maul zù ", ce qui signifie, en français poli : «Ferme ta bouche. » La Petite Charlotte, épouvantée de ces façons, indignée contre ces Allemandes qui ne ressentaient de pitié pour rien ni pour personne, apprit un jour, par Frau Ruge, que le typhus avait fait son apparition dans la prison, et accepta tout de suite la mission qu'on lui offrait de soigner ses compagnes. Elle avait pris depuis quelques jours son service au lazaret quand on lui donna l'ordre d'aller chercher, dans une salle commune où couchaient dix-sept prisonnières, une femme qu'on disait à l'agonie. C'était Mme Brousse, de Turnhout, en Belgique, mère de quatre enfants, coupable d'avoir aidé des soldats à passer la frontière. Quoique cette malheureuse fût fiévreuse et grelottante depuis huit jours, on avait exigé qu'elle allât travailler à la fabrique de munitions ; et, la veille encore, malgré ses supplications, on l'y avait traînée. Tandis qu'elle y épluchait des pommes de terre, elle s'était effondrée dans la cour. Au retour, on n'eut même pas l'idée de l'envoyer à l'infirmerie. Quand, après vingtquatre heures de délire parmi ses compagnes épouvantées, elle fut enlevée par Léonie Vanhoutte et une autre prisonnière, c'était presque une morte. Les deux jeunes filles durent seules porter ce corps douloureux, au contact duquel les Allemandes auraient craint de se salir et de prendre le typhus. Elle mourut après d'atroces souffrances. Son infirmière bénévole fit tout au monde pour adoucir sa fin ; mais elle n'avait rien à sa disposition, ni médicaments, ni ouate, ni toile pour les pansements, ni linge de rechange ; et les typhiques qui se mouraient, si elles maculaient leurs lits, il fallait que la petite Vanhoutte mît son mouchoir ou son essuie-mains ou son tablier entre leur corps brûlant et les draps empoisonnés. Une autre femme mourut peu après, une Française, Mme Cuvelier, mère de quatorze enfants. Son mari, détenu à la prison des hommes, trois cents mètres plus loin, ne fut pas admis à suivre son cercueil au cimetière. De même, Mme Ramet s'en était allée dans la tombe sans ses filles, à qui on avait eu le barbare courage de refuser de rendre à leur mère le dernier devoir. Comment ne pas vouer au mépris hautain de quiconque a des entrailles humaines l'homme et la femme qui régnaient dans cette prison et y imposaient une telle loi ?

Mais il y a des détails plus cruels. La mort de Mme Cuvelier avait bouleversé Léonie Vanhoutte. Cette pauvre femme s'était éteinte en récitant doucement la prière à la Vierge : Souvenez-vous, ô Vierge Marie... Elle s'interrompit un moment pour dire à sa petite gardienne: «Vais-je mourir sans mes enfants? Alors c'est 
vous, pauvre petite, qui les remplacez. Parlez-moi comme eux... Dites-moi si je vais vraiment m'en aller, afin que je fasse bien le sacrifice de ma vie. Prions, voulez-vous ? » Et elle reprenait : Souvenez-vous, ô Vierge Marie...

Une heure après sa mort, une geôlière dit à Léonie Vanhoutte et à une autre détenue, la charmante Mathilde Lemmens, qui la secondait :

- Descendez ; vous trouverez un cercueil et vous l'apporterez ici.

- Mais pour quoi faire ?

- Pour y mettre la dame. Ce travail est dangereux pour nous. Allez !

Jamais la pauvre enfant n'oubliera ces minutes-là. La prisonnière qu'elle avait soignée, donc aimée, elle dut la prendre dans ses bras, la placer avec mille peines dans la boite étroite, couvrir à jamais son visage...

- Mais dépêchez-vous ! criait la fraulein.

Elle souleva une dernière fois le drap qu'elle avait rabattu sur cette pauvre tête ; puis, tout en larmes, elle ajusta le couvercle et le vissa. Oui, une à une, elle dut tourner les pointes de fer dans le bois friable.

- Maintenant, descendez cela...

Les deux prisonnières se regardèrent.

- Vraiment, dit Mathilde Lemmens, nous devons descendre ce cercueil ?

- Qui voulez-vous qui s'en charge ? Vous l'aimiez : occupez-vous d'elle...

Représentez-vous ces deux petites dans l'escalier, portant gauchement leur charge, la heurtant aux murs, froissant leurs muscles affaiblis, fléchissant à tous les pas sous le fardeau brutal.

Ce fut ainsi pour deux autres qui moururent aussi du typhus. S'il n'y eut pas un plus grand nombre de victimes, c'est, au témoignage de toutes ses compagnes, à Léonie Vanhoutte qu'on le doit. Une admirable jeune fille, Mlle Gérard, de Philippeville, en Belgique, me l'a écrit, après d'autres, en ces termes : « Nous étions toutes si affaiblies que nous tremblions devant ce fléau : nous nous sentions des oiseaux pour le chat. J'ai toujours pensé que si le mal ne fit pas de pires ravages, nous l'avons dû au dévouement sans bornes et aussi aux précautions et à toutes les 
mesures d'hygiène si judicieuses et raisonnables prises et ordonnées par la douce Mlle Vanhoutte, qui savait à l'occasion montrer une extrême énergie. »

Et Mlle Gérard ajoute : « Je me rappelle combien mon cœur se serra quand j'appris un jour qu'elle aussi était frappée. » Car la pauvre enfant, comme il était inévitable, fut malade à son tour et faillit mourir. Comment elle en est revenue, il ne faut pas essayer de le comprendre, Des compagnes s'empressèrent autour d'elle, et d'abord celles qui l'avaient aidée à soigner toutes les autres, Mathilde Lemmens, Mme Delzène et l'admirable petite Jeanne Albert. D'ardentes prières montèrent à Dieu, même de certaines lèvres allemandes. Mais les vrais soins lui manquèrent, comme à toutes. Quand on lui tendait à boire, elle serrait les dents, sachant trop qu'à elle aussi on voudrait faire avaler de l'éther, seule médication connue dans ce lieu abominable.

Elle était malade pendant les derniers mois que passa à Siegburg Louise de Bettignies, dont elle apprit la mort avant d'être elle-même rétablie. Et, le 8 octobre 1918, sa faiblesse était encore grande et sa mine pitoyable, quand, vers trois heures de t'après-midi, on entendit de grands cris dans les couloirs. Des évadés français et belges de la prison voisine, entourés de soldats allemands débraillés, brandissaient d'énormes clefs et, une à une, ouvraient toutes les cellules, criant : « Habillez-vous ! vous êtes libres. La République est proclamée ! » Aux hésitantes, à toutes celles qui croyaient rêver, ils disaient encore : «Allons vite ! Vous avez un train pour Cologne à six heures! » Ce fut une débandade joyeuse. Chacune courait au secrétariat, réclamant ses effets et son argent. Les geôlières, devenues douces, s'acquittaient de leur mieux. La Hausmutter avait vivement ôté son bonnet et jeté loin d'elle ses rubans bleus. Herr Dürr était introuvable. À cinq heures, trois cents femmes et jeunes filles envahissaient la gare, et, quelques jours plus tard, exténuées mais contentes, elles tombaient dans les bras de leurs parents retrouvés.

Pas toutes, puisque la terre allemande gardait, parmi d'autres corps tombés, celui de Louise de Bettignies. Celle-là eût pourtant mérité de connaître la victoire comme une récompense personnelle.

Son lieutenant revint seule en France. Elle s'est remise au travail, oubliant peu à peu ses souffrances. Ceux pour qui elle les a endurées les ont malheureusement oubliées aussi et c'est seulement le 24 août 1919, que la Croix de guerre lui a été remise, avec cette citation insuffisante à l'ordre de la brigade «À fait preuve de 
courage et de patriotisme dans l'accomplissement de missions périlleuses et en facilitant le passage en Hollande de jeunes gens désireux de s'enrôler dans l'armée française. Arrêtée pour ces faits, condamnée par les Allemands à quinze ans de travaux forcés, a subi plus de trois années d'une rigoureuse détention. »

Tous ceux qui auront lu ces pages voudront sans doute qu'on orne au plus tôt d'un ruban rouge le corsage de cette modeste et charmante héroïne. 


\section{LA GUERRE DES FEMMES.}

Histoire de Louise de Bettignies et de ses compagnes.

\section{Chapitre XI}

\section{LE CACHOT}

Retour à la table des matières

Au printemps de 1916, la princesse de Croy, ayant à se plaindre qu'on interceptât ses lettres, avait été appelée au bureau de la directrice. Celle-ci, bienveillante cet après-midi-là, causait avec sa prisonnière.

- Je suis fatiguée, disait-elle. Mon poste est lourd.

- Préférez-vous ma place?

- Non. Mais vous êtes trop nombreuses, C'est écrasant.

- Il me semble, en effet, que plusieurs nouvelles sont arrivées.

- Oui, beaucoup. Quelques-unes sont de grandes condamnées, qui me donnent du souci. Une surtout. Au fait, vous devez la connaître.

- Qui donc ?

- C'est une Bettignies. Vous n'êtes pas sa parente?

- Du tout.

L'Allemande, âme méfiante, sourit et ajouta : 
- Tenez ! Voyez-la par la fenêtre. Alors vous ne nierez plus que vous savez qui elle est.

La princesse de Croy, qui avait ouï parler autrefois de la famille de Bettignies, mais ne savait rien de Louise, s'approcha de la vitre. Les prisonnières à la promenade avançaient deux à deux, de cinq mètres en cinq mètres. Il faisait beau et, sur cette lente théorie entre les hauts murs sinistres, le soleil d'avril jetait sa belle lumière caressant les joues pâles et jouant, autour des nattes, avec les mèches et les petits cheveux indociles.

- C'est celle-là, dit tout à coup Frau Ruge.

Elle montrait du doigt une prisonnière de petite taille, dont le mince visage était encadré, d'une lourde et magnifique couronne de tresses d'or. Jamais Louise de Bettignies n'a été plus jolie qu'à Siegburg. Ses yeux s'étaient agrandis, dans son visage encore affiné par la douleur ; et la coiffure réglementaire la ceignait d'un diadème qui eût fait envie à des reines.

- Eh ! bien, dit la hautaine geôlière, cette Bettignies que vous ne connaissez pas est une personne peu maniable. Vous devriez, quand vous la rencontrerez, l'exhorter à la prudence. Elle donne de mauvais conseils aux autres et ne réussira qu'à se faire punir et à nuire à ses compagnes.

Quelques jours plus fard, la princesse de Croy, causant avec la nouvelle venue, l'invitait discrètement à la résignation. Elle vit, dès les premiers mots, qu'elle perdait sa peine. Louise de Bettignies, tempérament de chef, n'a jamais accepté sa défaite. Elle a gardé, sous les fers, une âme rebelle. Comme le prévoyait la doucereuse Allemande, cela lui fit quelque tort dans l'esprit de plus d'une de ses compagnes. Elle prit tout de suite, dans cette assemblée de femmes malheureuses, la tête du parti extrême. De telles personnalités sont gênantes parfois : le bruit qu'elles font offense des natures plus calmes et non moins héroïques, car on peut discuter s'il n'y a pas un mérite plus certain à souffrir tout bas qu'à se plaindre, à refouler ses larmes qu'à livrer bataille quand on est le pot de terre. Je crois qu'il ne faut pas tant peser les mérites de toutes ces femmes également nobles et douloureuses, mais se souvenir qu'il y a des types humains différents. Louise de Bettignies, naturellement portée à l'offensive, remplissait un office nécessaire. La résistance du plus grand nombre était sourde et patiente : elle y mit du sel. 
Et puis elle était malade. Il faut songer à l'immense effort fourni sur les routes et à l'instruction par cette petite. Elle arrivait à Siegburg anéantie, les nerfs exaspérés. Nous savons qu'elle mangeait beaucoup : ces natures-là brûlent du charbon. L'alimentation de Saint-Gilles et celle, pire encore, de la prison allemande, devaient à la fin rompre l'équilibre de ce bel organisme.

Car on ne dira jamais assez quel chef-d'œuvre de femme elle était quand elle entra, au début de 1915, dans son héroïque carrière. J'ai eu la curiosité de montrer des documents de sa main à plusieurs personnalités expertes à reconnaître un caractère sous l'écriture. J'ai reçu des réponses toutes pareilles. L'une d'elles, qui formule mieux la pensée des autres, est de Mme Dussane, de la ComédieFrançaise. Elle ne savait rien de mon héroïne et voici son jugement, qui est curieux : «Extrême jeunesse ; l'écriture est même presque enfantine. Le caractère le plus saillant est un remarquable alliage de sensibilité et d'énergie. C'est le type des sensibles actifs, chez qui l'émotion pousse, non aux paroles ni aux larmes, mais à la conception et à la réalisation de l'acte. Différents des impulsifs en ceci : l'écriture garde son équilibre général. L'intelligence est la servante bénévole du cœur, et le cœur est toujours d'accord avec la conscience. Cette force exceptionnelle, qui ne pouvait, étant donnés les signes accessoires de droiture, de simplicité, même de candeur, qu'être noblement employée, cette bonté énergique, certains signes aussi qui semblent annoncer une grâce naturelle et engageante, tout cela constituait, chez cet être encore enfant, la promesse certaine d'une femme absolument supérieure, que j'imagine dans des postes où 1'activité et le rayonnement moral jouent le premier rôle. »

Oui, l'équilibre de cette riche nature était d'une qualité rare ; et le premier crime des Allemands est de l'avoir sciemment brisé. «Votre Bettignies! elle est en train de crever quelque part en Allemagne », disait un jour, à Bruxelles, un ignoble policier du nom de Levy. Elle mourait, c'était vrai.

Au début, elle était encore gaie et, sa résistance se traduisait seulement en gamineries. Une des corvées quotidiennes était l'astiquage des loquets. Les prisonnières appelaient cela faire les cliches, par déformation sans doute du mot allemand klinke. Tous les jours on ouvrait un instant les portes de trois cellules consécutives et les trois détenues, armées d'un chiffon, frottaient de tout leur cœur, au dedans, au dehors, par-dessus, par-dessous, jamais lasses, jamais pressées de finir. Car c'étaient des minutes précieuses, minutes de liberté, de bavarda- 
ges et de fous rires. On s'interpellait d'une porte à l'autre ; on se passait les nouvelles ; on daubait sur les geôlières. Quand passait la Hausmutter ou la sèche Werkmeisterin (maîtresse du travail), il fallait se redresser, immobile, les bras le long du corps et les yeux fixés avec respect sur la figure haineuse de l'Allemande. Louise et ses deux voisines, dont l'une était alors Léonie Vanhoutte, frottaient à ce moment avec une ardeur décuplée, afin de ne pas saluer. La grosse femme, ou l'autre, l'osseuse, se fâchaient.

- Je ne vous avais pas reconnue, disait Louise.

- Une autre fois, vous ferez attention à nos rupans pleus ; ou bien vous serez punie.

Un jour, le docteur vint à passer. Pour rien au monde, les pauvres petites n'auraient salué ce misérable. Il alla se plaindre à la Hausmutter, qui surgit, bondissante. Louise fit l'étonnée :

- Est-ce qu'il a donc aussi des rubans bleus, celui-là ? demanda-t-elle. Je ne les avais pas vus.

Et elle se remit à frotter de tout son cœur.

On les désignait au début par leurs numéros elles s'obstinèrent à ne pas répondre. Lasses des batailles que Louise et quelques autres leur livraient à ce propos tous les jours, les Allemandes se décidèrent à les appeler par leurs noms :

- Vanhoutte ! Bettignies ! criaient-elles.

- Frietag ! Muller ! répondaient les prisonnières.

- Mais vous n'êtes pas polies. Il faut dire fraulein Frietag...

- Alors soyez polie, vous aussi.

Peu à peu, en résistant ainsi, elles obtenaient le respect des gens de cette race qui cède aux coup de fouet.

Un jour vint où les Allemands qui, tout de même, étaient, dans la prison, les plus forts, se lassèrent et, d'un coup brutal, assommèrent leur victime.

Dans les derniers jours de novembre 1916, le bruit commençait à courir à la prison que certaines détenues avaient reçu l'ordre de faire un travail singulier. La plupart de celles qui n'étaient pas occupées au dehors, à la briqueterie ou aux 
champs, fabriquaient habituellement des boutons : c'étaient des boutons de culotte d'hommes, sur lesquels l'autorité allemande avait tranquillement inscrit la marque : Made in England. Au petit nombre de celles qui maniaient habilement l'aiguille, on confiait quelquefois des ouvrages de broderie. J'en sais qui s'adonnaient à cet art avec application, mais en omettant de nouer ou de passer le fil d'une certaine façon, de sorte que pas un des chefs-d'œuvre exécutés par elles n'a probablement survécu au premier lavage. Le nouveau travail commandé à quelques prisonnières consistait à enduire d'une mince couche de couleur verte le fond d'une sorte de capuchon d'acier de petite dimension; et l'on devait aussi recouvrir de papier blanc l'une des faces d'un disque de cuivre d'un centimètre de diamètre, percé d'un petit trou au centre. Une pauvre femme ayant fait part à Louise Thuliez des scrupules qu'elle éprouvait à exécuter un tel ouvrage, celle-ci la pria de lui apporter à la prochaine promenade une capsule et un disque. Au premier regard, elle reconnut les pièces constitutives d'une tête de grenade, et le dit à Louise de Bettignies. À la sortie suivante, les deux Louise marchaient côte à côte, derrière une toute jeune enfant, la petite Masurelle, accompagnée de sa mère. L'enfant, s'étant retournée, chuchota :

- Ce matin, quand j'ai dit que je ne ferais pas le nouveau travail, on m'a privée de « jus » et menacée de cachot. Alors j'ai cédé. Qu'est-ce qu'il faut faire ?

- Il faut, lui répondit Louise de Bettignies à voix basse, déclarer que vous ne voulez pas fabriquer de munitions, et tenir tête.

- Mais si on me demande qui m'a donné ce conseil ?

- Vous direz que c'est moi.

- Non, rectifia aussitôt Louise Thuliez; vous direz qu' « on »vous a avertie que ce travail-là, vous aviez le droit de vous y refuser.

Une heure après, on jetait Louise de Bettignies au cachot.

Ce n'est pas la petite Masurelle qui porte la responsabilité de cet événement. Il est probable que le conseil de Louise de Bettignies a été aussitôt transmis de rang en rang à toutes les détenues, et qu'une bavarde l'aura révélé à quelque fraulein.

Le lendemain, qui était un dimanche, une patriote belge, Mlle Marguerite Blanckaert, en montant à la chapelle, se tourna vers Louise Thuliez, qui la suivait immédiatement, et lui dit : 
- Est-il vrai que Mlle de Bettignies soit au cachot?

- Oui, à cause du nouveau travail, qu'elle a conseillé de ne pas faire.

- Mais ces ampoules d'acier sont-elles bien des munitions ?

- Oui, des têtes de grenade.

- Bien, dit Marguerite Blanckaert.

Et la messe commença. Les esprits étaient surexcités. La brutalité du coup porté à Louise de Bettignies avait surpris. Le cachot, que toutes connaissaient, ne faisait vraiment peur à personne ; mais on savait déjà, par des indiscrétions du personnel, que l'aventure menaçait de prendre un tour tragique et qu'entre la jeune Française et ses bourreaux la partie serait dure. Quelques-unes, portées par tempérament à négocier, regrettaient que Louise eût pris aussi vivement l'offensive. D'anciennes détenues disent encore aujourd'hui que le sacrifice de cette malheureuse jeune fille a été inutile et qui, les Allemands, après les observations qui s'imposaient et qu'on pouvait leur présenter dans les formes régulières, auraient d'eux-mêmes retiré le travail suspect. Ce n'est pas sûr ; et, d'ailleurs, l'acte vif n'a pas été celui de Louise de Bettignies, mais celui des Allemands. Elle a donné le seul conseil honnête ; ils ont riposté par des gestes sauvages. Quoi qu'il en fût, tout ce monde féminin suivait distraitement la messe : il faudrait demain prendre parti et s'exposer à des représailles, peut-être atroces. Le prêtre venait de se tourner vers les trois cents pauvres femmes et de leur donner une bénédiction où le cœur n'avait point de part, quand une d'elles surgit tout d'une pièce sur son banc. C'était Marguerite Blanckaert, qui, pâle comme une morte, fit un grand geste tragique pour appeler à soi l'attention de ses compagnes et leur jeta, d'une haleine, ces mots vibrants : «Au nom de l'Angleterre, de la France, de la Belgique et de tous les pays alliés, j'adjure mes compagnes de refuser énergiquement de travailler aux munitions! L'Allemagne n'a pas le droit de nous demander ce travail de mort contre nos patries, et de nous forcer à faire nous-mêmes les engins qui, dans les combats, vont frapper nos pères, nos frères, nos maris, nos fils! Nous toutes continuons à lutter et à souffrir courageusement ici pour le Roi, pour nos drapeaux, pour nos patries ! „ Et elle reprit en allemand, afin que geôliers et geôlières comprissent bien de quoi il s'agissait: "Immer für Fahne, König und Vaterland!» 
Une rumeur immense emplit alors la chapelle. On eût dit une ruche, avec une abeille furieuse bourdonnant dans chaque alvéole. Le pasteur, tourné vers tout ce peuple féminin en émoi, agitait ses grands bras, mais ce n'était plus pour bénir. Il faisait des signes aux gardiennes et jetait des ordres : «Schnell ! Schnell ! " entendait-on. Les fraulein se mirent à bondir, poussant dehors les révoltées, les jetant dans l'escalier, tandis que Marguerite Blanckaert, empoignée par deux filles vigoureuses, se retrouvait un instant plus tard, sans savoir par où ni comment, dans le cachot voisin de celui de Louise de Bettignies.

Ces cachots étaient des cellules plus étroites que les autres, et dont la fenêtre, haut placée et toute petite, était couverte d'un grillage qui ne laissait passer qu'un jour sinistre. Le lit consistait en un plancher à dix centimètres du sol. Point de table, ni de chaise, ni de tabouret. Il fallait rester debout ou s'asseoir sur la planche basse, les jambes allongées, à moins qu'on ne mît son menton sur ses genoux. Les cachots n'étant pas éloignés des bureaux de la direction, il pouvait arriver qu'ils fussent mieux chauffés que les autres cellules. En décembre 1916, alors que commençait cet hiver terrible, dont quiconque a fait la guerre a gardé le souvenir, le charbon manquait totalement à Siegburg; et le froid, dans les cachots comme ailleurs, était glacial. Des murs épais séparaient entre eux ces locaux maudits, dans lesquels on était trois fois enfermé : une première porte capitonnée donnait directement sur le couloir ; la seconde, massive, ressemblait à celles de toutes les cellules dans toutes les prisons du monde ; la troisième était une grille lourde, aux barreaux de fer verticaux, avec des contreforts en croix de Saint-André. Quand le directeur venait admonester une prisonnière, il lui parlait à travers ces barres de ménagerie. Un détail qu'on ose à peine rapporter ajoutait à l'horreur de ce lieu : on avait placé les water-closets entre la grille et la deuxième porte. Il fallait donc, pour user de ceux-ci, attendre le bon plaisir des gardiennes, qui venaient ouvrir la cage un instant. On pouvait d'ailleurs crier à son aise dans ces trous : il était impossible qu'on fût entendue. Il fallait en vérité toute la bonne humeur de ces prisonnières politiques, aux âmes vigoureuses, pour supporter un tel régime. Songez qu'on enlevait la maigre literie pendant tout le jour et qu'on ne pouvait ni se coucher, ni, comme dans la cellule, se couvrir le dos de couvertures, ni travailler, ni se rattraper sur la nourriture, car les rations étaient encore diminuées. Pour Louise de Bettignies, l'épreuve fut terrible, car elle était déjà, quand on lui porta ce coup, à bout de forces. Et puis il ne faut jamais oublier, quand il s'agit d'une telle jeune 
fille, qu'elle s'intéressait au bien général plus qu'au sien même, et que les malheurs de sa patrie pouvaient la faire souffrir jusqu'à la tuer. Que des femmes innocentes fussent exposées à commettre, à leur insu ou contraintes par la force, le crime de forger des armes contre leurs frères, c'était de quoi lui torturer le cœur. Frau Ruge étant venue lui faire, à travers les barreaux de sa cage, de violentes remontrances, elle avait riposté avec colère et dignité.

- Avant de donner à une détenue le conseil qui vous a irritée, dit-elle., j'avais engagé toutes celles de mes compagnes qui m'avaient consultée à vous demander l'assurance loyale que ces objets n'étaient pas des munitions. Nous étions prêtes à vous croire sur parole. Maintenant encore, je vous demande, moi, de me dire si, oui ou non, ce travail est destiné à armer vos soldats.

L'Allemande répondit, sur un ton hautain, qu'une fille condamnée à mort ne ferait pas la loi dans cette maison et qu'on viendrait à bout d'elle, coûte que conte. Un peu plus tard, herr Dürr apparut à son tour derrière les barreaux. Sa face mauvaise recevait directement la rare lumière que laissât passer la lucarne grillagée. Il était escorté, comme l'exigeait le règlement toutes les fois que ce loup visitait une prisonnière dans sa cellule, de deux femmes, Frau Ruge et l'intendante, qu'on nommait, pour son port majestueux et ses beaux restes, Pompadour ou la Marquise. Devant les réponses dépourvues d'aménité de Louise de Bettignies, il entra dans une colère violente et décida tout de suite qu'en lui ôtant ses effets personnels, pour la vêtir, conformément à l'usage, de la livrée des prisonnières, on lui ravirait aussi ses lainages. Cet homme avait trouvé la bonne recette. «Vous êtes ici pour souffrir ! » disait-il aux détenues à toute occasion. « Je la ferai mourir de froid ! » décréta-t-il ce jour-là. Et, tandis qu'au dehors il gelait à pierre fendre, la pauvre petite, coupable d'aimer sa patrie de tout son cœur, fut laissée entre ces murs de pierre, couverte seulement d'une chemise, d'une robe de coton et d'un fichu, sans feu, presque sans nourriture, sans même un peu de place pour aviver son sang en marchant.

Dürr, croyant qu'il viendrait vite à bout d'elle, lui fit, le lundi, une deuxième visite.

- Enfin, lui demanda Louise des sort entrée, me direz-vous ce que c'est que ce travail ? 
- Cela ne vous regarde pas, répondit l'Allemand, qui commençait à la considérer avec curiosité.

- Est-ce un travail militaire ?

- Je n'ai pas de comptes à vous rendre. Vous êtes une femme déchue, condamnée pour toujours aux travaux forcés. Taisez-vous.

- Je ne me tairai pas! Je suis une prisonnière politique de guerre. Si vous ne me donnez pas satisfaction, j'écrirai à Berlin.

- Berlin vous punira.

- J'écrirai quand même.

Ce qu'elle fit. La lettre n'alla d'ailleurs pas plus loin que Cologne ; le travail suspect, dans l'intervalle, avait été retiré.

C'était une victoire, mais à quel prix ! On a jugé, parmi certaines prisonnières, que cette affaire avait été grossie ; celles-là, je l'ai dit, ont pensé que, sans l'intervention de Marguerite Blanckaert et de Louise de Bettignies, les Allemands auraient renoncé à l'offense tentative ; d'autres, amies de la manière forte, ont surtout connu et admiré la scène de la chapelle, digne en vérité de demeurer dans la mémoire des hommes parmi les plus poignantes de ces temps héroïques ; je retiens seulement que sa résistance à la volonté criminelle des Allemands, Louise de Bettignies l'a payée de sa vie ; c'est de quoi donner à son acte la plus douloureuse primauté sur ceux de ses compagnes.

Le mardi, elle quittait le cachot et on l'envoyait à la promenade sans lainages. Le froid vif de la cour acheva de détruire cet organisme désormais sans résistance ; le lendemain, on la trouva étendue dans sa cellule, à demi morte. Pendant un mois sa température dépassa quarante degrés presque chaque jour. Aucun soin médical ne lui fut donné. Des compagnes s'empressaient autour d'elle : Louise Thuliez, Léonie Vanhoutte, surtout Mme Pol Boël. Le charbon manquant toujours, ces infirmières bénévoles, pour résister au froid cruel, s'enveloppaient de couvertures et marchaient sans arrêt dans la cellule de la moribonde. C'est longtemps après sa punition, et parce qu'elle avait fait écrire en son nom par des compagnes au Ministre de la Justice et à l'Ambassade d'Espagne, que l'ordre fut enfin donné de lui rendre ses vêtements chauds. Dürr l'aurait vue mourir alors avec délectation. Au surplus, il pouvait être tranquille : la blessure était bien mortelle. 
À la fin de l'hiver, la fièvre parut tomber et ses compagnes crurent qu'elle était sauvée. Sa vie monotone de prisonnière reprit au printemps, puis dans tout l'été de 1917. Elle occupa les longues journées de cette année lugubre à faire des ouvrages de broderie. La surveillance se relâchait un peu : moins confiants dans la victoire, les Allemands changeaient visiblement de ton. Un moment, Louise imagina de s'évader ; mais ses desseins n'étaient pas raisonnables et ses amies souffraient de la voir dans un état d'exaltation qui la conduisait à des crises de larmes fréquentes et pouvant durer tout un jour. Puis elle reprenait courage et toutes, même celles qui ne l'ont pas comprise ni jugée à sa valeur, vous disent aujourd'hui que son âme rayonnait alors et qu'elle était pour cette assemblée de femmes malheureuses l'image vivante du dévouement éclairé et superbe à la patrie.

Un jour, aux premiers froids de l'hiver 1917-1918, une petite glande apparut sous sa poitrine, entre deux côtes. Elle conçut tout de suite de l'inquiétude. Ses amies lui conseillèrent de s'adresser au médecin. Elle refusa, cet homme ne lui inspirant que du dégoût. « Je vais mettre un peu de vaseline », disait-elle. La grosseur se développant, elle prit peur et se fit enfin examiner. Le docteur se rendit-il compte de ce qui se passait ? S'il n'a pas compris de quel mal souffrait cette petite, quel âne était-ce ? Et s'il l'a vu, comment n'a-t-il pas agi tout de suite ? La vérité, telle qu'elle se révéla alors, est atroce à dire. Louise de Bettignies avait fait à sa sortie du cachot une pneumonie, sans autres soins que la tendresse de ses compagnes et leurs veilles avec des prières; et la défaillance du médecin avait laissé naître une pleurésie purulente ; celle-ci évoluant maintenant vers la peau, l'abcès pleural apparaissait entre les côtes et se développait de jour en jour d'une façon terrifiante. Elle était fort loin de connaître la nature de son mal, mais il lui faisait peur ; et quand le médecin, dont le devoir élémentaire était de l'envoyer sur-lechamp dans une bonne clinique, consentit à lui révéler, longtemps plus tard, qu'on serait peut-être contraint de l'opérer, elle n'eut qu'une idée : obtenir que l'intervention chirurgicale eût lieu à Cologne ou à Bonn. Sa compagne, la comtesse de Belleville, avait été opérée dans de bonnes conditions, dix-huit mois plus tôt, mais après une âpre lutte contre Dürr, qui aimait mieux voir mourir ses pensionnaires à Siegburg que les confier à des gens capables de les guérir.

Alors commença entre Louise de Bettignies et ce monstre une lutte douloureuse. Il faut dire que, dès ce moment, Frau Ruge redevint une femme pareille à d'autres : elle eut pitié de sa victime. Elle n'aimait pas le directeur brutal ; et Loui- 
se, qui le savait et, suivant le temps et son humeur, détestait chacun d'eux davantage à tour de rôle, utilisait leurs divisions comme elle pouvait. Dans cette crise, où sa vie n'était plus en cause, car elle était bien perdue, mais où se jouait la paix de ses derniers jours, la directrice la traita avec quelque douceur. Je ne crois d'ailleurs pas qu'elle eut encouragé la prisonnière à la résistance : l'idée qu'on opérât cette pauvre fille au lazaret où venait de régner le typhus ne la scandalisait point. Quant à la patiente, ce qu'elle redoutait surtout, c'était qu'on la livrât à certain chirurgien auquel on avait eu recours plusieurs fois à la prison et dont j'ignore le nom. Je sais seulement qu'ayant appris un beau matin la mort accidentelle de ce boucher, la pauvre enfant fit des gambades et battit des mains comme une gamine. Elle recevait des conseils différents. Léonie Vanhoutte et beaucoup d'autres, effrayées de voir se développer ce mal qu'elles prenaient naïvement pour un cancer, la suppliaient de se laisser opérer par n'importe qui, n'importe où, mais tout de suite. D'autres, comme la comtesse de Belleville, l'engageaient à la résistance, l'assurant qu'à Siegburg on la tuerait. Elle hésitait et son mal empirait. Un soir, appelée par Dürr, elle le supplia une dernière fois de permettre qu'elle allât à Bonn ; elle lui rappela les lettres qu'elle avait écrites à Cologne, à Berlin, à l'Ambassade d'Espagne, demandant qu'on eût pitié de sort état et qu'on la soignât avec humanité. L'Allemand, plus dur que jamais, lui répondit qu'elle aurait les soins que méritait une criminelle, qu'elle ne sortirait pas de Siegburg, quoi qu'elle fit ; qu'enfin, si elle refusait d'être opérée immédiatement, il fallait qu'elle sût qu'elle était perdue sans retour. Elle se sentit alors à bout de forces. Entrée dans le bureau avec la volonté de vaincre, elle devait en sortir battue : elle signa tout ce que voulut cet homme et, le lendemain 18 avril, à quatre heures de l'après-midi, l'opération avait lieu au lazaret.

Aucun cas de typhus n'avait été traité depuis quelque temps déjà dans cette sorte d'infirmerie, grande pièce à quatre lits avec de vraies fenêtres souvent ouvertes ; mais dans les chambres voisines, appartenant aussi au lazaret, des typhiques convalescentes étaient encore couchées. On prit quelques mesures, nettement insuffisantes, pour désinfecter la salle. L'opération eut lieu à quatre heures. Le temps était sombre et un jeune chirurgien de Bonn, assisté du médecin de la prison et de deux religieuses, dut travailler dans une demi-obscurité, car on n'alluma point les lampes. Aucun soin préalable n'avait été donné à l'opérée, qui arriva dans la salle à l'heure dite, venant seule de sa cellule. La pièce n'était pas chauffée et 
sans doute estima-t-on superflu d'entourer d'ouate les membres d'une criminelle ; on n'avait pas pensé non plus qu'il fût nécessaire de flamber les outils. À la dernière minute, on fit demander deux cruchons pour réchauffer la pauvre fille et je n'ai pas pu savoir si la fraulein envoyée à la recherche d'un peu d'alcool en avait rapporté. La principale intéressée n'a d'ailleurs jamais élevé de plaintes contre la façon dont on la traita ce soir-là. Mais ses compagnes, voyant sa plaie peu de jours après, eurent toutes une impression douloureuse.

J'ai sous les yeux les notes écrites au jour le jour par Mlle Anne-Marie Gérard, qui fut sa compagne au lazaret pendant un mois. Le premier mot de Louise à son réveil après le chloroforme fut une plainte : ( J'ai froid », murmura-t-elle. Elle passa une soirée douce. La nuit la malade et sa gardienne prirent un peu de thé froid. Anne-Marie Gérard écrit qu'il était délicieux. On est d'ailleurs tout surpris de trouver dans ces notes des formules habituellement réservées aux gens heureux : «Heures douces... Calme indicible... Journée exquise... Adorable paix du soir... » L'explication, elle-même la donne quand elle écrit quelque part : «Il y avait assez de souffle dans nos âmes pour les faire bondir par-dessus les murs de la prison. » Ces deux petites, toutes seules dans cette grande salle du lazaret, goûtaient à la fois les plaisirs de l'amitié et ceux de la vie intérieure. Louise Thuliez, qui possédait les exercices de saint Ignace, les avait prêtés à la malade avant son opération et celle-ci, pendant huit jours avait fait une retraite ardente dans sa cellule. Maintenant elle priait avec sa compagne. « Ce matin, N. S. chez nous », écrit presque à toutes les pages de son carnet Anne-Marie Gérard. L'aumônier leur apportait la communion, puis il leur rendait visite l'après-midi. C'était l'abbé Behler, prêtre dévoué, mais Allemand implacable. Les détenues ne l'aimaient pas. Il a été bon pour Louise, mais avec une réserve glaciale, qui, venant d'un ministre de Dieu, fait horreur. Le Père Materne, qui le secondait, inspirait plus de confiance à toutes ces pauvres femmes. Elles appréciaient aussi le Père Philippe, un bénédictin du voisinage. Car ils étaient trois, et fort occupés par toutes ces âmes souffrantes, que Dieu seul consolait.

Louise, toujours charmeuse, finit par apprivoiser des Allemandes autour d'elle; et c'est ainsi qu'on lit dans les notes d'Anne-Marie Gérard: " Dimanche 28 avril des fleurs... Dimanche 5 mai : lilas... Mardi 7 lilas, genêts, myosotis... » Un jour, Frau Ruge elle-même lui apporta un rameau de pommier fleuri. On gâtait 
déjà la mort ; à Cologne, les Anglais devaient trouver sa tombe toute jonchée de couronnes et de gerbes.

Cependant la plaie se fermait mal. Le chirurgien n'était pas revenu et le médecin de la prison, reprenant ses manières, dédaignait cette malade, ne la visitait plus que rarement, ne la pansait pas lui-même. Louise, tantôt sur une chaise dans la cour, tantôt errant dans les couloirs où on lui laissait quelque liberté, voyait ses compagnes et leur faisait part, d'une voix qui s'affaiblissait chaque jour, de ses craintes folles, de son fol espoir aussi. Elle entrevoyait la mort, mais la mort en Suisse, près des siens, la main dans celle de sa mère.

Vint un jour où elle crut que ce vœu suprême de son pauvre cœur était exaucé. On avait fait partout les démarches les plus pressantes. Le Saint-Père et le roi d'Espagne étaient intervenus, elle le savait. Elle ignorait la réponse brutale de l'autorité allemande, que j'ai sous les yeux et qu'on peut résumer ainsi : « Impossible : elle nous a fait trop de mal. »

Certes, elle avait frappé de grands coups contre eux, mais c'était une noble femme, et qui s'éteignait.

Ils décidèrent qu'elle rendrait son dernier souffle à Cologne ; et le 24 juillet, vers quatre heures, ses compagnes les plus chères, l'ayant embrassée, virent disparaître son visage douloureux dans la voiture qu'avait commandée Frau Ruge pour la conduire à son lit de mort. 
LA GUERRE DES FEMMES.

Histoire de Louise de Bettignies et de ses compagnes.

\section{Chapitre XII}

\section{LA CROIX DE BOIS}

$\underline{\text { Retour à la table des matières }}$

Un père jésuite appartenant à la Province belge de cet ordre, le Père Cadow, se trouvait à Cologne, à la fin du mois de juillet 1918, quand il reçut un coup de téléphone l'appelant à l'hôpital Sainte-Marie, auprès d'une malade française. On l'informait qu'il s'agissait d'une prisonnière très surveillée. Il obtint avec peine l'autorisation de l'entendre sans témoin.

Le religieux, s'étant aussitôt rendu à l'hôpital, fut introduit par la supérieure, une franciscaine, dans une chambre du rez-de-chaussée donnant sur la cour intérieure. Le store à demi baissé et des fleurs hautes dans un grand vase assombrissaient encore cette petite pièce. Deux lits bout à bout longeaient le mur de droite. À gauche, entre deux lavabos, une armoire. Devant la fenêtre, assises à une table ronde couverte d'un tapis sombre, deux femmes. Elles se levèrent. L'une eut un moment d'hésitation. Le prêtre coula alors un regard assez impératif vers la porte ouverte, et la fraulein, ayant salué, disparut comme une ombre.

Louise de Bettignies, seule devant ce nouveau venu, lui fit tout de suite une forte impression. Vêtue d'une chemisette de coton blanc avec une jupe sombre, elle portait sa belle parure de prisonnière : les deux nattes roulées en lourde cou- 
ronne sur sa pauvre tête si lasse. Elle paraissait assez petite, ayant aux pieds des pantoufles ; mais elle relevait la tête et, de ses grands yeux toujours vifs, elle interrogeait le prêtre :

- Alors, vous voulez bien vous intéresser un peu à moi ? Que je suis contente ! Parlons, voulez-vous ? Parlons français.

Il vit tout de suite que cette âme était noble, et tout entière à sa patrie et à Dieu. Elle se souciait de savoir si vraiment elle supportait sa croix, ses croix, avec le courage et la résignation d'une Française et d'une chrétienne. Sur la table, elle avait placé, appuyés contre un petit support, une image religieuse et le portrait de sa mère : c'était une pauvre photographie toute fanée, montrant, sur un fond de feuillage, un visage à contre-jour et sans traits. Au-dessus, un drapeau minuscule à nos trois couleurs. Au pied de ce petit autel à Dieu, à la France, à sa maison, un chapelet de fer et de bois noir,

- J'irai, dit-elle, la voir en Suisse, ma pauvre maman. Mais il faut d'abord que je me soigne, car je ne suis pas en état de faire le voyage.

Le Père, qui savait bien qu'elle n'aurait jamais plus la force de voyager, ni la permission, l'écoutait avec compassion. Alors elle lui contait sa vie douloureuse en prison ; puis, si le souvenir du temps où elle courait comme une fourmi de Lillo à Flessingue montait en elle, son regard s'animait, et le prêtre sentait quelle servante de tous les grands devoirs il avait devant lui.

Il lui rendit visite par la suite, chaque jeudi, toujours avec la même émotion. Une fois seulement, il fut empêché de l'aller voir. C'était dans la deuxième quinzaine de septembre. Peu de jours après, la supérieure des Franciscaines l'appela au téléphone, disant que Mlle de Bettignies était au plus mal et qu'il faudrait sans doute lui donner les derniers sacrements. Il courut à Sainte-Marie et trouva la petite prisonnière alitée et sans souffle. Ses deux nattes encadraient son visage tout pâle et s'allongeaient, toujours belles, sur le drap d'hôpital. Elle lui tendit la main en s'efforçant de sourire.

- Mon père, dit-elle, je vais mourir.

Il voulut la rassurer.

- Mais si, mon père, je sens que c'est fini. 
Alors ce fut lui qui pleura. Il eut un frisson d'épouvante devant cette femme d'élite qui mourait pour avoir, avec un courage au-dessus de son sexe, fait la guerre aux agresseurs de sa patrie : elle mourait seule, sur la terre ennemie, sans un regard tendre, sans un sourire. On l'avait séparée de ses compagnes, qui l'auraient entourée comme des sœurs ; et son rêve de fermer doucement les yeux en Suisse, sous le regard de sa mère, ou celui d'entendre avant son dernier soupir les cloches, les chants et les clairons de la victoire, Dieu les brisait. Il la regarda : elle souriait. Tant d'héroïsme souleva son propre courage ; il tendit à l'admirable fille un grand crucifix, qu'elle pressa sur ses lèvres ; puis il lui donna l'absolution. Un peu plus tard arriva l'aumônier de la prison avec les saintes huiles.

Le lendemain, vers neuf heures et demie, le Père Cadow, au chevet de sa pénitente, observait avec tristesse son beau visage. Ses traits plus altérés, son front moite, sa respiration dure, ses pauvres yeux, naguère si ardents, clos aujourd'hui, annonçaient la mort. Il demanda à la sœur de garde si Louise reconnaissait encore son entourage. La sœur, qui en doutait, se pencha sur le lit et, par deux fois, appela :

\section{- Louise ! Louise !}

Alors les lourdes paupières s'ouvrirent un peu, laissant passer un regard déjà fixe ; les doigts de la malade pressèrent ceux du religieux, qui tremblaient. Il fît signe aux sœurs de le laisser seul avec elle et, sans abandonner la petite main chaude et si faible, il murmura :

- Mon enfant, avez-vous un message à me confier pour les vôtres ?

Elle se taisait. Il reprit :

- Pour votre maman ?...

Alors les yeux s'ouvrirent tout à fait, la tête se tourna du côté du Père, qui y lut une grande souffrance, et les doigts brûlants pressèrent la main compatissante. Louise de Bettignies se mourait. Aucun mot ne sortit de ses lèvres, désormais jointes à jamais. Et c'est en sentant se desserrer l'étreinte de son honnête et vigoureuse petite main, que le religieux comprit que l'âme de la noble fille était partie.

Les sœurs l'ensevelirent. Jugeant que le corps d'une telle héroïne serait réclamé après la guerre, elles commandèrent un double cercueil, de zinc et de chêne. 
On la conduisit le surlendemain dans le hall mortuaire du cimetière de Bichendorf, nouvelle nécropole récemment ouverte. Le temps était pluvieux et frais. Le Père Cadow arriva vers quatre heures, comme on le lui avait prescrit. Il ne trouva là que l'employé, du hall. On avait placé le cercueil sur des tréteaux avec un drap noir frangé d'argent. Une main inconnue avait apporté un bouquet de fleurs rouges avec du feuillage de hêtre rouge. Quatre cierges et de gros lauriers en boule entouraient ce corps, aux pieds duquel nulle créature humaine n'était encore venue prier. Enfin l'aumônier de l'hôpital, puis deux sœurs, se présentèrent. Le prêtre chargé de la bénédiction des sépultures sortit alors d'une sacristie, précédé d'un assistant avec la croix et de deux enfants du chœur. Chacun s'agenouilla. Après la levée du corps, on plaça le cercueil dans une voiturette à deux roues et le cortège s'ébranla : la croix d'abord, puis l'officiant; et, derrière le corps, cinq personnes, dont Frau Ruge, arrivée en retard de Siegburg.

La pluie avait cessé ; mais le ciel restait bas sur ces quelques humains courbant la tête. Ils marchaient, et le fin gravier, qui grinçait sous leurs souliers, troublait seul le silence de ce lieu vide et désolé. La fosse avait été préparée tout au commencement de l'allée centrale, à droite. Deux terrassiers ayant surgi, le cercueil fut descendu par eux avec des cordes. Puis, après des prières liturgiques et trois Pater et trois Ave, auxquels répondirent ensemble les assistants, chacun jeta sur la morte un peu de terre et d'eau bénite et s'en fut.

Couchée dans un coin, une croix de bois blanc portait ce mots :

\section{LOUISE DE BETTIGNIES}

gest.

27-9-18

Elle finissait comme elle avait vécu, en soldat. 


\section{LA GUERRE DES FEMMES.}

Histoire de Louise de Bettignies et de ses compagnes.

\section{ÉPILOGUE}

\section{$\underline{\text { Retour à la table des matières }}$}

Quand les Britanniques entrèrent à Cologne, ils trouvèrent la tombe encore fraîche de celle qui les avait si vaillamment servis sous le nom d'Alice, et la fleurirent. Mme de Bettignies ayant demandé que sa fille lui fût rendue, nos alliés décidèrent de rendre à son corps, au moment de s'en dessaisir, les plus hauts honneurs. Le 20 février 1920, les états-majors français et britannique, avec les généraux Degoutte et Simon, et le major général Fuller, représentant le général William Robertson, commandant les forces britanniques du Rhin, accompagnèrent sa dépouille à travers les rues de Cologne. On l'avait placée sur un canon français ; un drap à nos trois couleurs couvrait le cercueil. Les troupes de la garnison rendaient les honneurs. À la gare, des discours furent prononcés par des officiers généraux des deux armées. Derrière le corps, un soldat portait sur un coussin les quatre médailles de la morte. Car nos alliés lui avaient décerné leur médaille de guerre et la croix d'officier de l'ordre de l'Empire britannique (O.B.E.) ; et la croix de la Légion d'honneur avec la croix de guerre lui avaient été offertes par la France, avec cette citation. "S'est volontairement dévouée pendant plusieurs mois, animée uniquement par le sentiment patriotique le plus élevé, pour rendre à son pays un service des plus importants pour la défense nationale. A affronté avec un courage inflexible toutes les difficultés périlleuses de sa tâche patriotique. A surmonté pendant longtemps ces difficultés grâce à ses capacités et à son dévoue- 
ment, risquant sa vie en plusieurs occasions, assumant les plus graves responsabilités, déployant, en un mot, un héroïsme qui a été rarement surpassé. »

À Lille, le 4 mars, ses compatriotes lui firent de magnifiques funérailles. Le cardinal Charost, lors évêque de cette ville, prononça un panégyrique émouvant ; et, entourée des honneurs militaires et de la piété de toute une population attristée et reconnaissante, elle traversa une dernière fois la grande cité, pour s'en aller reposer, parmi les siens, dans le petit cimetière de Saint-Amand.

Les Britanniques l'ont donc honorée ; les Lillois aussi ; et les autorités françaises ont publié et récompensé son héroïsme. Mais les hommages officiels sont froids ; et la mémoire de Louise de Bettignies, qui méritait l'amitié de la foule, n'est pas satisfaite.

\section{Fin du texte}

